By

R. A. Schatzinger

M. J. Szpakiewicz

S. R. Jackson

M. M. Chang

B. Sharma

M. K. Tham

A. M. Cheng

April 1992

Work Performed Under Cooperative Agreement No. FC22-83FE60149

Prepared for

U. S. Department of Energy

Assistant Secretary for Fossil Energy

Edith Allison, Project Manager

Bartlesville Project Office

P. C. Box 1398

Bartlesville, OK 74005

Prepared by

IIT Research Institute

National Institute for Petroleum and Energy Research

P. O. Box 2128

Bartlesville, OK 74005 
TABLE OF CONTENTS

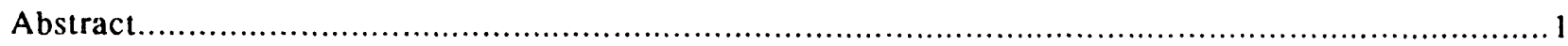

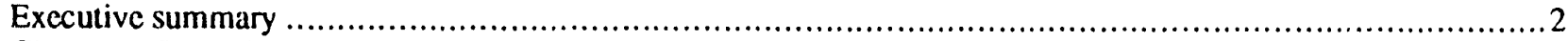

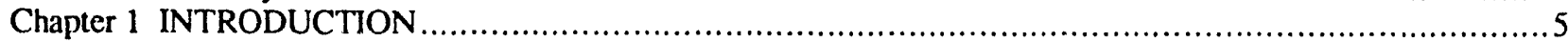

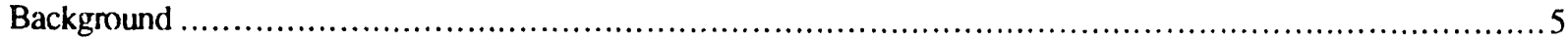

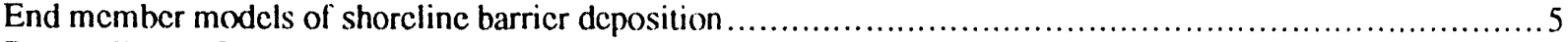

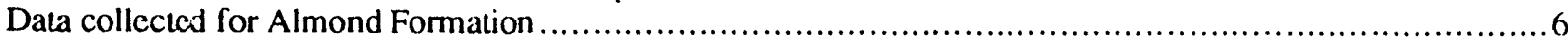

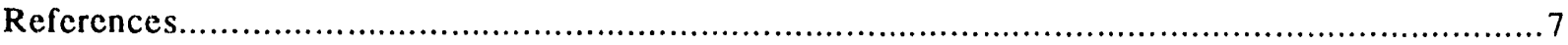

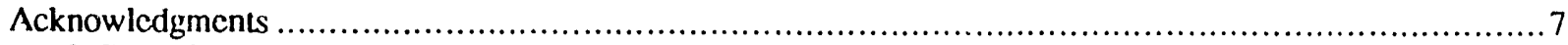

Chapter 2 INTEGRATED GEOLOGICAL-ENGINEERING MODEL OF PATRICK DRAW FIELD

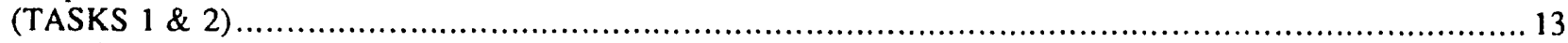

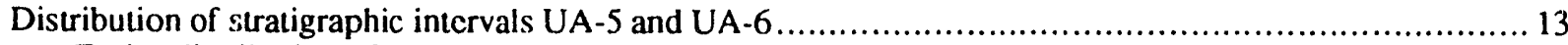

Facies distribution of the UA-5 sand in the Arch Unit ................................................ 13

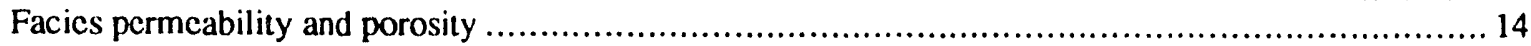

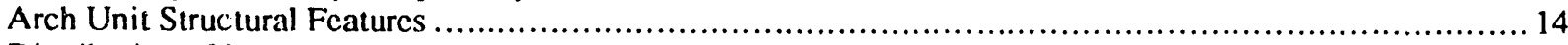

Distribution of $\log$ and core-derived petrophysical properties in the Arch Unit............................... 14

Distribution of average clay content and thickness of cemented zones ................................. 15

Relationship of permeability, grain sizc and sorting characteristics of facies in Patrick Draw ficld

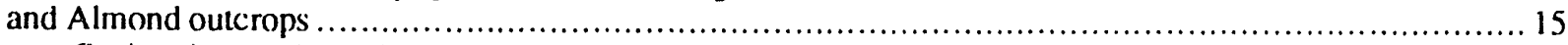

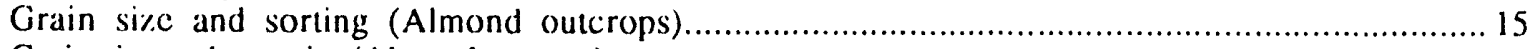

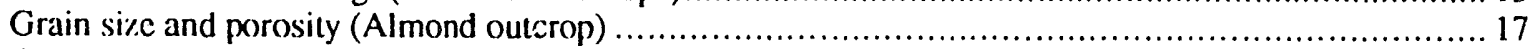

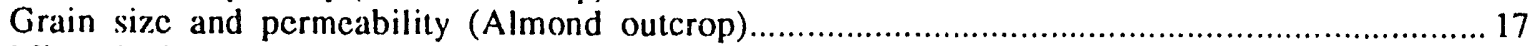

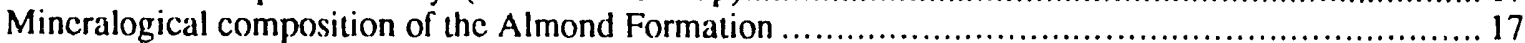

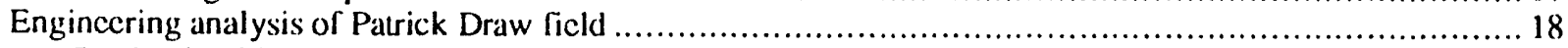

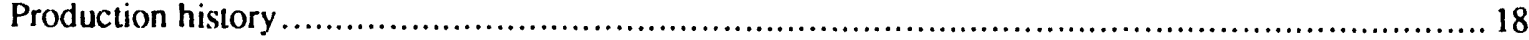

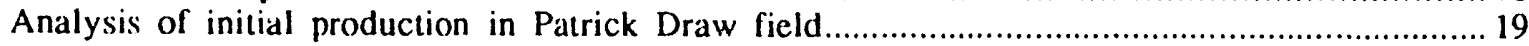

Analysis of specific production in sclected areas of Patrick Draw ficld....................................... 19

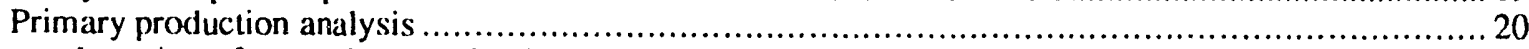

Location of anomalous production arcas by using initial and cumulative production data in

Arch Unit .................................................................................. 20

Effect of petrophysical property variations on primary oil production .............................. 21

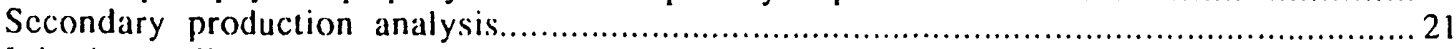

Injection well analysis of the Arch Unit by using Hall plots............................................2 21

Secondary production analysis of the Arch Unit......................................................222

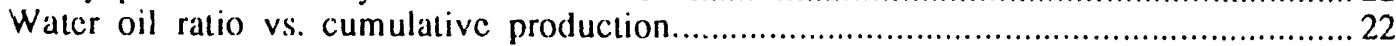

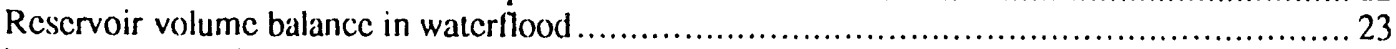

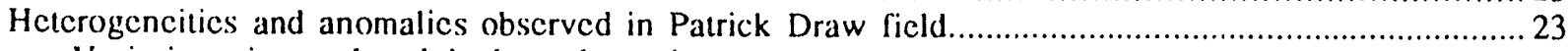

Variations in produced hydrocarbon phasc............................................................ 23

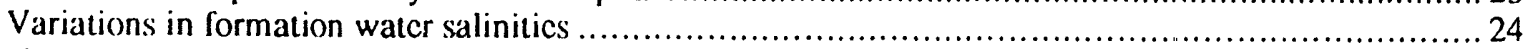

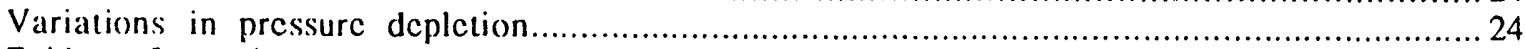

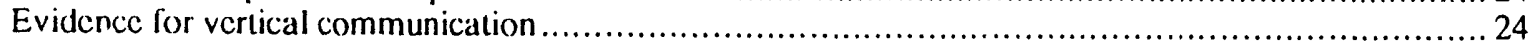

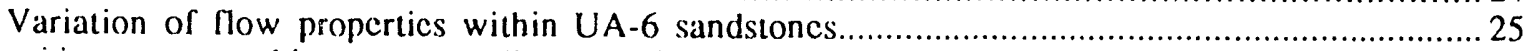

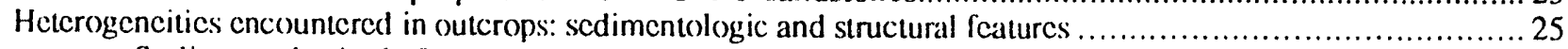

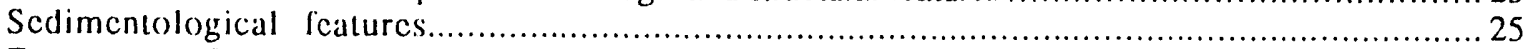

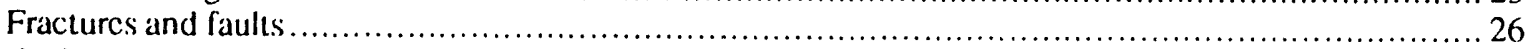

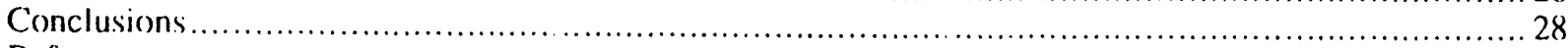

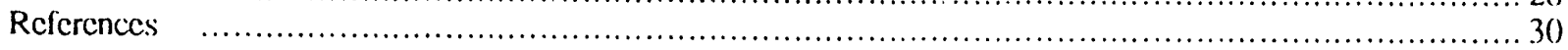

Chapter 3 SIMILARITIES AND DIFFERENCES AMONG VARIOUS SHORELINE

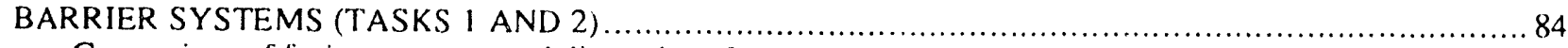

Comparison of facics geometry and dimensions from other shoreline barricr deposits reported in the

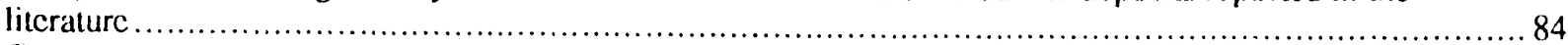

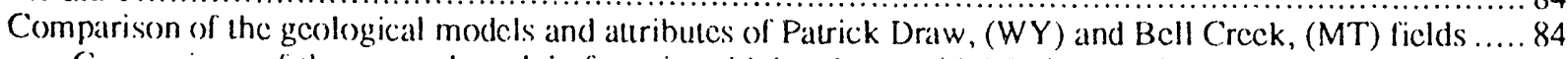

Comparison of the gencral models for microtidal and mesotidal facies architecture......................... 84 
TABLE OF CONTENTS (continued)

Pagc

Comparison of Muddy Formation (Boll Creck) and Almond Formation (Patrick Draw) shorcline barricr facies architccture.

Comparison of Almond Formation and Muddy Formation surlace and subsurface sandstone rescrvoir mineralogy and petrography.

Comparison of grain size, sorting, and petrophysical properties of the Almond and

Muddy Formations . .88

Comparison of the production/injection performance attributes of Patrick Draw and Bell Creck ficlds .......... 89

Comparison of initial oil production in Bcll Crcck and Patrick Draw ficlds............................... 90)

Comparison of injection and secondary production performance of Bell Creck and Patrick Draw ficlds... 90)

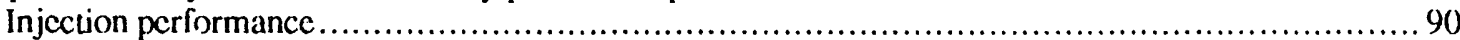

Secondary production performance ......................................................... 90

Summary of the similarities and differences between Bell Creck and Patrick Draw shoreline

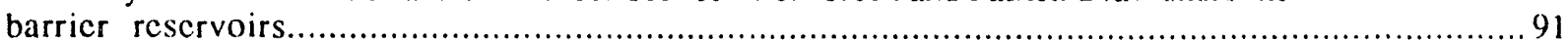

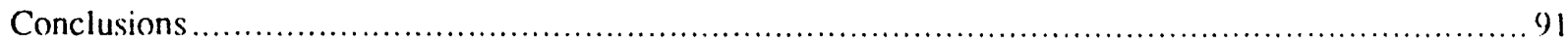

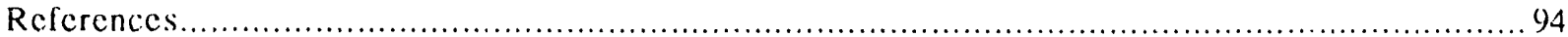

Chapter 4 EFFECTIVE TECHNIQUES FOR CHARACTERIZING SHORELINE

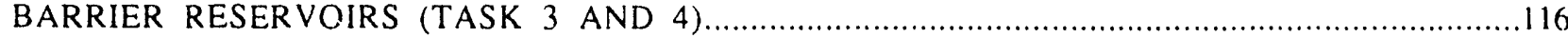

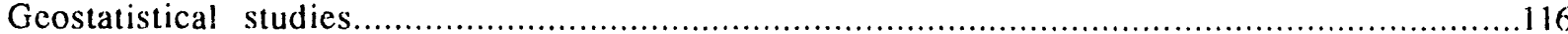

Variogram and cross-variogram analysis............................................................116

Analysis of porosity and permeability distribution ............................................

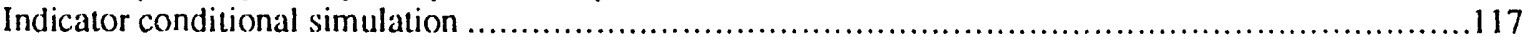

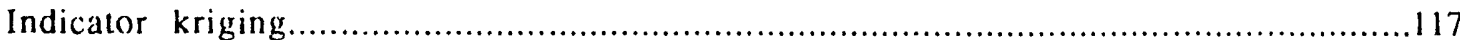

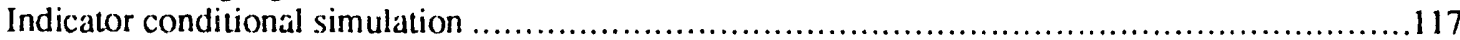

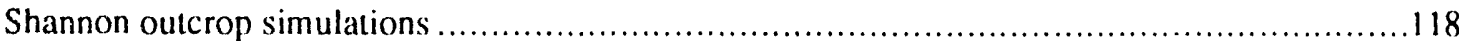

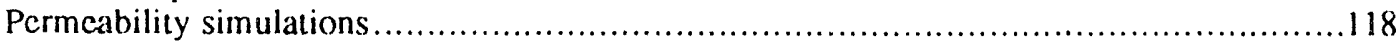

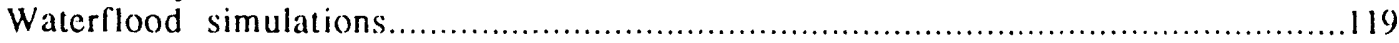

Intcrwell simulations in Patrick Draw ficld.............................................................199

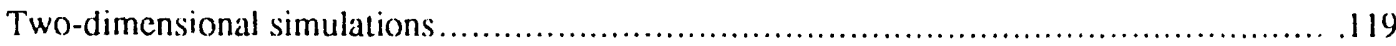

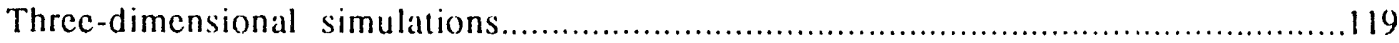

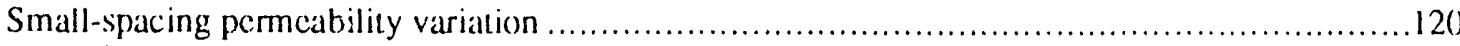

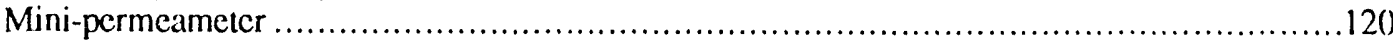

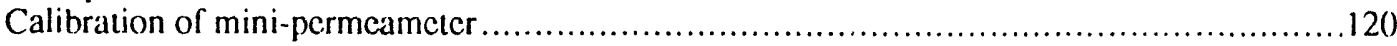

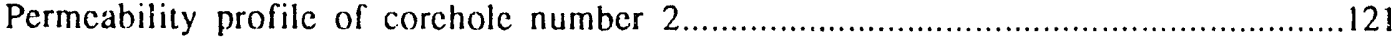

Permeability profiles of cored wells in Patrick Draw ficld.........................................121

Wireline log investigation of the effect of suhsurface stresses on fluid production in

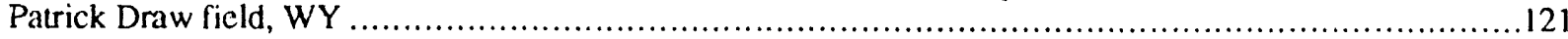

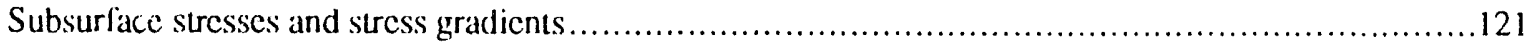

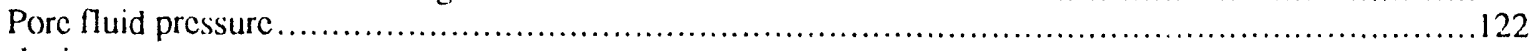

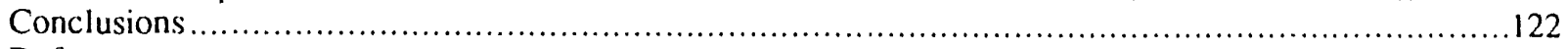

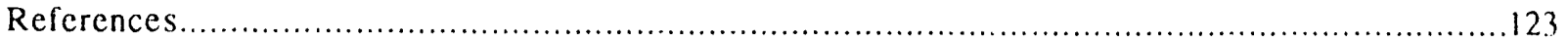




\section{TABLES}

1.1 - Some general geomorphological differences between microtidal and mesotidal barrier islands 8

2.1 - Whole rock X-ray diffraction analysis in weight percent for samples from Patrick Draw and upper Almond Formation outcrops.

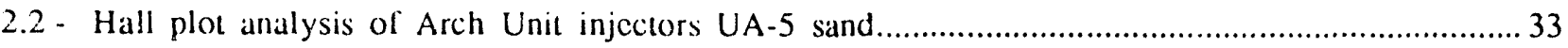

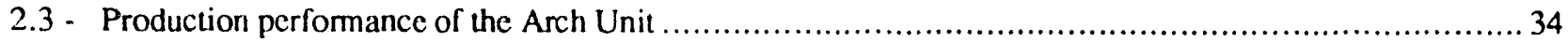

2.4 - Analysis of Arch Unit wells OOIP using WOR vs. cumulative oil plots ..................................... 34

3.1 - Common shapes and dimensions of major tide related facies in recent and ancient

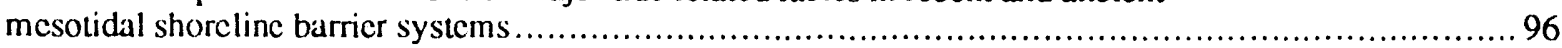

3.2 - Some general geomorphological differences between microtidal and mesotidal barrier islands..................97

3.3 - Quantitative XRD detcrmination in weight percent of mineralogy for subsurface samples from Bell Creck ficld and a nearby outcrop...

3.4 - Whole rock X-ray diffraction analysis in weight percent for samples from Patrick Draw and outcropping upper Almond Formation.

3.5 - Major diagenetic phases identified within the barried sandstone facies and their potential effect on porosity and permeability Muddy Formation, Bell Creek field, Unit ' $A$ ' .

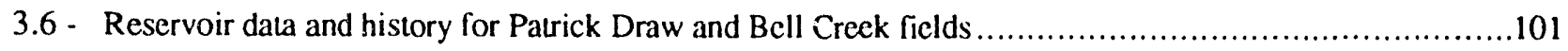

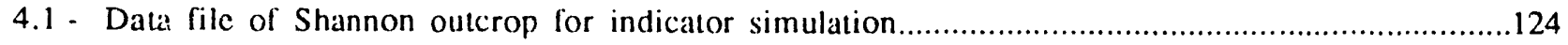

4.2 - Permeability profiles from wells 13, 15, and 21, Patrick Draw ficld.......................................125

4.3 - Input parameters for three-dimensional indicator simulation of permeability values among wclls 13, 15, and 21, Patrick Draw field

4.4 - Overburden stresses for Arch well nos. 91 and 100.

\section{ILLUSTRATIONS}

1.1 - Locality map of Bcll Creck ficld, WY and Patrick Draw ficld, MT...

1.2 - Morphological models for microtidal, and mesotidal barricr shorclines with medium wave encrgy.

1.3 - Basc map of Patrick Draw ficld well locations......................................................................... 11

1.4 - Map of cast flank of the Rock Springs Uplife, Swectwater County, WY ......................................... 12

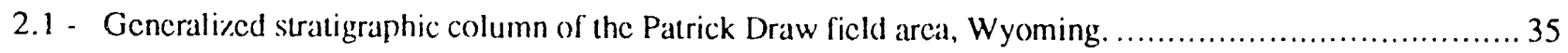

2.2. Type log of the Almond Formation in the Arch Unit of Pattrick Draw ficld...................................... 36 


\section{ILLUSTRATIONS (continued)}

2.3 - UA-5A permeable sandstone isolith map. 37

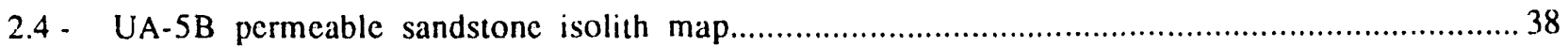

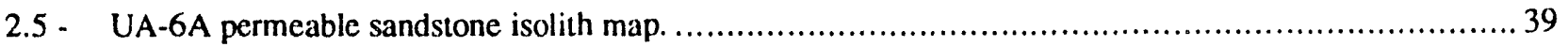

2.6 - UA-6B permeable sandstone isolith map..............................................................40

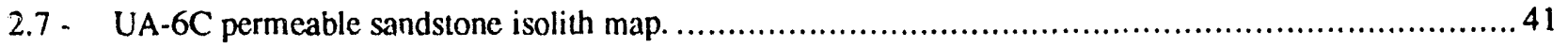

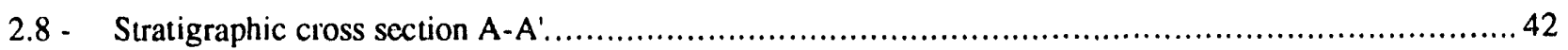

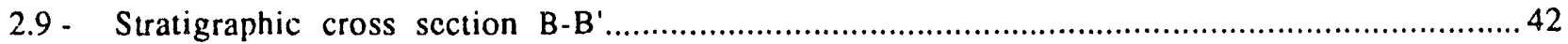

2.10 - Fence diagram of wircline log-derived subdivisions of stratigraphic unit UA-5B.................... 43

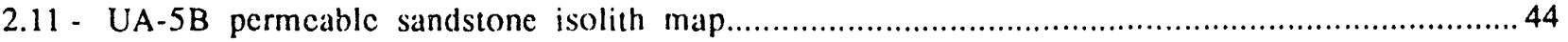

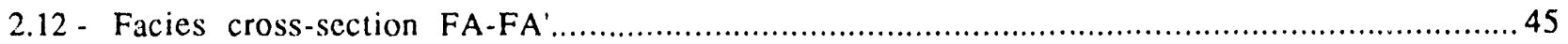

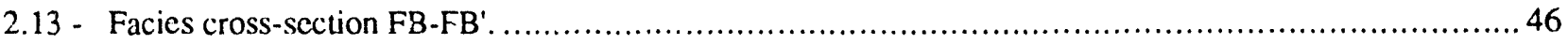

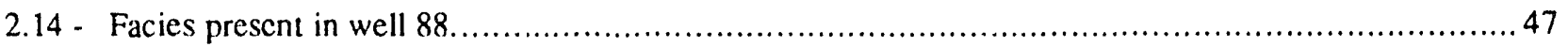

2.15 - Natural log of permeability distribution for facies permeability classes in the UA-5 sand ...............48

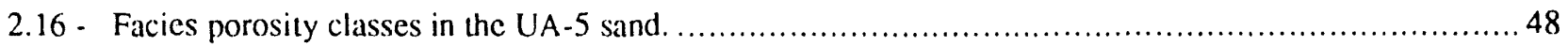

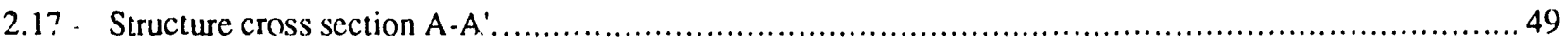

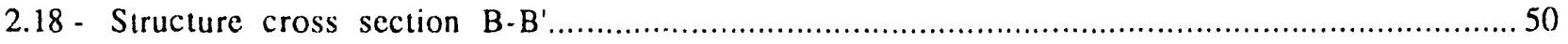

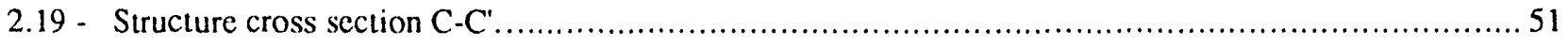

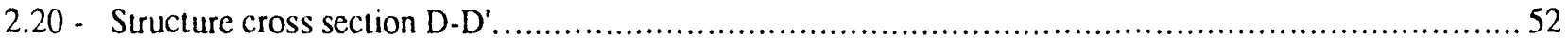

2.21 - Base map showing location of wells, structure cross sections A-A', B-B', C-C', and D-D', and the production limits of Arch Unit of Patrick Draw ficld.

2.22 - Locations of profiles for investigations of structure and petrophysical properties in the Arch Unit, Patrick Draw field, Wyoming.

2.23 - Distributions of average porosity $(\varnothing)$, average permeability $(\overline{\mathrm{k}})$, and average permeability thickness product $(\overline{\mathrm{kh}})$ along profile $\# 1$

2.24 - Distributions of average porosity $(\varnothing)$, average permeability $(\overline{\mathrm{k}})$, and average permeability thickness product $(\overline{\mathrm{kh}})$ along profile $\# 2$.

2.25 - Distributions of average porosity $(\varnothing)$, average permeability $(\overline{\mathrm{k}})$, and average permeahility thickness product $(\overline{\mathrm{kh}})$ along profile $\$ 3$...... 


\section{ILLUSTRATIONS (continued)}

2.26 - (a) Average clay content $\left(\mathrm{V}_{\mathrm{cl}}\right)$ from interpretations of gamma ray logs and variability in clay content $\left(\sigma_{\text {sh }}\right)$ in profile \#4. (b) Percentage of carbonate rocks in profile \#4.........................56

2.27 - Grain size distribution for combined outcrop and subsurface facies in the Almond Formation 57

2.28 - Comparison of outcrop and subsurface grain size distribution for various facies in the Almond Formation 57

2.29 - Standard deviation (sorting) for various outcrop and subsurface facies in the Almond Formation.

2.30 - Standard deviation (sorting) versus mean grain size for outcrop and subsurface Almond Formation.

2.31 - Standard deviation (sorting) versus mean grain size for subsurface Almond Formation facies. .59

2.32 - Standard deviation (sorting) versus mean grain size for outcrop Almond Formation facies.

2.33 - Comparison of subsurfacc and outcrop facics porosity, Almond Formation

2.34 - Natural $\log$ of permcability versus porosity for outcrop and subsurface Almond Formation.

2.35 - Comparison of subsurface and outcrop permeability distribution for Almond facics. 61

2.36 - Primary and secondary recovery behaviors of well Arch 44

2.37 - Distribution of the initial oil production (bbl/d) for Patrick Draw ficld. 62

2.38 - Imbibition and drainage oil-water relative permeability analysis measured in the Almond Formation from wcll Champlin Pctrolcum Company No. 1 (Arch \#12B, section 19), Patrick Draw field. 63

2.39 - Two-ycar primary cumulative oil production map.

2.40 - Plot of two-ycar cumulative oil production vs. initial production (IP)

2.41 - Plot of cumulative and initial oil production as functions of nermcability thickness product (kh) in wells along (a) profile 1 , (b) profilc 2 , and (c) profile 3

2.42 - An cxample Hall plot from an Arch unit well 4

2.43 - Calculated $\mathrm{k}_{w h}$ (Hall plot) distributions of UA-5 sandstone water injectors in Arch Unit 68

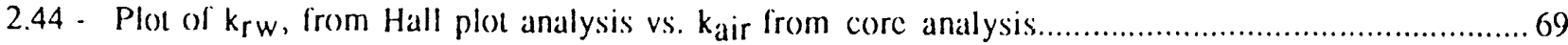

2.45 - Distribution of $k_{r w}$ calculated from water injection.......................................................... 70

2.46- Watcr oil ratio (WOR) vs. cumulative oil production plot illustrating threc types of curves. (a) noisy or irrcgular data, (b) asymptotic responsc, and (c) double water brcakthrough

2.47 - Cumulative oil preduction volume and cumulative fluid (oil and water) production volume vs. cumulative water injection through 1983 for Arch unit 72

2.48. Distribution of tolal water injection. 


\section{ILLUSTRATIONS (continucd)}

2.49 - Distribution of cumulative oil production from 1966 to 1986.

2.50 - Distribution of wells producing single hydrocarbon phasc (oil) versus those producing oil and gas during initial production in Patrick Draw ficld.

2.51 - Relationship of the initial oil and gas production in wells of the entire Patrick Draw ficld. 76

2.52 - Compositc map illustrating major fluid, pressurc, and production anomalies in Patrick Draw ficld and postulated hydrodynamic barriers to fluid flow.

2.53 - Distributions of log derived and laboratory measured porosity and water saturations in UA-6 sand in well 81

2.54 - Distributions of clay content $\left(\mathrm{V}_{\mathrm{cl}}\right)$ and porosity in the UA-6 sand obtained from $\log$ interpretations in wells 81,71 and 67.

2.55 - Distributions of log derived water saturations in highly helcrogencous UA-6 sand in wells 81,71 and 67 .

2.56 - Rose diagrams of fracture orientations and related statistics for the all measured outcrops located on the southcastern flank of the Rock Springs Uplift, all sandstone intervals in outcrop $G$, and all sandstonc intervals in outcrop $\mathrm{H}$

2.57 - Rose diagrams of fracture orientations and related statistics for the Oyster Marker Bed (OMB); Tidal Channcl; and Spit and Shoreface facics in outcrop G.

2.58 - Rose diagrams of fracture orientations and related statistics for three major sandstone layers in outcrop H ( Tidal Channel and Tidal Delta; Tidal Flat and Tidal Channcl; Flood

Tidal Delta, Tidal Inlet, and Tidal Channel facies stacked in stratigraphically ascending order)

2.59 - (a) Rose diagram of fracture oricntations and related statistics in outcrop VH8

(Van Horn arca). (b) Rose diagram of fracture orientations and rclated statistics in

"White Sands" overlying bar G in oulcrop G.

2.60 - (a) Rose diagram fracture orientations and related statistics in outcrops "Whitc Sands 2" and "Major Whtte Sands" northeast and north of outcrop G. (b) Rose diagram of fracture oricntations and related statistics in sandstones underlying marine sequence of the Upper Almond in outcrop $\mathrm{H}$.

3.1 - Palcogeographic map of upper Almond Formation barrier bar $G$ and associated facies located in the Rock Springs Uplift, Wyoming.

3.2 - Depositional model for barrier island deposits and valley cut and lill at Unit 'A' in Bell Creck licld.......103

3.3 - Ternary plot of quartz-feldspar-rock fragment composition of outcrop and subsurface Almond and Muddy formations.

3.4 - Comparison of outcrop and subsurface grain sizc distribution for various Muddy Formation facies in and and around Bell Creck licld, MT. Boxes indicate limits of second and third quartiles, "whiskers" indicate ranges of data to 5 th and 95th percentiles, circles indicate datia outlicrs beyond 5th and 95th percentiles. "N" represents number of samples in cach class of data. 


\section{ILLUSTRATIONS (continued)}

3.5 - Comparison of outcrop and subsurface grain size distribution for various facies in the

Almond Formation.

3.6 - Comparison of outcrop and subsurface standard deviation of grain size for various Muddy

Formation facies in and around Bell Creek field, MT.

3.7 - Standard deviation (sorting) for various outcrop and subsurface facies in the Almond

Formation.

3.8 - Standard deviation of grain size versus mean grain size for Muddy Formation outcrop facies

3.9 - Standard deviation of grain size versus mean grain size for Muddy Formation subsurface facies.

3.10 - Standard deviation (sorting) versus mean grain size for outcrop Almond Formation facies. 108

3.11 - Standard deviation (sorting) versus mean grain size for subsurface Almond Formation facics.

3.12 - Comparison of outcrop and subsurface porosity for various facies in the Muddy Formation in and around Bell Creck field, MT.

3.13 - Comparison of subsurface and outcrop facies porosity, Almond Formation.

3.14 - Natural log of permcability (Ink) versus porosity for combined outcrop and subsurface Muddy Formation samples.

3.15 - Natural log of permeability versus porosity for outcrop and subsurface Almond Formation.

3.16 - Comparison of subsurface and outcrop permeability distribution for Almond facies

3.17 - Comparison of outcrop and subsurface natural log of permeability for various facies in the Muddy Formation in and around Bell Crcck ficld, MT.

3.18- Natural log of permeability (Ink) versus mean grain size for outcropping Almond Formation facics......112

3.19 - Natural log of permeability (Ink) versus mean grain size for subsurface Almond Formation facies. .......112

3.20 - Natural log of permeability (Ink) versus mean grain size for outcropping Muddy Formation facies........113

3.21 - Natural log of permeability (Ink) versus mean grain size for subsurface Muddy Formation facics.

3.22 - Porosity versus mcan grain sizc for outcropping Muddy Formation facies.

3.23 - Porosity versus mean grain sizc for outcropping Almond Formation facics.

3.24 - Porosity versus mean grain sizc for subsurface Muddy Formation facies.

3.25 - Porosity versus mcan grain sizc for subsurface Almond Formation facics.

4.1 - Permeability and porosity variograms of well 15, Arch Unit, Patrick Draw ficld.

4.2 - Permcability and porosity variograms of well 20, Arch Unit, Patrick Draw ficld.

4.3 - Permcability-porosity cross-variogram of well 20, Arch Unit, Patrick Draw lield. 


\section{ILLUSTRATIONS (continued)}

4.4 - Permeability and porosity variograms of well 88, Arch Unit, Patrick Draw ficld.

4.5 - Permeability-porosity cross-variogram of permeability-porosity well 88, Arch Unit, Patrick Draw field.

4.6 - Geological permeability model of Shannon outcrop area

.130

4.7 - Indicator kriging permeability model of part of Shannon outcrop area using 50 core control data points.

4.8 - Indicator kriging permcability model of Shannon outcrop area using two vertical profiles of permeability as control data and various seed numbers: (a) 10, (b) 30, (c) 50, and (d) 100

4.9 - Indicator kriging permeability model of Shannon outcrop area using two vertica! profiles of permeability as control data and various seed numbers: (a) 10, (b) 30 , and (c) 50

4.10 - Indicator kriging permeability model of Shannon outcrop area using two vertical profilcs of permeability as control data and two horizontal scalc lengths: (a) $10 \mathrm{ft}$ and (b) $20 \mathrm{ft}$.

4.11 - Oil recovery of waterflood simulations from geological and indicator kriging models for $35^{\circ}$ API oil gravity.

4.12 - Oil recovery of waterflood simulations from geological and indicator kriging models for $20^{\circ}$ API oil gravity

4.13 - Cross-section permeability models between wells 15 and 21 in Patrick Draw ficld from indicator kriging using three seed numbers: (a) 10 , (b) 30 , and (c) 100 .

4.14 - Three-dimensional permeability models $(30 \times 30 \times 8)$ for wells 13,15 , and 21 in Patrick Draw field from indicator kriging using secd number 10.

4.14 - Three-dimensional permeability models (Continued).

4.15 - Calibration of pressure gauges of mini-permeameter.

4.16 - Calibration of high-flow meter of mini-permeameter

4.17 - Calibration of permeability measurements of mini-permeameter

4.18 - Permeability profile of corehole No. 2 .

4.19 - Permeability variogram of corehole No.2, depth $56-89 \mathrm{ft}$

4.20) - Permeability variogram of corchole No.2, depth $147-166 \mathrm{ft}$.

4.21 - Permeability variogram of corchole No.2, depth $190-266 \mathrm{ft}$

4.22 - Permeability profiles of wells 120,121 , and 123 of Patrick Draw ficld

4.23 - Permeability variogram of well 120 , Patrick Draw ficld 144

4.24 - Permeability variogram of well 121, Patrick Draw ficld 


\section{ILLUSTRATIONS (continued)}

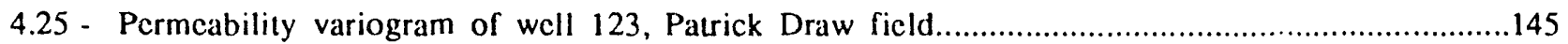

4.26 - Overburden stress and stress gradient as a function of depth for wells Arch 91 and Arch 100 derived from density wircline logs.

4.27 - Distribution of sonic transit times (delta time) and resistivity in shales as a function of depth in wells Arch 79 and Arch 84. 


\title{
INTEGRATED GEOLOGICAL-ENGINEERING MODEL OF PATRICK DRAW FIELD AND EXAMPLES OF SIMILARITIES AND DIFFERENCES AMONG VARIOUS SHORELINE BARRIER SYSTEMS
}

\author{
By
}

\author{
R. A. Schatzinger, M. J. Szpakiewicz, S. R. Jackson, M.-M. Chang, B. Sharma, M. K. Tham and A. M. Cheng
}

\begin{abstract}
The Reservoir Assessment and Characterization Research Program at NIPER employs an interdisciplinary approach that focuses on the high priority reservoir class of shoreline barrier deposits to: (1) determine the pioblerns specific to this class of reservoirs by identifying the reservoir heterogeneities that influence the movement and trapping of fluids; and (2) develop methods to characterizc cticctively this class of reservoirs to predict residual oil saturation (ROS) on interwell scaies and improve prediction of the flow patterns of injected and produced fluids.

Accurate descriptions of the spatial distribution of critical reservoir parameters (c.g. permeability, porosity, pore geometry, mineralogy, and oil saturation) are essential for designing and implementing processes to improve sweep efficiency and thereby increase oil recovery. The methodologies and models developed in this program will, in the near- to mid-term, assist producers in the implementation of effective reservoir management strategies such as location of infill wells and selection of optimum enhanced oil recovery methods to maximize oil production from their reservoirs.

The scope of the work for FY 91 consisted of the following four main areas: (1) the development of the quantitative geological and engineering model for Patrick Draw ficld; (2) the comparison of similaritics and differences between the meso-tidal shoreline barrier reservoir in Patrick Draw ficl't and the micro-tidal shoreline barrier reservoir in Beil Creek field; (3) the application of geostatistical techniques such as kriging and fractal analysis to estimatc interwell reservoir properties in Patrick Draw field; and (4) the continued development of methodologies for improved characterization of shorcline barrier reservoirs.

Development of the geologic model indicated that two broad permeability and porosity classes can be distinguished within the Arch Unit of Patrick Draw ficld according to facies groups. Facies comprising the higher permeability group include tidal inlet fill, tidal channel, and tidal delta facies with a gcometric mcan permeability of $20 \mathrm{mD}$ and porosities of $20 \%$. The higher permeabilities of this group of facies are consistent with higher depositional energies and corresponding coarser grain sizes and lower detrital clay content. The lower permeability class consists of tidal creck, tidal flat, swamp, and lagoonal facics with a geometric mcan
\end{abstract}

permeability of $1.5 \mathrm{mD}$ and mean porosity of $14 \%$. Major depcsitional features of the Almond Formation within the Arch Unit that are important to fluid flow consist of thin sand areas that have poor petrophysical properties because of carbonate cement or high clay content; sand thicks that contain the best reservoir quality rocks; facies with limited lateral extent; and coal beds. The relative timing of various carbonate cement phases plays a significant role in determining ro ir quality: early carbonate cements strengthened the reservoir rock, preventing or delaying compaction; however, large amounts of cement drastically reduce the storage capacity of the reservoir sandstones.

At least three lines of evidence indicate lateral compartmentalization in Patrick Draw ficld: (a) anomalous production of caly oil in the updip portion of the reservoir, close to the oil/gas contact, versus oil and gas production in the downdip portion, close to the oil/water contact; (b) an anomalous, precipitous drop in formation water salinity downdip in deeper parts of the reservoir; and (c) an anomalously large decrease of formation pressure during primary production in the eastern (downdip) portion of the reservoir. Timing, origin, and scale of occurrence of reservoir barriers are critical to optimal selection of advanced recovery schemes. Channeling and poor waterflond sweep efficiency in the Arch Unit are indicated by low waterflood recovery. Fractures are suspected as conduits to fluid flow because matrix permeability contrasts are not high enough to cause such severe channcling.

In the second area of study, important similarities found between the shoreline barrier reservoirs in Patrick Draw field and Bell Creck field were: (1) both rescrvoir systems are compatunentalized on a field scale - Bell Creck field has six major producing units and Patrick Draw ficld has three; (2) pay thicknesses are comparable - $23 \mathrm{ft}$ in Bell Creck ficld and $20 \mathrm{ft}$ in Patrick Draw field; (3) initial production in both reservoirs appears to be strongly influenced by the architecture of the depositional systems, while secondary and tertiary production appears to be more strongly controlled by structural and diagenetic features; and (4) faults play an important role in both reservoirs and contribute to the poor sweep efficiency during watcrlooding as well as salinity anomalies which may significantly affect EOR processes. Significant differences found between Patrick Draw field and Bell Creek field were: (1) diagenetic processes and timing were different in Bell Creck licld, early stage leaching created oversize 
pores and enhanced reservoir quality (average perme ability is $2,250 \mathrm{mD}$, average porosity is $28.5 \%$ ), while in Patrick Draw field, early stage leaching was relatively insignificant, but later stage cementation by carbonates and clays significantly degraded reservoir quality (average permeability is $36 \mathrm{mD}$, average porosity is $19.6 \%$ ); (2) the scale of major depositional heterogencitics differs due to the different depositional processes-in the micro-tidal Bell Creek field, major heterogeneities are on the scale of 1000 's ft along depositional strike, whereis in the mesotidal Patrick Draw field, the scale is conmonly 10 's to 100 's ft; and (3) the production mechanist in Bell Creck field was solution gas drive, whercas in Patrick Draw ficld, a strong gas-cap drive produced oil.

The third area of investigation consisted of geostatistical analysis of perncability and porosity data from Patrick Draw field using variogram analysis and indicator simulation techniques. Vertical correlation lengths for three wells in Patrick Draw field ranged from $4 \mathrm{lo} 15 \mathrm{lt}$, which could be related to thicknesses of cross bed sets. Indicator simulation results indicated poor interwell continuity of high permeability sands a nong the three wells. These results are supported by lower lluid injectivities found in this part of the reservoir.

The fourth area of study was the investigation of efficient characterization methods. Permeability models based on closely spaced outcrop samples were consuructed using various techniques including indicator simulation techniques. Predictions of oil recovery from the indicator models were compared to those from the most detailed model and were found to be within $5 \%$ of each other for the $20^{\circ}$ API oil case. The similar oil recovery predictions suggest that the indicator permcability models reasonably represent the most detailed model. Wireline log analysis of the effect of subsurface stresses on fluid production at Patrick Draw indicated that the integration of density log data provides a good estimation of overburden stresses.

\section{EXECUTIVE SUMMARY}

The broad objectives of the National Energy Strategy 1 are to reduce U.S. vulnerability to crude oil supply disruptions by expanding U.S. oil production capacity and strategic stocks. This goal is addressed by threc timespecific, strategic objectives that (1) preserve access 10 reservoirs with high potential which are rapidly approaching their economic limits, in the the near-term; (2) develop, test, and transfer the best, currently defined, advanced technologies to operators, in the mid-term; and (3) develop sufficient fundamental understanding to define new recovery techniques for the remaining oil, in the long. term.

NIPER's Reservoir Assessment and Characterization Research Program incorporates elements of each of these

\footnotetext{
National Energy Strategy - First Edition 1991/1992. DOE Report DOE/S-0082P, Fcb. 1991.
}

objectives. The reservoirs studied, shoreline barrier reservoirs, represent a class of reservoirs with large amounts of remaining oil in place (ROIP) located in mature fields with a high number of shut-in and abandoned wells. The analysis and models developed in the course of the research will directly benefit the operators of the fields, as well as those companies operating in similar types of reservoirs in the near term. For example, as a result of this work, the information needed to reposition water injection and production wells is available to operators to optimize production and potentially prevent further well abandonments. An evaluation of a proposed $\mathrm{CO}_{2}$ pilot project is also provided.

Near- to mid-term applications of the results of this research comprise a methodology to quantify the effects of heterogencities and construct accurate reservoir models. Long-term results of the research will be the determination of the transferability of reservoir and production characteristics among reservoirs of similar depositional historics. Identification of similar hetcrogeneities will allow application of similar reservoir management strategies and advanced recovery methods to maximize recovery efficiency. Because of the similarity between shoreline barrier and some delta-front depositional settings, the scope of work will be expanded to include comparison of reservoir heterogeneities from selected delta-related barriers with shoreline barriers (FY93). Preliminary work on fluvial-dominated deltas will begin in FY92.

The research program at NIPER employs an interdisciplinary approach that focuses on the high-priority reservoir class of shoreline barrier deposits to: (1) determine the problems specific to this class of reservoirs by identifying the reservoir heterogeneities that influence the movement and trapping of fluids and (2) develop methods to characterize effectively this class of reservoirs to predict residual oil saturation (ROS) on interwell scales and improve prediction of the flow patterns of injected and produced lluids.

Accurate descriptions of the spatial distribution of critical reservoir parameters (c.g. permeability, porosity, pore geometry, mincralogy, and oil saturation) are cssential for designing and implementing processes to improve sweep efficiency and thereby increase oil recovery. The methodologies and models developed in this program will, in the near- 10 mid-term, assist producers in the implementation of effective reservoir management strategies such as location of infill wells and selection of optimum enhanced oil recovery methods to maximizc oil production from their reservoirs.

As in previous years, an interdisciplinary team approach was used to characterize Patrick Draw (WY) field and to compare the developed geological and enginecring models with models from Bell Creek (MT) field. The scope of the work for FY91 consisted of the following four main areas: (1) the development of the quantitative geological model for Patrick Draw ficld and the construction of the engincering model for Patrick Draw field; (2) comparison of the similarities and differences between the meso-tidal 
shoreline barrier reservoir in Patrick Draw field and the micro-tidal shoreline barricr reservoir in Bell Creck ficld; (3) the application of geostatistical techniques such as kriging and fractal analysis to estimate interwell reservoir propertics in Patrick Draw field; and (4) the continued development of methodologies for improved characterization of shoreline barrier reservoirs.

In the first area, reservoir and outcrop information was used to construct the quantitative geological shoreline barrier model for Patrick Draw ficld. Preliminary investigations have suggested that mesotidal processes $(2$ to $4 \mathrm{~m}$ range) dominated the depositional setting at Patrick Draw ficld. The work in FY91 provided more detailed information about the reservoir model for Patrick Draw iicld.

Two broad permcability and porosity classes can be distinguished according to groups of facies. The higher permeability class consists of tidal inlet, tidal channel, and tidal delta facies and is consistent with the higher depositional energies of the facies. A lower permeability class consists of lidal crcek, tidal flat, swamp, and lagoonal facies. Low-permeability intervals appear to be the result of carbonate cementation, detrital ciay, and clay cement.

Major depositional features of the Almond Formation within the Arch Unit, Patrick Draw field that are important to fluid flow consist of: (a) sand thin arcas containing low-permeability sediments consisting of oyster coquina, carbonaccous shalc, and shalcy sand; (b) sand thick areas that contain the best reservoir quality rocks; (c) facies with limited lateral extent (10's to 1000's $\mathrm{ft}$ ); (d) coal beds prone to parting and fracturing during fluid injection; and (d) calcite cemented oyster-shell \%ones.

The analysis of outcrop exposures of the Almond Formation indicated that the rocks are genetically and scdimentologically similar to those observed in subsurface cores from Patrick Draw ficld. The tendency is, however, for outcrop sandstones to be less quartzose than subsurface samples. Subsurface Almond samples contain higher and more variable amounts of carbonate matcrial than outcrop samples.

XRD analyses indicatc a mean of only about $3.6 \%$ total clays from Patrick Draw reservoir sandstones and $2.2 \%$ from outcrop Almond sandstones, which is generally less than the values determined from wircline log analysis. This indicates that log-derived petrophysical propertics may be more pessimistic than those determined from corc analysis.

Ficld measurements and analysis of fracture parancers in the outcrops studicd on the southeastern flank of the Rock Springs Uplift revealed that the fracture pattern of barricr "bar $G$ " rock is laterally consistent over a distance of at least 2 miles.

Analysis of primary and secondary production/injection data was used to construct the enginecring model for Patrick Draw ficld. Analysis of primary production data indicated that intial production (IP) appears to be predominantly controlled by the thickness of the UA - 5B sandstone. However, structural features may also play a role in the distribution of cumulative primary and secondary production.

Channeling and poor waterflood swcep efficiency in the Arch Unit are indicated by low waterflood recovery. Fractures are the suspected conduits to fluid flow because matrix permcability contrasts are not high enough to cause such sevare channeling.

At lcast three convergent lines of evidence indicate lateral compartmentalization in Patrick Draw field: (a) anomalous production of only oil in the updip portion of the reservoir, close to the oil/gas contact, versus oil and gas production in the downdip portion, close to the oil/water contact; (b) an anomalous precipitous drop in formation water salinity downdip in deeper parts of the reservoir; and c) an anomalously large decrease of formation pressure during primary production in the castem (downdip) portion of the reservoir.

Primary and waterlood production/injection analysis at Patrick Draw and Bell Creck ficlds indicated that water relative permeability ( $\mathrm{K}_{\mathrm{rw}}$ ) is very low compared to oil relative permeability at both Patrick Draw and Bell Creck ficlds. Although $\mathrm{krw}_{\mathrm{rw}}$ is low in both ficlds, water injectivity and waterllood oil recovery are significantly lower at Patrick Draw field. Sandstone thickness is the major control of primary production performance in the Arch Unit. Bcll Creck (TIP arca) and Patrick Diaw (Arch Unit) have similar primary production characteristics but different waterflood performances.

The second arca of investigation was the comparison of the microtidal shorcline system of the Muddy Formation with the mesotidal shoreline barrier system of the Almond Formation and indicate the following: the Almond Formation shorelinc barricr deposits have a facies architecture that is characterized by short barrier island segments separated by abundant tidal inlets. Tidal inlet fill, tidal delta, and tidal channel/tidal creck deposits are all well represented at Patrick Draw and in the analogous outcrops. Lateral migration of the tidal inlets was the dominant process lcading to formation of a broad belt behind the barricr that is dominated by tidal delta and tidal channel deposits. The dimensions of facies within the mesolidal system at Patrick Draw field are generally smaller than for microtidal shoreline barricr systems such as al Bell Creck ficld.

Mcan grain sizc for Muddy and Almond Formation depositional facies are similar. Sorting of Muddy and Almond formation sandstones also overlaps; however, Almond facies have a much larger range of sorting than do facies from the Muddy Formation. These differences may reflect different suites of facies which were created by different intensities of wave and tidal depositional processes.

The uend of increased grain size with decreased sorting for both Almond and Muddy Formations probably represents a iundamental relationship caused by availability of a wider range of grain sizes for the coarser samples. This relationship implies that small rock 
samples the size of cuttings may prove useful in determining depositional facies at Patrick Draw field.

The lithological and mineralogical composition of Bell Creek and Patrick Draw reservoir sandstones is a function of both initial lithologies and diagenetic history. Relative increase in the amount of clay-rich sedimentary rock fragments in the Almond Formation make the UA-5 reservoir at Patrick Draw field more susceptible to compaction and reduced pore throat sizes, while the distribution and crystallographic habits of kaolinite and illite in the Muddy Formation make the reservoir rocks at Bell Creek field sensitive to the migration of fines during completion and production.

The third area of investigation consisted of geostatistical analysis of Almond Formation and Patrick Draw porosity and permeability data. Variograms and cross-variograms developed in FY91 for porosity and permeability will be used for mapping interwell porosity and permeability using kriging and $\infty$-kriging techniques.

Heterogeneous permeability profiles determine injection profiles and fingering phenomena in the vertical direction and flow paths in the areal direction. More than 600 closely spaced permeability readings were made with a portable mini-permeameter from outcrop core No, 2 which included the fluvial Lower Almond as well as the shoreline barrier Upper Almond. Based on variogram analysis, a vertical correlation length for permeability values was found to be between 18 and $27 \mathrm{ft}$, which is approximately the thickness of one fluvial and barrier island depositional cycle, respectively, in the Almond Formation in the corehole studied.

The fourth area addressed was the investigation of economical methods for shoreline barrier/barrier island reservoir description and simulation (methodology development). Two activities were undertaken: (1) development and testing of a mini-permeameter for application of geostatistical techniques to reservoir and outcrop rock samples; and (2) wireline log analysis of the effect of subsurface stresses on fluid production at Patrick Draw. The wireline log investigation of subsurface stresses found that: (1) good estimation of overburden stresses could be obtained from integration of density log data, and (2) variation of shale resistivity with depth at Patrick Draw field is a function of the amount of water in the pores and is also dependent on the salinity of the formation water. 


\section{Chapter 1 \\ INTRODUCTION}

\section{BACKGROUND}

The broad objectives of the Department of Energy's program for geoscience research are to develop methods for locating residual oil saturation distribution in oil reservoirs and to evaluate suitable methods for recovering the oil. The objectives of the NIPER BEl program fit within those of the Department of Energy's geoscience program by providing a methodology for the effective characterization of shoreline barrier reservoirs and increasing the understanding of the heterogeneities that influence movement and trapping of fluids within this class of reservoirs. Two reservoirs were selected for study: Bell Creck field, MT and the Patrick Draw field, WY (fig 1.1).

At first, a microtidal system at Bell Creek (MT) field was sclected for reservoir assessment and characterization research (FY86-FY89) (fig. 1.2). A combined quantified geological/engineering model was developed and used to identify the types and scales of heterogeneities in the shoreline barrier system at Bell Creek. From this basis, the influence of various heterogeneities on fluid flow and hydrocarbon trapping was investigated (Honarpour et al., 1989).

To broaden the geological and engineering understanding of comparative aspects of shoreline barrier reservoirs, a mesotidal shoreline barrier example, Patrick Draw field, was selected during FY90 (fig. 1.2). By incorporating the Patrick Draw field model into the generalized barrier island model, the product became more broadly applicable.

The work during FY90 consisted of three main areas. First, a mesotidal, tide-dominated shoreline barrier/barricr island reservoir, (Patrick Draw field) was selected. The second area of work focused on determining the fundamental relationships between geological, petrophysical, and reservoir production/injection characteristics. The third area of investigation consisted of determining more efficient and economical methods for shoreline barrier/barrier island reservoir description and simulation (methodology).

During FY91, characterization of the mesotidal system at Patrick Draw ficld continued primarily through work in four areas. First was continued improvement and quantification of the geological shoreline barricr model for Patrick Draw field. The sccond area included construction of the enginecring model for Patrick Draw field through improved reservoir description and its integration with the geological model. The third area included geostatistical analysis in order to estimate interwell reservoir propertics in Patrick Draw field. This activity provided an opportunity to investigate the strengths and weaknesses of different geostatistical techniques. The finat area of work during FY91 was to continuc to improve and generalize the methodology for characterizing shoreline barrier reservoirs. Advances in each of these areas are described in this report.

\section{END MEMBER MODELS OF SHORELINE BARRIER DEPOSITION}

Description of shoreline barrier depositional systems by a single model is unrealistic. The morphology of shoreline barrier sand deposits is related to a number of processes including tidal range, tidal currents, wave conditions, and storm action (Hayes, 1975). Tidal range has the greatest effect on the resultant architecture of the depositional facies. After several years of studying tidal deltas under different conditions of wave and tidal regimes, Hayes (1975), Hayes and Kana (1976), and Hayes and Sexton (1989) concluded that tidal range has the principal control over the distribution and form (facies architecture) of shoreline barrier sand deposits. Davies (1964) recognized the importance of tidal range and suggested that coasts with tidal fluctuations less than $2 \mathrm{~m}$ be classified as microtidal; those from 2 to $4 \mathrm{~m}$, mesotidal; and when greater than $4 \mathrm{~m}$, macrotidal. Microtidal and mesotidal shoreline barriers are common along modern shorelines, and equivalent deposits are important petroleum reservoirs. Shoreline barriers are generally not developed under macrotidal conditions.

Processes that dominate microtidal barrier shorelines are created by wind and wave effects. Wind tidal flats are commonly associated with microtidal shoreline barriers, as are aligned beaches and recurved and cuspate spits. Tidal currents are generally important only at the mouths of inlets (Hayes, 1975), so that flood tidal deltas are usually small, but larger than ebb tidal deltas (Hayes and Sexton, 1989). Another characteristic deposit of microtidal shoreline barriers includes washover fans deposited during storm surge floods that push fan-shaped sand accumulations onto the lagoonal side of the barrier. Wave-dominated, or microtidal barrier islands tend to be long and continuous with few inlets (fig. 1.2).

Mesotidal barriers differ in that sediments deposited by tidal currents predominate. The barrier islands tend to be short and "drumstick" shaped deposits (fig. 1.2) with abundant brcaks between islands occupied by inlets, and on the lagoonay side, large, conspicuous tidal deltas. Important loci of sand deposition in mesotidal shoreline barricrs arc bchind the barrier on the tidal deltas and within the tidal channels. Although flood tidal deltas are prominent on mesotidal barriers, they are often smaller than associated ebb tidal deltas. Comparison of microtida! and mesotidal barrier island geomorphological characteristics is given in table 1.1. 
The ultimate control of barrier morphology is related to the ratio of wave energy flux to tidal energy flux (hydrologic regime) as previously described (Hayes, 1979). However, barrier morphology is also a function of the stratigraphic context. Landward migrating (transgressive) barriers have different vertical sequences and often have different morphologies than seaward prograding (regressive) barriers. Transgressive barriers are similar morphologically (Hayes and Sexton, 1989), regardless of hydrodynamic regime. They are generally composed of straight washover terraces whose lengths are determined by the hydrographic regime. Rigressive barriers, in contrast, show great morphological differences depending on the hydrographic regime.

Preservation potential of reservoir quality sand deposits is higher on the sheltered iagoonal side of the barrier. The facies with the greatest potential for preservation include those deposited in depositional lows such as tidal channels and inlet fill deposits, and those associated with the lobes of tidal deltas. Downdrift migration (and occasionally updrift migration) of tidal inlets also has a significant impact on the preserved sequence and architecture of mesotidal barrier sandbodies. Inlets migrate in response to preferential addition of sediment by longshore transport to one side of the inlet (FitzGerald, 1976). As the inlet migrates so do the associated flood and ebb-tidal deltas. On the lagoonal side of the barrier, the result is often a laterally continuous, interconnected accumulation of sands which are dominated by tidal delta and tidal channel facies. The lateral extent of these potential reservoir quality sands is controlled by the distance between inlets, the size of flood tidal deltas, the rate of inlet migration, rate of transgression or regression, syndepositional and post depositional erosion, and the preservation of non-reservoir facies associated with the tidal delta and tidal channel sands.

Permanent tidal inlets may also be fixed relative to their lateral position along the coastline. Fixed inlets are generally related to preexisting depressions such as flooded river valleys cut into semiconsolidated marine clays (FitzGerald, 1976; Morton and Donaldson, 1973). Al fixed inlets, constructional processes include shoreline progradation due to landward marine bar inigration, and spit accretion welding the newly emergent bar to the existing beach. Sediment capture is also created by transport reversal as waves refract around the cbb delta reintroducing downdrift migrating sand to the inlet or inlet marginal shoals.

\section{DATA COLLECTED FOR ALMOND FORMATION}

The basis for understanding the architecture of reservoir quality sandstones and ultimately production/injection behavior is the analysis of geological data and its integration with the production/injection records at Patrick Draw field. Fifteen cores from the Almond Formation housed in the U. S. Geological Survey core collection
(Denver) were correlated with wireline logs and subjected to sedimentological analysis. From these cores 33 oneinch diameter plugs were laken from six cores for petrophysical measurements and thin sections.

Additionally, two cores taken from locations near the outcrops of Almond stratigraphic intervals UA-1, UA-2, and UA-3 were examined, and the locations of the two corcholes were visited during a field reconnaissance (see fig. 1.4).

Confidence of certain facies identifications may be dramatically increased through outcrop studies where directional features can be identified and types and scales of identified heterogeneities can be traced laterally. During the field reconnaissance, it was determined that the depositional facies observed in the outcrop exposures were similar to those encountered in subsurface cores from Patrick Draw field and that the depositional environments were hydrodynamically similar. At that time, it was found that some of the outcrops extend laterally for thousands of feet and provide three-dimensional exposure of the facies.

The presence of good outcrops which are depositionally similar to the setting at Patrick Draw ficld and can provide uscful information about subsurface reservoir performance suggested that further outcrop investigation was warranted. Therefore, a second geological field trip to the outcrop exposures of the Almond Formation along the Rock Springs Uplift was conducted in June, 1991. Geological ficld work during this trip included selection of the best outcrops for geological measurement and detailed future sampling, detailed sedimentological characterization of three selected outcrop profiles, drilling of approximately 80 one inch plugs for petrophysical measurements and the petrographic study, and documentation of fracture orientation, density, continuity, and fracture filling.

Outcrops RG and RH, which were previously desc: ibed by Rochler (1988), and are located about 2 miles apart and oriented generally along depositional dip, were selected for detailed section measuring and drilling of core plugs (fig. 1.4). One 257-ft-thick section was measured at the northern outcrop (RG) and two sections (145 and $140 \mathrm{ft}$ thick) were measured at the southem outcrop (RH).

Information about heterogencity of formation fluids and their chemical characteristics at different locations and producing horizons is crucial for correct interpretation of certain $\log$ responses and for estimation of rock-fluid interaction processes and products which may affect rock permeability. Strong anomalies in water salinity and chemical composition were documented earlier in some Almond Formation wells at Patrick Draw field (S\%pakicwic\% and Collins, 1985; S\%pakiewicz et al., 1991). Variations in fluid chemistry have also been used to identify compartmentalization within the reservoir.

Because of the importance of tluid heterogencities, it was decided to check the wellheads of about 20 selected wells in Patrick Draw field with the cooperation of Union Pacific Resources Co. (UPRC) personnel from Rock Springs, $W Y$, to determine sampling techniques for future sampling of formation fluids. During the June field trip 
updated chemical analyses of natural gas and co-produced formation waters were also icquired from UPRC. Unfortunately, oil analyses are not available from UPRC files.

\section{REFERENCES}

Barlow, J. A., Jr. 1961, Almond Formation and Lower Lewis Shale, East Flank of Rock Springs Uplift, Sweetwater County, Wyoming. in: Wyoming Geologic Association Symposium on Late Cretaceous Rocks, Sixteenth Annual Field Confierence Green River, Washakie, Wind River and Powder River Basins, p. 114.

Davies, J. L. 1964, A Morphogenetic Approach to World Shorelines. Zeits. fur Geomorph. v. 8, p. 127-142.

FitzGerald, D. M. 1976, Ebb-Tidal Delta of Price Inlet, South Carolina: Geomorphology, Physical Processes, and Associated Inlet Shoreline Changes. In Hayes, M. O., and T. W. Kana, eds., Terrigenous Clastic Depositional Environments. Coastal Research Division, Dept. of Gcology, Univ. of South Carolina, p. II-143-11-157.

Hayes, M. O. 1975, Morphology of Sand Accumulation in Estuarics: An Introduction to the Symposium. In Cronin, L. E., ed., Estuarine Research, v. 2, Gcology and Enginecring, p. 3-22.

Hayes, M. O. 1979, Barrier Island Morphology as a Function of Tidal and Wave Regime. In Leatherman, S.P., ed., Barrier Islands from the Gulf of St. Lawrence to the Gulf of Mexico. Academic Press, N.Y., p. 1-27.

Hayes, M. O. and T. W. Kana. 1976, Terrigenous Clastic Depositional Environments- Some Modern Examples. AAPG Ficld Course Guidebook and Lecture Notes. Tech. Rept. No. 11-CRD, Coastal Res. Div., Dept. of Gcology, Univ. of S. Carolina, Columbia, Part I, 131 p., Part II, 184 p.

Haycs, M. O. and W. J. Sexton. 1989, Modern Clastic Depositional Environments, South Carolina. Ficld Trip Guidebook T371. 28th Intern. Geol. Congress. Amer. Gcophysical Union, Washington, D. C., 85 p.

Honarpour, M., and others. 1989, Integrated Reservoir Asscssment and Characterization Covering the Period October 1, 1985 - September 30, 1988. Final Report. DOE Report NIPER-39().
Morton, R. A., and Donaldson, A. C. 1973, Sediment Distribution and Evolution of Tidal Deltas Along a TideDominated Shoreline, Wachapreague, Virginia. Sed. Geol. v. 10, p. 285-299.

Roehler, H. W. 1988, The Pintail Coal Bed and Barrier Bar G - A Model for Coa! of Barrier Bar-Lagoon Origin, Upper Cretaceous Almond Formation, Rock Springs Coal Field, Wyoming. USGS Prof. Paper 1398,60 p.

Srpakiewicz, M. J., and A. G. Collins. 1985, Hydrochemical Study of the Upper Cretaceous and Lower Tertiary Formations in the Uinta, Piceance and Greater green River Basins; Implications for Oil and Gas Related Problems. D.O.E. Report NIPER-95,.

Szpakiewicz, M. J., R. Schatzinger, S. Jackson, B. Sharma, A. Cheng, and M. Honarpour. 1991, Selection and Initial Characterization of a Second Barrier Island Reservoir System and Refining of Methodology for Characterization of Shoreline Barrier Reservoirs. DOE Report NIPER -484.

\section{ACKNOWLEDGMENTS}

The research team for Project BEl gratefully acknowledges the counsel and guidance of Tom Burchfield of NIPER in performing this work. The team also acknowledges Mike Madden, Min Tham, and Bill Linville for their continued guidance throughout the continuation of this project. The efforts of Viola Rawn-Schatzinger and Kathy Bertus helped to improve the manuscript. The support of Edith Allison, Project Manager, Bartlesville Project Office, U. S. Department of Encrgy is greatly appreciated. We appreciate the financial support of this research by the U.S. Department of Energy through Coopcrative Agreement DE-FC22-83FE60149. Special thanks arc duc to Frank Lim, Scnior Staff Engineer, Union Pacific Resources Co., Fort Worth, TX, and Jack Lane of the UPRC ficld office, Rock Springs, WY. This manuscript was word processed by Edna Hatcher. 
TABLE 1.1 - Some general geomorphological differences between microtidal and mesotidal barrier islands. After Hayes and Kana, 1976

\begin{tabular}{|c|c|c|c|c|c|c|}
\hline Barrier type & Length & Shape & $\begin{array}{l}\text { Washover } \\
\text { features }\end{array}$ & $\begin{array}{l}\text { Tidal } \\
\text { inlets }\end{array}$ & $\begin{array}{l}\text { Flood-tidal } \\
\text { deltas }\end{array}$ & $\begin{array}{l}\text { Ebb-tidal } \\
\text { dcltas }\end{array}$ \\
\hline Microridal & $\begin{array}{l}\text { long } \\
(30-100 \mathrm{~km})\end{array}$ & $\begin{array}{l}\text { elongated } \\
\text { hot dog }\end{array}$ & $\begin{array}{l}\text { abundant; } \\
\text { washover } \\
\text { terraces } \\
\text { and wash- } \\
\text { over fans } \\
\text { numerous }\end{array}$ & infrequent & $\begin{array}{l}\text { large; com- } \\
\text { monly coupled } \\
\text { with washovers }\end{array}$ & $\begin{array}{l}\text { small to } \\
\text { absent }\end{array}$ \\
\hline Mesotidal & $\begin{array}{l}\text { stunted } \\
(3-20 \mathrm{~km})\end{array}$ & drumstick & $\begin{array}{l}\text { minor; beach } \\
\text { ridges or } \\
\text { washover ter- } \\
\text { races; wash- } \\
\text { over fans rare }\end{array}$ & $\begin{array}{l}\text { numer- } \\
\text { ous }\end{array}$ & $\begin{array}{l}\text { moderate size } \\
\text { to absent }\end{array}$ & $\begin{array}{l}\text { large with } \\
\text { strong wave } \\
\text { refraction } \\
\text { effects }\end{array}$ \\
\hline
\end{tabular}




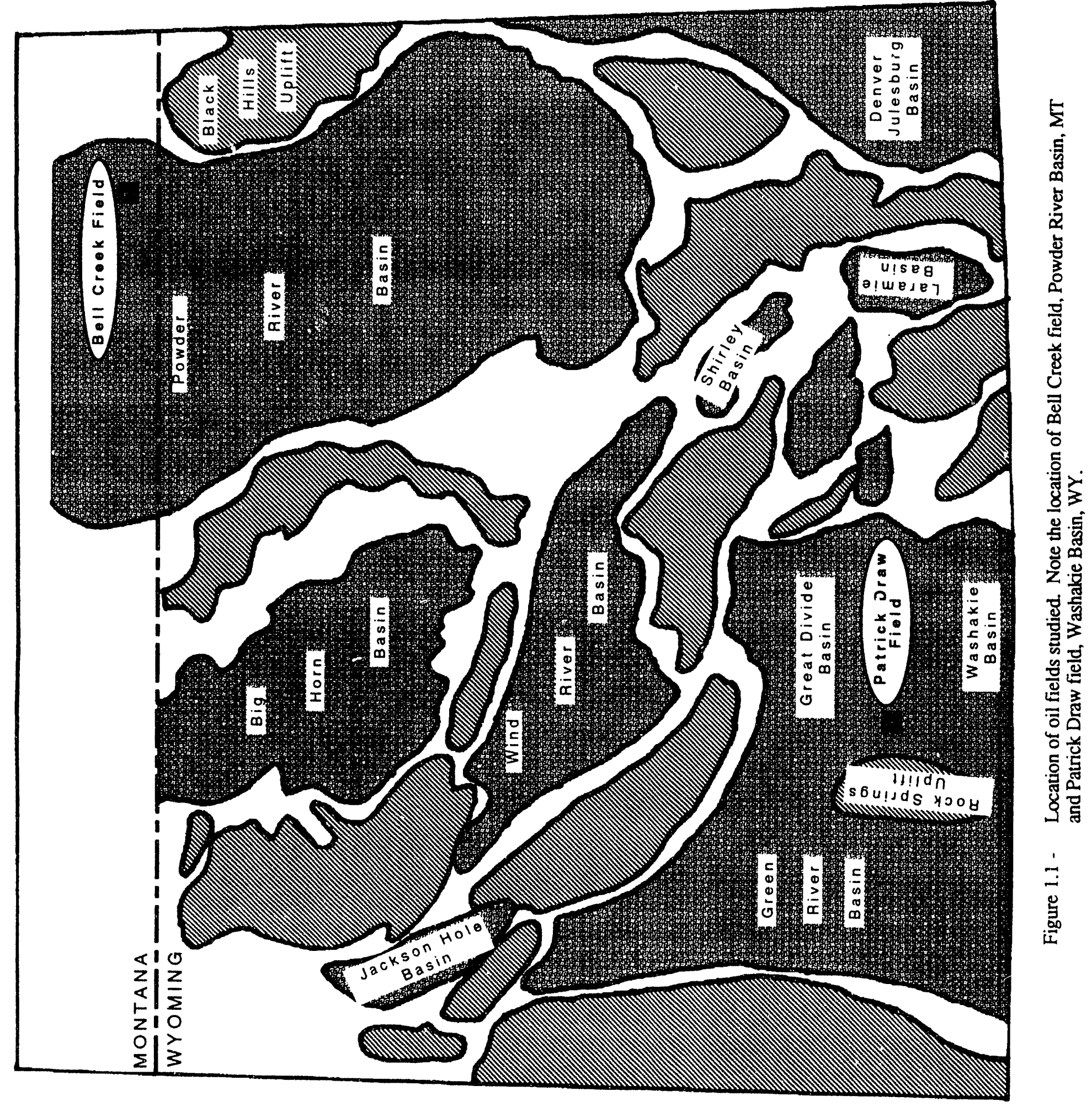



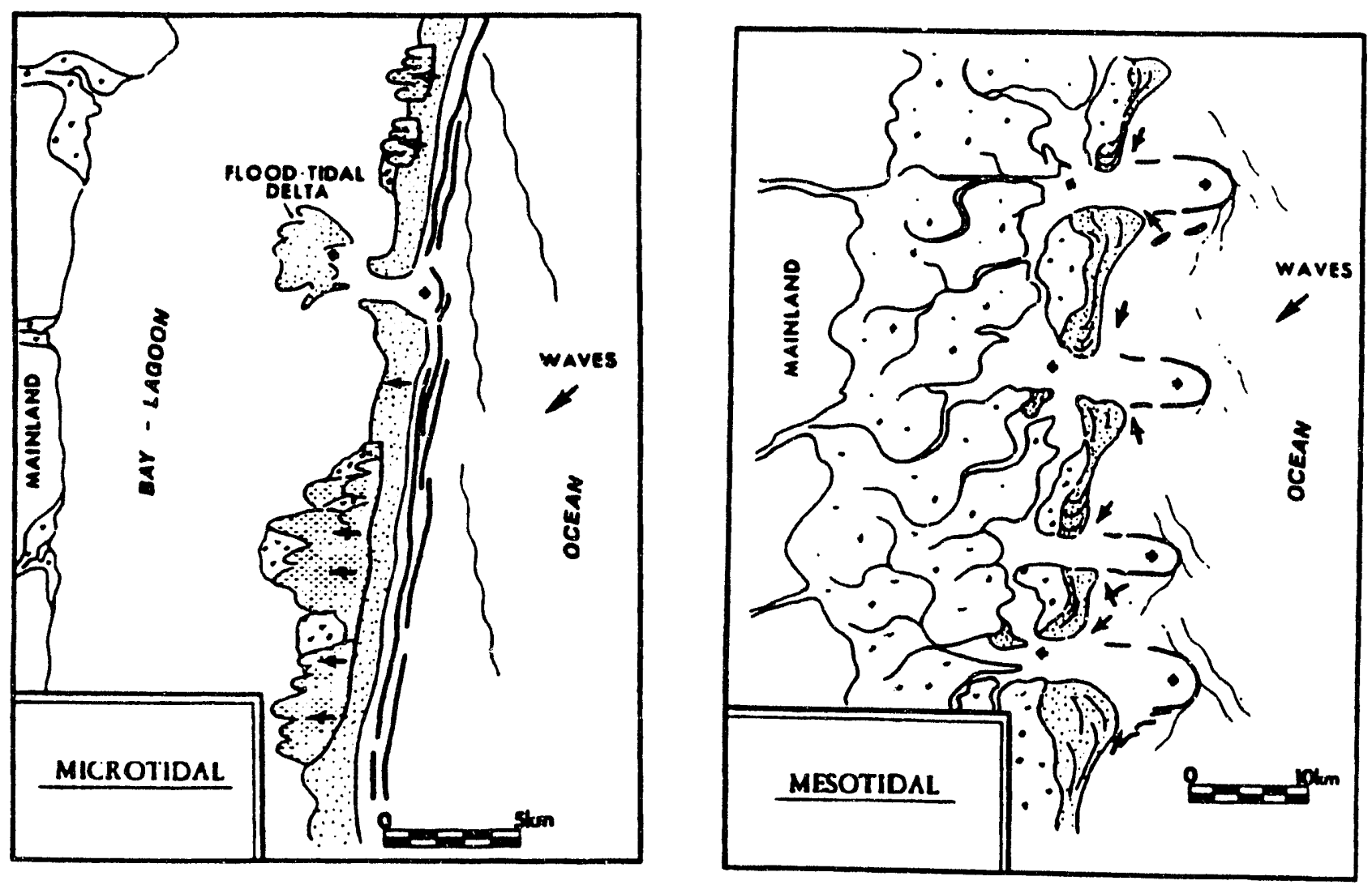

Figure 1.2 - Morphological models for microtidal, and mesotidal barrier shorelines with medium wave energy. Note that in microtidal barrier shorelines flood-tidal deltas tend to be considerably larger than cbb-tidal deltas. Also note the abundance of inlets in the mesotidal model. After Hayes (1979). 


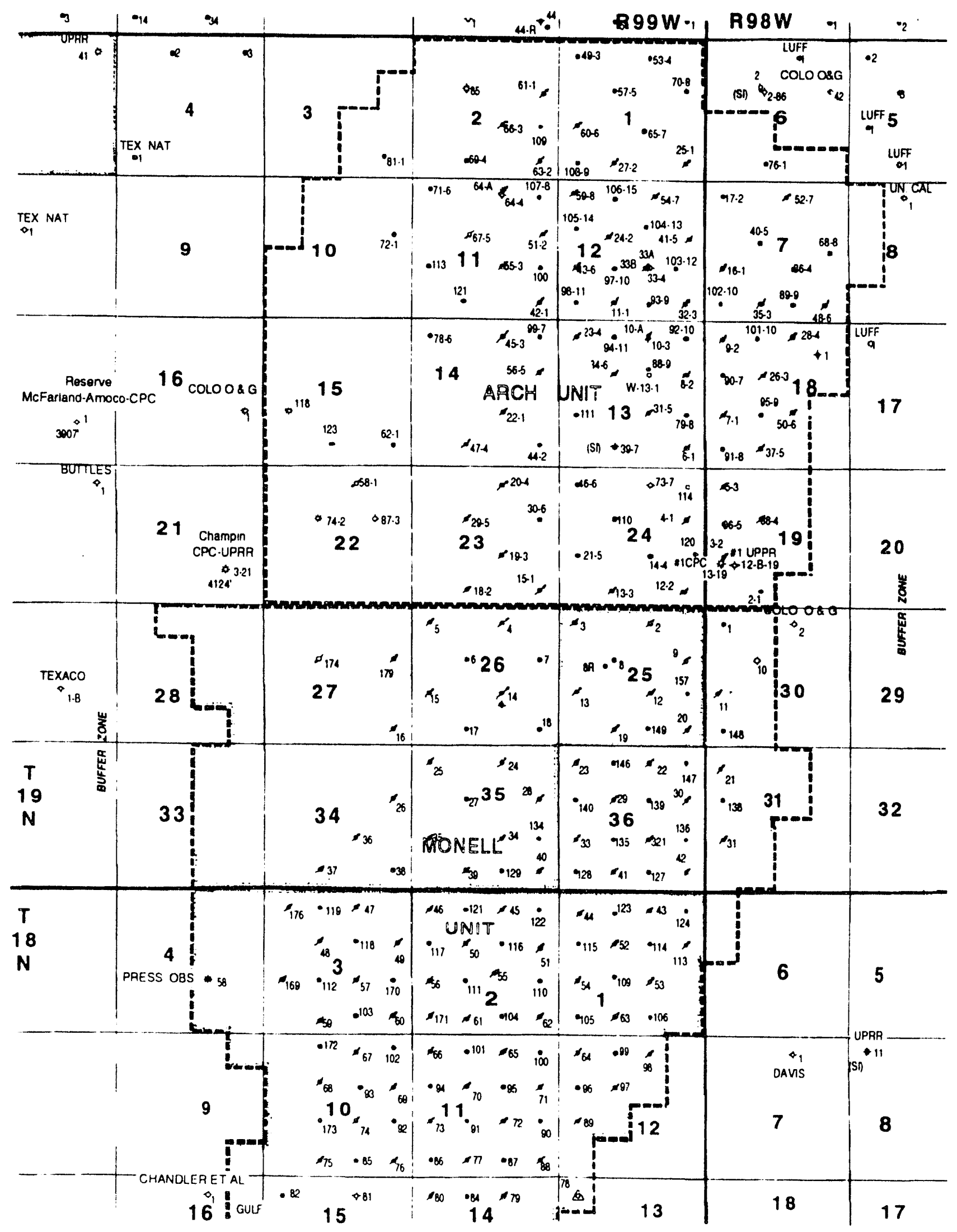

Figure 1.3 - Base map of Patrick Draw field wel'. locations. 


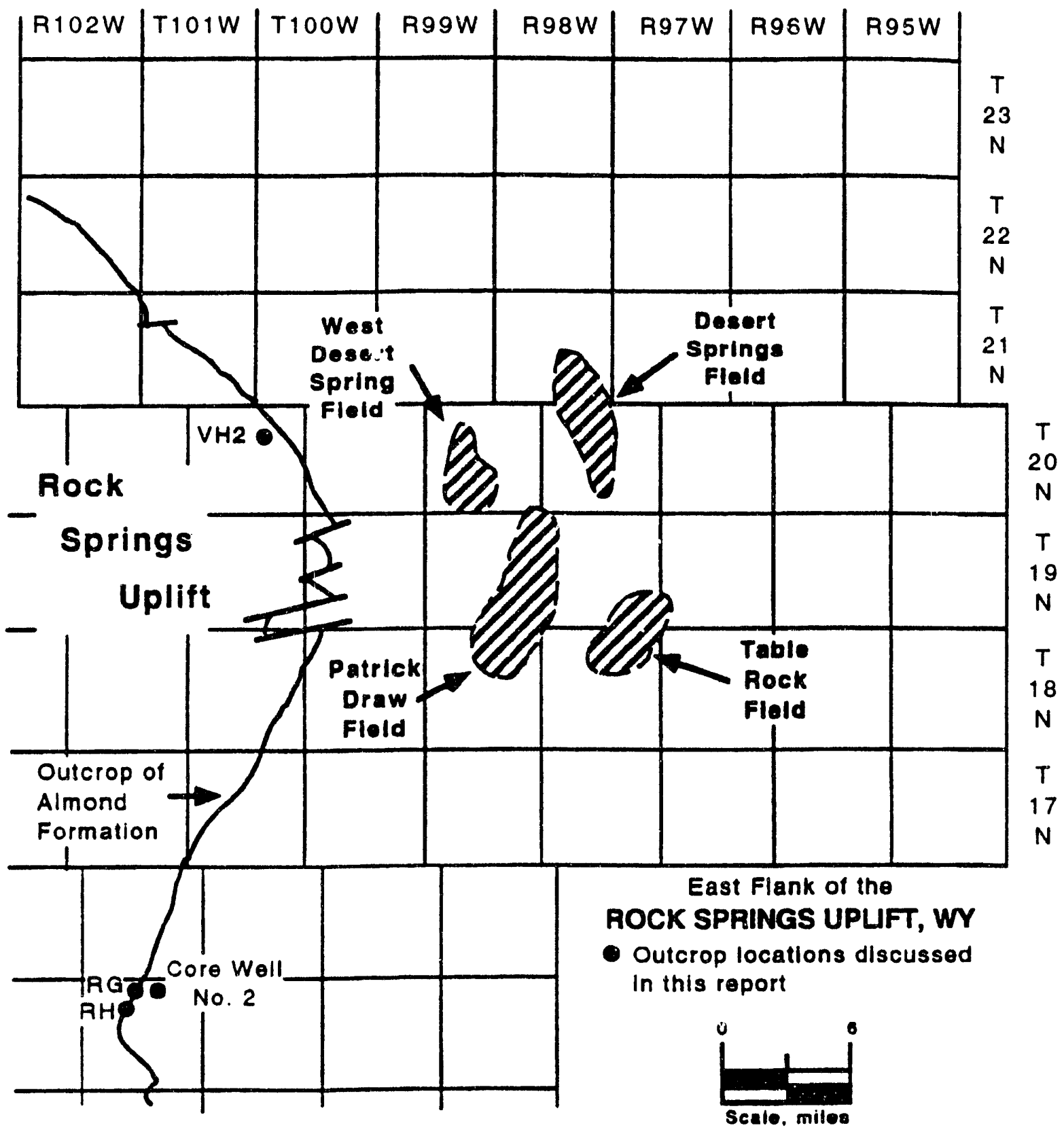

Figure 1.4 - Map of the east flank of the Rock Springs Uplift, Sweetwater County, WY. Note locations of Almond outcrop exposures and Patrick Draw field. 


\section{Chapter 2}

\section{INTEGRATED GEOLOGICAL-ENGINEERING MODEL OF PATRICK DRAW FIELD (TASKS $1 \& 2$ )}

\section{DISTRIBUTION OF STRATIGRAPHIC INTERVALS UA-5 AND UA-6}

The palcogeographic and stratigraphic setting of the Almond Formation has been described elsewhere and will not be repcated here (Weimer, 1966; Meyers, 1977; Van Horn, 1979; Roehler, 1988). The generalized stratigraphic column for western Wyoming is presented in figure 2.1. Production from the Arch Unit of Patrick Draw (WY) ficld is dominantly from the upper stratigraphic interval called UA-5, but some production is from UA-6, the next successively lower interval (fig. 2.2). Permeable sand isolith maps for each unit were constructed by Irwin (1976), and the successive distribution of subunits UA-5A and $B$ as well as UA-6A, B, and C are shown in figures 2.3 through 2.7 .

Within Patrick Draw field, the upper stratigraphic interval near the top of the Almond Formation is called UA-5 and can be divided vertically into A (upper) and B (lower) intervals. UA-5B (fig 2.4) is the source of most of the oil production from Arch Unit. An uppermost oyster-bearing high resistivity marker is present at the top of UA-5B in part of the Arch Unit, as shown in stratigraphic cross sections $\mathrm{A}-\mathrm{A}^{\prime}$ and $\mathrm{B}-\mathrm{B}^{\prime}$ (figs 2.8 and 2.9 ), and a shale marker generally separates UA-5A from UA-5B. North-south oriented thins in the permeable sandstone isolith map for UA-5B approximate the boundary between the castern and western sand accumulations ("bars") within UA-5B and have previously been interpreted as distinct reservoirs (Weimer, 1966; McCubbin \& Brady, 1969). The sandstone isolith map (fig. 2.6) also indicates that UA-5B extends well east of Patrick Draw field to Table Rock Unit. The western extent of UA-5B is not well defined but extends beyond the western limits of Patrick Draw field.

UA-5A, the uppermost interval, is shown by the sandstone isolith map (fig. 2.3) and the stratigraphic cross sections (figs. 2.8 and 2.9) to have a discontinuous distribution. It is poorly developed within the Arch Unit but is greater than $25 \mathrm{ft}$ thick north of the production unit. UA-5A sandstones in Moncll Unit are clearly not hydraulically connected to the UA-5A sandstones developed within Arch Unit, where it is wet and nonproductive. Within Monell Unit, the north-south oriented UA-5A interval tends to overlie UA-5B sand thicks in the northern part of the unit, but UA-5A contains thicks that extend farther south than do the UA5B sandstone thicks.

In an attempt to illustrate the smaller scale reservoir sandstone geometry, a fence diagram was constructed of stratigraphic interval UA-5B within the confines of section 7 (T19N R98E) in the castern portion of Arch Unit. The fence diagram (fig. 2.10) shows that two widespread UA-
5B sandstone $\log$ intervals can be distinguished. The uppermost (shaded pattern in fig. 2.10) sandstone has a high resistivity and probably contains oyster-rich and calcite cement-rich sandstone and dolomite-cemented intervals (reiatively poor reservoir quality) while the immediately underlying sandstone characteristically has a much lower resistivity associated with a moderate to high spontancous potential. Beneath these two units, which are well defined by wireline logs, are ihree very thin (less than $5 \mathrm{ft}$ ) sandstones which are enveloped in shale and terminate within section 7 . One of the thin sandstones is present only within weli $36-7-4$, in the eastern portion of the section; therefore, is lateral extent is limited entirely to section 7. Based on this fence diagram, it may be concluded that subdivisions of the UA-5 sandstone intervals may be defined based on log correlations alone; however, the log-based units generally will not have the spatial resolution of discrete sedimentary facies. Where it can be shown that flow units comprise more than a single depositional facies the log-defined units may be adequate to help visualize major stratigraphic-based reservoir compartments.

Stratigraphic interval UA-6 immediately underlies UA-5 and can be subdivided vertically into three units, $A$ (upper), B (middle), and C (lower) (figs. 2.5, 2.6 and 2.7). Each of these subunits shows a generally northeastern directed trend to the sand bodies. According to Irwin (1976), these sand units are generally separated by a thin shale break, often contain thin coals at their tops, and do locally communicate. These sands have been interpreted as part of a prograding deltaic sequence which was overridden by a swamp (Irwin, 1976). Based on such an interpretation, the irregular sandstone geometry, particularly in UA-6A may indicate that the overall progradational packages may have been subjected locally to severe destructional processes. Irwin (1976) interpreted several isolated sand bodies noted in each of the UA-6 subintervals as small nearshore bars deposited in very shallow water. UA-6C (fig. 2.5) has the smallest aerial extent and is mostly restricted to northwestern portion of Arch Unit.

\section{Eacies Distribution of the UA-5 Sand in the Arch Unit}

The dominant features in the sandstone distribution in the Arch Unit are elongate sand-thin features trending north-south and northwest-southeast and sand-thick areas in sections 23 and 30 (fig. 2.11). The north-south sand thin occurs in the area between two distinct barrier sandbodics within the UA-5 sand, designated as the "castern" and "western" bars (Weimer, 1966). The sandthin areas consist of low- to zero-permeability sediments 
of oyster coquina, carbonaceous shale and finc-grained, shaley sand which may have formed either in a lagoonal setting behind the "western" bar or as an abandoned channel fill deposit. Whether this feature formed contemporaneously with the barrier island complex or as a post-depositional erosional feature is currently not well understood. The two bars are similar in lithologic character and facies types; however, limited hydraulic connectivity between the two sandbodies is indicated by different oil-water contacts, the pattern of oil production, and the presence of a gas cap in the "eastern" bar and not in the western bar.

The thickest sands correspond to the best reservoir quality in the Arch Unit and consist of tidal channel deposits overlain by tidal delta deposits that can be correlated laterally on a scale of miles (fig. 2.12). Within the "western" bar, the sand thins to the north with an attendant decrease in grain size, and reservoir quality. The facies present, indicate lower energy, backbarrier conditions, where the tidal channel (fig. 2.12) grades laterally into a tidal creck deposit in well 49. The overlying tidal delta becomes thinner in well 63 and is laterally equivalent to a low energy tidal creck deposit in well 49 (fig. 2.13). The facies sequence of tidal channel overlain by tidal delta occurs in both the "eastern" and "western" bar (fig. 2.14), and is consistent with the depositional model for mesotidal barrier island systems where the tidal inlet and associated tidal channels and tidal deltas migrate laterally, parallel to the shoreline.

\section{Eucies Permeability and Porosity}

Two broad permeability and porosity classes can be distinguished according to groups of facies (figs. 2.15 and 2.16). The higher permeability class consists of sands from the tidal inlet, tidal channel and tidal delta facies. In this class, permeabilities range from 0.03 to $280 \mathrm{md}$, with an arithmetic mean of $45 \mathrm{md}$ and a geometric mean of 20 md. Porosity values values range from 1.9 to $28.9 \%$ with a mean value of $20 \%$. The higher permeabilities and porosities within this group of facies are consistent with the higher depositional energies, and corresponding coarser grain sizes and lower amounts of detrital clay. The lower permeability class consists of tidal creck, tidal flat, swamp, and lagoonal facies, where permeabilitics range from 0.03 to $106 \mathrm{md}$, with an arithmetic mean of $8.9 \mathrm{md}$ and a geometric mean of $1.5 \mathrm{md}$. Porosity values range from 1.6 to $22.3 \%$, with a mean value of $14 \%$. The overlap in permeabilities and porosities of the two classes is due to lateral permeability changes within the facies and cemented zones within the high permeability class. Geostatistical analysis of lateral permeability variations in outcrop exposures would provide correlation lengths for permeability and porosity within a facies.

\section{ARCH UNIT STRUCTURAL FEATURES}

Two strike-oriented (figs. 2.17 and 2.18) and two diporiented (figs. 2.19 and 2.20) structural cross sections were constructed for Arch Unit. These intersecting cross sections (fig. 2.21) were designed to provide a large-scale view of possible structural complications within the upper Almond intervals UA-5, UA-6, UA-7, and the top of UA8. Structural cross section $A-A^{\prime}$ (fig. 2.17) extends considerably north of Arch Unit and shows that the crest of the Wamsutter Arch is located immediately adjacent to the northern margin of Arch Unit. Note the absence of stratigraphic unit UA-5A in structural cross section B-B' (fig. 2.18). Comparison of stike-oriented structural cross sections $A-A^{\prime}$ and $B-B^{\prime}$ with the map showing the lateral extent of UA-5A (fig. 2.3) shows that, although the two strike lines are only 1 mile apar, the eastern section (B-B') is located just east of the pinchout of UA-5A in Arch Unit. An interesting feature illustrated in strike section A$A^{\prime}$ is the relative thickening of UA-5A north of the crest of the Wamsutter Arch while the UA-5B thickens south of the crest of the arch. This relationship suggests the possibility of some structural control of depositional rates in the UA-5B sand. Strike-oriented structure section B-B' provides a more complex profile of upper Almond stratigraphic markers, mostly due to the presence of two normal faults. Faults in these structure sections were suspected when the dip between adjacent segments of the cross sections exceeded $4^{\circ}$ of calculated dip, or deviated to a great extent from the overall dip in that portion of the cross section (as in the case of the dip-oriented sections). Only in dip-oriented cross section C-C' (fig. 2.19), where the overall dip of the section is aboui $4^{\circ}$, was convincing evidence for faults absent. However, even in cross section C-C', the abrupt eastward termination of UA-5A and a structural anomaly centered around well 106-12-15 suggests that a fault may be present. The presence of five previously undocumented faults in four structure sections points out, at the very least, that geological structure must be taken into account in determining reservoir continuity and lateral extent of flow units in Arch Unit of Patrick Draw ficld. These cross sections show that flow along stratigraphic units within the upper Almond Formation may be constricted at significant, structural choke points, or completely truncated by faults within the production limits of the field (c.g. between wells 25-1-1 and 17-7-2 in cross section B-B').

\section{DISTRIBUTION OF LOG AND CORE- DERIVED PETROPHYSICAL PROPERTIES IN THE ARCH UNIT}

The distributions of wore derived average porosity $(\bar{\phi})$, average permeability $(\bar{k})$, and the product of average permeability times thickness $(\overline{\mathrm{kh}})$ along profiles 1,2 , and 3 (sce fig. 2.22 for location) are shown in figures 2.23 , 2.24 and 2.25 . Due to the limited availability of core and 
porosity log data, some amount of extrapolation was required from wells offset from the straight-line profile typically used for structural cross-sections. The geometric mean of the permeabilities $(\bar{k})$ and a cutoff valuc of $1 \mathrm{md}$ was selected for analysis of the UA-5B sandstone. Perneability values are from conventional core analysis. When the entire sand interval was not cored, average permeability from the cored interval were used for the entire sand interval. From an examination of the petrophysical profiles, the following may be concluded:

(1) The best reservoir quality along the profiles studied occurs in profile No. 2 (fig. 2.24) where, east of well 55, the petrophysical properties indicate sharp improvement. Similar high values are observed for certain wells along profiles No. 1. Along profile No. 3 (fig. 2.25), two high regions, one centering at well 20 and the other in well 3 areas, are observed. The cause of these trends are currently bcing investigatcd.

(2) As discussed previously, the wells with best petrophysical properties in each profile could be connected to form at least one NE-SW linear trend which coincides with the distributions of the maximum sandstone thickness (obtained from the isolith map) and the maximum primary oil production (discussed later).

\section{Distribution of Average Clay Content and Thickness of Cemented Zones}

The distribution of average clay content along wells within profile No. 4 obtained from analysis of gamma ray $\operatorname{logs}$ is shown in figure 2.26a along with the standard deviations of clay distributions in cach well along the profile. The low standard deviation of $\overline{\mathrm{V}_{\mathrm{cl}}}$ indicates more uniform petrophysical properties of sandstone east of well 67 along profile 4 . The thickness of the carbonate cemented zones in UA-5B sandstone obtained from interpretations of sonic and density logs and calculated as a percentage of the total sandstone (UA-5B) thickness is shown in figure $2.26 \mathrm{~b}$.

From figures $2.26 \mathrm{a}$ and $2.26 \mathrm{~b}$, it may be seen that the average clay content in UA-5B sandstones increases away from well 100 along profile No. 4 except at the end. The high clay content in some of the wclls cast of well 100 , such as wells 79 and 114 is intriguing because the sandstones in these wells have good porosity and permeability (sec figs. 2.23 and 2.24). One possible reason for this apparent high clay content could be the presence of larger amounts of radioactive mincrals (potassium fcldspar, mica, etc.) which may increase gamma ray readings for clean sandstones in thesc arcas. Locality-enhanced radioactivity of oil-associatcd formation waters may also provide such an anomaly. The variability in clay content $\left(\overline{V_{c 1}}\right)$, on the other hand, assumes low values cast of well 67. The carbonate content (fig. 2.26b) also sharply diminishes cast of well $1(0)$ along the same profiles.

\section{RELATIONSHIP OF PERMEABILITY, GRAIN SIZE, AND SORTING CHARACTERISTICS OF FACIES IN PATRICK DRAW FIELD AND ALMOND OUTCROPS}

\author{
Grain Size and Sorting (Almond Dutcrop)
}

Grain size and sorting (standard deviation of grain size) were determined from 75 thin sections by petrographic image analysis of 300 points from each thin section. Thirty of the samples were from Almond Formation outcrops located on the eastern flank of the Rock Springs Uplift. The remainder of the samples were from cored wells located in Arch Unit of Patrick Draw ficld. Analysis of grain size is important to this study both in determining the degree of depositional similarity between the outcrop and subsurface rocks, as well as in distinguishing reservoir rock types and their relationship to depositional and diagenetic facies. Subsequent correlations between grain sizc, pore size distributions, permcability, and other petrophysical properties will be an important component in defining the flow units within the reservoir.

Grain size in sandy facics from the Almond Formation ranges from coarse silt to fine sand (30 - 225 microns). Grain size distribution among combined Almond outcrop and subsurface data falls into two groups (fig. 2.27). These include a fine-grained group comprising tidal creck and tidal flat facies and a second, relatively coarser-grained group, comprising all of the other facies. Among the coarser-grained group of facies, middle shoreface and some tidal delta samples tend to overlap the finer-grained facies group.

Comparison of mean grain size distribution for facies that are present in thin sections from both the outcrop and the subsurface (fig. 2.28) indicate that tidal channel grain size distributions are similar. Outcrop tidal delta samples tend to be coarser grained than their subsurface counterparts, as do tidal creck and tidal inlet samples (although there is only a single subsurface tidal inlet sample). Although only data from subsurface samples is available, tidal flat mean grain size are consistently finer than all other facies.

A good measure of the sorting of framework grains within sandstone is standard deviation of the mean grain size. Higher values of standard deviation reflect less well sorted samples. Comparison of the distribution of outcrop and subsurface Almons. sorting data (fig. 2.29) is strikingly similar to that for grain size for respective facies. And, as with grain size, corresponding facies in outcrop and subsurface appear to have somewhat different ranges of sorting values. A possible explanation may be found by looking at the relationship between mean grain size and sorting. 
A cross plot of mean grain size versus sorting for the cntire Almond data set (fig. 2.30) shows a lincar relationship with a high correlation coefficient $(R=0.95)$ and this same general relationship exists for oulcrop as well as for sub,urface data sets (figs. 2.32 and 2.31). The gencral trend of increasing grain size with decreasing sorting may represent a fundamental relationship created by the greater availability of a wide range of grain sizes for the coarser samples. The tight cluster of data around the best fit line is an indication of the overall good sorting created by tidal processes which dominated deposition of many of the Almond facies. More poorly sorted sandstones, particularly those from medium to coarsegrained samples from other depositional systems (such as fluvial sands), might be expected to show a much greater divergence irom the best fit line as one procecds toward coarser grain size. Further work, however, would be necessary to confirm such a relationship.

Almond grain size and sorting data are clustered in facies-dependent groups which are, in turn, somewhat different for subsurface and outcrop samples (figs. 2.31 and 2.32). Samples from the subsurface at Patrick Draw ficld may be divided into two groups. In the first group, tidal delta, tidal channel, and tidal inlet facies have coarser grain size and poorer sorting. In the second group, tidal llat and tidal creek facies have finer grain size and better sorting. Some tidal dela data overlap the second group, as does a single point from the tidal channel facies. These relationships are generally expected because the tidal channel, tidal inlet, and tidal delta facies were deposited in higher energy setting than were the tidal flat and tidal creck facies.

In contrast to the Almond Formation at Patrick Draw field, a study of the Parker River Estuary, Massachusetts (DaBoll, 1969) showed that tidal delta and main tidal channel sediments are coarsest and best sorted, whereas small tidal creek sediments which contain fine silt and clay were among the finest and most poorly sorted. The Almond data reflect point counts on framework grains alone, ignoring the overall mud content of tidal flat samples, some of which contained significant amounts of mud. Nevertheless, most of the Almond tidal flat samples were from sand tidal flats and the overall trend of the Almond data is exactly opposite to that determined for tidal facies in the Parker River estuary.

A study of modern mesotidal barriers along the Georgia coast (Moslow, 1980) found a relationship between mean grain size and sorting more similar to subsurface Almond data. This study showed that for the Georgia barricrs, tidal channel, washover, and most inner shelf (shoal) sandstones were the coarsest and generally the least well sorted.

There is a wide range of energy across the lidal delta, which could account for the overlap with the finer grained samples. Most of the sediments in tidal channels, tidal inlet, and some tidal delta locations would be moved during the period typified by greatest tidal currents. This, in turn, tends to remove the fines and may creatc lags of coarser materials. Flow across tidal delta cbb shield and asymmetrical oscillating lower energy tidal flow on tidal crecks and tidal flats tend to better sort out finer sediments. Fine sands in the case of most tidal delas, and very fine sand, silt, and mud in the case of tidal flats are concentrated in the low energy facies (Nichols \& Biggs, 1985). On flood tidal delas the higher sandy portions (cbb shiclds) are usually coarser than the lower flood ramp arcas (DaBoll, 1969).

Data from the Almond Formation outcrops (fig. 2.32) can also be divided into three groups. Tidal inlet fill and tidal delta facies consistently contain the coarsest and leaist well sorted (greatest stand deviation) sands while middle shoreface, tidal creck and tidal channal facies contain the fincst sandstones with the best sorting (lowest standard deviation). A poorly-defined group of data from swash bar and oyster bed facies generally contain intermediate grain size and intermediate standard deviation values. The association of outcrop tidal channel sandstones with the finest, best sortec' samples is gencrally the opposite of the relationship noted in the subsurfare Almond data, but is more like the relationship defined in the Parker River Estuary. It should be noted that there is virtually no overlap, however, between the tidal channel data and that from the middle shoreface and tidal creck sandstones. !t may be that the relative grain sizc and sorting of tidal channel sandstones in shoreline barricrs is related to the lidal energy flux, sources of sand, and channel configuration, all of which may differ between various barriers. The grain size and sorting relationships of the subsurface Almond Formation appear to be more like those exemplified by the modern Georgia coastal barriers, while those of the outcrop Almond Formation appear to be more like those of the tidal sands from the Parker River Estuary, Massachusctts.

For all facies which were recognized in both outcrop and the subsurface, the grain size and standard deviation (sorting) "field" values overlap. However, outcrop samples from the tidal delta and tidal inlet fill facies all lic among the coarsest and least well sorted overall values; outcrop tidal channel samples are among the finest and best sorted overall values; and outcrop tidal creck facics occur in the middle of the overall data set. Because the measurements were from framework grains, most of which are quart\%, it is unlikely that the differences between outcrop grain size and sorting are related to different diagenetic histories. Rather, it secms more likely that there were differing intensitics of similar processes operating on similar but not identical grain populations in the present Almond Formation outcrop and subsurface (UA-5) shoreline barriers.

Differences in facies grain size and sorting between outcrop and subsurface samples may result, in part from the areal distribution of the samples. The subsurface samples were taken from wells over an about 8 square mile area, whereas the outcrop samples are from two outcrop exposures located approximately 4 miles apart. The samples from the outcrop exposures may represent 
more local conditions while the subsurface samples may represent more average conditions over the barrier system.

\section{Grain Size and Porosity (Almond Outcrop)}

Outcrop samples tend to have greater porosity (generally brtween 24 and 33\%) than samples taken from the stbsurfacc at Patrick Draw field (generally less than 24\%) (fig. 2.33). Comparison of reservoir and outcrop $k / \emptyset$ scatter plots (fig. 2.34) indicates different trends for subsurface and outcrop data. Outcrop rocks in general tend to be more porous and permeable than subsurface rocks, and this relationship becomes even more obvious when the data are examined on a facies by facies basis. The consistently better permeability and generally better porosity of outcrop rocks from the same facies indicates that although outcrop samples are distinct from the reservoir samples, the petrophysical properties of outcrop samples have all tended to move in the same general direction (relative to porosity and permeability).

When examined individually, tidal channel, tidal creek, middle shoreface, and the oyster bed facies cach have a well established reiationship between vorosity and permeability. In addition, outcrop Almond sandstones from various facies show an obvious trend between increasing porosity and increasing permeability with a high correlation cuefficient $(\mathrm{R}=0.91)$.

If the six very low permcability subsurface data points in figure 2.34 are considered separately, it becomes apparent that permeability is independent of porosity for subsurface samples taken together as a group. Bccause the six very low permeability samples were the result of abundant detrital clays or very abundant calcite cement they appear to reflect different depositional and/or diagenetic processes as compared to the rest of the subsurface samples and probably should be considered independently. Because of the apparent overall lack of dependence between permeability and porosity in subsurfacc samples, it may be difficult to apply outcropderived petrophysical properties to the reservoir units at Patrick Draw field unless the data are examined on a facies by facies basis.

Because of the high correlation between grain size and sorting discussed above, scatter plots of porosity versus grain size and porosity versus sorting (standard deviation of grain size) show similar but highly overlapping facies distributions. Subsurface tidai creek and tidal flat facies, however, consistently tend to have lower porosity, finer grain sirc, and better $\mathrm{s}$,rting than tidal channel and tidal delta samples. Outcrop samples from tidal channel, middle shoreface, and tidal creek facies tend to be slightly less porous, have finer grain size, and better sorting than exhibited by swash bar, tidal delta, tidal inlet, and oyster bed facies. A lincar relationship does not exist between porosity versus grain size or porosity and sorting for cither subsurface or outcrop samples.

\section{Grain Size and Permeability (Almond Outcrop)}

There is virtually no overlap between the permeability of Almond outcrop samples (fig. 2.35) with tiose from the UA-5 sandstone at Patrick Draw field, the outcrop samples having greater permeability. Because of the small number of outcrop samples analyzed and the absence of swamp, idal flat, and lagoonai facies in the outcrop data set, it is difficult to draw further conclusions about the distinction between outcrop and subsurface facies based on permeability distributions alone.

Because of the close relationship between grain size and sorting (standard deviation of grain size) mentioned above, the scatter plots of permeability versus grain size and permeability versus sorting are very similar. For samples from which thin sections were made, data from these same scatter plots are clustered into facies dependent groups. Outcrop middle shoreface and tidal channel data tend to be finer grained, better sorted, and slightly less permeable than outcrop tidal delta, tidal swash bar, and oyster bed facies. Subsurface facies grain size and sorting appears to be independent of permeability if the same very low permeability samples are treated as is distinct group, as discusiod for the porosity versus permeability scatter plots aúove.

\section{Mineralogical Composition of the Almond Eormation}

Based on bulk mineral composition derived from X-ray diffraction (XRD) of sandstones and shales in the Almond Formation, Keighin, Law, and Pollastro (1989) found that sandstones buried $4,500-7,500 \mathrm{ft}$ tend to contain more carbonate minerals and less quartz than do upper Almond sandstones which are buried to greater depths east of Patrick Draw. Recent XRD data (table 2.1) indicate that sandstones in Patri:k Draw field also tend to contain more carbonate and less qu irty than outcrop Almond sandstones which are exposed west of Patrick Draw field. Keighin, et al., (1989) reported a mean quartz content for shallow core samples (Patrick Draw field) of $57 \%$, while our data indicate a mean of $76.5 \%$ quartz for UA-5 sandstone samples. Although these two values vary greatly, they are both significantly less thar ne mean value of $89 \%$ quartz. thai we found for outcrop samples.

Total carbonates including dolomite, ferroan dolomite (ankerite), sidcrite, and calcitc also vary greatly among the subsurface samples, rangin, from icss than 1 to $37 \%$ in sandstones (table 2.1). '-ncally, subsurface oyster rubble beds are completely cemcnted by calcite and dolomitc, and are carbonate lithofacies. Total carbonate in analyzed outcrop samples ranges from less than 1 to $4 \%$, although visual examination of additional outcrop samples indicates that some, particularly oyster-rich beds, may be extensively calcite cemented. Dolomite was present in most subsurface sandstones (mean value of $6.9 \%$ ) and was present but in generally lesser amounts in outcrop sandstones (mean of $0.9 \%$ ). Fetroan dolomi's was present 
only in some subsurface samples, particularly those that were the most tightly cemented. It also appcars that nonferroan dolomite is more common in the subsurface samples than in the samples from the outcrop.

The total feldspar content of Patrick Draw sandstones averages $4.8 \%$ based on our data, and is in close agrecment with $5 \%$ determined by Keighin et al., (1989). In addition, our data in table 2.1 indicate that there is about twice the feldspar content in outcrop Almond sandstones than those from Patrick Draw ficld. Thin sections indicate that both in outcrop and in the subsurface considerable detrital feldspar has been rem oved by dissolution arid some has been replace by carbonate minerals. Potassium feldspar (dominantly orthoclase) is more common in upper Almond sandstones at depths less than $6,000 \mathrm{ft}$ in conirast to plagioclase feldspar which is more common in the more deeply buried upper Almond sandstones (Keighin $\mathrm{ct}$ al., 1989). Table 2.1 also indicates that, although there is more feldspar in typical outcrop Almond sandstones, the proportion of orthoclase to plagioclase feldspar is about equal in both outcrop sandstones and those from Patrick Draw field. We also found that pyrite, a diagenetic mineral which is formed only under anacrobic conditions, was present in virtually all sandstone samples from Patrick Draw field and absent from all outcrop sandstones examined.

Keighin et al., (1989) found a mean value of $18 \%$ total clays from sandstones buried 4,500 to 7,000 ft. Our XRD daat (table 2.1), however, indicate a mean of only about $3.6 \%$ total clays from Patrick Draw reservoir sandstoncs and $2.2 \%$ from outcrop Almond sandstones. These values are generally less than those derived from log analysis (mean of $7-8 \%$ ) of UA-5 reservoir sandstone at Patrick Draw ficld. This discrepancy may be explained partly by the selection of "s relatively small number of "clean" samples examiried by XRD aialysis which may not be as representative as the "average" values which are ivermined by $\log$ analysis. Additionally, the amount of clays and carbonate cements varies greatly on the scale of a tew millimeters to a few inches. Log-derived clay values may, thereiore, be expected to indicate generally more clays than those determined by XRD analysis in this highly heterogeneous type of formation. The mean clay content for shallowly buried upper Almond sandstones given by Keighin et al., (1989) was based on 46 samples collected from over much of the Greater Green River Basin east of the Rock Springs Uplift. Only five of those samples were from Patrick Draw field.

Nevertheless, a large discrepancy exists between the clay content of our current XRD data (table 2.1) and that of Keighin et al., (1989). Point count data from 12 thin sections of samples from Patrick Draw field indicatc an average of $7.9 \%$ total clay, which is in gencsally close agreement with our log-derived values. Therefore, our petrographic and wireline log analyses indicate on average less than half of the total clay content for reservoir sandstones at Patrick Draw field than Keighin et al.,
(1989) found based on widespread subsurface data for the upper Almond Formation.

Two other important constituents that may account for the generally low average permeability of reservoir sandstones at Patrick Draw ficld are rock fragments and total carbonate cement. Of 12 thin sections analyzed, the average rock fragment content was $16.1 \%$. One-third to onc-half of the rock fragments are of the fine grained sedimentary type with some recognizable metamorphic and igneous (possibly volcanic) types. The types of rock fragments are important because sedimentary fragments and altered volcanic fragments are ductile to extremely ductile (Pittman \& Larese, 1991). Obviously, the greater the content of ductile rock fragments, the greater the potential for compaction and reduction of the reservoir pore and throat system. The average total carbonate cement from point counted thin sections was $15.1 \%$, with extreme values of 0.0 and $41.5 \%$. Such abundant yet variable amounts of carbonate cement could have a significant effect on the reservoir rock quality. It is not yet known whether calcite or dolomite is more important with respect to petrophysical properties because the dolomitc/calcitc ratio varies widely from 1:93 to as much as 25:1.

Keighin et al., (1989) found that kaolinite is the most abundant clay in the shallow reservoir sandstones and that the abundance of kaolinite decreases with increasing depth of burial. Kaolinite is generally not present in upper Almond sandstones buried greater than 9,000 ft. Keighin et al., (1989) also reported that chlorite was not present in any sandstone samples, that illitic clays dominated the clay fraction below $9,(0) 0 \mathrm{ft}$, and included discrete illite and illite/smectite. Illite/smectite is of the ordered variety and contains less than $25 \%$ expandable layers. Very little smectite is present in either sandstones or shales. Keighin et al., (1989) concluded that even upper Almond rocks that are now at depths as shallow as $4,50 \mathrm{C}$ ft may once have been buried to depths where the temperature excecded $212^{\circ}$ F, or may have experienced a heating event.

Our mineralogical analysis of the upper Almond sandstones (table 2.1), both from outcrop and from Patrick Draw ficld found the same suite of clay minerals as was reported by Keighin et al., (1989). XRD analysis of our samples indicates that kaolinite is the dominant clay mineral present in reservoir samples and is about equal to mixed layered illite/smectite in samples from the outcrop. Chlorite was not found in any of the samples.

\section{ENGINEERING ANALYSIS OF PATRICK DRAW FIELI)}

\section{Production History}

Patrick Draw ficld is located in Townships 18 and 19 North, Ranges 98 and 99 West, Swectwater County, in southwestern Wyoming. Currently the field is divided into two units, Arch (north) and Monell (south). The field was discovered on April 11, 1959, with the completion of 
the discovery well, El Paso Natural Gas Company, Patrick Draw Unit 1 with an initial production rate (IP) of 638 BOPD. Oil and gas were found in the upper part of the Almond Formation at a depth of about 4,600 $\mathrm{ft}$. The ficld is about $81 / 2$ miles long and 3 miles wide. Well depths range from 4,300 to $5,300 \mathrm{ft}$. The average well diameter is 8 inches. Most wells werc completed with a $51 / 2$-inch casing and 2 -inch tubing and perforated at 4 (most frequently used) or 2 shots per foot (spf). All wells were stimulated by using acidization and hydraulic fracturing.

The average field porosity, permeability, and net pay are $20 \%, 36 \mathrm{md}$, ar.d $20 \mathrm{ft}$, respectively. The total original oil-in-place (OOIP) for Patrick Draw field was estimated between 200 and 250 MMSTB from volumetrics, and between 140 and 150 MMSTB from material balance calculations. A total of approximately 78.5 MMSTB oil has been produced through primary and secondary operations. The primary production reservoir drive mechanism was mainly solution ga:s. Since the initial rescrvoir pressurc $(1,790$ psig) was at or near the bubble point of the crude oil, the average gas-oil ratio (GOR) for the first month of production ranged between 388 and 850 for the group of wells producing during the period 1960. 1964, before watcrflood started. As production continued, the GOR increased as the oil production rate declined. A typical example is that of well Arch 44 (fig. 2.36). Depending upon the length of time of production, the GOR increased to as high as 25,000 before being shut in. Typically, the production was terminated when the GOR reached above 8,000 . Unless the well was located in a thin and low-permeability zonc, little or no water was produced during the entire primary production period. If the production of a well was continued beyond the start of waterflood, the GOR was reduced duc to water injection, and oil production stabilized until an increase in oil production duc to oil bank formation was obscrved. This continued until water breakthrough occurred when the water-oil ratio (WOR) increased rapidly, and the well watered out within a short period.

Watcrflood in the Arch Unit began in October 1964 where a single normal 5-spot waterflood pilot was initiated by converting !our production wells (Arch 6, Arch 7, Arch 8 , and Arch 31) to injection wells. A new well, Arch 79 was drilled in April 1964 as the central production well. Before watcr injection, Arch 79 produced at a GOR of 2,595 (as compared $t 0<8(0)$ for the first wells drilled in the field). This was expected because the field had already depleted well below the bubble point, and some frec gas had accumulated in the reservoir. The waterflood response after water injection was similar to that of Arch 44, with a significant oil bank generated by waterflooding. In 1967, a major waterflood expansion was undertaken using a 5spot 8()-acre pattern. In most cases, the other waterflood pattern responses were similar to that which included well Arch 79. Some wells had significant initial water cut at the first month of production. These wells which had very poor waterlloed response recovered less than 9\%, OOIP in Arch Unit.
The Monell Unit has a higher recovery efficiency than the Arch Unit. As of July 1983, the daily oil production for the Arch and Monell Units was 180 and 1,300 BOPD, respectively. More than 21 of the Arch Unit producing wells were watered out and were shut down. Compared with its primary production, waterflood recovery in Patrick Draw ficld was low. The Arch Unit produced 13.1 MMSTB (23\%) during primary production by 1967 . An additional 5.0 MMSTB (9\%) was produced after the initiation of waterflooding in 1967. The primary recovery for the Monell Unit was 24 MMSTB $(24 \%)$ and waterflood recovery was 14 MMSTB (14\%). This performance difference between Arch and Monell Units is being investigated.

\section{Analysis of Initial Production in Patrick Draw Field}

The initial production (IP) in Patrick Draw ficld varies broadly, as illustrated in figure 2.37. In the northern and northeastern section of the field, comprising about twothirds of Arch Unit, the IP varied greatly between adjacent wells and created a highly non-uniform "mosaic" pattem. A similar mosaic pattern was found in the southern and southeastern sections of Patrick Draw field, comprising more than half of the Monell Unit. In extreme cases, the IP from adjacent wells, drilled at ncarly the same time, significantly differed; for example, wells 65 and 70 (Scc.1, Arch Unit) produced 488 and about 20 BOPD respectively from UA-6 sandstone, the latter one also producing a large amount of water; wells 22 and 47 (Sec.14, Arch Unit) produced 112 and 1,460 BOPD respectively from UA-5 sandstone; and wells 13 and 21 (Sec.24, Arch Unit) produced 212 and 1,020 BOPD respectively from UA-5 sandstone. Gross sandstone thickness, lengths of perforated intervals, and number of shots per foot of perforation could all affect the IP's, but were essentially the same in the compared pairs of wells.

In the west-central updip portion of the field, however, uniformly high (above 700 BOPD) initial production prevailed (fig. 2.37). Threc wells clustered in section 23 of Arch Un I (15, 19, and 20) initially produced the record high volume of oil in the entire ficld: $1,800,1,680$, and 1,578 BOPD, respectively.

\section{Analysis of Specific Production in Selected Areas of Patrick Draw Field}

The productivity index and the specific productivity index cannot be calculated at this point because the pressure drawdown data are not available. However, the calculated ratio of initial production (IP) to the length of perforated interval, called "specific production," provides a more reliable indication of contrasts in formation productivity between adjicent wells as well as the larger areas of the ficld than the initial production alone.

The specific production values have becn checked for wclls within and around sections 18 and 23 (T19N R99W) 
existing data provided by Union Pacific Resources Company (UPRC). The parameters $q_{i}$ and $\mathrm{N}_{2}$-year were determined, and a plot of $\mathrm{N}_{2}$-year vs. qi was prepared (fig. 2.40). $\quad N_{2}$-year is the first 2-year primary cumulative oil production. It was assumed that $\mathrm{N}_{2}$-year was proportional to $\mathrm{N}_{\text {pi }}$. The parameter $\mathrm{N}_{2}$-year was used to compare the primary production efficiency of each well because it normalizes production for an equal time period.

A plot of the 2-year primary cumulative oil production vs. IP for the Arch Unit indicates a positive trend of the increase of the primary cumulative oil production with IP (fig. 2.40). A linear regression of the plot gives a $\mathrm{R}^{2}$ of 0.680 , showing a fair correlation. The data points that deviate most from the fitted straight line represent wells $10 \mathrm{~A}, 21,41$, and 47 of sections 13,24, 12, and 14, respectively (fig. 2.40). These wells could be producing from anomalous regions in the Arch Unit, and further studies on these regions and the production mechanics of the wells are required to explain their abnormal production phenomena.

\section{Effect of Petronhysical Prooerty Variations on Primary Qil Production}

The effect of petrophysical property variations estimated from core and log data, on initial and 2-year cumulative primary oil production in the UA-5B sand, was investigated in wells located along three profiles (sec fig. 2.22 for location). Figure $2.41 \mathrm{a}-\mathrm{c}$ shows the plots of 2 year cumulative primary oil production and initial oil production rates as functions of the average permeabilitythickness product along profiles 1,2 and 3. Only those wells drilled early in the life of the field were used in the profiles. Along profile 3 (fig. $2.41 \mathrm{c}$ ), there is a distinct trend of increase of cumulative primary and initial oil production with an improvement in petrophysical properties. The abrupt departure of well 3 from this general trend could be ascribed to geological heterogeneities which are now being investigated. For example, the shortfall in production in well 3 compared to the general production trend could be due to low oil saturation (as indicated by the core analysis) resulting from the proximity of the sandstone to the oil-water margin. Similar low oil saturations have been observed in other wells located close to the oil water margin (for example, wells 49 and 50 located in sections 7 and 18 , respectively). Wells along profiles 1 and 2 (fig. $2.41 \mathrm{a}$ and b) generally show an increase in primary production with an increase in the $\overline{k h}$ product, although duc to the paucity of data, a clear trend is not easily seen in these two plots. The production in well 33 (fig. 2.41a) is sharply below the normal production trend of the other wells in this profile and factors such as limited size of rescrvoir compartment or well damage duc to the migration of fincs could be responsible for lower production.

A comparison of primary oil production along the threc profiles (fig. $2.41 \mathrm{a}-\mathrm{c}$ ) indicates that the production of wells along profile 3 are higher compared to that of wells in the other two profiles. The reasons for the higher production in this area are currently being investigated.

The variation in initial production rates plotted in fig. 2.41 a-c generally show the same trend as the cumulative primary production. Sharply higher initial production rates compared to cumulative production in a few wells (such as well 4 in fig. $2.41 \mathrm{c}$ ) could be due to fracture production and limited reservoir compartment size. Attcmpts will be made to delincate wells with such anomalous production behavior with detailed geophysical structural investigation of the study area to identify structural features.

\section{Secondary Production Analysis}

The injection and production performances of the Arch Unit waterflood were analyzed. The analyses focused on the water injection and oil production data interpretation. In the water injection analysis, the Hall plot (Hall, 1963) technique was used to evaluate the injection well performance and properties. In the waterflood production analysis, the improved technique of water-oil ratio WOR vs. cumulative oil production plot by Lo et al. (1990) was used. Both techniques provided valuable reservoir information on the Arch Unit.

\section{Injection Well Analysis of the Arch Unit by Using Hall Plots}

Water injection well data of the Arch Unit were analyzed by using the Hall plots (Hall, 1963). Most water injectors were on an 80-acre five-spot flood pattem. Using the original oil-in-place (OOIP), field primary oil production, and average connate water saturation, the average gas saturation was estimated to be $13 \%$ at start of waterflood of the Arch Unit. Water fillup volume for each injector can be cstimated by using the equation $\mathrm{W}_{\text {if }}=\mathrm{S}_{\mathrm{g}} \mathrm{x}$ $\mathrm{PV}$, where $S_{\mathrm{g}}=$ gas saturation, and $\mathrm{PV}=$ pattern pore volume. The fillup volume was required to determine when stcady-state condition begins for the injected water in the reservoir. Figure 2.42 shows a Hall plot of an Arch Unit water injector that has achicved steady state condition. Hall plots for all Arch Unit injectors are available on open file at NIPER. Each figure has two curves: (1) Hall plot - plot of $S\left(p_{t} l\right)$, cumulative pressures, vs. $\mathrm{W}_{\mathrm{i}}$, cumulative water injection, where $\mathrm{p}_{\mathrm{t}}=$ tubing head pressure, and $t=$ time of injection, and (2) Derivative plot $-\mathrm{d}\left(\mathrm{S}(\mathrm{p}, \mathrm{t}) / \mathrm{d}\left(\mathrm{W}_{\mathrm{i}}\right)\right.$. The derivative plot is used to aid in detecting stcady state condition and constant Hall plot slope region; it also provides direct reading of the Hall plot slope for analysis. Table 2.2 shows the Hall plot analysis of the Arch Unit UA-5 sand injectors including information of estimated fillup volume, stabilized slope after fillup starts (if any), $k_{w} h, k_{w}$ and relative permeability to water $k_{r w}$. From UPRC special core analysis, $k_{r w}=0.035$ at residual oil saturation. Figure 
2.43 shows the distribution of $\mathrm{k}_{\mathrm{w}} \mathrm{h}$ (Hall plot) of the Arch Unit UA-5 sand injection wells. The Hall plots results suggest that the Almond Formation in the Arch Unit may be sensitive to water, i.c., significantly lower water relative permeability. This agrees with the finding of Baptist et al. (1964) in that the Almond Formation is sensitive to fresh water based on laboratory core analysis. Additionally, as mentioned by UPRC, the injected water may have gone through channels and did not sweep the oil zone. It is possible that certain constituents in the Almond Formation were conducive to severe formation damage after interacting with injected water, however further investigation is required to establish the mechanism for reduced permeability. An examination of the data shows that there are two extremely low $k_{w} h$ \%oncs in the Arch Unit covering: (1) wells 13,34, 11, and 14, of sections $24,13,12$, and 1 respectively, and (2) wells 38 , $5,37,50$, and 48 , of sections $19,19,18,18$, and 7 , respectively. All of these wells have a calculated $k_{w} h$ (from Hall plot) of less than $20 \mathrm{md}-\mathrm{ft}$. On the other hand, wells $15,18,19,20,29$, all of section 23 , and well 47 of section 14 , have a calculated $\mathrm{k}_{\mathrm{w}} \mathrm{h}$ of more than $300 \mathrm{md}-\mathrm{ft}$. These are the best water injectors in the Arch Unit. The Almond Formation contains much less than $1 \%$ watcr swelling clays. So clay swelling may not be expected in the Almond Formation to cause the loss of permeability of the rock due to water.

Figure 2.44 shows the calculated water relative permeability $k_{r w}$ from Hall plot vs. measured permeability $\mathrm{k}_{\text {air }}$ from core analysis, $\mathrm{k}_{\mathrm{rw}}$ is defined as $\mathrm{k}_{w} / \mathrm{k}_{\mathrm{air}}$. This figure indicates that the loss of permeability in the UA-5 sand in response to injected water occurs in both low- and high-kair sands. Only wells 15,18 , and 20 of section 23 , and wells 22 and 47 of section 14 have a calculated $k_{r w}$ of greater than 0.4 . The $\mathrm{k}_{\text {air }}$ of well 19 of section 23 is not available. From Hall plot analysis, $k_{w}=40.6 \mathrm{md}$, and using the $k_{\text {air }}$ data of wells in section $23, \mathrm{k}_{\mathrm{rw}}$ of well 19 is estimated to be greater than 0.4. Most of the remaining injectors in the Arch Unit have a calculated $\mathrm{k}_{\mathrm{rw}}$ of less than 0.1. Figure 2.45 presents the $k_{r w}$ distribution of the Arch Unit injection wells and indicates the southwest portion of the Arch Unit to be the best water injection area (higher $k_{r w}$ ). The $k_{W} h$ map corresponds well to the sand isopach map indicating a relationship between $k_{w}$ h derived from the Hall plots and the sand thickness. Reasons for the significant permeability decrease in the UA-5 sand in response to injected water will be further investigated.

Although most of the Hall plots have an increasing slope, indicating an increasing resistance 10 water injection, the Hall plot for well 22 remained constant or decreased slightly, indicating possible channeling.

\section{Secondary Broduction Analysis of the Arch Unit}

\section{Water Oil Ratio vs. Cumulative Production}

Production data (primary and watcrflood) provided by Union Pacific Resources Company (UPRC), were analyzed for 114 wells in the Arch Unit. Of these 114 wells, about one-half of them are water injectors. The modified technique of producing water-oil ratio (WOR) vs. cumulative oil production $\left(\mathrm{N}_{\mathrm{p}}\right)$ plot developed by Lo $\mathrm{ct}$ al. (1990) was used to analyze the waterflood performance of the Arch Unit wells. This technique can be used to evaluate the waterflood efficiency, original oil-in-place (OOIP), or determine the in situ water-oil relative permeability characteristics of the reservoir. The principle of this technique is to detect a post water breakthrough straight line relationship on a plot of WOR vs. cumulative oil produced on a semilog scale. The absence of a straight line relationship could indicate well or field operational changes or other causes.

Figure 2.46a-c shows the WOR vs. cumulative oil produced plot for a producer in the Arch Unit during the watcrlood operation. All the plots of WOR vs, cumulative oil produced are available on open file at NIPER. These plots show three distinct features: (a) noisy or irregular data, (b) presence of a sharp increase at the end of plot, and (c) double water breakthrough or peak on plot (figs. 2.46a-c). Noisy data are probably duc to operational changes of the well such as shut-in, workover and injection and production rate changes. The sharp increase may indicate the existence of a conduit or channel between the producer and the injector(s) in each flood pattern. Once the injected water fills the channel or the conduit, the water-oil ratio increases rapidly (the channel or conduit is short-circuited). Most Arch Unit producers exhibit this property.

Table 2.3 shows the production performance of the 39 analyzed UA-5 sand producers of the Arch Unit including well name, current or last WOR, and cumulative oil produced (primary and waterflood). If we define water breakthrough as WOR greater than or equal to 3 , the data indicate that 24 wells have achieved this. Arch well nos. $2,21,27,40,46,49,78,110,111,113$, and 114 all have a WOR of less than or equal 0.2 . I I is apparent that all these wells had a minimal waterflood response. Of the 39 analyzed producers, the average last or current WOR is 25.8 , and cumulative oil produced (primary and waterflood) is $178 \mathrm{Mbbl}$. As discussed before, most wells dispiay an asymptote on the WOR vs. cumulative oil produced plots. Because of this abrupt increase in WOR, all of these high WOR wells were shut down. An examination of all the plots indicates that only a lew of them have a post water hreakthrough lincar relationship: Arch well nos. 88, 90, $91,92,96,98$, and 100 . 
Table 2.4 shows the original oil-in-place (OOIP) analysis of these wells using the Lo et al., (1990) technique. Also shown are the estimated 80-acre well OOIP values from volumetric calculations and the ratios of OOIP calculated from WOR plots to that from volumetrics. The average ratio is 0.084 . In other words, each of these 5-spot waterflood pattems apparently has less than $10 \%$ of the volumetric OOIP available for waterflood recovery. Such a drastic difference between the two calculated OOIP values indicates that the waterflood in these patterns is probably not following the routine immiscible water displacement of oil bank in waterflooding. This may indicate that the injected water is flowing through certain channels or conduits that have a very small pore volume compared to that of the oilbcaring zonc.

\section{Reservoir Volume Balance in Waterflood}

The reservoir volume balance during waterflood is being analyzed in the Arch Unit to determine if injected water was lost to sands other than the UA-5 and UA-6 sands. The cumulative oil production volume and cumulative fluid production (oil and water) plotted against cumulative water injection (CWI) volume through 1983 are presented in fig. 2.47. An oil formation volume factor of 1.2 was used 10 correct the cumulative oil production volume to rescrvoir volumes.

The following four phases during the injection period are indicated in fig. 2.47: (1) water filling the gas-filled pore space for CWI less than 7 million barrels; (2) increasing production for CWI ranging from 7 to 15 million barrels; (3) water filling the southwest area of the Arch Unit, for CWI ranging from 15 to 31.5 million barrcls; and (4) increasing production for CWI greater than 31.5 million barrels.

The two periods of water fillup are probably due to different waterflood initiation times in different sections of the Arch Unit. Figure 2.47 shows that the cumulative production volume is $73 \%$ of the cumulative injection volume. The reason for this imbalance may be due to the filling of the initial gas cap in the west edge of the Arch Unit or the escape of injected water into other sands. It is not clear whether the injection water was lost to other sands. Similar volume balance curves are being plotted for different sections in the Arch Unit to examine this hypothesis.

Figures 2.48 and 2.49 show the Arch Unit total water injection and the cumulative oil production to 1986 since the full-scale waterifood started in 1966. Except for a Scw wells which were completed in UA- 5 and UA-6 or UA-6, the mapped fluids injection and production are from the UA-5 sand. Figure 2.48 clearly indicates that the arcas that accept the most water are the southwest portion of the Arch Unit (west of the permeability barrier), and the areas around wells $8,10 \mathrm{~A}$ and 31 , which have very good petrophysical propertics. Figure 2.49 displays two preductive arcas during the waterfloxd period corresponding to the two good injection areas, i.c., the southwest portion of the Arch Unit enclosing wells 44, 30, and 15 (most productive), and the areas enclosing wells 88,90 , and 91 . The relatively higher production surrounding well 69 was from the UA-6 sand. As shown in fig. 2.49, except the two productive arcas of the UA-5 sand and the area surrounding well 69 , the waterflood oil recovery in the Arch Unit was very low; the average recovery is approximatcly $50 \mathrm{Mbbl}$. The contour lines in figures 2.48 and 2.49 also indicate the UA-5 sand to have better continuity in the northeast-southwest direction than the southeast-northwest direction.

\section{HETEROGENEITIES AND ANOMALIES OBSERVED IN PATRICK DRAW FIELD}

Analyses of the distributions of produced hydrocarbon, formation water salinitics, and pressure depletion patterns were used to identify areas of restricted or non-existent hydrodynamic communication within the field. These anomalies along with an offset of the oil-water and oil-gas contacts indicate major compartments within the reservoir and comprise the reservoir scale heterogeneities that are the primary controls on production from that field.

\section{Variations In Produced Hydrocarbon Phase}

Figure 2.50 illustrates the distribution of wells producing a single hydrocarbon (oil or gas) versus wells producing oil and gas phases simultaneously. Comparison of the distribution of hydrocarbon phase in fig. 2.50 with the initial oil production in fig. 2.37, shows that higher initial oil production rates correspond with those areas where only oil is produced while the areas with a "mosaic" pattern of initial production correspond with simultaneous production of oil and gas. A cross plot of initial gas production vs. initial oil production indicates that when oil and gas are produced together, the quantity of oil produced drops significantly (fig. 2.51).

In the Moncll Unit, the simultaneous production of oil and gas during initial production predominates in the downdip portion of the reservoir (close to the oil-water contact) where both the initial production and the 2 -year cumulative production is relatively low $(10$ to 1000 's $\mathrm{BOPD}$ and 100 to $200 \mathrm{MBBL}$, respectively), while the exclusively oil-producing wells dominate in a broad area updip, below the oil-gas contact where the initial production and 2-ycar cumulative production is much higher, reaching up to 1,800 BOPD and $350 \mathrm{MBBL}$ of oil respectively (fig. 2.50). Such an arrangement of fluids within productive UA-5 and UA-6 Almond sandstones at the initial stage of production suggest isolation of the downdip and updip portions of the reservoir. A possible explanation for this type of distribution is as follows: the updip portion of the reservoir is in equilibrium with the gas in the gas cap at reservoir conditions. Initial production at this condition will produce little or no gas. In the downdip portion of the reservoir the confining 
pressure is slightly below bubble point and the reservoir compartmentalization causes the oil to be supersaturated with solution gas. Both oil and solution gas are produced during initial production. The high production ratc of gas depletes the reservoir pressure rapidly resulting in a low recovery of oil during primary production. An alternative explanation, although less likely, is that there is vertical lcakage of gas into the southeastern (downdip) portion of Monell Unit from underlying horizons. The presence of gas in the underlying UA-8 sandstone is demonstrated by the 1,226 Mcf gas production from well 178 (Sec.15 T18N R99W) located near the southern tip of Monell Unit.

Analysis of the hydrocarbon phases produced during initial production indicates a barrier to lateral flow within the Monell Unit. The fact that no active water drive was observed during production in the western (updip) portion of the Monell Unit further substantiates a lack of hydrodynamic communication with the aquifer. In the Arch Unit, restricted hydraulic communication is indicated by the mosaic pattern of initial production; however, no absolute scaling barriers have been observed.

\section{Variations In Formation Water_Salinities}

A strong anomaly in the Almond Formation water salinity and composition across the Monell Unit has been reported (Szpakiewicz and Collins, 1985; Szpakicwic\% ct al., 1991). High total salinity (TDS) values of $50,0(0)$ to $70,000 \mathrm{ppm}$ was recorded in the updip (shallower) portion of Moncll Unit versus $20,000 \mathrm{ppm}$ (and much less) in the downdip (decper) portion, a reversal of the typical trend of increasing salinity with depth. This anomaly secms to correspond with the obscrved change in pattern of hydrocarbu.. production (oil vs. oil and gas) and provides a second line of evidence indicating impaired horizontal communication between the downdip and updip sections of the Monell part of Patrick Draw ficld. Irregularities in the general salinity trend support a separated rather than laterally unrestricted model of fluid communication within the major compartments.

The hydrochemical anomalics must be considered when interpreting resistivity logs in the area. The common occurrence of low salinity formation waters below a depth of 5,000 ft in the Greater Green River Basin cast of the Rock Springs Uplift may lead to misinterpretation of oil saturation and hydrocarbon resources in the Upper Almond multireservoir system. It is well known that the injection of incompatible fluids will cause formation damage; however, little information is currently available on the spatial distribution of huid composition and properties within reservoirs. Analyses of water and gas are sparse and incomplete, and oil analyses are virtually non-existent for the Patrick Draw field. The fluid geochemistry (including the isotopic composition) is definitely one of the important missing diagnostic clements required for modeling of heterogeneities in the Patrick Draw ficld.

\section{Variations In Pressure Depletion}

Two distinct arcas of significant formation pressure drop) in Patrick Draw ficld developed at the early stage of hydrocarbon production betwecn April-May, 1961 and June, 1966 (UPC Isobaric Map, 1966). The low pressure arcas are located in downdip portions of the Arch and Moncll productive units, close to the oil-water contacis. During the 5-ycar production period, the pressure dropped at least 800 to 1,000 psi below the original formation pressurc, down to $700 \mathrm{psi}$ in both arcas. In the Moncll Unit, the arca of maximum pressure drop corresponds well with the production and geochemical anomalies discussed above. The 90()-psi isobar curves around the 700)-psi isobar in Arch and Moncll Units indicating potential for some kind of flow barrier between well drained areas where formation pressurc dropped significantly in comparison with the rest of the ficld. The pressure anomaly provides third line of evidence for disrupted hydrodynamic communication across Monell Unit.

A composite map including the variations in the distribution of produced hydrocarbons, water salinities, and formation pressures are presented in fig. 2.52. Locations of the areas of restricted communication indicated by the three convergent lines of evidence are shown. In the Arch Unit, the anomalies along with an offset in the oil-water and oil-gas contacts correspond to the sand thin areas (compare with lig. 2.11) and indicates that limited communication is due to poor connectivity of the reservoir sands. The anomalies in the Monell Unit indicate a barrier to fluid flow trending northwest-southeast. This orientation is consistent with photo lincaments observed in the area and suggests the presence of a sealing fault. However, further work is needed to substantiate the cause of the barricr.

\section{Evidence for Vertical Communication}

High gas production $(9,500$ Mcf from well 1 in Sec. 8 and 2,264 Mcf from well 1 in Sec. 5 Tl9N R98W) from the Fox Hills Formation, which overlics the Almond Formation, may suggest that gas migrated through the Lewis Shale Formation to horizons above the Almond Formation. There are no other known hydrocarbon accumulations above the Almond Formation in Patrick Draw area (F. Lim, UPRC personal communication, 1991). However, a distinct soil gas anomaly has been recorded over gas cap in Patrick Draw ficld (Richers et al., 1982) strongly indicates vertical lcakage of gas from Almond Formation.

The presence and conductivity of vertical conduits should be investigated before implementation of planned $\mathrm{CO}_{2}$ injection for enhanced oil recovery. One powerful tool that can provide valuable data to substantiate the hypothesis of vertical cross-formational flow is geochemical and isotopic analysis of fluids. Isotopic analyses of hydrocarbon gas produced from different horizons (UA-8, UA-6, UA-5, and Fox Hills) and in 
different areas of Patrick Draw field could cast new light on the connectivity of the system and help to design a more effective method of oil recovery (Szpakicwicz, 1991). Most wells produce from individual well-defined horizons, and (as indicated by ficld reconnaissance) the gas samples for stable isotopes can be taken at selected wellheads. A good opportunity now exists for sampling the formation fluids - a new gas well completed in early October, 1990 (in Sec. 34 T19N R99W) was perforated in the UA-5 sand at 4, 180 to 4,200 ft and other new wells are planned to better define better the gas cap in the UA-5 horizon (Lane, personal communication, 1990 and 1991).

\section{Variation of Flow Properties within UA-6 Sandstones}

By integrating information from log, petrophysical measurements on cores and geological descriptions of cores, variations in petrophysical properties duc to different types of heterogeneitics in UA-6 sandstonc in wells 81,71 and 67 along profiles 2 and 4 (Sec fig. 2.22 for location ) were studicd. Along this profilc, no production from the UA-6 sand has been reported cast of well 67. Geological descriptions of cores were available from well 81 so that the dominant log signatures in the three wells could be calibrated with lithology of the producing sandstonc. This calibration of geology with gamma ray and sonic log signatures indicates that besides ample coal/shale/silt beds within the sandstones, appreciable variations in clay content exist in the sandstone pore spaces, and hard, cemented zones are present in wells 71 and 67.

The distributions of porosity and water saturation within the UA-6 sandstone in well 81 indicatc very good agreement between porosity values obtained from sonic transit time data and those measured in the laboratory (fig. 2.53). The departure in the two curves below 4,241 fl in well 81 is because the lithology changed from sandstone to coal at this depth. The distribution of water saturation $\left(S_{w}\right)$ values obtained from laboratory measurements on cores does not agree well with log cvaluated values for most depths. The method used to calculate saturation from wireline logs was Simandoux's total shale volume method (Crane, 1986). This method has been found to give reliable saturation values in sandstones containing low to moderately high amounts of clays, and the tolal volume of water absorbing clays (smectite, for example) does not exceed 3 to $4 \%$. Saturation measurements based on conventional coring, as for wells Arch 81, 71, and 67, scldom give reliable saturation values.

The distribution of clay content $\left(\mathrm{V}_{\mathrm{cl}}\right)$ and porosity $(8)$ within the UA-6 sandstoncs in wells 81, 71, and 67 is shown in figure 2.54. The depth scale in this ligure refers to the distance from the top of the individual sandstones. The $\mathrm{V}_{\mathrm{cl}}$ and $\emptyset$ values were computed from gamma ray and sonic logs, respectively. These plots (fig. 2.54) clcarly demonstrate the large variations in distribution of llow propertics within the three sandstones. The maximum clay content is encountered in well 67 and the minimum in well 71. Both wells 71 and 67 , have a zone where both porosity (sonic transit time) and clay content (gamma ray response) are low. This is due to carbonate cement which normally has low sonic transit time (and hence low porosity) and low gamma ray response duc to the deficiency in potassium, uranium and thorium content in the carbonate cement. The low value for $\mathrm{V}_{\mathrm{cl}}$ in the cemented zones is therefore due to the low gamma ray readings in calcitic or dolomitic cernents. It is apparent therefore, that to identify the best parts of a sandstone, the distribution of clay content has to be studied in conjunction with the distribution of porosity. The distribution of log-derived water saturation $\left(S_{W}\right)$ in the three sandstones obtained by application of Simadoux's total shale volume method (Crain, 1986) is shown in fig. 2.55. Only small portions of sandstones in wells 81 and 71 appear to have sufficiently high oil saturations for sustained production. Figure 2.55 , indicates that at the top and the bottom of the sand in well 71, there are thin zones with low water saturations $(<20 \%)$ whereas no such zones of low water saturation occur in well 67.

The plots of core-measured air permeability data for wells 81 and 71 indicate the presence of several relatively high-permeability streaks in well 71 in the high oil saturated portion of sandstones in this well (fig. 2.55), however because of the averaging effect of log readings, the streaks could not be identificd from the well log data. The presence of these high-permeability streaks could explain the relatively high oil production in Arch 71 compared to that in well 81 . Permeability data were not available for well 67 , but the distribution of all other flow propertics $\left(\mathrm{V}_{\mathrm{cl}}, \emptyset\right.$, etc.) indicated that the reservoir quality of this sandstone is much inferior compared to that of well 71 or even well 81 .

\section{HETROGENEITIES ENCOUNTERED IN OUTCROPS: SEDIMENTOLOGIC AND STRUCTURAL FEATURES}

\section{Sedimentological Features}

Outcrop exposures of the Almond Formation along the castern tlank of the Rock Springs Uplift form a 100-mile long belt and are as close as 6 miles from Patrick Draw ficld. The Upper Almond shoreline barrier sandstones cxposed there (UA-1, UA-2, and UA-3) are stratigraphically younger and structurally higher than those which produce oil and gas in Patrick Draw field (UA-5, UA-6, and UA-8), however, the facies observed in the examined outcrops are generally similar to those observed in subsurface corcs from Patrick Draw ficld.

Two corcholes drilled by Citics Service Company behind the Almond Formation outcrops were interpreted by Meycrs (1977). Corc hole no. 2 (525 ft deep) is located on the southeastern flank of the Rock Springs Uplift near the exposure " $\mathrm{G}$ " described initially by Roehler (1988). Facies documented in the upper Almond section 
(1988). Facies documented in the upper Almond section in core no. 2 are primarily composed of the shoreface, tidal channel, tidal delta, and associated facies-the major productive facies in the Arch Unit of Patrick Draw rield. The location of this core provides an unique opportunity to compare sedimentological and diagenetic features of the Upper Almond shoreline barrier sandstones between the outcrop, the shallow corchole, and the oil-bearing reservoir at depth of 4,500 ft. More detailed work on such a comparison is recommended for FY 1992.

Emphasis of the field work was on documentation of the depositional, structural, and geochemical heterogeneities in the exposed sandstones which appear to affect the productivity of depositionally similar hydrocarbon bearing sandstones in the Arch and Monell Units of Patrick Draw ficld.

The outcrops provide laterally continuous exposures of the Upper Almond facies for distances of 100's to 1000's feet. Comparison of the sedimentological facies of the outcrop exposures and the facies observed in cores from the producing intervals in the Patrick Draw field indicate that the rocks exposed in the outcrops were deposited in similar environments and under similar hydrodynamic conditions as those producing oil and gas from the UA-5 sandstone intervals at depths of about 4,500 - 5,000 ft.

Four outcrops located on the southeastern flank of the Rock Springs Uplift at an approximate distance of 25 miles from Paurick Draw field; namely, G, H, I, and J previously described by Roehler (1988), were evaluated for detailed investigation. Sandstone sequences deposited predominantly as barrier associated tidal inlet, tidal delta, tidal channel, tidal creek, tidal flat, washover, and lagoonal/bay sediments, are well represented there. Some remnants of the open marine facies forming the barricr bar $G$ (mostly shoreface) also are present. The $G$ and $H$ outcrops located about two miles apart are oriented perpendicular to the general paleoshoreline direction (along depositional dip) and were finally selected for measuring sections and drilling the core plugs. Facies formed by tidal currents predominate in the two outcrops. One vertical section RG-7 of $257 \mathrm{ft}$ was measured in outcrop $\mathrm{G}$ and two sections RH-2 of $145 \mathrm{ft}$ and $\mathrm{RH}-3$ of $140 \mathrm{ft}$ were measured in outcrop $\mathrm{H}$. The examination of physical and biogenic structures in 2 and 3 dimensional exposures allowed measurements of paleoflow directions, dimensions of sand waves, and observation of abundant burrows which provided diagnostic facies characteristics. Abrupt vertical and in some cases lateral changes of facies inherited from the specific type of deposition and erosion in the highly dynamic mesotidal environment were observed in the outcrops. The "mosaic" productivity of adjacent wells in certain areas of Patrick Draw ficld sometimes may be attributed to the abrupt termination of the best productive facies. In most cases, however, the major sandstone horizons interlayered by the shaly, silty, and coaly backbarrier tidal tlat, bay, and marsh sediments of poor reservoir quality are laterally continuous at least for hundreds of feet.
Depositional and crosional contacts between superimposed sandstone facies of shoreface, tidal delta, and tidal channel facics are sharp, sand-on-sand contacts, and except for changes in grain size affecting their permeability, should not provide significant barriers to huid distribution and flow. Shocstring geometry of high energy and potentially high permeability tidal channel facies may provide, however, preferential "channels" for directional flow of produced and injected fluids even within otherwise favorable sandstones of lobate geometries such as flood (or ebb) tidal delta. Prediction of the facies distribution in subsurface is important for estimation of drainage potential and design of injection pattern although is very difficult.

Highly calcite-cemented, low- to zero-permeability oyster recfs as well as the associated bay-front gray shales and mudstones which cover the depositional cycle of bar $\mathrm{G}$ are continuous for several miles and provide potential for flow barriers. However, a well developed fracture system within the oyster bed, where not filled with carbonates, may enable frec communication of fluids between bar $\mathrm{G}$ and the overlying sandstone layers belonging to the next depositional cycle (bar F).

Common and fairly continuous coal laycrs $(0.5$ to $6.0 \mathrm{ft}$ thick), associated with carbonaceous shales (salt marsh deposits), may severely impair vertical fluid communication in the interwell area. Migrating coal fines under existing hydrodynamic conditions can effectively block pore throats in the adjacent sandstones and decrease their permeability. Extremely porous and adsorptive coals probably could interact with injected fluids and act as selective barricrs. Coals and carbonaceous shales in the Almond Formation commonly contain enhanced amounts of trace elements such as barium, strontium, boron, nickel, cesium, cobalt, chromium, copper, lead, manganese, zinc, zircon, vanadium, and yturium (Rochler, 1988), which usually occur in negligible quantities in common reservoir rocks. Little is known about potential for their mobilization and geochemical interaction with injecled chemicals. Coal layers and dispersed coal particles are much more abundant in the Almond Formation than in the Muddy Formation what makes an important mincralogic difference between the two types of shoreline deposits compared in this study.

\section{Fractures and Faults}

General tectonics of the Greater Green River Basin and Patrick Draw ficld was discussed earlier (Szpakiewicz et al., 1991). A number of east to northeast trending normal fatults have been documented in the outcrop belt of Almond Formation on the east flank of the Rock Springs Uplift (Greer et al., 1987; Van Horn, 1979). Few of these faults, however, extend lar enough to the cast to cut through the Cretaceous sediments in Patrick Draw field, according to the USGS structural map (Greer et al., 1987). Documented soil-gas anomaly above Patrick Draw field and their relationship to photolinear features in that area 
(Richers et al., 1982) indicate, however, that fluid conductive structural discontinuities may extend from the Almond Formation, where first documented hydrocarbon accumulations are present at depth of about 4,500, up to the surface. Structural analysis of the oil and gas productive UA-5 and UA-6 sandstone suites (this study) along cross-sections cutting through the Arch Unit strongly indicates that low offset (less than $100 \mathrm{ft}$ ) normal faults exist there (figs. 2.17, 2.18 and 2.20). Production and geochemical anomalies which were discussed earlicr in this study also indicate a possibility of vertical fluid migration in Patrick Draw field and their lateral compartmentalization.

The role of natural fractures in the Upper Almond sandstones and their influence on fluid flow to the production wells and on water injectivity is not well understood. Few complete and full diameter cores are availablc for cxamination from Patrick Draw ficld. Several fractures were observed in studied incomplete cores and most of them were filled with carbonates. Therefore, the possibility exist for opening pathways for undesirable fluid migration within and between sandstone horizons by acidization of wells and to some cxtent by injection of water which might be strongly undersaturated with respect to calcite and dolomite. The indication is that a slight increase of permeability in sections of core from well 102 in Arch Unit may be due to presence of microfractures because the corresponding matrix porosity is very low. Distribution of natural fractures and their characteristics between cored wells cannot be estimated from available geological, geophysical, and engineering data. The geochemical and production anomalies, however, indicate a possibility of at least migration of gas between horizons, which can be attributed to flow through partially open vertical fractures associated with faults.

The lack of information on fracture characteristics in Patrick Draw ficld and, therefore, the role of natural fractures in hydrocarbon production prompted the study of fracture distribution (oricntation, continuity, and spacing) in the outcrops of the Upper Almond Formation on the cast flank of the Rock Springs Uplift. Sedimentological examination of outcrop sequences increased our confidence that the upper Almond sandstones producing oil and gas in Patrick Draw ficld and those which crop out several miles to the west were deposited by similar processes acting in analogous environments of deposition. Assuming also that the tectonic history was somewhat similar within the same part of the Greater Green River Basin, we expected similar cffects in fracturing of analogous facies and lithologics. Thus, we also assumed that surface mcasurements of fracture parameters might apply with some restrictions to the Patrick Draw rescrvoirs at depth of about $4,5(0)-5,0)(0) \mathrm{ft}$.

Two gencral arcas on the cast Mank of the Rock Springs Uplift where the upper Almond sediments were previously described sedimentologically in a number of surface exposures: those located west of Patrick Draw ficld, in a distance of 6 to 10 miles, studied by Van Horn (1979) and the ones located on the southeast flank of the Rock Springs Uplift, up to 20 miles away from Patrick Draw field, studied by Rochler (1988). Major faults oriented nearly cast-west $\left(75^{\circ}\right.$ to $\left.80^{\circ}\right)$ dominate in the area of Van Horn's study, and some of them extend toward Patrick Draw field (Szpakiewicz ct al., 1991) (fig. 16).

Within Patrick Draw field, fault orientations published by Greer et al., $1987\left(74^{\circ}\right.$ and $\left.80^{\circ}\right)$, and Van Horn, 1979 $\left(77^{\circ}\right)$ generally correspond to the $75^{\circ}$ to $80^{\circ}$ directions measured in outcrop exposures. Orientations of photolineament measurements published by Richers et al., (1982), vary more widely $\left(33^{\circ}, 50^{\circ}, 84^{\circ}, 122^{\circ}, 164^{\circ}\right)$.

Virtually no documented major faults are in the immediate area of the outcrops located on the southeastern flank of the Rock Springs Uplift where fractures were measured for this study. However, most faults shown on the map by Greer et al., (1987) located near the crest of the Rock Springs Uplift, west and northwest of studied outcrops, are oriented differently $\left(30^{\circ}\right.$ to $\left.40^{\circ}\right)$ than those in the area studied by Van Horn on the east-centrail flank of the Uplift $\left(70^{\circ}-80^{\circ}\right)$ which tend to continue toward Patrick Draw ficld.

Approximately $1,(0)(0)$ inctonic fractures were measured at three major sandstone horizons in outcrops $R G$ and $R H$ along lateral distances of 800 to $1,500 \mathrm{ft}$. The approximate vertical continuity and lateral spacing were recorded. Obvious weathering or gravitational fractures were climinated from the record. A strong indication of minor faults was observed in a few cases. Gcological and statistical analyses of measured fractures and their relationship to faults in the general area can be summarized.

Predominant major fractures in studied outcrops are usually vertical or near vertical and tend to cut the entire sandstonc sequence formed by the same sedimentary process (facies) or the superimposed sequences of facies, at vertical distances of several feet to tens of feet; they tend to discontinue in "soft" rocks such as lagoonal or bay facies but may re-appear in the under- or overlying sandstone sequences. Minor sets of fractures usually cut an individual sandstone layer at a vertical distance of several inches or a few feet. Density of major fractures vary greatly from a couple of feet to tens of fect, while the density of minor fractures usually varies from inches to a few fect.

Fractures at the outcrop surface are exposed 10 atmospheric conditions and are predominantly open, although calcite or gypsum fillings also were sporadically observed. The abundance of very well preserved shells in the upper Almond deposits which are commonly observed in the outcrops, the two cores from holes drilled behind the outcrops, and the cores from Patrick Draw field, provide evidence that at the time of deposition and during post-depositional history the sediments were exposed primarily to formation lluids in thermodynamic equilibrium or oversaturated with respect to calcite and possibly dolomite. This leads to the conclusion that the rock matrix, as well as fractures and faults in subsurface, 
might have been subjected to extensive cementation or scaling. Engincering processes, however, such as acidization of wells and llooding with water incompatible with original formation fluids could dissolve the precipitate. Planned injection of carbon dioxide to stimulate oil flow certainly would magnify the dissolution process. Also, the hydraulic fractures primarily tend to develop along completely or partially sealed tectonic joints and may re-open the original channels to flow. The geochemical and enginecring aspects of the Almond reservoir strengthen the importance of studying natural fractures in the system to predict the fluid flow pattern in Patrick Draw ficld.

There are two major sets of fractures characteristic for all outcrops in the studied arca; $20^{\circ}$ to $80^{\circ}$ and $110^{\circ}$ to $160^{\circ}$. Computed mean orientation of the prevailing set is near $130^{\circ}$, while the $95 \%$ confidence interval is about $23^{\circ}$ (fig. 2.56). It has to be noted, however, that the differentiation between the systematic and nonsystematic joints has not been attempted at this stage of the fracture study in the Almond outcrops. Typically, the greatest local or regional permeability would be along the systematic joints (Kurlander et al., 1991). Therefore, the rose diagrams of cumulative fracture frequency may not adequately reflect the preferential directions of fluid flow suggested by orientation of the longer rose pelals.

The orientation of measured fracture scts in outcrops and the calculated means vary somewhat among sandstone horizons and among individual outcrops located onc to three miles apart (fig. 2.57).

In most cases, however, the two nearly perpendicular directions of fractures, i.c., $30^{\circ}$ to $40^{\circ}$ and $130^{\circ}$ to $140^{\circ}$ definitely prevail in most of the outcrops studied and in the individual sandstone horizons (figs. 2.56, 2.57 and 2.58).

Orientation of dominant fractures in most of the studied outcrops and sandstone horizons does not correspond well with dominant fault directions and orientations of some photolinear features $\left(70^{\circ}\right.$ to $\left.80^{\circ}\right)$ mapped in Patrick Draw ficld area (Greer et al., 1987; Richers ct al., 1982) and in the Almond outcrops located west of Patrick Draw (Van Horn's outcrop area). It does correspond, however, with dominant fault directions $\left(30^{\circ}\right.$ to $40^{\circ}$ ) on the crest of the Rock Springs Uplift, west and northwest of measured outcrops as shown on the Greer et al., (1987) map.

Few fracture measurements from outcrop VH8 (located further north on the Rock Springs Uplift in the "Van Horn's area" indicate a prevailing orientation of $60^{\circ}$ to $70^{\circ}$ which is fairly close to the dominant fault direction in the general area $\left(70^{\circ} 1080^{\circ}\right.$ ) (fig. 2.59a). Surprisingly, fracture sets measured in sandstone bodics overlying bar RG in the Rochler's outcrop G (c.g. "Whitc Sands" fig. $2.59 \mathrm{~b}$ ), as well as the "Whitc Sands 2" and "Major White Sands" (fig. 2.60)a) exposed north and northeast of outcrop $\mathrm{RG}$, reveal two predominant fracture orientations of $130^{\circ}$ to $160^{\circ}$ and near perpendicular orientation of $70^{\circ}$ to $80^{\circ}$. The latter coincides with dominant fault directions in
Patrick Draw ficld and in adjacent outcrop arca studicel by Van Horn (1979). Similar fracture orientations were revealed in sandstones underlying the marine sequence of the bar $G$ in outcrop $H$ (fig. 2.6()b) which may belong 10 the Lower Almond (continental) sedimentary sequence. This indicates a possibility that the predominantly marinc sediments forming bar RG might have been subjected to a different fracturing episode of the Laramide orogenesis than the older and the younger sediments.

Fracture characteristics from the measured Rochler's bar RG outcrop area may not be best representative for fracture characteristics in Patrick Draw rescrvoir horizons. It may apply even less to its northern part, i.c., Arch Unit. A good indication is that the studicd outcrop area and Patrick Draw ficld belong to different tectonic blocks outlined by domain boundaries of the predominant oricntation of systematic fractures. There also is a possibility that the two arcas were subjected to different fracturing episodes resulting in gencration of differentiated patterns of the superimposed fracture sets.

Comparison of measured fracture distributions and their characteristics with those in the central section of the Rock Springs Uplift, located immediately west of Patrick Draw field (in the Van Horn's area), would be highly desirable for the best possible characterization of fracture distribution, orientation, density, chronology, and permcability which may strongly alfect lluid flow palterns in Paurick Draw ficld.

\section{CONCLUSIONS}

1. Major depositional fcatures of the Almond Formation within the Arch Unit, Patrick Draw liceld that are important to fluid flow, consist of: (a) sand thin areas containing low-permeability sediments of oyster coquina, carbonaceous shale and shaley sand formed either in a lagoonal setting behind one of the two bars within the ficld, or as an abandoned channel fill deposit, that restrict hydraulic communication; (b) sand thick areas consisting of tidal channel overlain by tidal delta deposits, that contain the best reservoir quality rocks, (c) impermeable rock units with limited lateral extent (10's to 1,00)'s fi) that may be a source of restricted lateral hydraulic communication; (d) coal beds prone to parting and fracturing during fluid injection that may be conduits for fluid flow, if fraclured, or barricrs to verlical flow if not; and (d) calcite cemented oyster-shell zones, if unfractured, that are barriers to vertical fluid flow.

2. Two broad permeability and porosily classes can be distinguished according to groups of facies. The higher permeability class consists of tidal inlet, tidal channel and tidal delta facies with mean (geometric) permeabilities of 20 md and mean porositics of $20 \%$. The higher permeabilites within this group are consistent with the higher depositional energies of the lacies. The lower permcability class consists of tidal creck, tidal flat, swamp and lagoonal facies, with mean (geometric) permeabilites 
of 1.5 md and mean porosities of $14 \%$. The lowpermeability intervals (with a wide range of porosity) appear to be the result of clay (matrix and diagenetic clay) and carbonate cementation.

3. Major structural features within the Arch Unit, determined from cross-sections, consist of live previously undocumented faults. The offset of the reservoir due to faulting may create choke points or total harricrs to lluid flow. The effect of these faults on produciion/injection will be further investigated.

4. Lithologic controls on reservoir quality consist of the relatively high proportion of sedimentary rock fragments (up to $8 \%$ ) within the sandstones, which are highly susceptible to compaction and thereby reduce permeability. Large and highly variable amounts of rock-strengthening diagenetic carbonate cement noted in UA-5 sandstones, drastically reduce permeability where they occur. The relative timing of various carbonate phases and the abundance of evidence for leaching of rescrvoir sandstones seen in thin section indicate that the amount and timing of carbonate cement plays a significant role in determining reservoir rock quality.

5. Sorting, expressed as the standard deviation of grain size, has a strong inverse linear relationship with mean grain size. In the UA-5 sandstones the tidal channel facies is coarsest grained and least well sorted. Tidal flat and tidal creek facies are the finest grained and the best sorted. Samples from tidal delta facies exhibit a wide range of grain size and sorting. These relationships indicate that this technique has a high potential for distinguishing facies, if the general depositional system is known.

6. Initial production (IP) appears to be controlled predominantly by the thickness of the UA-5B sandstone, however the analysis of "specific production" (initial production divided by length of perforation) indicates that the co-cxistance of produced fluids (oil and gas) which affect relative permeability in Patrick Draw are important controlling factors on production.

7. Channeling and poor waterflood sweep efficiency in the Arch Unit are indicated by low waterflood recovery and volumetric imbalance of injected and produced water. Fractures are highly suspected as conduits to fluid flow, because matrix permeability contrasts are not high enough to cause such severe channeling.

8. At least three convergent lines of evidence indicate lateral compartmentalization in Patrick Draw ficld: (a) production of only oil in the updip portion of the reservoir, close to the oil/gas contact, versus oil and gas production in the downdip portion, close to oil/water contact; (b) precipitous drop in formation watcr salinity downdip in decper parts of the reservoir; and c) marked decrease of formation pressure during primary production in the castern (downdip) portion of the reservoir.

9. The analysis of outcrop exposures of the Almond Formation indicated that the rocks are genetically and sedimentologically similar to those observed in subsurface cores from Patrick Draw field. The study of the outcrop rocks enabled the refinement of sedimentological interpretation of reservoir cores, determination of the geometrics and dimensions of facies (rock units), and the nature of contacts between facies.

10. Comparison shows grain sizes from outcrop tidal delta and tidal creek facies tend to be coarser grained than their subsurface counterparts. The reasons for these differences are not certain at this time, but may include expected variations of intensities of depositional processes within depositional settings, slight differences in source of grains, and different size of areas over which the samples were taken. Outcrop porosities tend to exceed subsurface porositics; however, for a given porosity, the permeability of outcrop facies is consistently greater.

11. XRD analyses indicate that outcropping Almond sandstones are more quartzose than those at Patrick Draw field. Ternary diagrams of the essential components of Almond sandstones, indicatc that, although outcrop and subsurface sandstones tend to have similar compositions, there is a tendency for outcrop sandstones to be less quartzose, than subsurface samples. This apparent conflict may be rclated to the inability of XRD analysis to identify lithologics (c.g. rock fragments) so that different types and proportions of rock fragments may not affect the reported XRD-based quartz. content. The type of mineralogical analysis chosen must, therefore be carefully selected depending upon its ultimate usage.

Total carbonate in subsurface Almond samples includes dolomite, ferroan dolomite (ankerite), siderite, and calcite and is highly variable. None of the analyzed outcrop samples contained abundant dolomite.

XRD analyses indicate a mean of only about $3.6 \%$ total clays from Patrick Draw reservoir sandstones and $2.2 \%$ from outcrop Almond sandstones, which is generally less than the values determined from wircline log analysis this difference indicates that log-derived petrophysical properties may be more pessimistic than those determined from core analysis. Reasons for this difference could include the locations of XRD samples (cg. cleaner sands sampled), the relatively few XRD samples analysed, or the presence of minerals with higher than normal radioactivitics such as potassium feldspar, or mica.

13. Examination of the Upper Almond exposures (outcrops) located on the cast flank of the Rock Springs Uplift, WY provided valuable information and data on facies arrangement, geometries, and continuity, fracture characteristics, and distribution of petrophysical properties. These data have been used for improving the geological 
model of Patrick Draw ficld and for predicting its performance in course of reservoir development.

14. Field measurements and analysis of fracture parameters in the outcrops studicd on the southeastern flank of the Rock Springs Uplift revealed that the fracture pattern in the Rochler's bar RG rock system is consistent at a distance of at least a couple of miles. The fracture pattern provided an excellent insight into the potential for preferential fluid flow pathways in the area. However, the data collected from the Rochler's bar RG system may not be representative of the fracture characteristics in the reservoir horizons of Patrick Draw ficld. There is a strong indication that the two studied areas belong to different fracture domains or were subjected to different fracturing episodes resulting in gencration of separate patterns of the superimposed fracture sets.

\section{REFERENCES}

Baptist, O. C., E. J. White, and C. S. Land. May 25-26, 1964, Laboratory Predictions of Water Sensitivity Compared with Field Observations of Well Damage Patrick Draw, Wyoming. Paper presented at the Rocky Mountain Petroleum Section Regional Mecting, Casper, Wyoming. Paper SPE 839. 6 p.

Crain, E. R. 1986, The Log Analysis Handbook, v. 1. PennWell Books, Tulsa, OK. p. 214-218.

DaBoll, J. M. 1969, Holocene Sediments of the Parker River Estuary, Massachusetts. Contrib. No. 3-CRG, Dept. of Geology, Univ. of Massachusetts. 138 p.

Fertl, W. H. 1978, Knowing Basin Reservoir Parametcrs First Step in Log Analysis. Oil \& Gas Jour., v. 76, no. 21, p. 98.

Fetkovich, M. J. 1980, Decline Curve Analysis Using Type Curves. J. Pet. Tech., v. 32, p. 1065-1077.

Greer, P. L., King, J. K., and Ver Plocg, A. J. 1987 , Preliminary Map of Known Surficial Structural Fcatures for the Rock Springs $1^{\circ} \times 2^{\circ}$ Quadrangle. USGS Open File Report 87-1N.

Hall, H. N. 1963, How to Analyze Waterflood Injection Well Performance. World Oil, v. 157, p. 128-130.

Law, B. E. 1984, Relationships of Source-rock. Thermal Maturity, and Overpressuring to Gas Generation and Occurrence in Low-permeability Upper Cretaccous Rocks, Greater Green River Basin, Wyoming, Colorado, and Utah, in R.M.A.G., Hydrocarbon Source Rocks of the Greater Rocky Mountain Region, eds: J. Woodward, F. Meissner, and J. Clayton, $557 \mathrm{p}$.
Irwin, D. 1976, Arch and Moncll Units, Patrick DrawTable Rock Area, Sweetwater County, Wyoming- Upper Almond Sandstone Study. in, Unpublished Union Pacific Resources Co. Data Files.

Kcighin, C. W., B. E. Law, and R. M. Pollastro. 1989 , Petrology and Rescrvoir Characteristics of the Almond Formation, Greater Green River Basin, Wyoming, in Coalson, E. B., ed., Petrogenesis and Petrophysics of Selected Sandstone Reservoirs of the Rocky Mountain Region. The Rocky Mountain Association of Gcologists, Denver, CO, p. 281-298.

Kurlander, B.R., Dean, S., and Ward, B. 1991, AAPG Applied Fracture Analysis Workshop, Sept. 9-13, 1991, Hagerstown, Maryland. Course Manual, $458 \mathrm{p}$.

Lane, J. 1990 and 1991, Union Pacific Resources Company, Field Office in Bitter Creek (Patrick Draw Ficld) and in Rock Springs, WY, personal communication.

Lim, Frank. 1990, Union Pacific Resources Company, personal communication.

Lo, K. K., H. R. Warner, and J. B. Johnson. April 4, 1990, A Study of the Post-Brcakthrough Characteristics of Waterfloods. Paper presented at the 60th California Regional Mecting, Ventura, California. Paper SPE 20064. $10 \mathrm{p}$.

Matthews, C. S., F. Brons, and P. Hazdrock. 1954, A Method for Determination of Average Pressure in a Bounded Reservoir. Trans., AIME, v. 201, p. 182-191.

McCubbin, D. G., and M. J. Brady. 1969, Depositional Environment of the Almond Reservoirs, Patrick Draw Ficld, Wyoming. The Mountain Geologist, v. 6, p. 3-26.

Meyers, W.C. 1977, Environmental Analysis of Almond Formation (Upper Cretaccous) from the Rock Springs Uplift, Wyoming. Ph. D. Dissertation, The University of Tulsa.

Moslow, T. F. 1980, Stratigraphy of Mesotidal Barrier Islands. Ph.D Dissertation, Dept. of Geology, University of South Carolina, $187 \mathrm{p}$.

Nichols, M. M., and R. B. Biggs. 1985, Estuaries, In Davis, R. A. Jr., ed., Coastal Sedimentary Environments. Springer-Verlag, NY, p. 77-186.

Pittman, E. D., and R. E. Laresc. 1991, Compaction of Lithic Sands: Experimental Results and Applications. AAPG Bull., v. 75, p. 1279-1299. 
Richers, D. M., J. R. Reed, K. C. Horstman, G. D. Michels, R. N. Baker, L. Lundell, and W. Marrs. 1982, Landsat and Geochemical Study of Patrick Draw Oil Ficld, Sweetwater County, Wyoming. AAPG Bull., v. 66, p. 90)3-922.

Rochler H.W. 1988, The Pintail Coal Bed and Barrier Bar G - A Model for Coal of Barricr Bar - Lagoon Origin, Upper Cretaccous Almond Formation, Rock Springs Coal Field, Wyoming. U.S Geological Survey Professional Paper 1398, p.1-60.

Szpakicwicz, M. May 1991, Identification of CrossFormation Flow in Multirescrvoir Systems Using Isotopic Techniques (Phase I). Final Report, DOE Report NIPER-538, $38 \mathrm{p}$.

Srpakicwicz, M., and A. G. Collins. August 1985, Hydrochemical Study of the Upper Cretaceous and Lower Tertiary Formation in the Uinta, Piceance and Greater Green River Basins; Implications for Oil and Gas Related Problems. DOE Report NIPER-95, 70 p.

Szpakirwič, M., R. Schatringer, S. Jackson, B. Sharma, A. Cheng, and M. Honarpour. 1991, Sclection and Initial Characterization of a Second Barricr Island Reservoir System and Relining of Methodology for Characterization of Shoreline Barrier Reservoirs. DOE NIPER $-484,170 \mathrm{p}$.
Union Pacific Resources Company File - November, 1966 Upper Almond Sand, Patrick Draw Ficld, Isobaric Contour Map - Pressure Survey.

Van Horn, M.D. 1979, Stratigraphy of the Almond Formation, East-Central Flank of the Rock Springs Uplift, Sweetwater County, Wyoming: A Mesotidal Shoreline Model for the Late Cretaceous. M.S. Thesis, Colorado School of Mines, 150 p.

Weimer, R.J. 1966, Time-Stratigraphic analysis and petrolcum accumulations, Patrick Draw Field, Sweetwater County, Wyoming: AAPG Bulletin, v.5(), p.2, 15().2, 175.

Weimer, R.J. and R.W. Tillman 1982, Sandstone Reservoirs: SPE 10009 , pres. at the International Petrolcum Exhibition and Technical Symposium of the Socicly of Pctrolcum Engincers, Beijing, China, 18-26 March. 
TABLE 2.1 - Wholc rock X-ray diffraction analysis in weight percent, for samples fre m Patrick Draw and upper Almcad Formation outcrops

\begin{tabular}{|c|c|c|c|c|c|c|c|c|c|c|c|c|c|c|}
\hline Well & Jepth, ff & $\begin{array}{l}\text { Stratigraphic } \\
\text { Interval }\end{array}$ & 茅 & 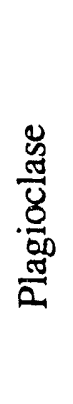 & 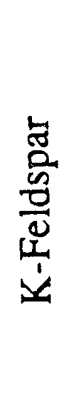 & $\frac{\stackrel{\mathscr{Z}}{E}}{\frac{0}{8}}$ & 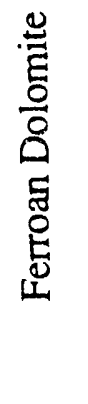 & 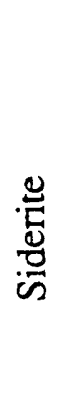 & 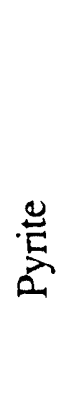 & $\frac{.3}{\tilde{J}}$ & $\begin{array}{l}\vec{E} \\
\text { 总 } \\
\text { 空 }\end{array}$ & 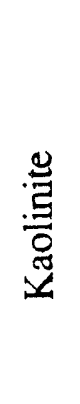 & 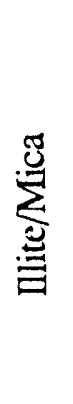 & 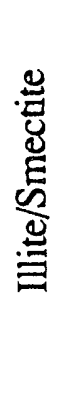 \\
\hline $7-18-1$ & 4.945 & UA5 & 61 & 4 & 4 & - & 21 & - & 3 & 3 & - & 3 & 1 & tr \\
\hline $45-14-3$ & 4,450 & UA5 & 5 & - & tr & - & ur & - & - & 93 & - & 2 & tr & tr \\
\hline $78-14-6$ & 4,305 & UA5 & 78 & 2 & 3 & 5 & tr & 2 & 1 & 5 & - & 2 & 2 & tr \\
\hline $49-1-3$ & 4,615 & UA-6 & 69 & - & 2 & 10 & 15 & - & 1 & 1 & - & 2 & 2 & $\mathrm{t}$ \\
\hline Arch 120 & $4,942.4$ & UA5 & 52 & 1 & 2 & 1 & - & - & 4 & 36 & - & 2 & 1 & 1 \\
\hline & $4,944.6$ & UA5 & 66 & 3 & 3 & 19 & - & - & 2 & 3 & - & 3 & 1 & tr \\
\hline & $4,948.7$ & UA5 & 82 & 2 & 4 & 1 & - & - & 3 & 4 & - & 3 & 1 & - \\
\hline & $4,949.5$ & LA5 & 88 & 3 & 3 & tr & - & - & 1 & 1 & - & 3 & 1 & tr \\
\hline & $4,962.4$ & UA5 & 91 & 3 & 2 & ur & - & - & ur & tr & -- & 4 & ur & tr \\
\hline & $4,962.5$ & UA5 & 86 & 3 & 4 & - & - & tr & 2 & tr & - & 4 & 1 & tr \\
\hline & $4,966.5$ & UA5 & 85 & 3 & 2 & 4 & - & - & 3 & tr & - & tr & 2 & 1 \\
\hline \multicolumn{15}{|c|}{ Outcrop Samples } \\
\hline G7-26B & & & 89 & 2 & 3 & 3 & - & - & - & -- & - & 1 & 1 & - \\
\hline G7-47 & & & 95 & 1 & 2 & tr & - & - & - & tr & - & 1 & 1 & - \\
\hline G7-91 & & & 83 & 5 & 8 & tr & - & - & - & tr & - & 1 & 1 & - \\
\hline G7-174 & & & 89 & 4 & 4 & $\mathbf{t r}$ & - & - & - & -- & tr & 2 & 1 & - \\
\hline G7-191 & & & 90) & 3 & 4 & 1 & - & ur & - & -- & - & 1 & 1 & - \\
\hline
\end{tabular}


TABLE 2.2. - Hall plot analysis of Arch Unit injectors UA-5 sand

\begin{tabular}{|c|c|c|c|c|c|c|c|}
\hline $\begin{array}{l}\text { Arch } \\
\text { Well No. }\end{array}$ & $\begin{array}{c}V_{p} . \\
M \quad b b l\end{array}$ & $\begin{array}{c}\mathrm{W}_{\mathrm{if}}, \\
\mathrm{M} \mathrm{bbl}\end{array}$ & $\begin{array}{c}\mathrm{m}, \\
\mathrm{psi}-\mathrm{D} / \mathrm{bbl}\end{array}$ & $\begin{array}{l}\mathrm{k}_{\mathrm{w}} \mathrm{h}, \\
\mathrm{md}-\mathrm{ft}\end{array}$ & $\begin{array}{l}\mathbf{k}_{\mathrm{w}} \\
\mathrm{md}\end{array}$ & $\begin{array}{l}\text { kair, } \\
\text { md }\end{array}$ & $\mathrm{k}_{\mathrm{rw}}$ \\
\hline 3 & 2,898 & 377 & 14.0 & 53.60 & 2.33 & 42.85 & 0.054 \\
\hline 4 & 2,309 & 300 & 13.0 & 57.72 & 3.04 & 30.36 & 0.100 \\
\hline 5 & 2,430 & 316 & 87.3 & 8.60 & 0.41 & 24.05 & 0.017 \\
\hline 6 & 3,264 & 424 & 10.0 & 75.04 & 2.89 & 49.40 & 0.059 \\
\hline 7 & 2,340 & 304 & 15.0 & 50.03 & 2.50 & 33.20 & 0.075 \\
\hline 8 & 3,251 & 423 & 5.0 & 150.08 & 6.00 & 58.59 & 0.102 \\
\hline 9 & 2,142 & 278 & 41.0 & 18.30 & 1.14 & 66.69 & 0.017 \\
\hline $10 \mathrm{~A}$ & 4,024 & 523 & 6.0 & 125.07 & 4.17 & 68.43 & 0.061 \\
\hline 11 & 1,869 & 243 & 57.0 & 13.16 & 0.66 & 24.77 & 0.027 \\
\hline 12 & 1,491 & 194 & 51.0 & 14.71 & 1.23 & 73.72 & 0.017 \\
\hline 13 & 2,167 & 282 & 42.5 & 17.66 & 1.04 & 23.34 & 0.045 \\
\hline 15 & 4,518 & 587 & 0.9 & 833.77 & 24.52 & 55.77 & 0.440 \\
\hline 16 & 2,671 & 347 & 9.0 & 83.40 & 4.17 & 64.30 & 0.065 \\
\hline 18 & 4,944 & 643 & 1.0 & 750.39 & 19.75 & 44.32 & 0.446 \\
\hline 19 & 4,403 & 572 & 0.5 & $1,340.00$ & 40.60 & NA & - \\
\hline 20 & 3,423 & 445 & 1.3 & 577.20 & 23.10 & 43.9 & 0.526 \\
\hline 22 & 1,340 & 174 & 7.3 & 102.80 & 9.35 & 21.82 & 0.429 \\
\hline 23 & 2,692 & 350 & 23.0 & 32.63 & 1.63 & 65.4 & 0.025 \\
\hline 24 & 1,939 & 252 & 15.0 & 50.03 & 3.34 & 59.71 & 0.056 \\
\hline 25 & 1,560 & 203 & 55.0 & 13.64 & 1.05 & 26.47 & 0.040 \\
\hline 26 & 2,295 & 298 & 11.0 & 68.22 & 3.59 & 38.33 & 0.094 \\
\hline 28 & 2,418 & 314 & 12.0 & 62.53 & 3.29 & 53.82 & 0.061 \\
\hline 29 & 2,428 & 316 & 2.5 & 300.20 & 15.80 & 66.06 & 0.239 \\
\hline 31 & 3,098 & 403 & 7.0 & 107.20 & 4.47 & NA & - \\
\hline 34 & 1,983 & 258 & 68.6 & 10.94 & 0.73 & $\mathrm{NA}$ & - \\
\hline 35 & 2,622 & 341 & 19.() & 39.49 & 1.80 & NA & - \\
\hline 36 & 1,563 & 203 & - & - & -. & 60.3 & - \\
\hline 37 & 2,299 & 299 & 60.0 & 12.51 & 0.66 & NA & - \\
\hline 38 & 2,568 & 334 & 55.8 & 13.45 & 0.64 & - & - \\
\hline 41 & 2,119 & 275 & 23.0 & 32.63 & 1.92 & 40.96 & 0.047 \\
\hline 42 & 2,618 & 340 & 28.0 & 26.80 & 2.68 & 33.10 & 0.081 \\
\hline 43 & 1,584 & 206 & 11.5 & 65.25 & 5.02 & 40.35 & 0.124 \\
\hline 45 & 2,080 & 270 & 16.0 & -46.90 & 2.76 & 22.32 & 0.124 \\
\hline 47 & 2,664 & 346 & 1.5 & 500.26 & 23.82 & 35.79 & 0.666 \\
\hline 48 & 3,108 & 404 & 55.0 & 13.64 & 0.55 & 17.42 & 0.032 \\
\hline 50 & 2.571 & 334 & 40.0 & 18.76 & 0.89 & 37.30 & 0.024 \\
\hline 52 & 1,513 & 197 & 28.0 & 16.80 & 2.23 & 50.78 & 0.044 \\
\hline 56 & 2,163 & 281 & 23.0 & 32.63 & 1.92 & NA & - \\
\hline
\end{tabular}

Explanation of tcrms

$\mathrm{V}_{\mathrm{p}}=$ pore volume of pattern.

$\mathrm{W}_{\text {if }}=$ fillup volume of pattern.

$\mathrm{m}=$ Hall plot slope at stcady-state condition.

$k_{w}=$ effective water permeability.

$\mathrm{h}=$ formation thickncss.

$\mathrm{k}_{\mathrm{air}}=$ mcasured core permeability using air.

$\mathrm{k}_{\mathrm{rw}}=$ water relative permeability $=\mathrm{k}_{\mathrm{w}} / \mathrm{k}_{\mathrm{ail}}$.

$\mathrm{NA}=$ not available.

$-\quad=$ not analy ${ }_{-}$ed. 
TABLE 2.3 - Production performance of the Arch Unit

\begin{tabular}{|c|c|c|c|c|c|}
\hline $\begin{array}{l}\text { Arch } \\
\text { well } \\
\text { no. }\end{array}$ & $\begin{array}{c}\text { June } 1986 \text { or last } \\
\text { water-oil ratio, } \\
\text { bbl/bbl }\end{array}$ & $\begin{array}{l}\text { Cumulative oil produced } \\
\text { (primary and waterflood), } \\
\text { Mbhi }\end{array}$ & $\begin{array}{l}\text { Arch } \\
\text { well. } \\
\text { no. }\end{array}$ & $\begin{array}{l}\text { June } 1986 \text { or last } \\
\text { water -oil ratio, } \\
\text { bbl/shl }\end{array}$ & $\begin{array}{l}\text { Cumulative oil produced } \\
\text { (primary and waterllood) } \\
\text { Mbbl }\end{array}$ \\
\hline 2 & 0.2 & 225 & 95 & 8.1 & 96 \\
\hline 14 & 4.5 & 9 & 96 & 19.0 & 155 \\
\hline 17 & 8.0 & 213 & 97 & 22.0 & 15 \\
\hline 21 & 0.1 & 779 & 98 & 15.8 & 146 \\
\hline 27 & 0.0 & 34 & 99 & 4.3 & 217 \\
\hline 30 & 7.4 & 898 & 100 & 6.7 & 76 \\
\hline 40 & 0.2 & 38 & 101 & 66.7 & 141 \\
\hline 44 & 64.1 & 1,063 & 102 & 109.0 & 82 \\
\hline 46 & 0.1 & 328 & 103 & 36.4 & 66 \\
\hline 49 & 0.2 & 575 & 104 & 9.9 & 44 \\
\hline 78 & 0.2 & 118 & 105 & 31.1 & 75 \\
\hline 79 & 203.5 & 288 & 106 & 17.7 & 28 \\
\hline 81 & 0.7 & 14 & 107 & 1.4 & 23 \\
\hline 88 & 70.7 & 270 & 108 & 1.5 & 185 \\
\hline 89 & 129.7 & 9 & 109 & 1.1 & 54 \\
\hline 90 & 26.7 & 216 & 110 & 0.0 & 35 \\
\hline 91 & 36.5 & 212 & 111 & 0.0 & 32 \\
\hline 92 & 69.7 & 110 & 113 & 0.0 & 24 \\
\hline 93 & 29.5 & 26 & 114 & 0.1 & 28 \\
\hline 94 & 4.5 & 7 & & & \\
\hline
\end{tabular}

TABLE 2.4 - Analysis of Arch Unit wells OOIP using WOR vs. cumulative oil plots (Lo el al., 1990)

\begin{tabular}{|c|c|c|c|c|c|c|}
\hline $\begin{array}{l}\text { Arch } \\
\text { well no. }\end{array}$ & $\begin{array}{l}\text { Slope } \\
\times 10^{-3}\end{array}$ & $S_{w c}, \%$ & ho $\left(1-S_{w c}\right)$ & $\begin{array}{l}\text { OOIP, Mbbl } \\
\text { WOR plot }\end{array}$ & $\begin{array}{l}\text { OOIP, Mbbl } \\
\text { Volumetrics }\end{array}$ & $\begin{array}{l}\text { OOIP(WOR) } \\
\text { OOIP(Vol) }\end{array}$ \\
\hline 88 & 0.0397 & 36.9 & 4.332 & 223 & 2,204 & 0.101 \\
\hline 90 & 0.1110 & 38.6 & 1.411 & 77 & 718 & 0.107 \\
\hline 91 & 0.0781 & 50.2 & 1.873 & 89 & 953 & 0.093 \\
\hline 92 & 0.1290 & 50.8 & 1.660 & 53 & 844 & 0.063 \\
\hline 96 & 0.0440 & 38.7 & 3.191 & 195 & 1,623 & 0.120 \\
\hline 98 & 0.5830 & 53.2 & 1.317 & 11 & 670 & 0.016 \\
\hline 100 & 0.0709 & 47.1 & 2.357 & 104 & 1,199 & 0.087 \\
\hline
\end{tabular}

\section{Explanation of terms:}

Slope - Slope of the $\log _{10}\left(\mathrm{k}_{\mathrm{rw}} / \mathrm{k}_{\mathrm{ro}}\right)$ vs. $\mathrm{S}_{\mathrm{W}}$ straight line $S_{w c}$ - Connate water saturation

hf $\left(1-S_{w c}\right)-$ Hydrocarbon porosity thickness

OOIP - Original oil-in-place 


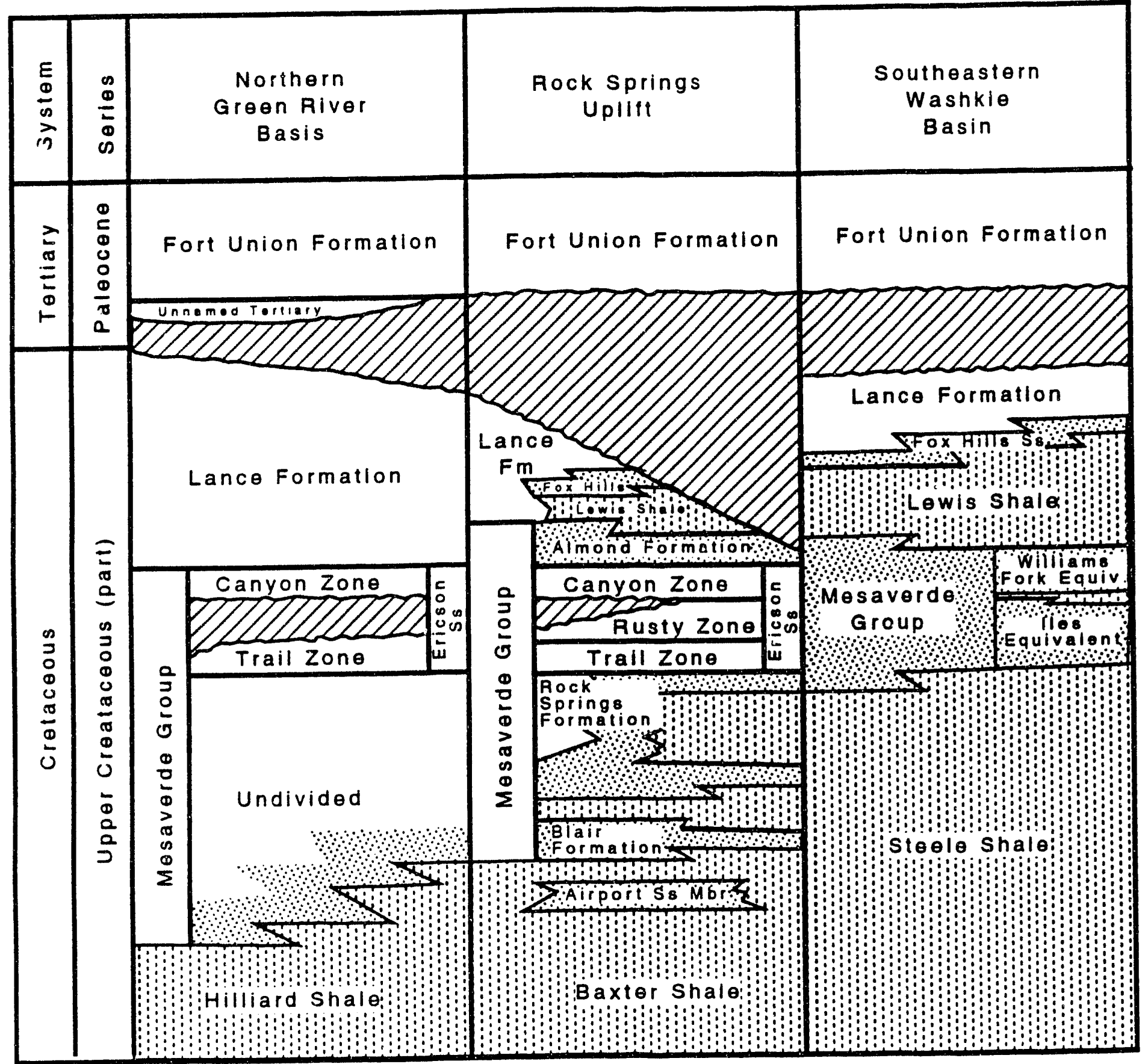

\section{Nonmarine \\ Marginal Marine}

Sandstone

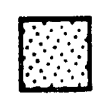

Sandstone

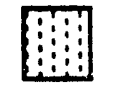

Marine

Shale
Eroded

Interval

Figure 2.1 - Gencralized stratigraphic column of the Patrick Draw field area, WY. After Law (1984). 
Forrest Oil Arch 11-51-2

SENW SEC. 11-19N-99W, Swootwater Co. Wyo.

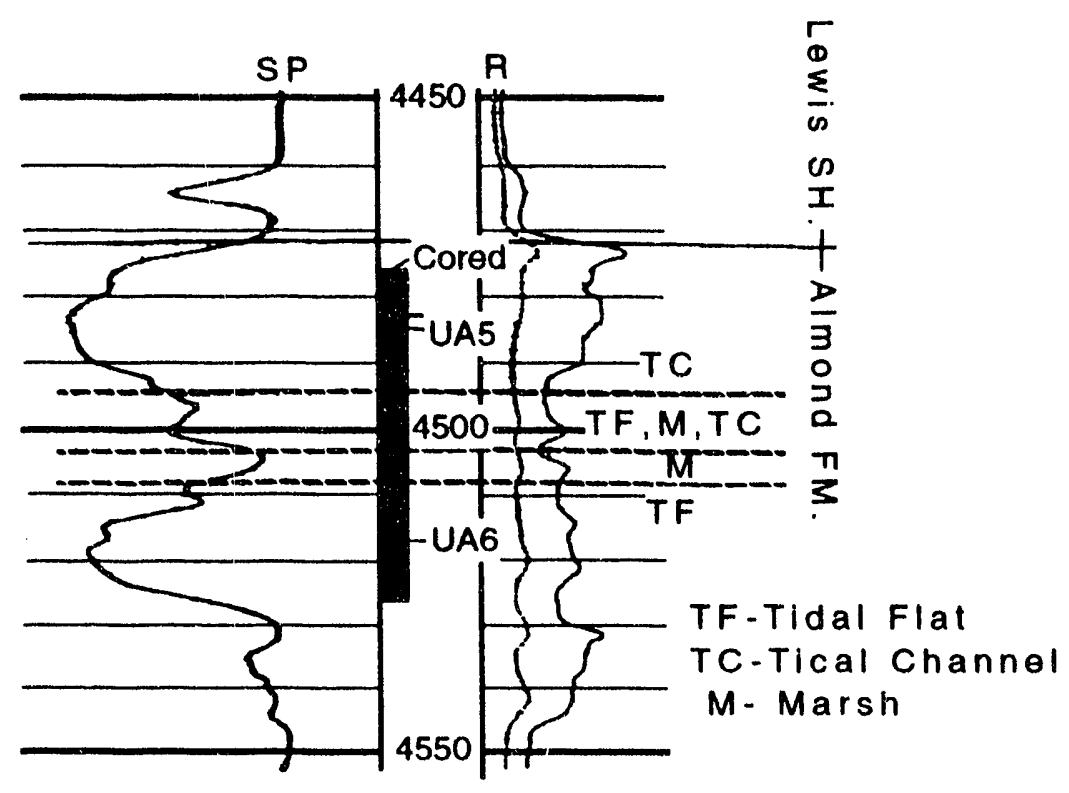

Figure 2.2 - Type log of the Almond Formation in the Arch Unit of Patrick Draw field. After Weimer and Tillman (1982). 


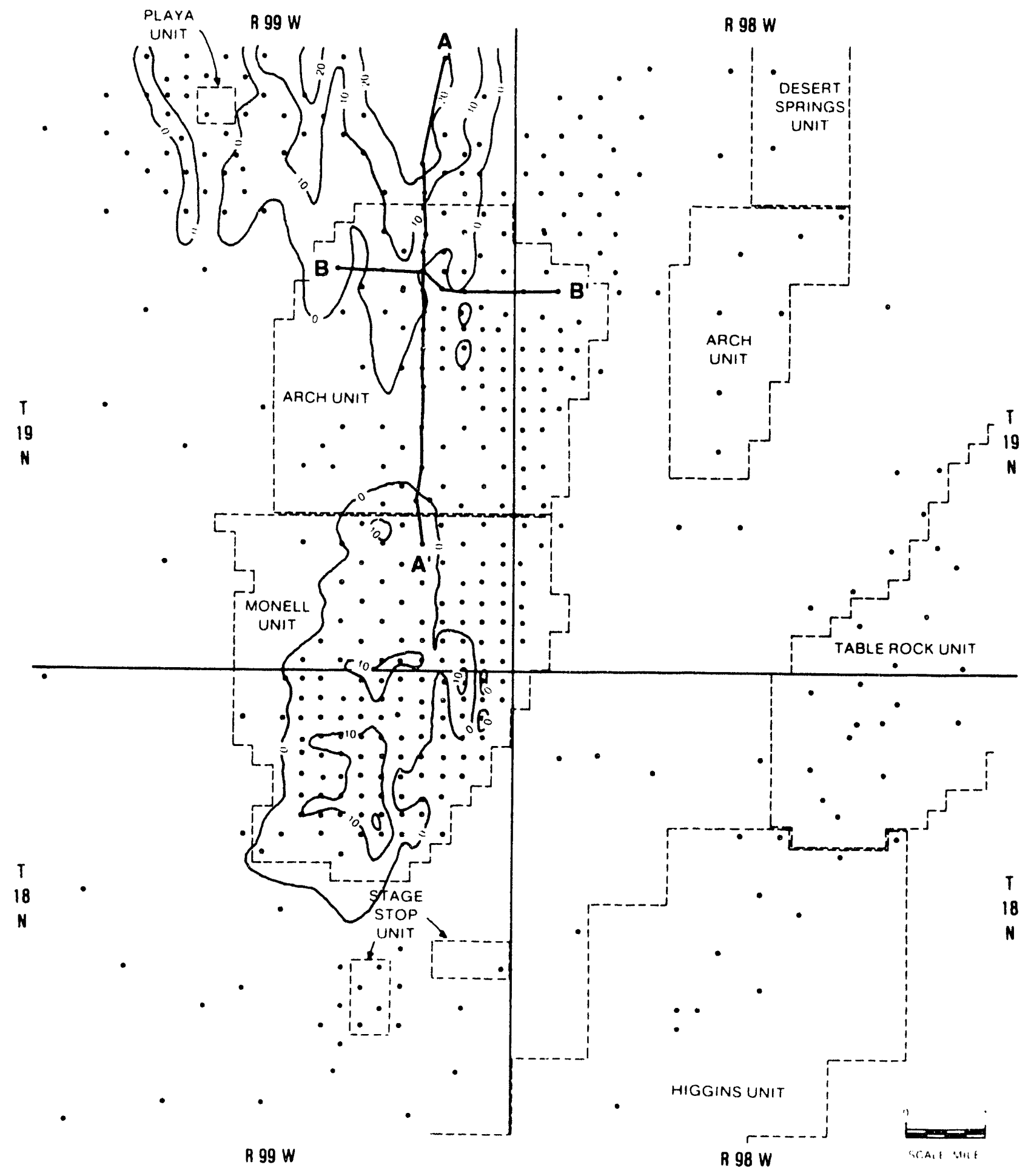

Figure 2.3 - UA-5A permeable sandstone isolith map. After Irwin (1976). The locations of stratigraphic cross-section $\mathrm{A}-\mathrm{A}^{\prime}$ and $\mathrm{B}-\mathrm{B}^{\prime}$ are also shown. 


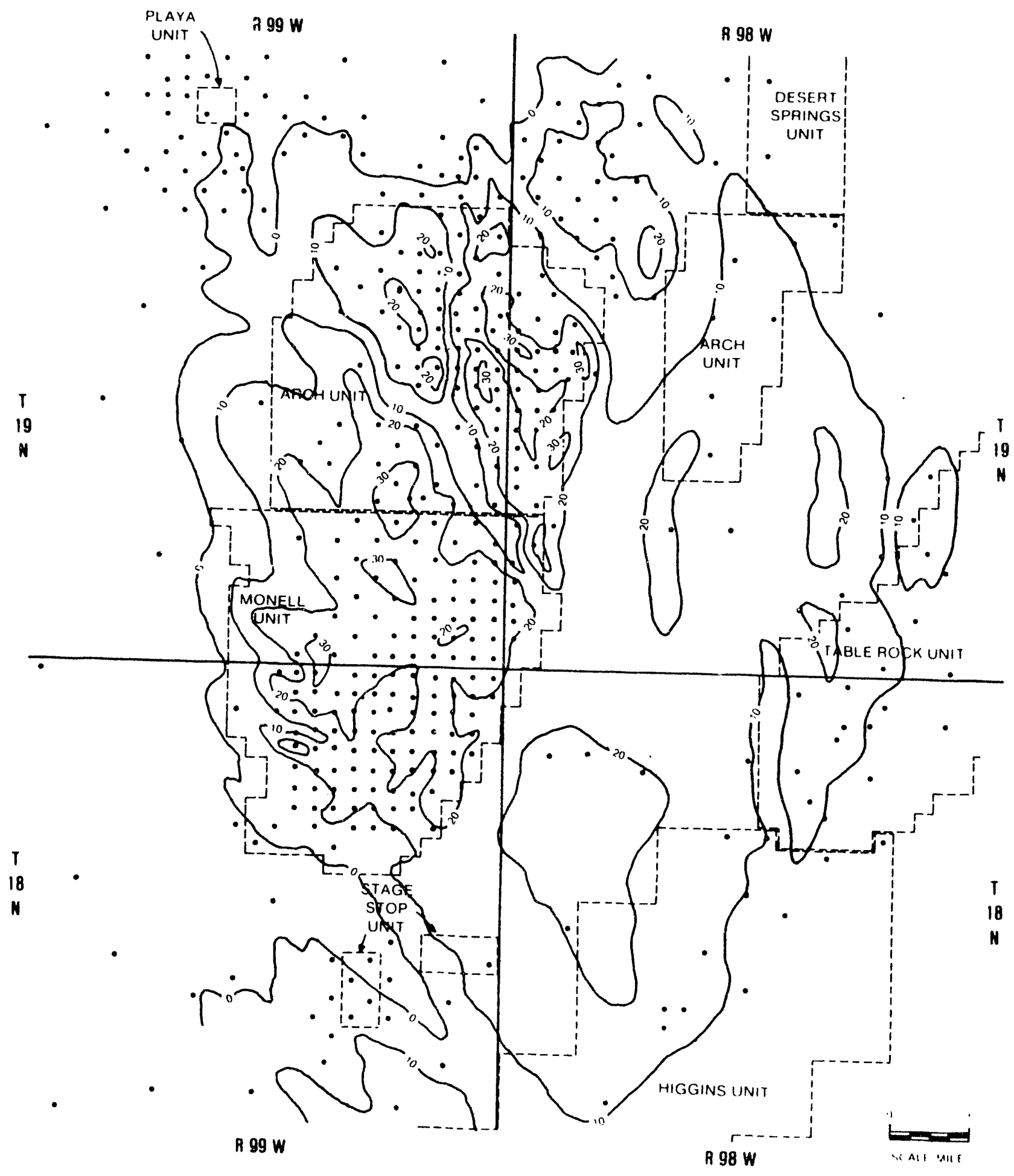

Figure 2.4 - UA-5B permeable sandstone isolith map. After Irwin (1976). A more detailed map of the Patrick Draw field is presented in fig. 2.11. 


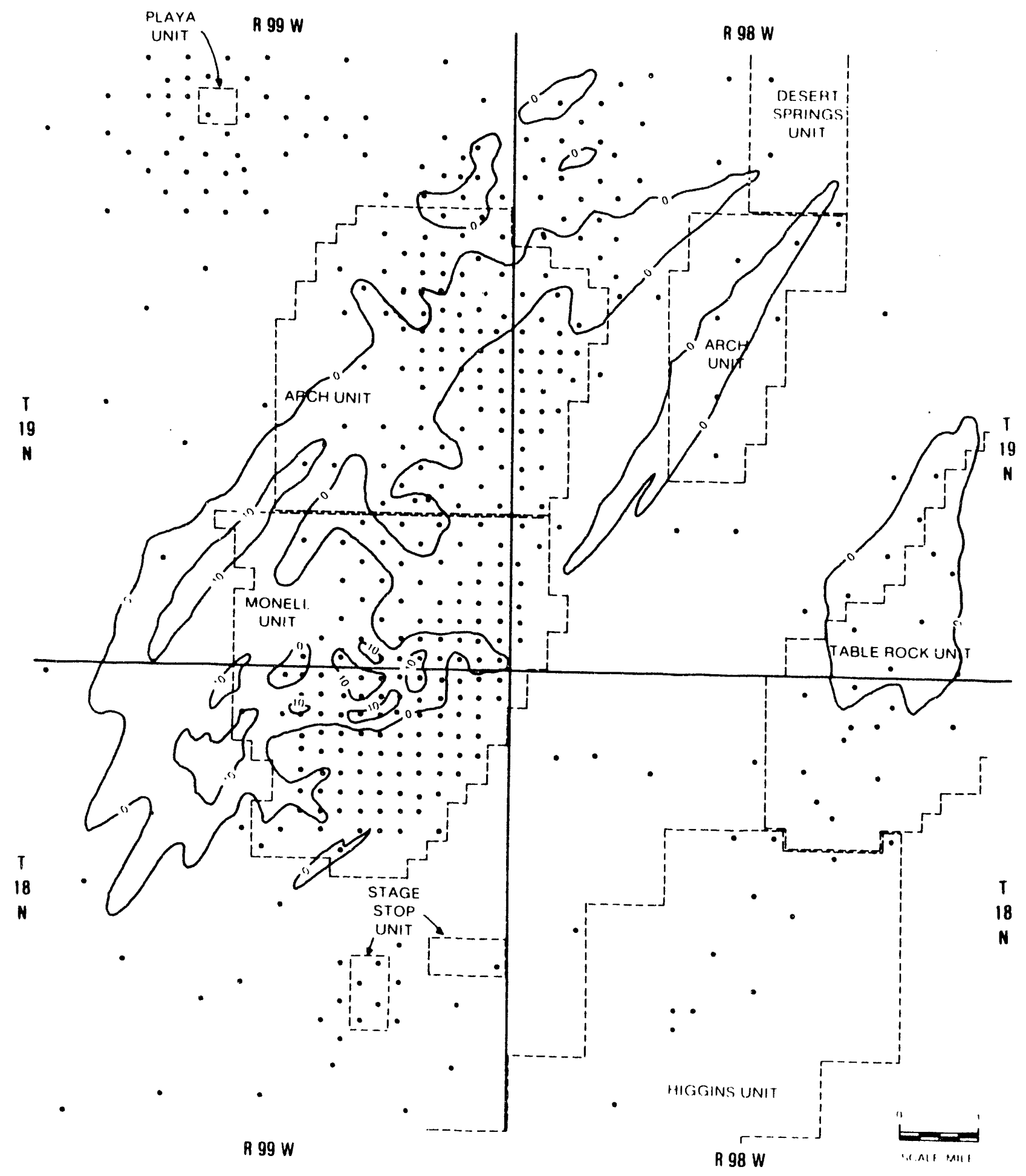

Figurc 2.5 - UA -6A permeable sandstone isolith map. After Irwin (1976). 


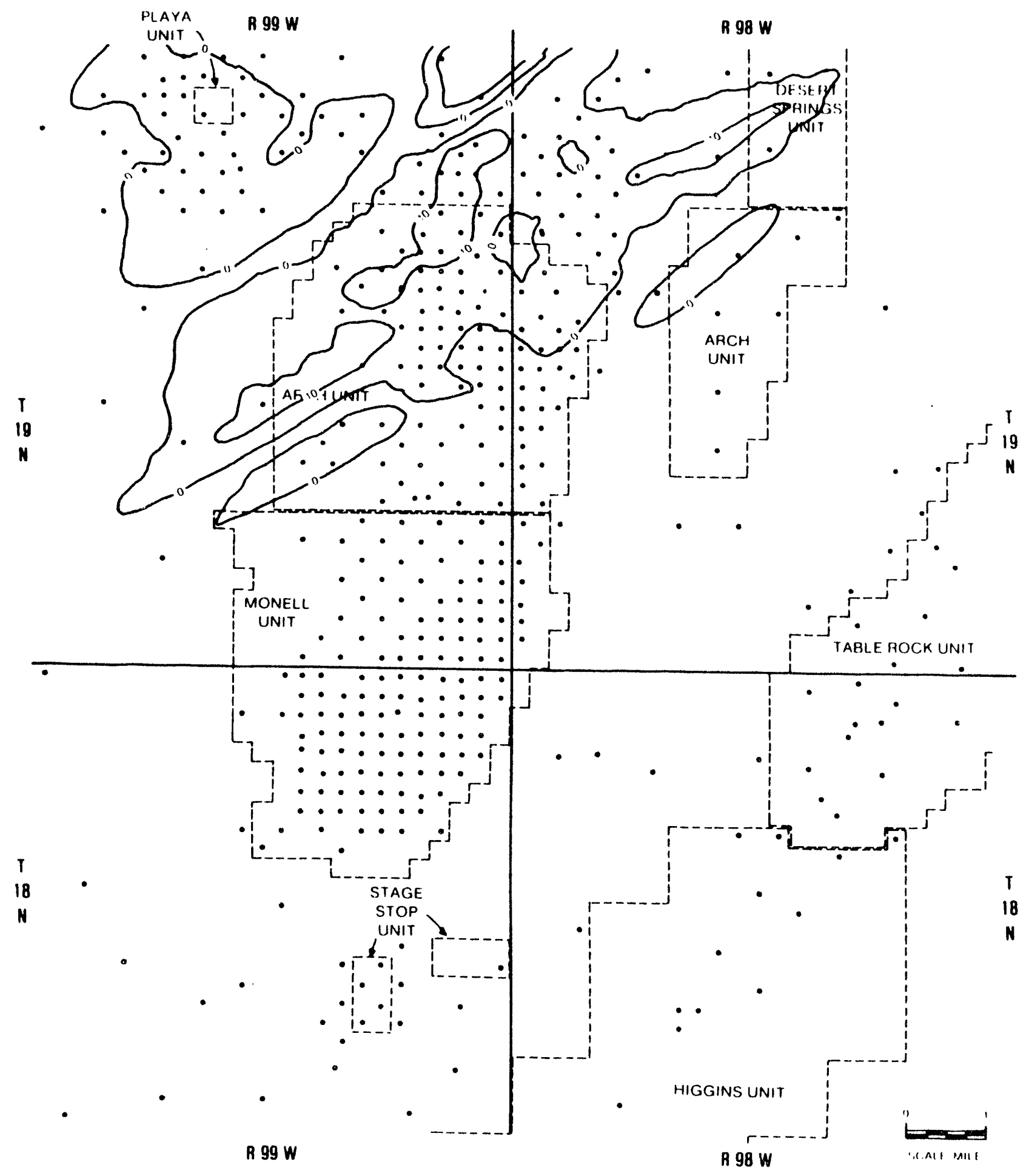

Figure 2.6 - UA-6B permeable sandstone isolith map. After Irwin (1976). 


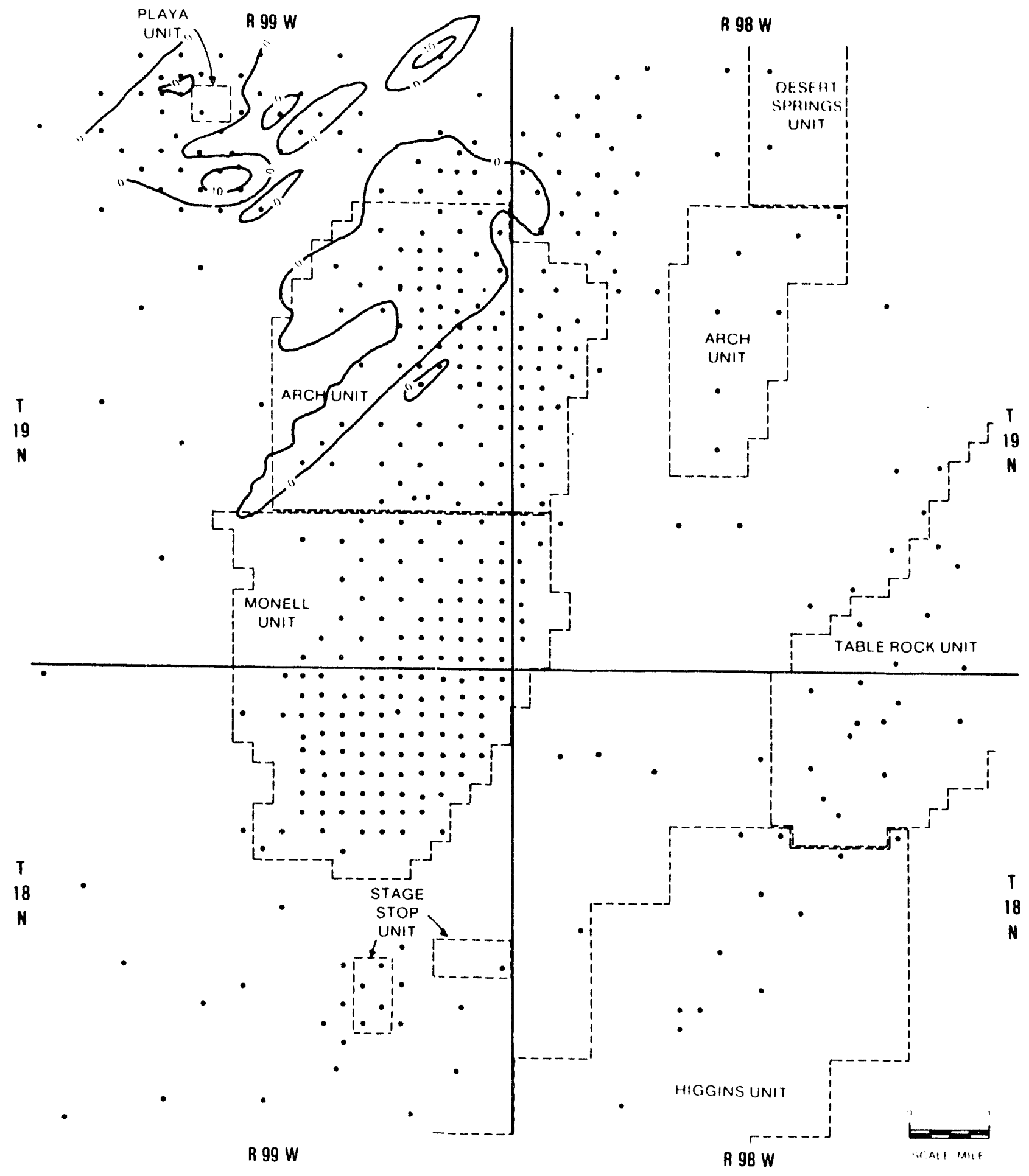

Figure 2.7 - UA-6C permeable sandstone isolith map. After Irwin (1976). 

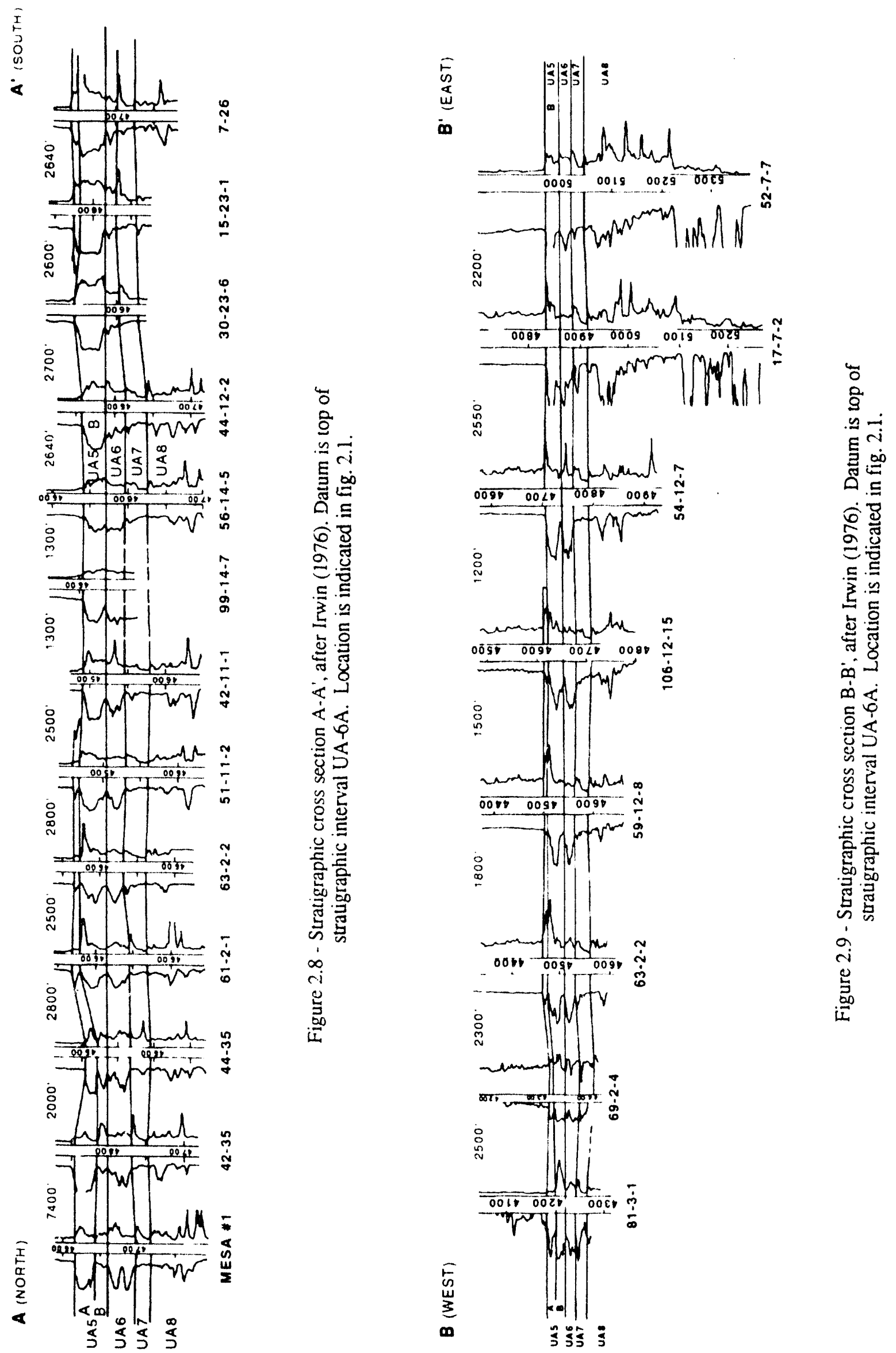


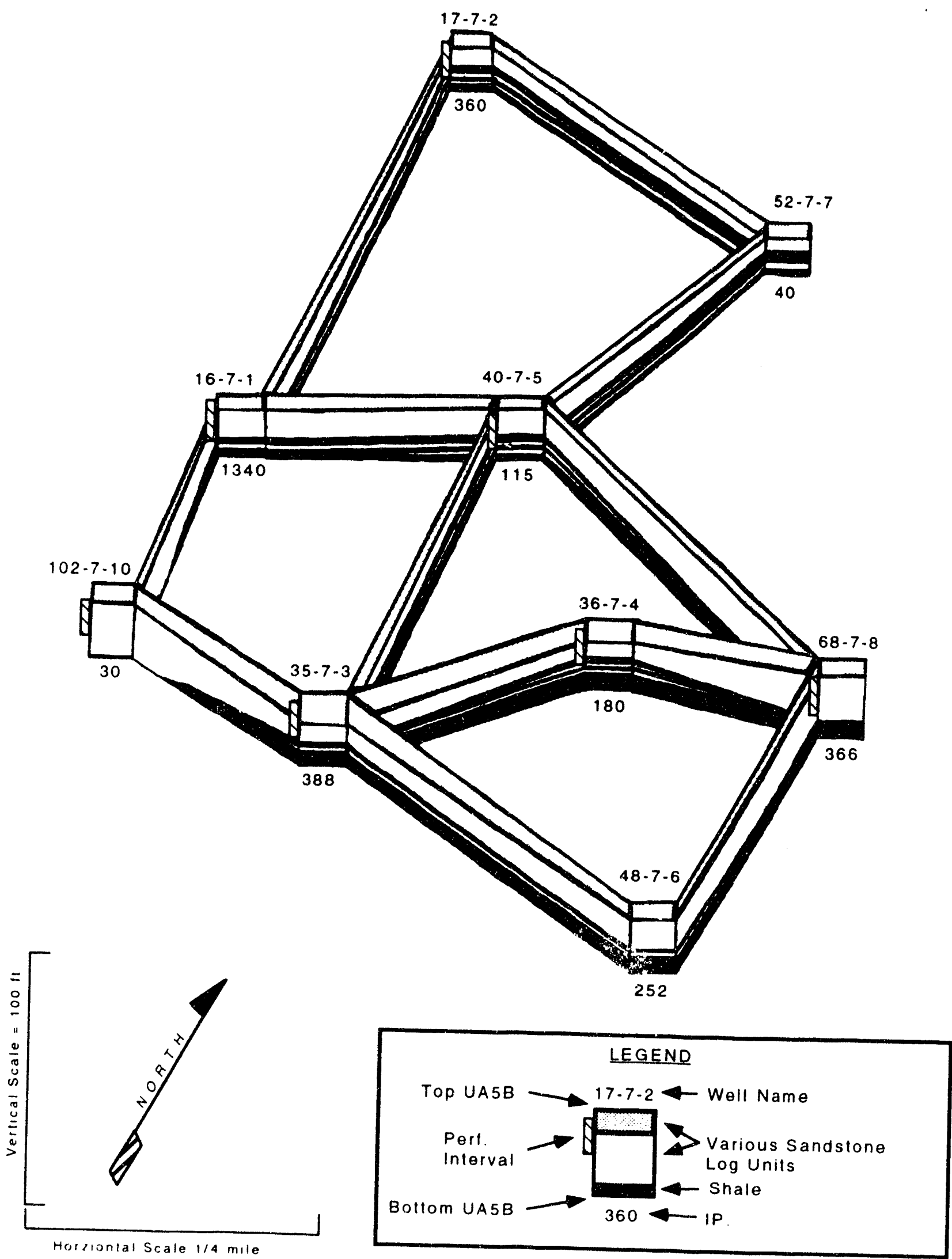

Figure 2.10 - Fence diagram of wireline log-derived subdivisions of stratigraphic unit UA-5B in section 7 (T19N R98W). 


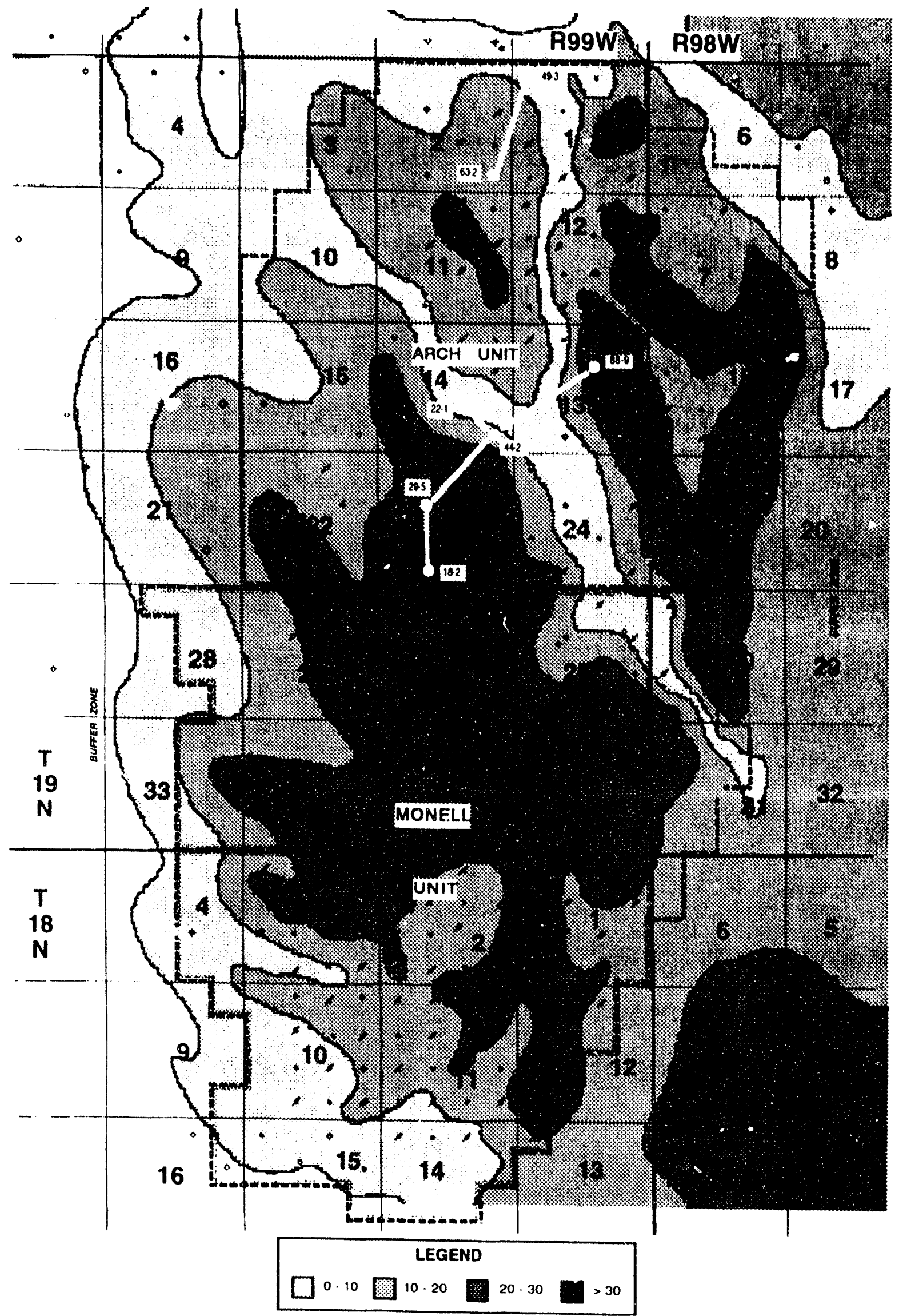

Figure 2.11 - UA-5B permeable sandstone isolith map (-35 mv cutoff). After Irwin
(1976). 


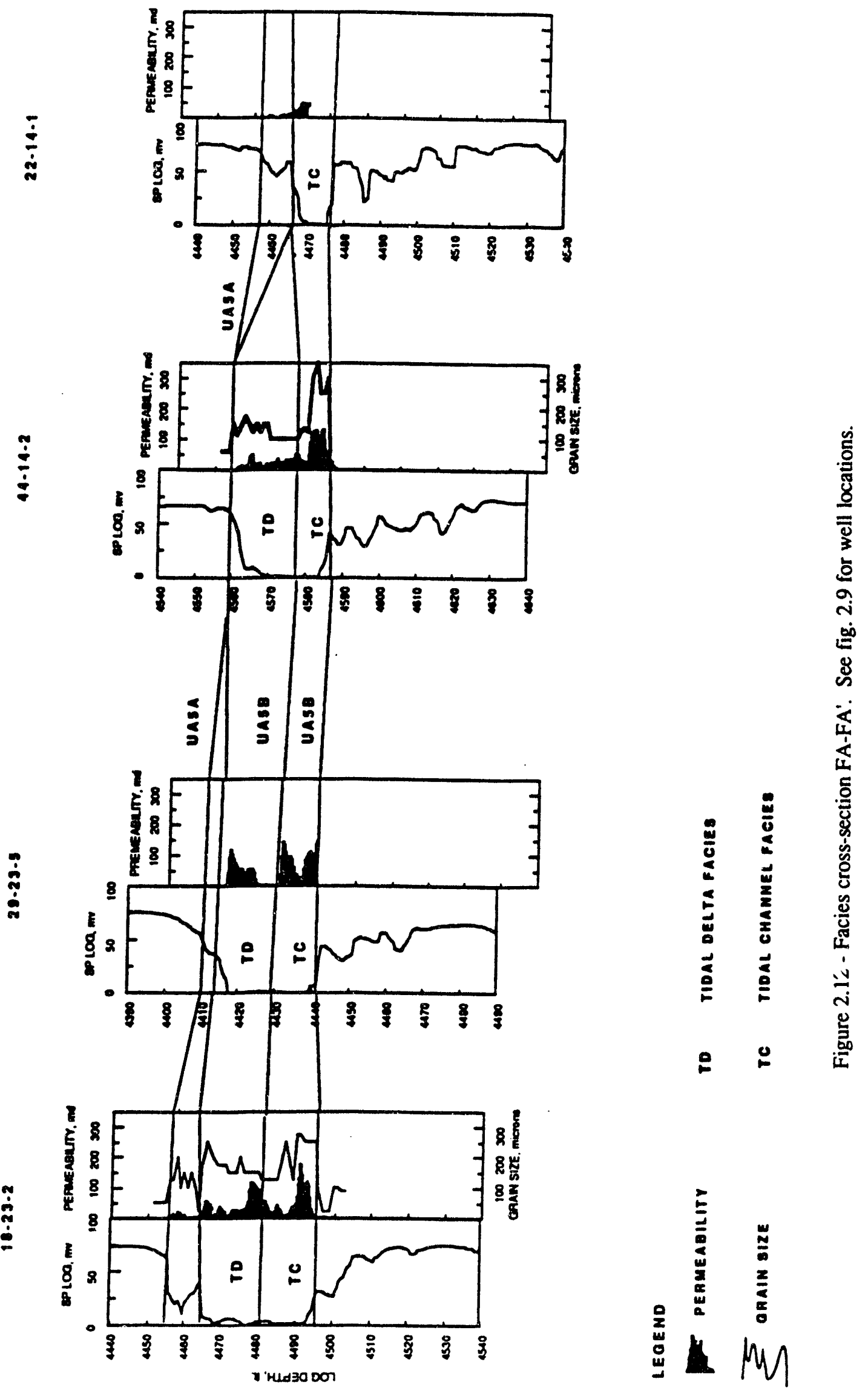


$49 \cdot 1 \cdot 3$

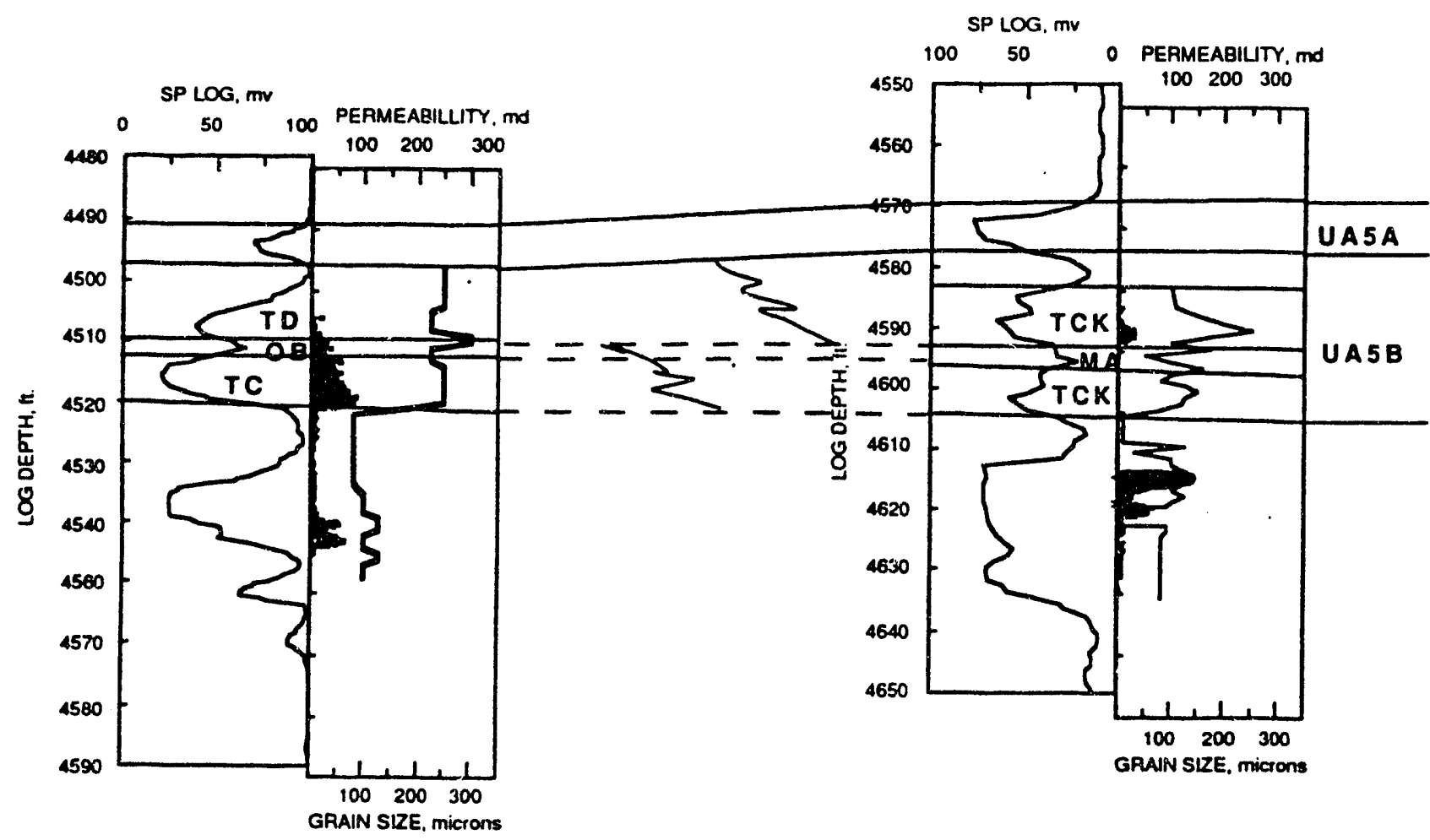

\section{LEGEN D}

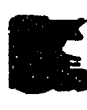

$T$

TIDAL DELTA

OB

OrSTER DE

$\sum_{S}^{3} \operatorname{analn} \operatorname{size}$

TC TIDAL CHAMNEL

MA

MAns

TCK MOAL CNEEK

Figure 2.13- Facies cross-section FB-FB'. See fig. 2.11 for well locations. 


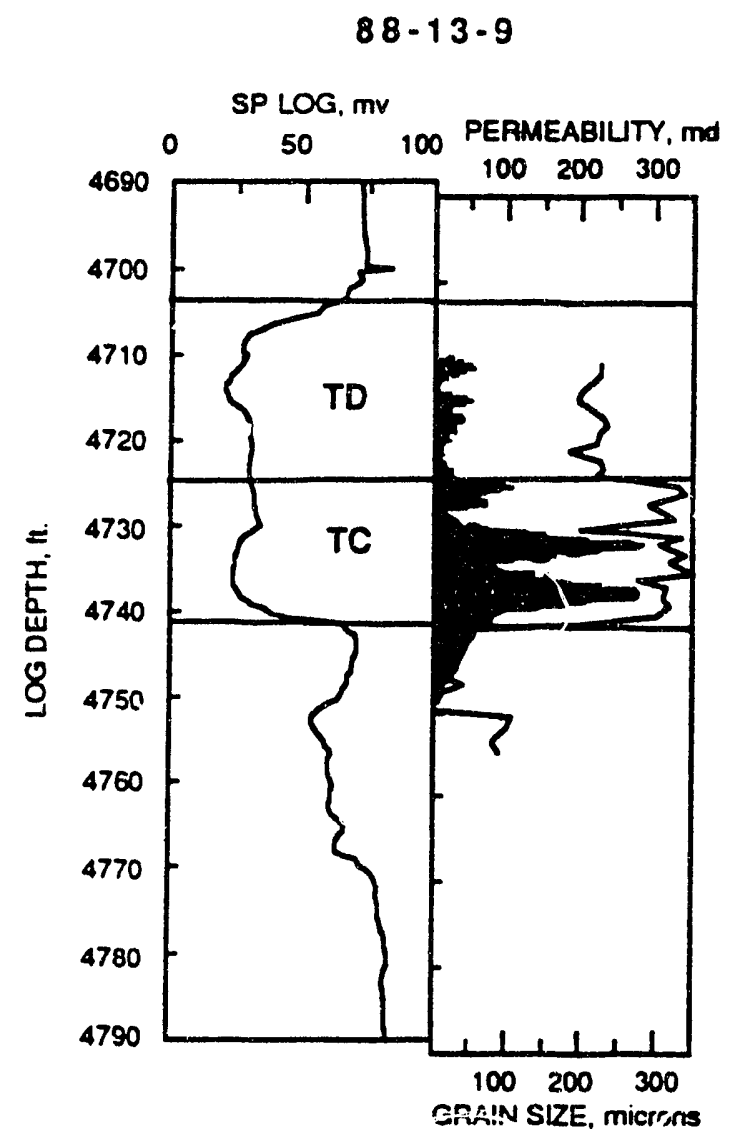

LEGEND

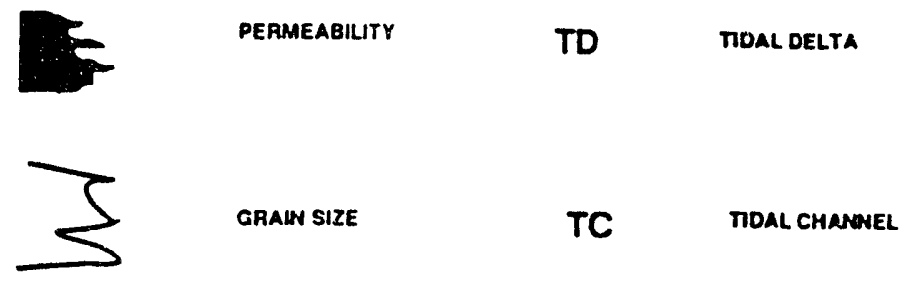

Figure 2.14 - Facies present in well 88. See fig. 2.11 for well location. 


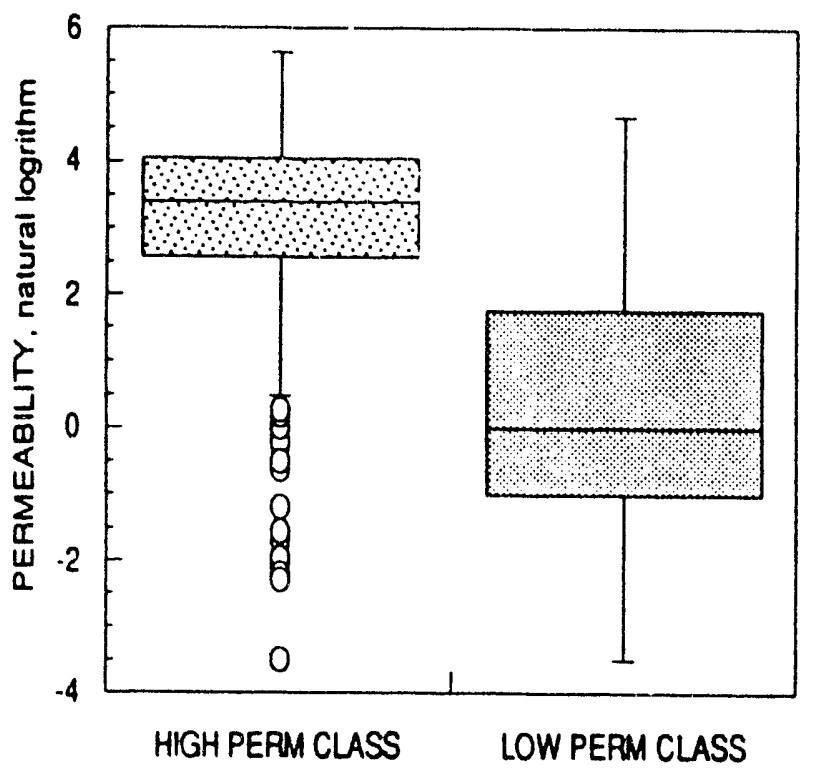

Figure 2.15 - Natural log of permeability distribution for facies permeability classes in the UA-5 sand. Boxes third quartiles, "whiskers" indicate ranges of data to 5th and 95th percentiles, circles indicate data outliers beyond the 5th and 95th percentiles. " $\mathrm{N}$ " represents number of samples in each class of data.

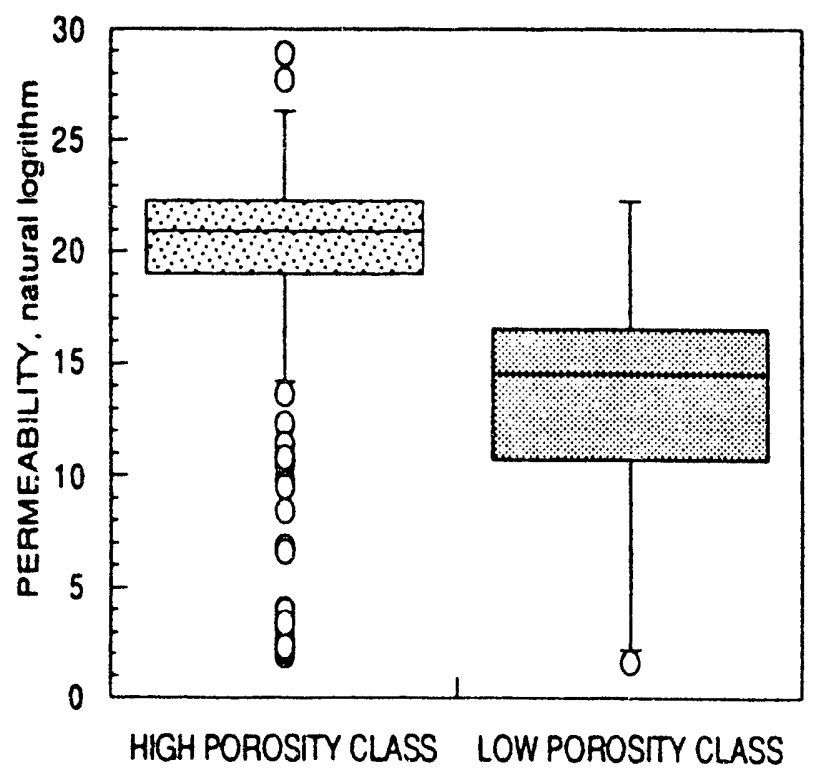

Figure 2.16 - Facies porosity classes in the UA-5 sand. For explanation of symbols, see fig. 2.15. 


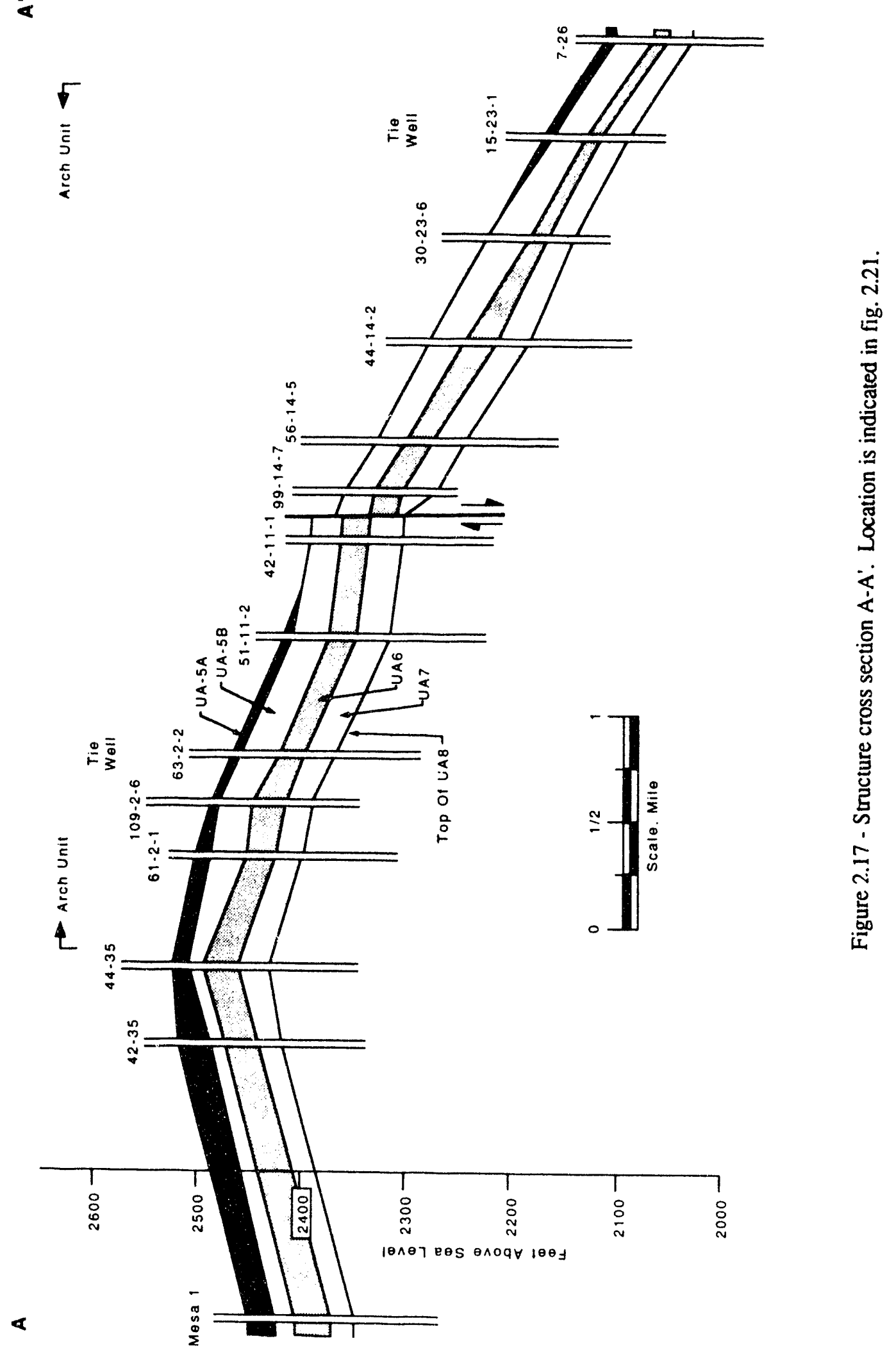




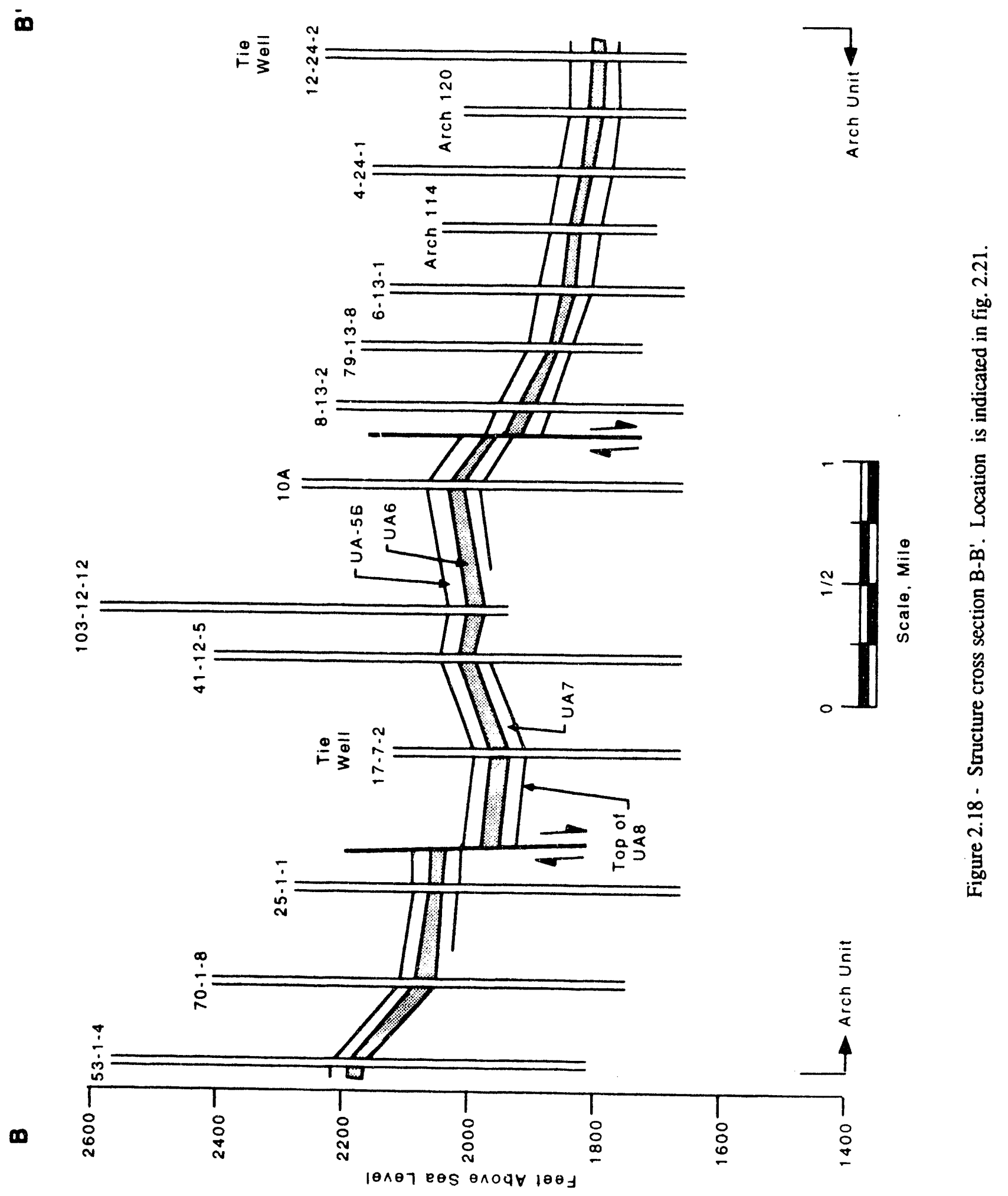


C

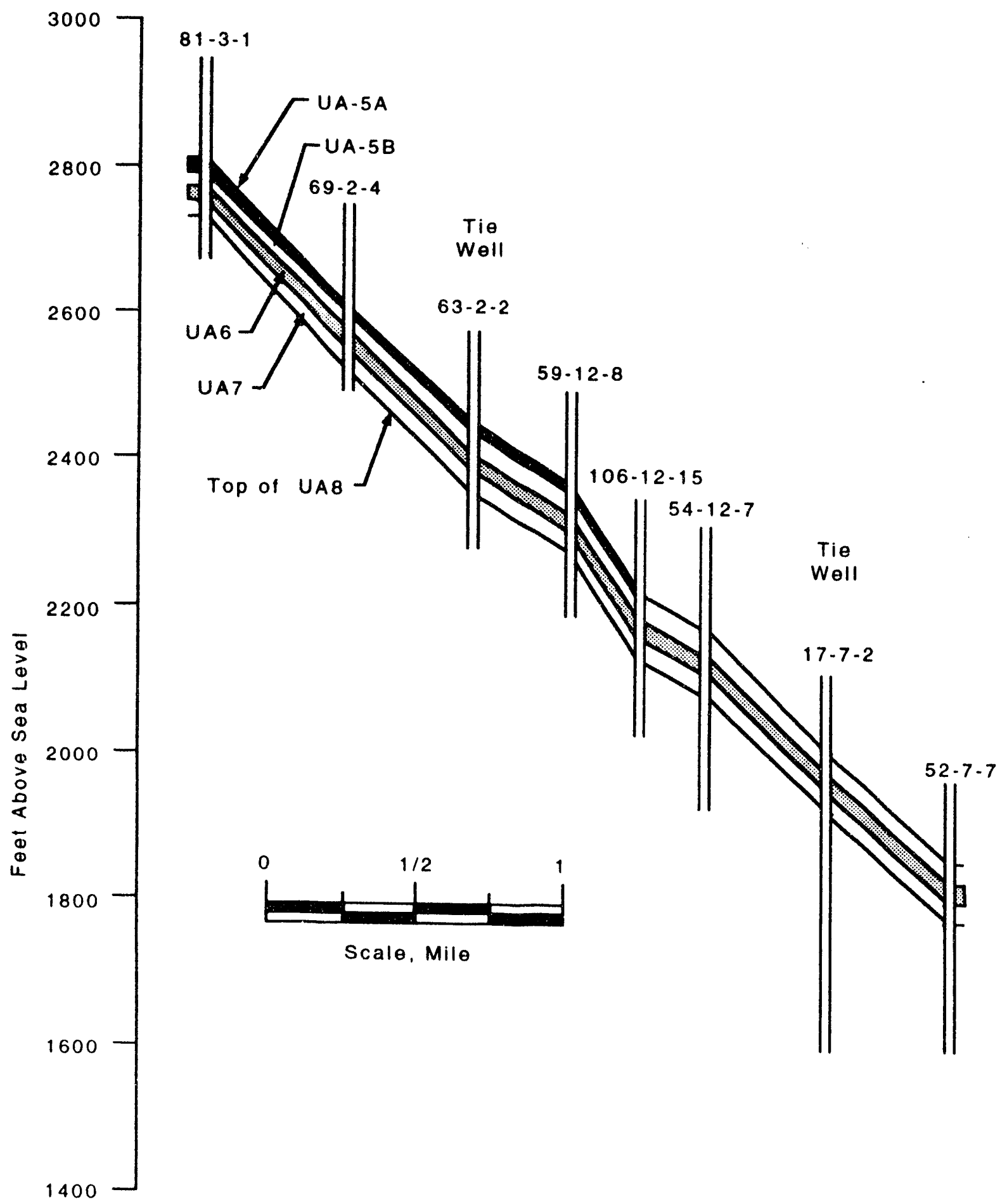

Figure 2.19- Structure cross section C-C'. Location is indicated in fig. 2.21. 


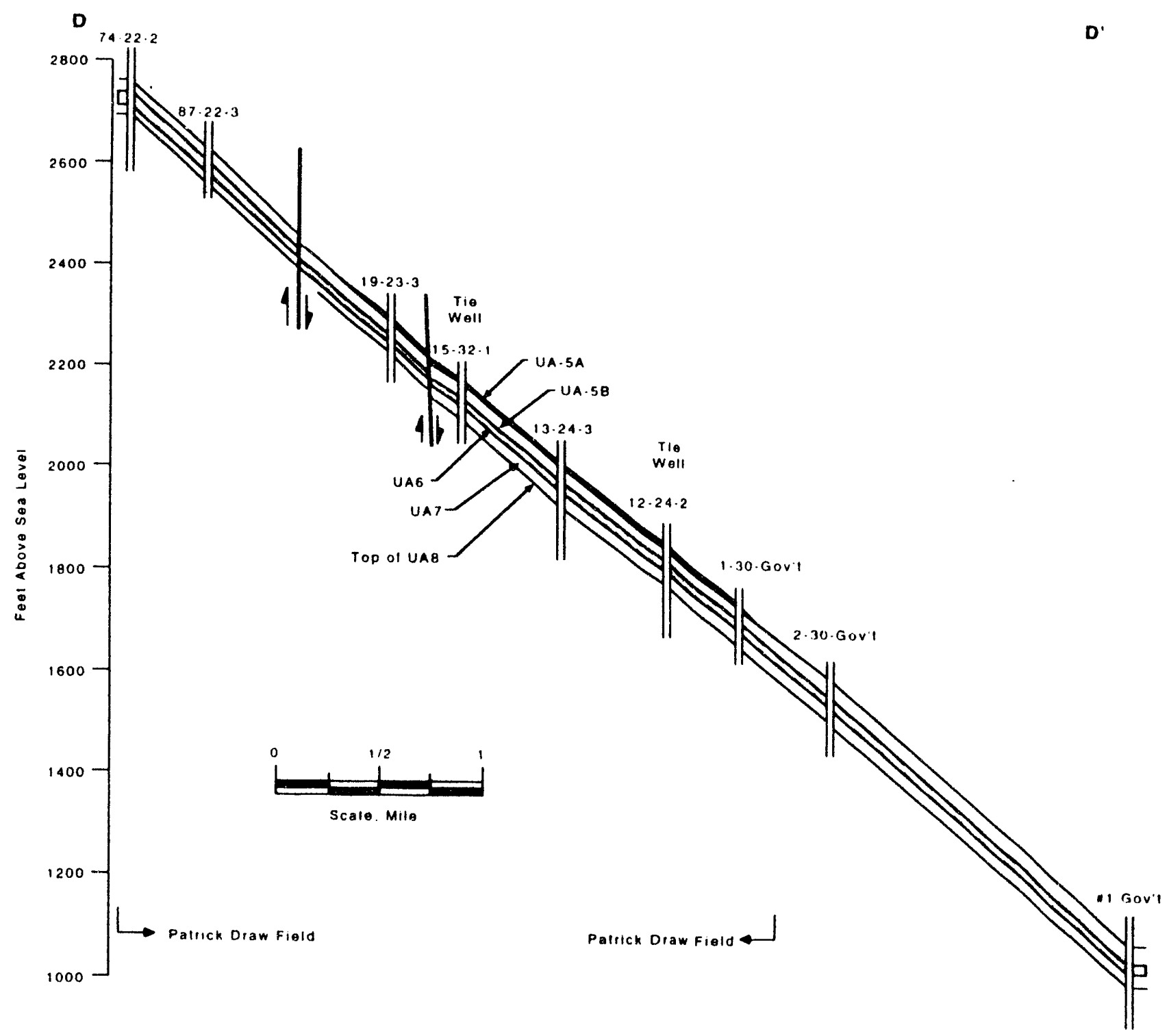

Figure 2.20 - Structure cross section D-D'. Location is indicated in fig. 2.21. 


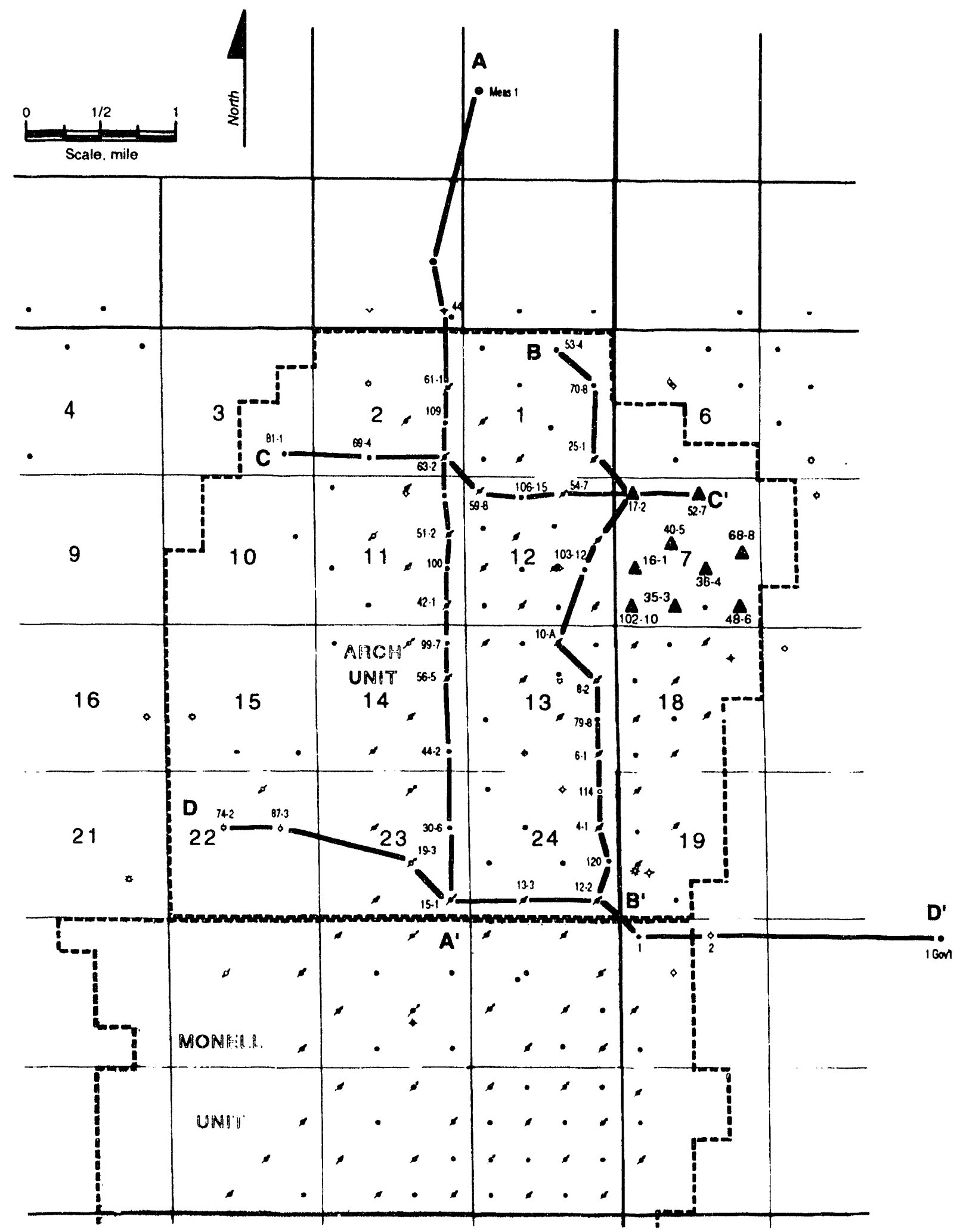

- Wells usedin tence diagram

Figure 2.21 - Base map showing location of wclls, structure cross sections A-A', B-B', C$C^{\prime}$, and D-D', and the production limits of Arch Unit of Patrick Draw field. 


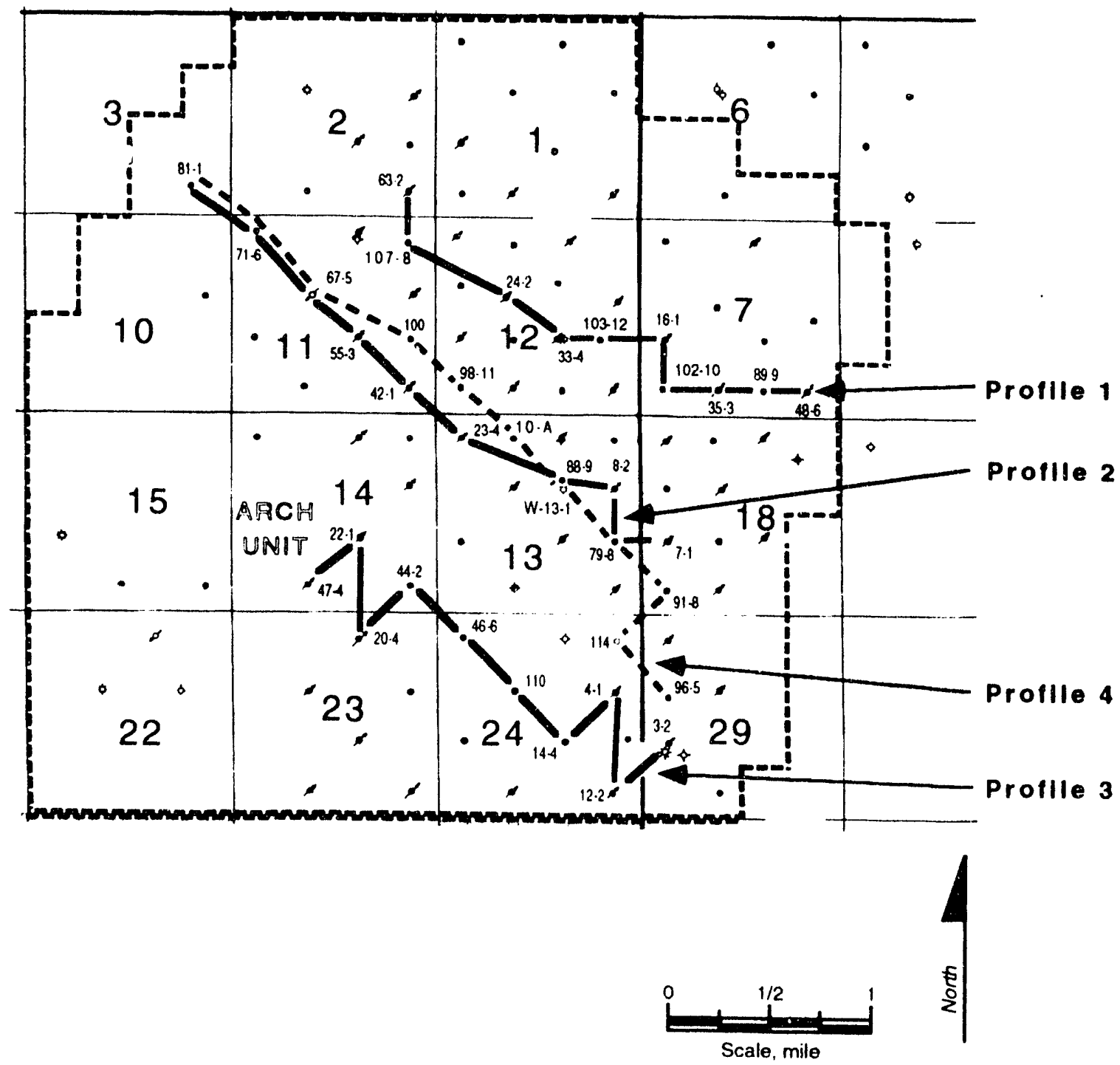

Figure 2.22 - Locations of profiles for investigations of structure and petrophysical properties in the Arch Unit, Patrick Draw field, WY. 


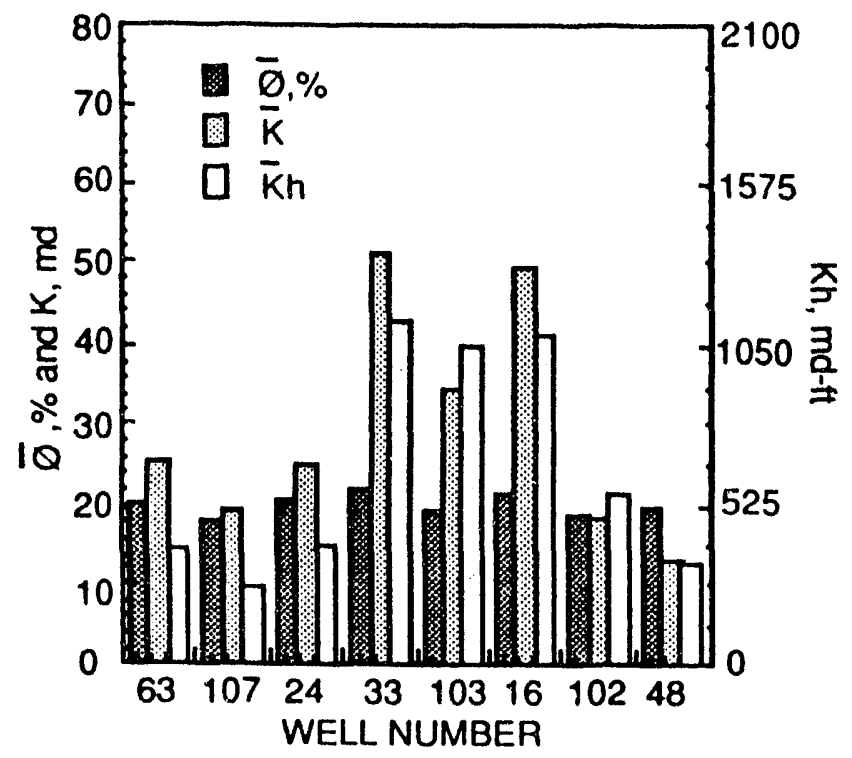

Figure 2.23 - Distributions of average porosity $(\varnothing)$, average permeability $(\vec{k})$, and average permcability thickness product (kh) along profilc \#1.

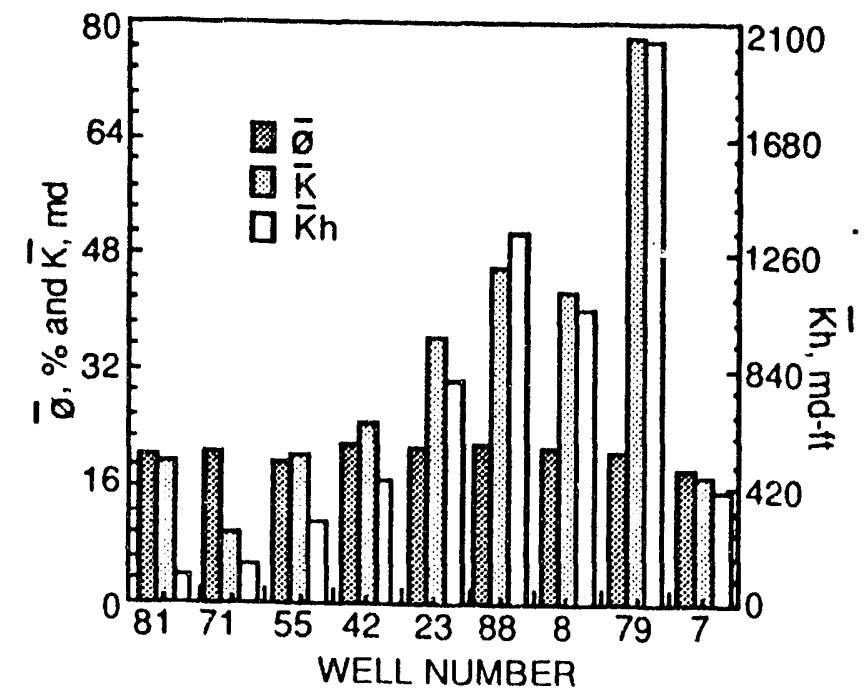

Figurc 2.24 - Distributions of average porosity $(\emptyset)$, average permeability $(\overline{\mathbf{k}})$, and average permcability thickness product $(\overline{k h})$ along profilc \#2. 


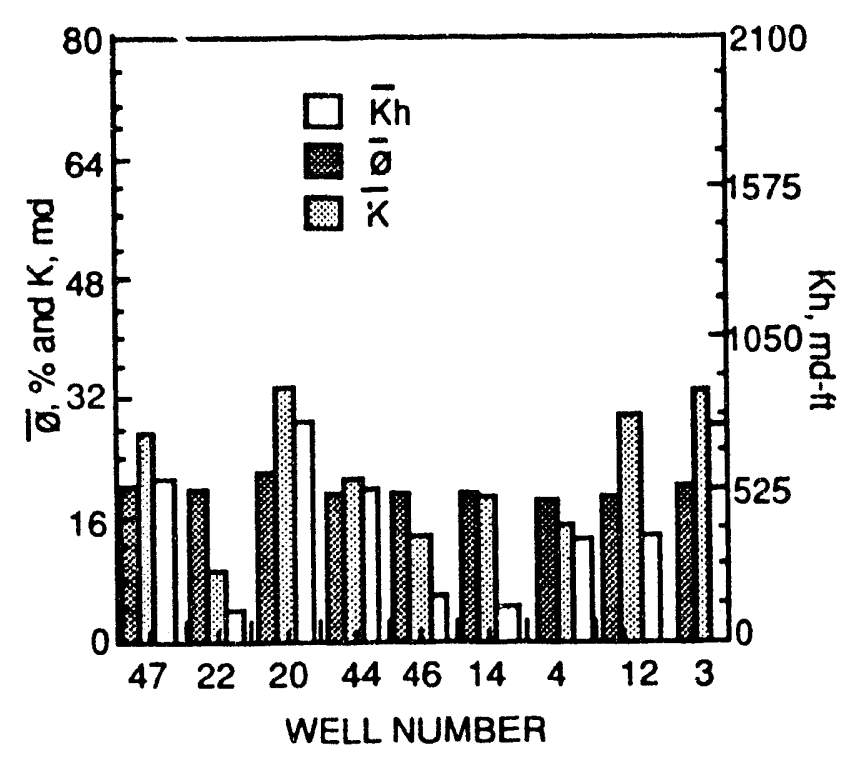

Figure 2.25 - Distributions of average porosity $(\varnothing)$, average permeability $(\overline{\mathbf{k}})$, and average permeability thickness product $(\overline{\mathrm{kh}})$ along profile $\sharp 3$.
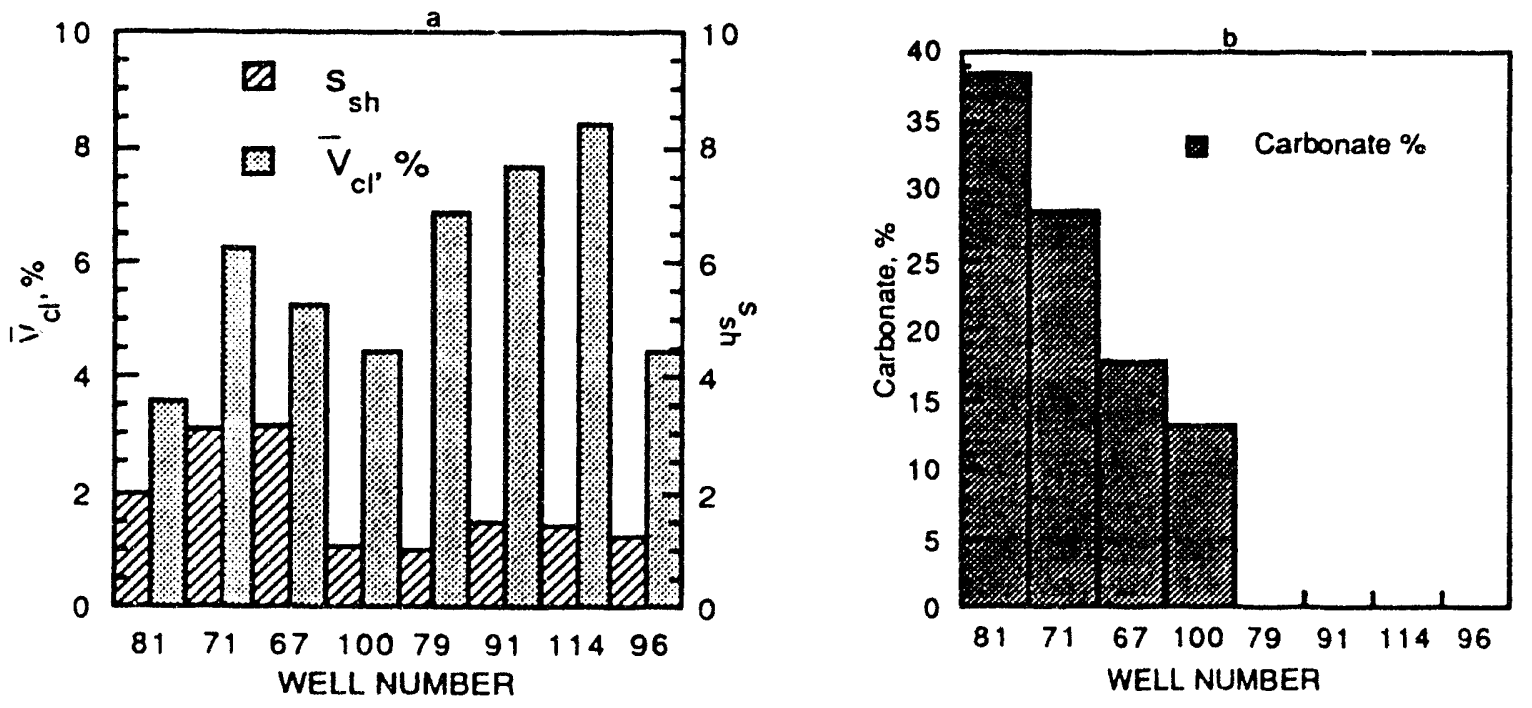

Figure 2.26 - (a) Average clay content ( $\mathrm{Vcl})$ from interpretations of gamma ray logs and variability in clay content $\left(\sigma_{\text {sh }}\right)$ in profile $\# 4$. (b) Percentage of carbonate rocks in profile \#4. 


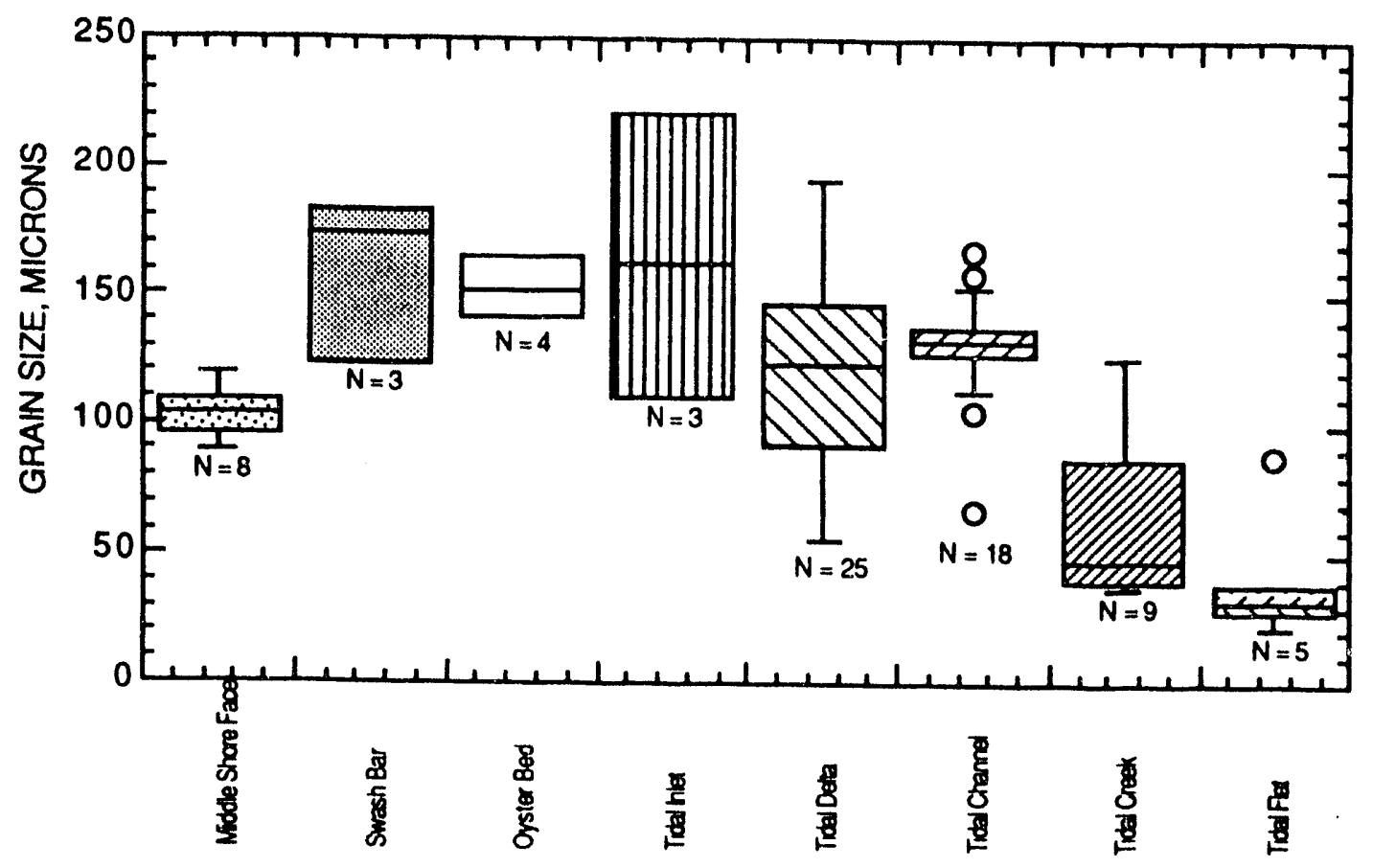

Figure 2.27 - Grain size distribution for combined outcrop and subsurface facies in the Almond Formation. For explanation of symbols see fig. 2.15.

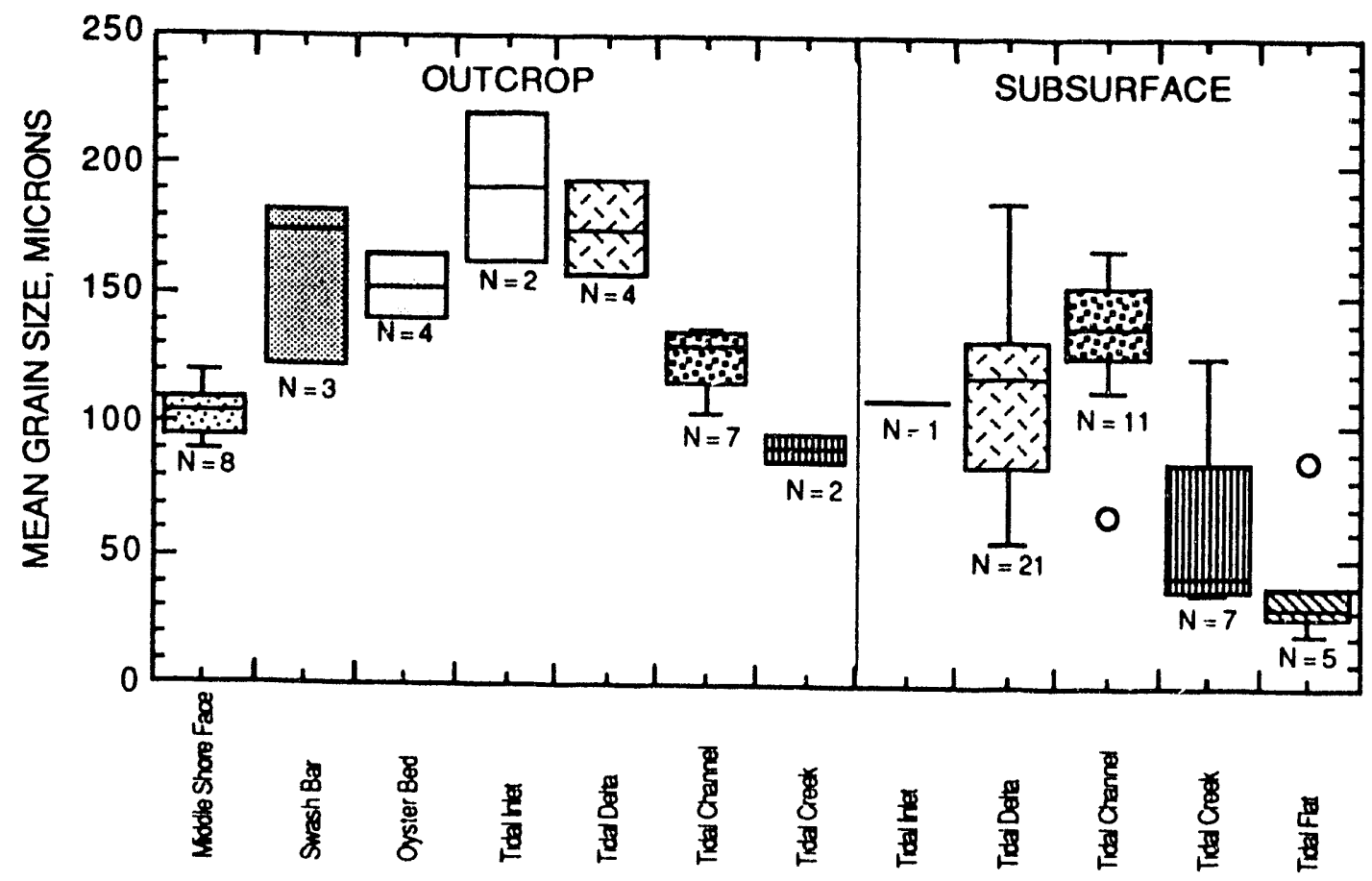

Figure 2.28 - Comparison of outcrop and subsurface grain size distribution for various facics in the Almond Formation. For explanation of symbols sce fig. 2.15. 


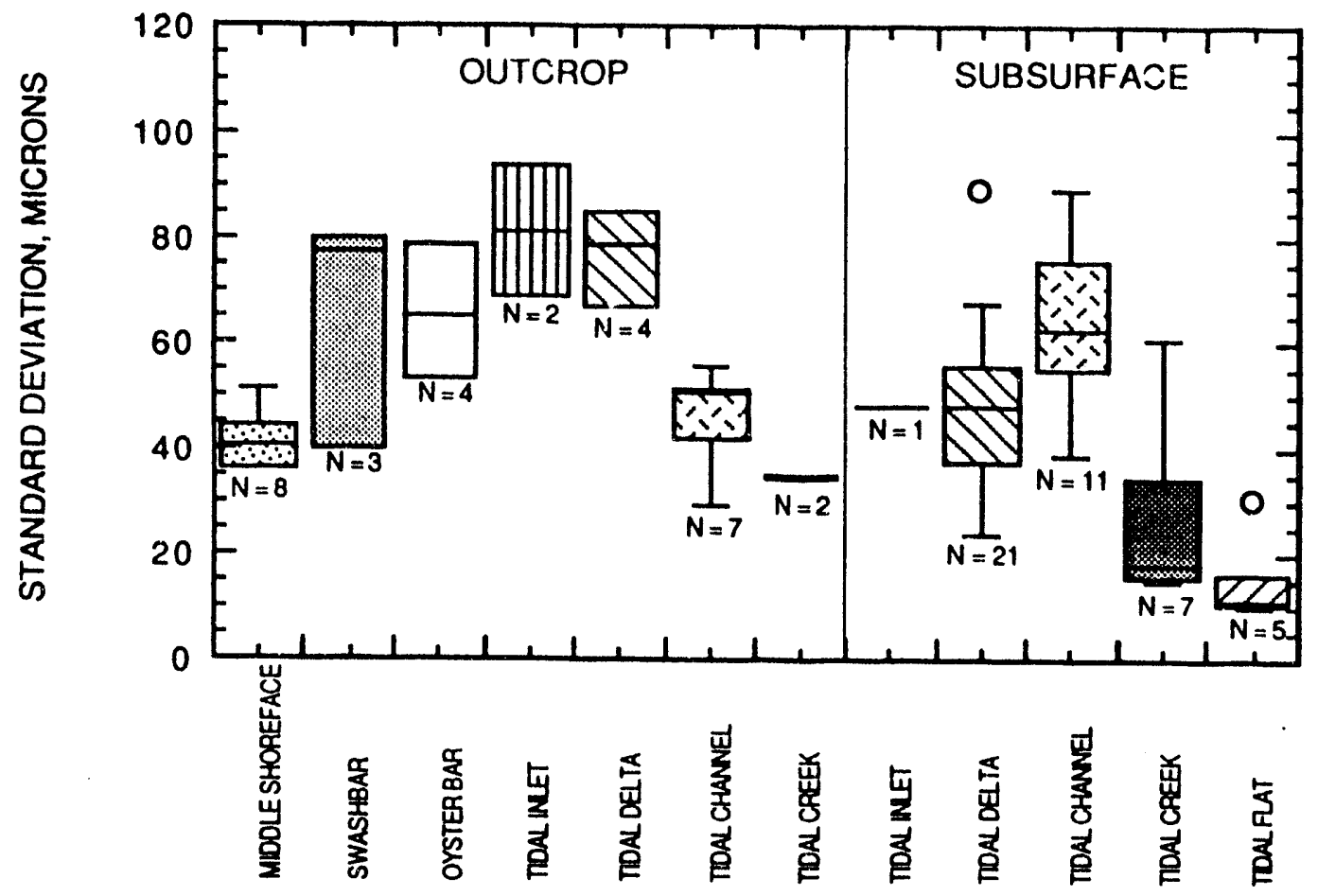

Figure 2.29 - Standard deviation (sorting) for various outcrop and subsurface facies in the Almond Formation. For explanation of symbols see fig. 2.15.

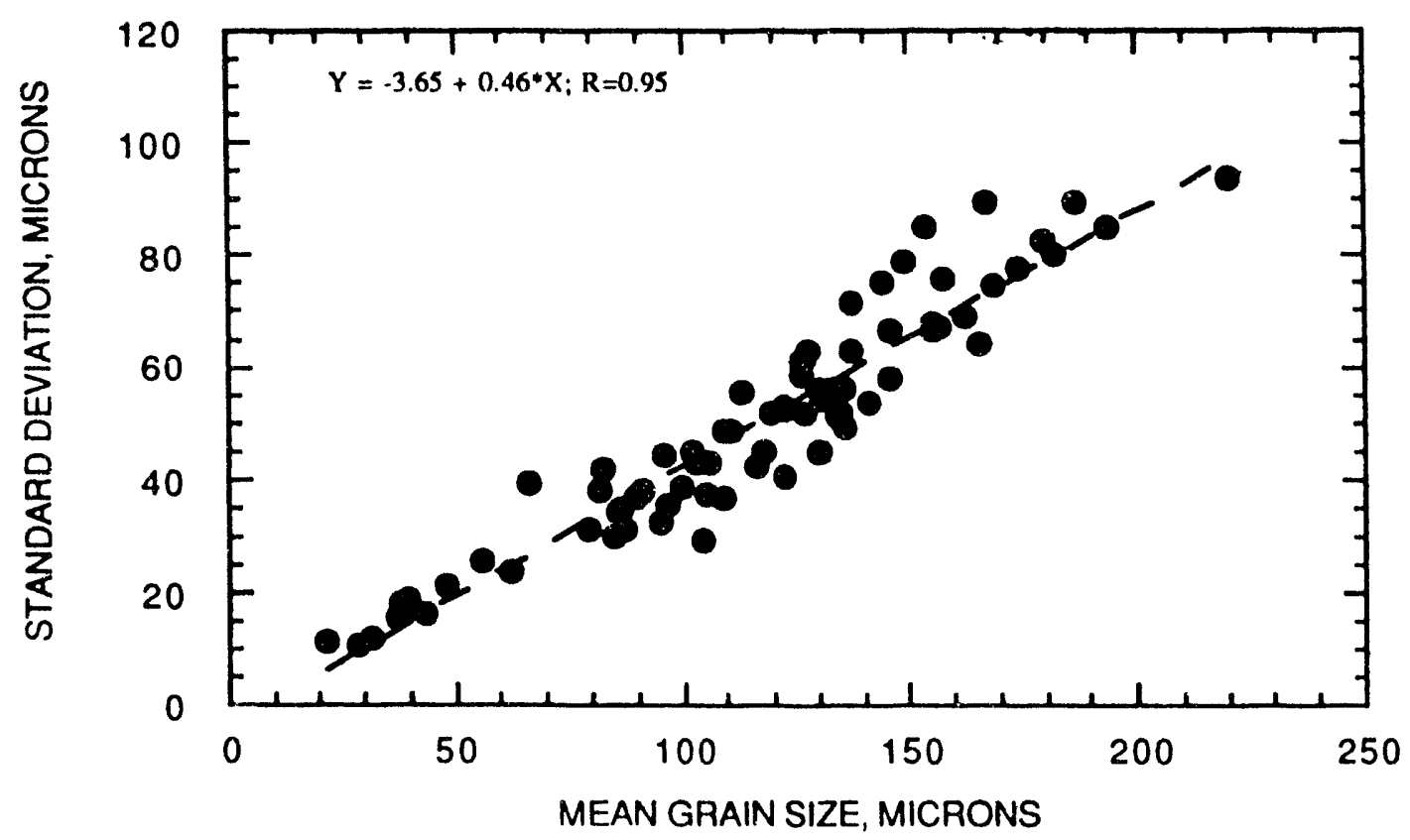

Figure 2.30 - Standard deviation (sorting) versus mean grain size for outcrop and subsurface Almond Formation. Based on image analysis of 300 points for each thin section. 


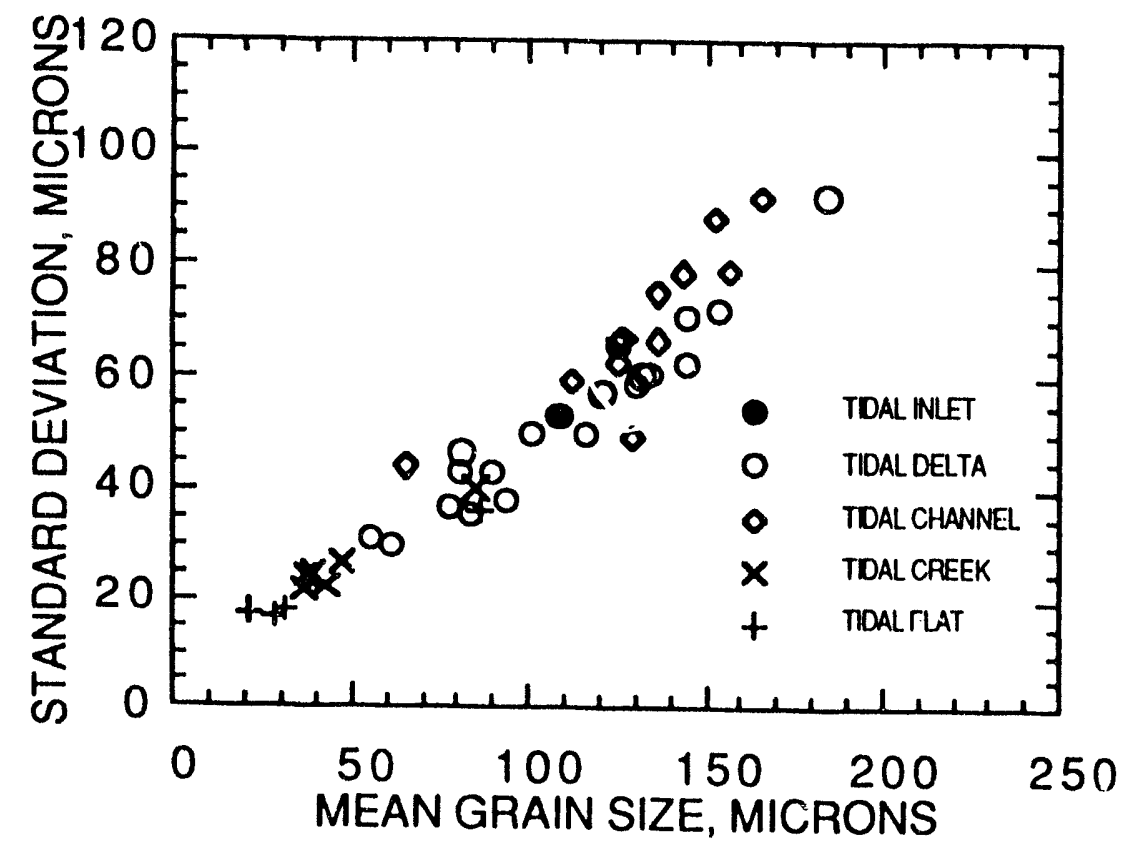

Figure 2.31 - Standard deviation (sorting) versus mean grain size for subsurface Almond Formation facies. Based on image analysis of 300 points for each thin section.

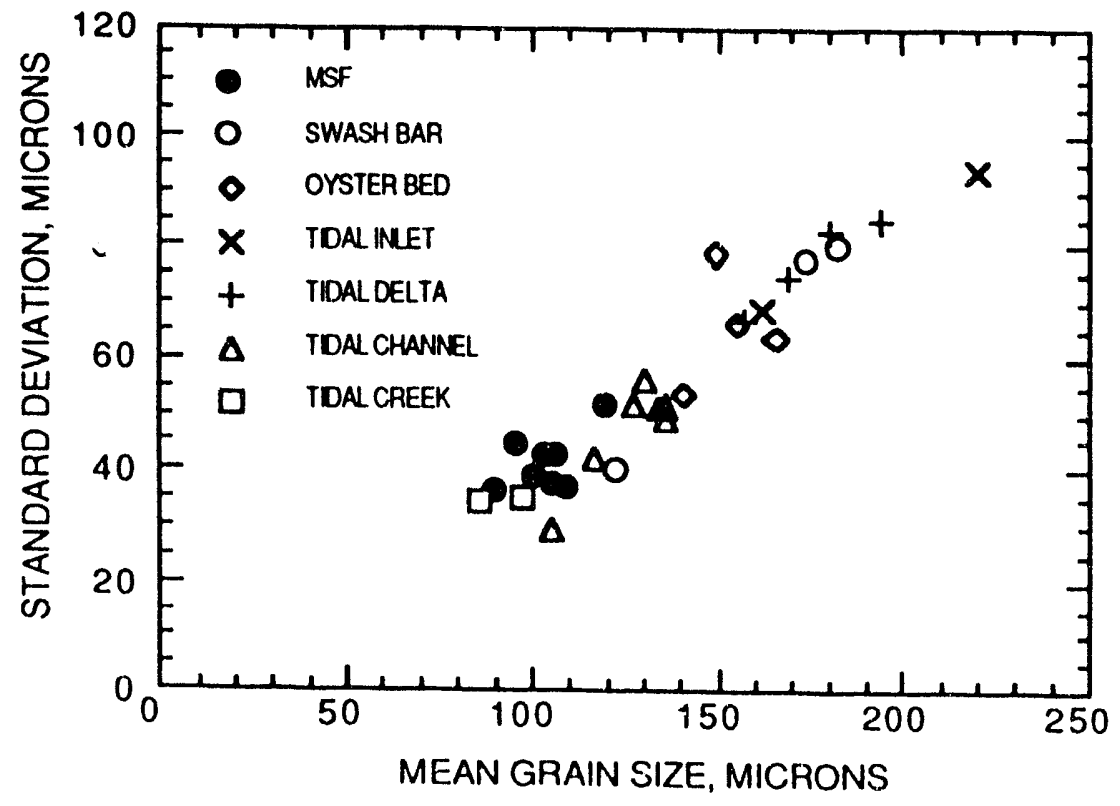

Figure 2.32 - Standard deviation (sorting) versus mean grain size for outcrop Almond Formation facies. Based on image analysis of 300 points for each thin scction. 


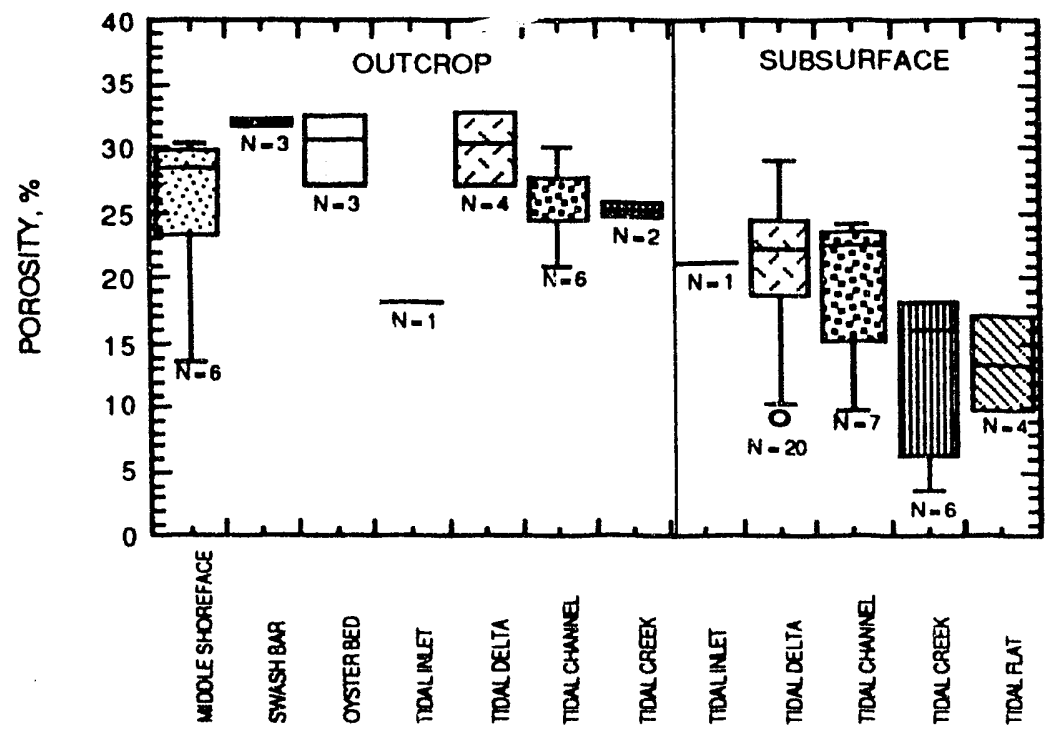

Figure 2.33 - Comparison of subsurface and outcrop facies porosity, Almond Formation. For explanation of symbols see fig. 2.15 .

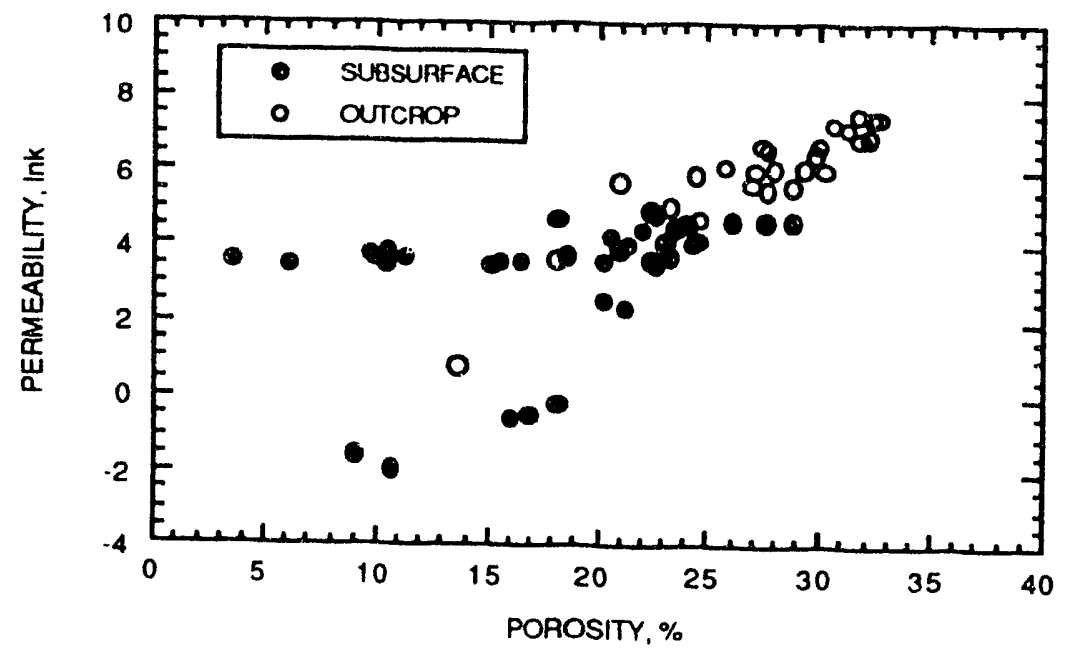

Figure 2.34 - Natural log of permeability versus porosity for outcrop and subsurface Almond Formation. 


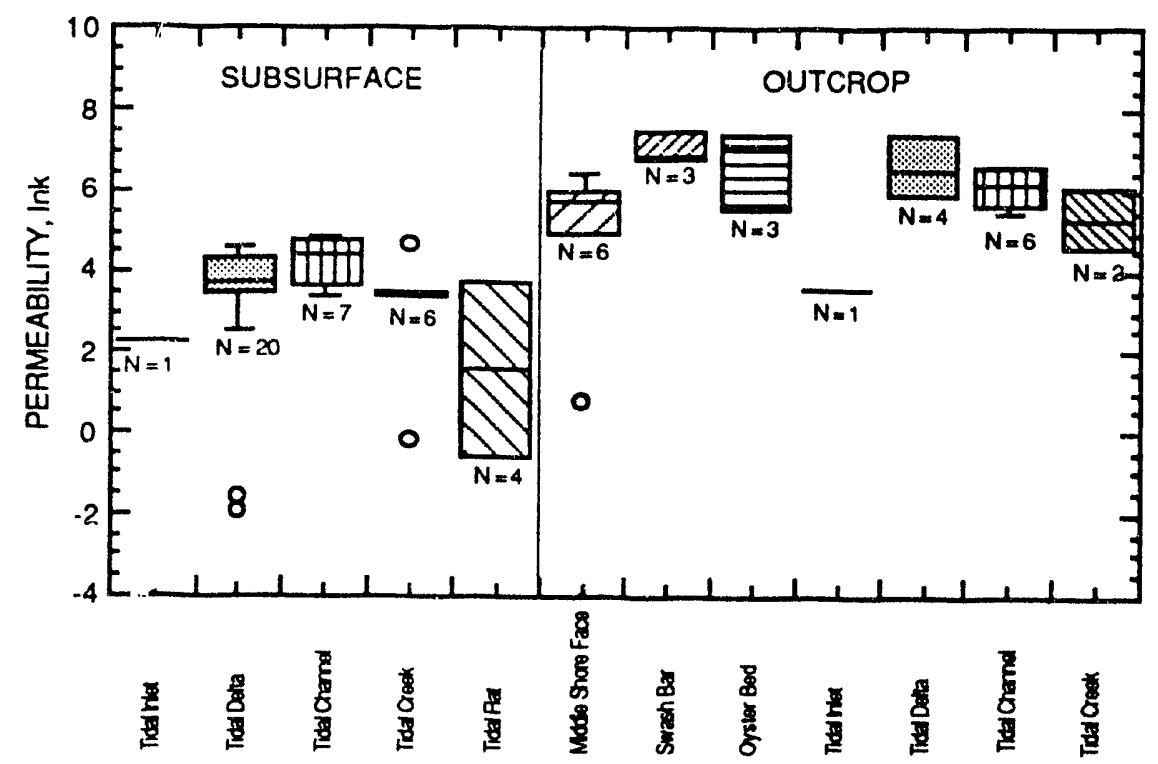

Figure 2.35 - Comparison of subsurface and outcrop permeability distribution for Almond facies. For explanation of symbols see fig. 2.15.

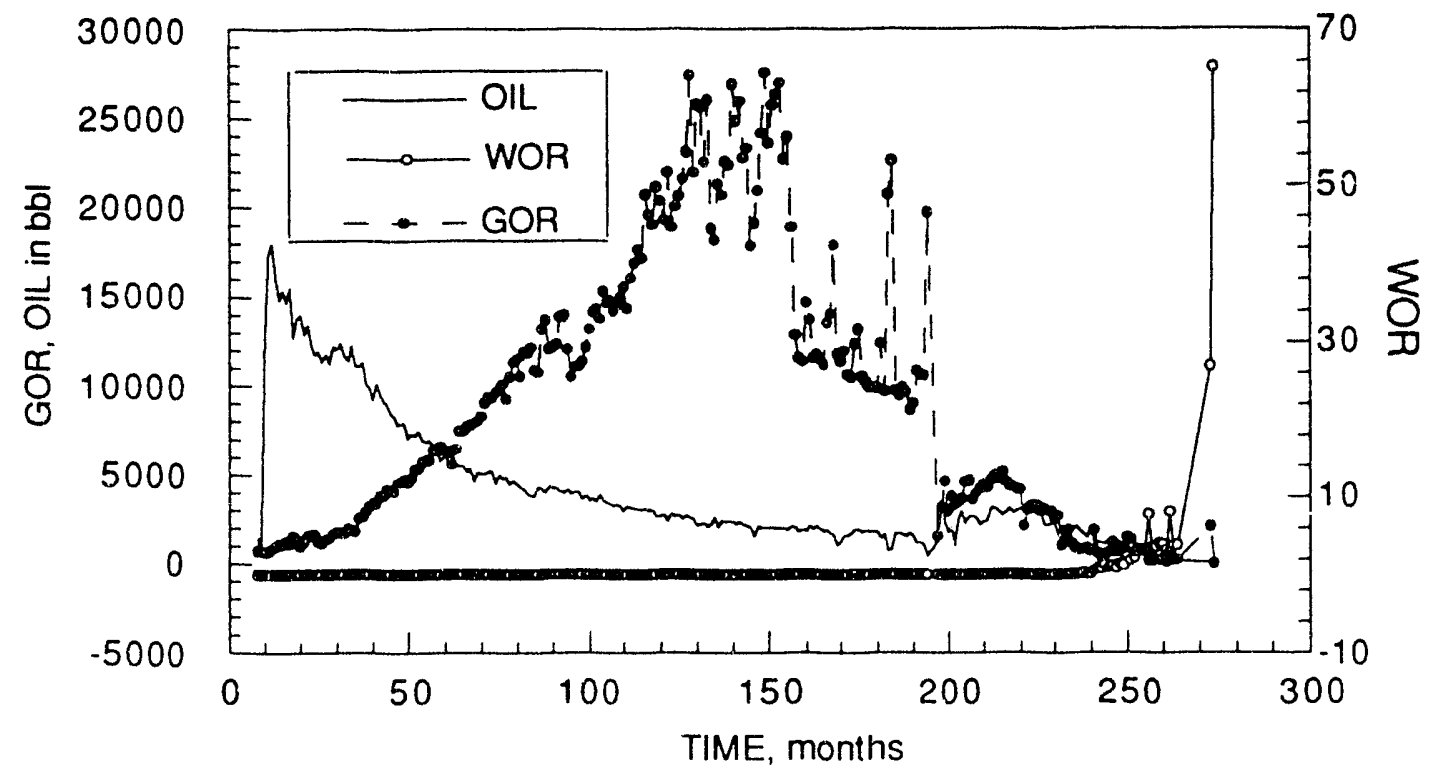

Figure 2.36 - Primary and secondary recovery behaviors of well Arch 44. 


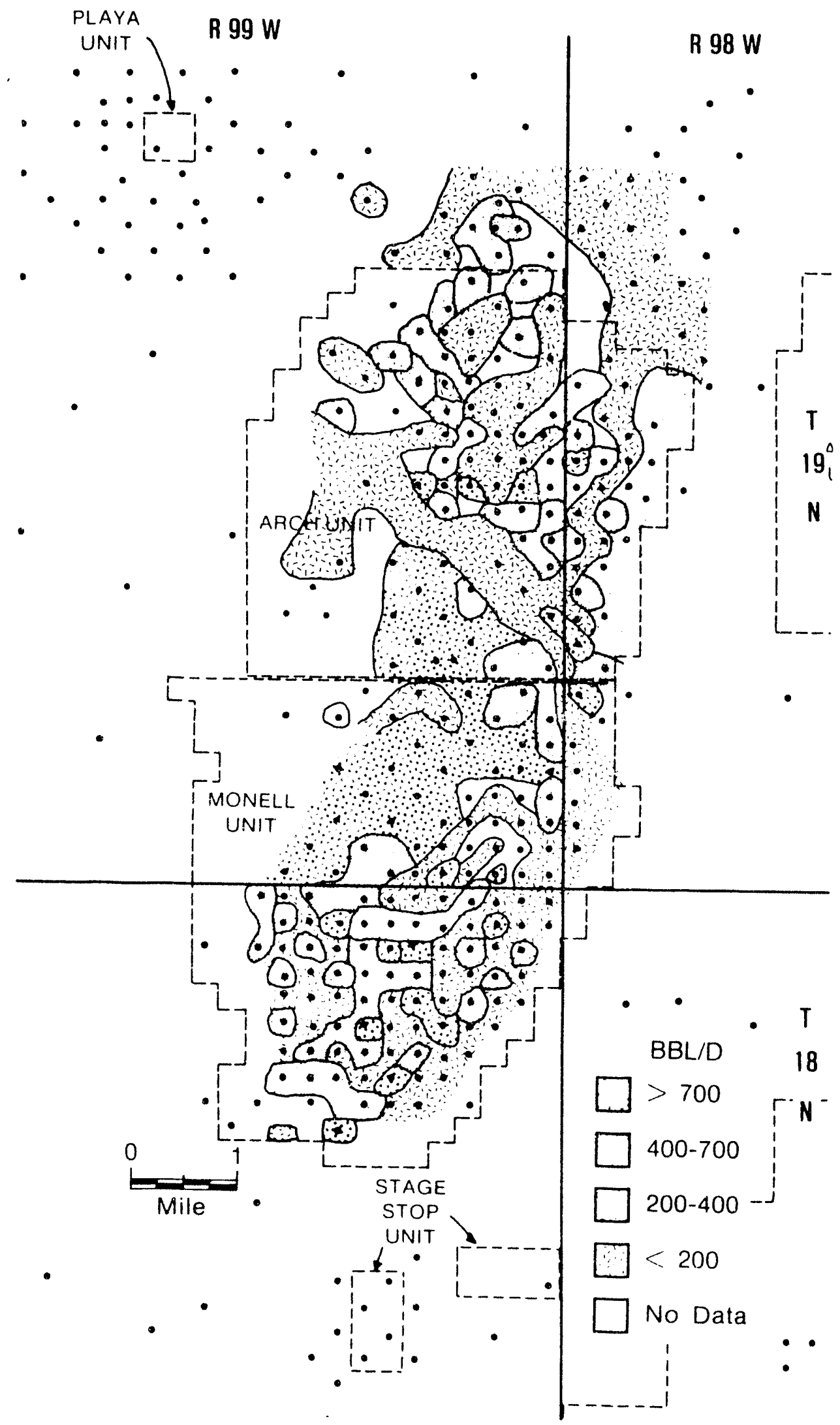

Figure 2.37 - Distribution of the initial oil production (bbl/d) for Patrick Draw field. 


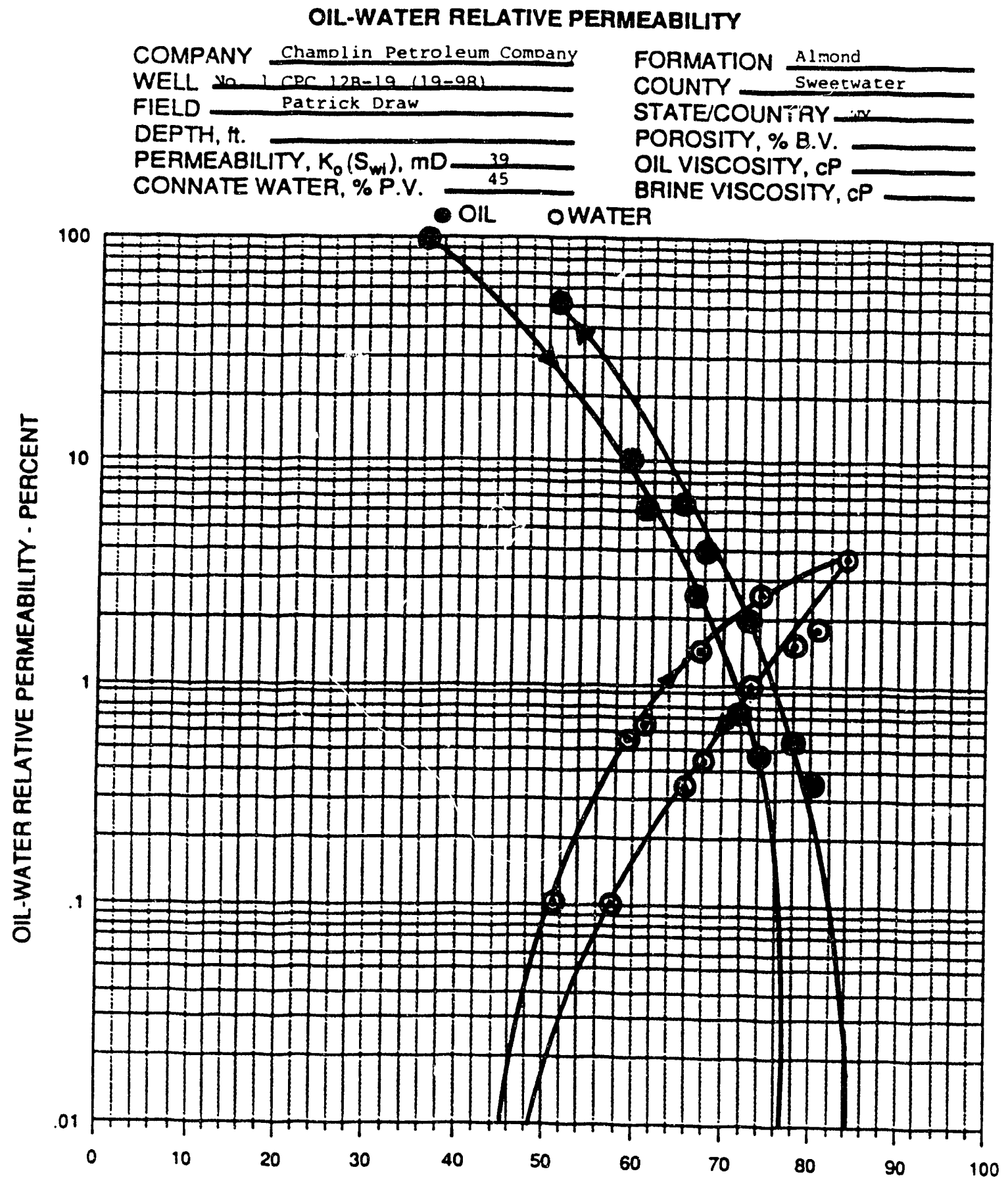

WATER SATURATION - PERCENT PORE VOLUME

Figurc 2.38 - Imbibition and drainage oil-water relative permeability analysis measured in Almond Formation. Depth of the sample measured is not known. From well Champlin Petrolcum Company No. 1 (Arch \#12B of section 19), Patrick Draw ficld. 


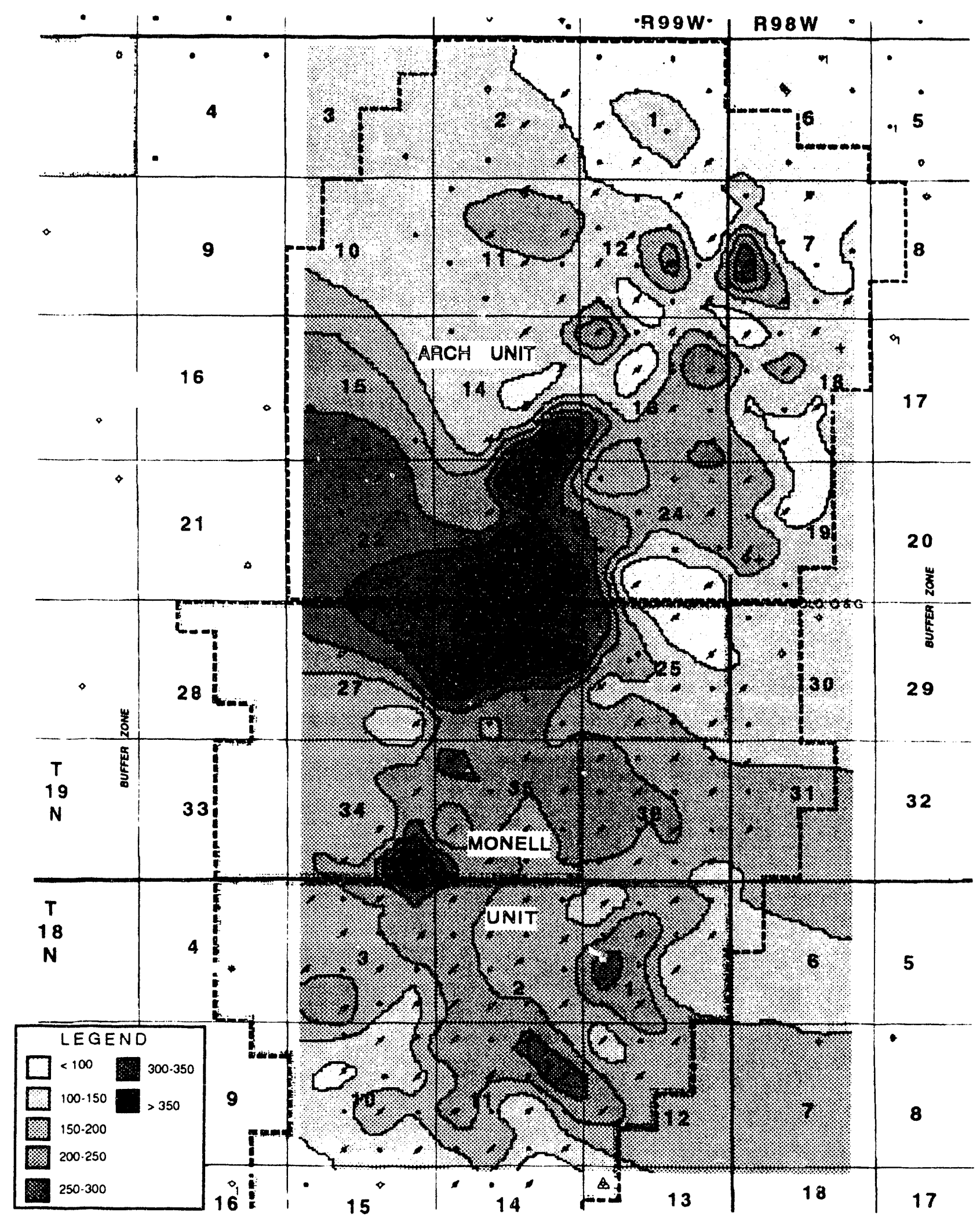

Figure 2.39 - Two-year primary cumulative oil production map. Contour Intervals $=50$ Mbbl. 


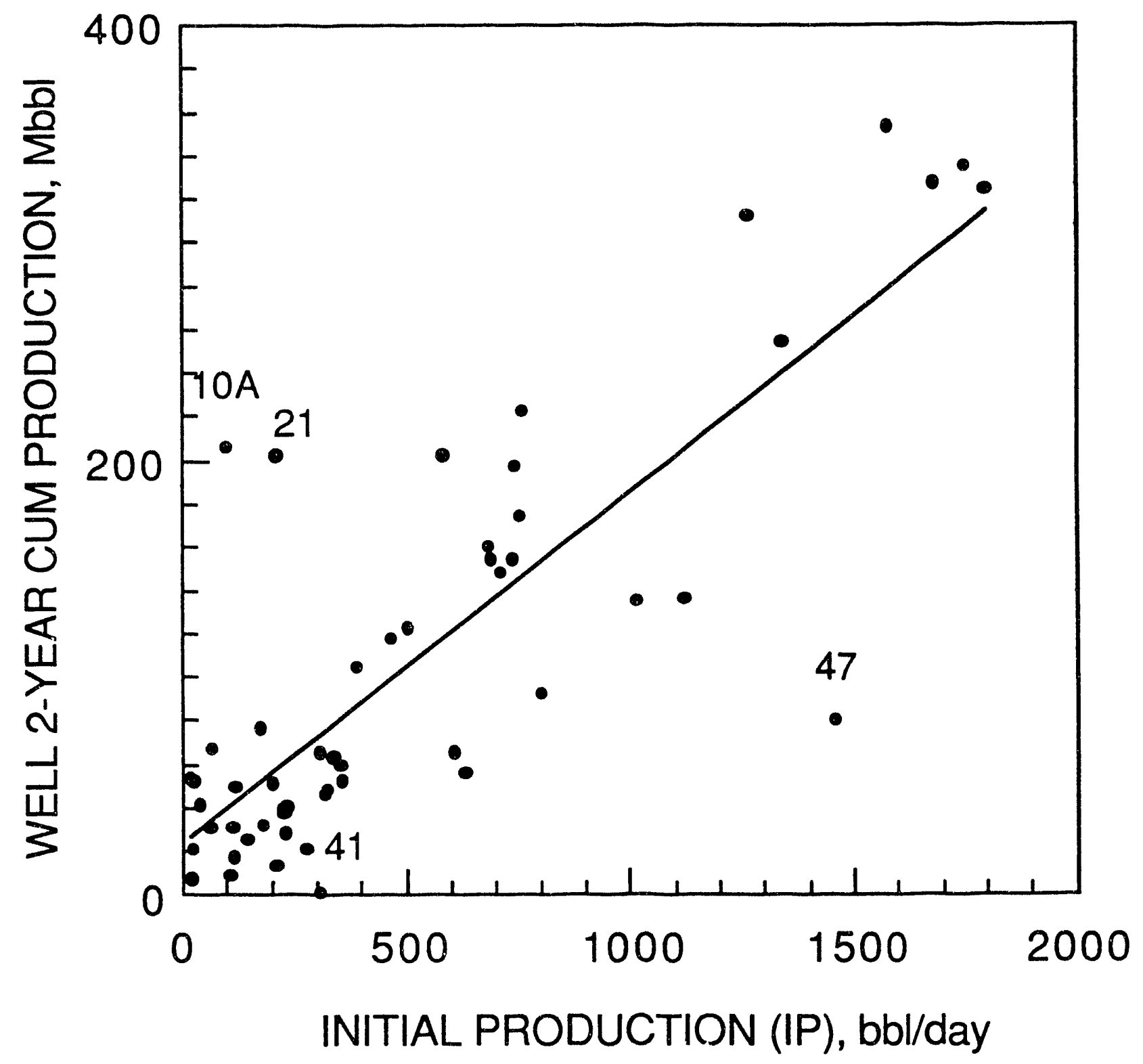

Figure 2.40 - Plot of 2-year cumulative oil production vs. initial production (IP). Well numbers are indicated for wells discussed in the text. 
a

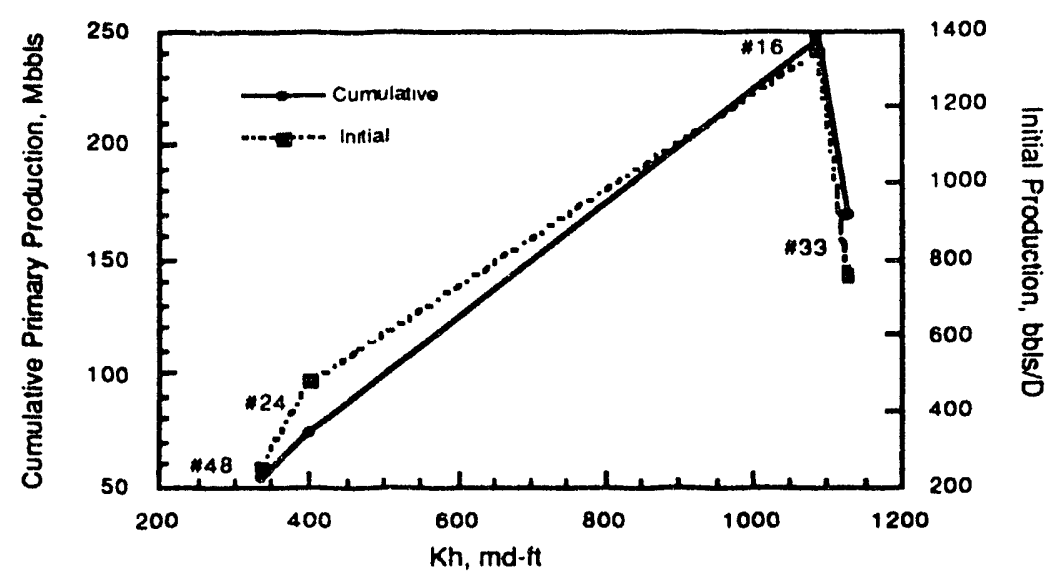

b

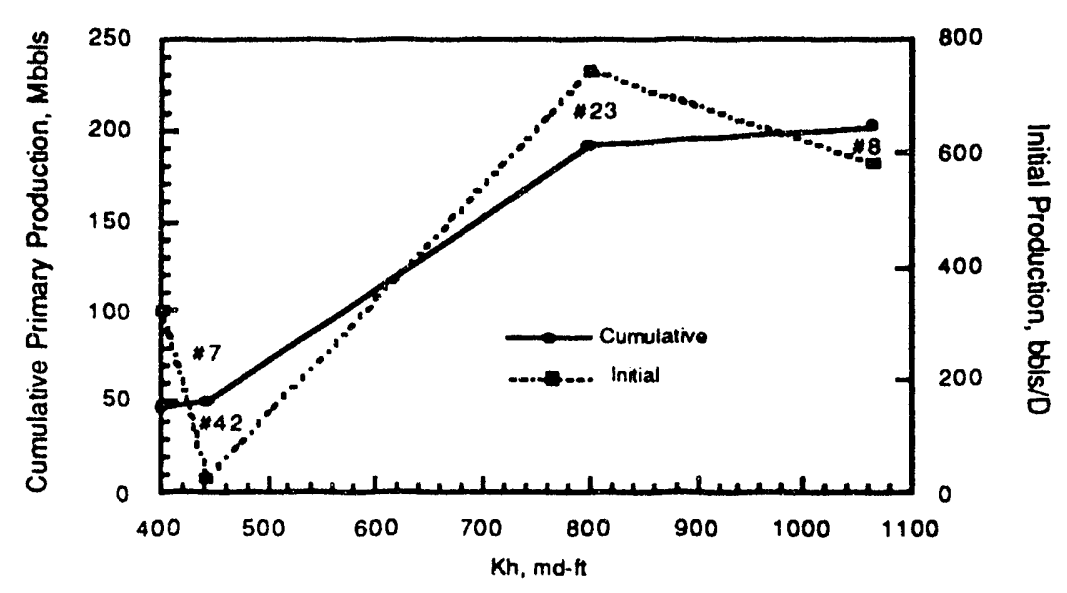

c

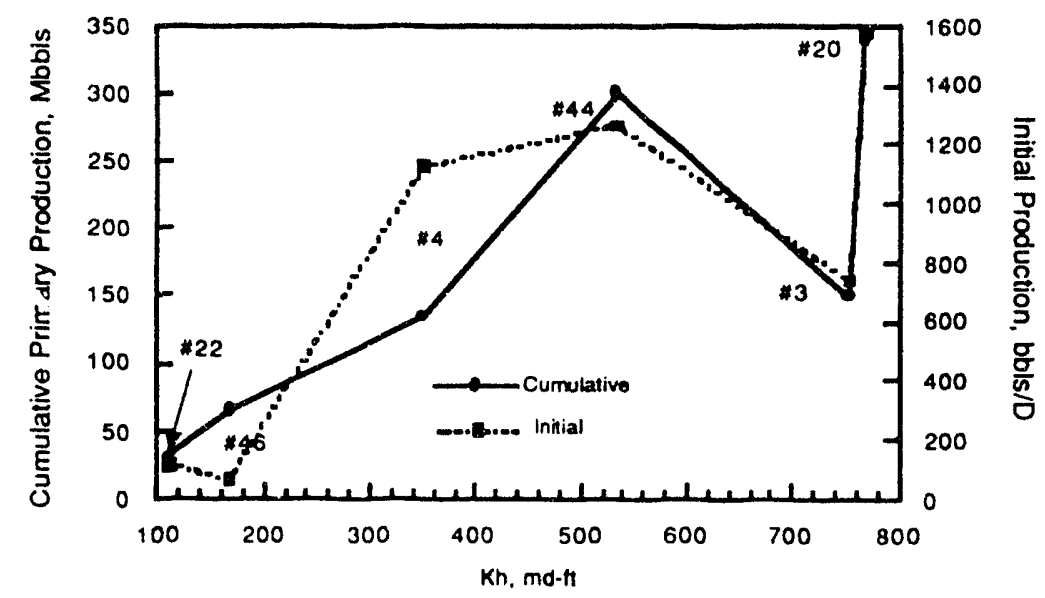

Figure 2.41 - Plot of cumulative and initial oil pioduction as functions of permeability thicknsess product $(\mathrm{kh})$ in wells along (a) profile $1,(\mathrm{~b})$ profile 2 , (c) profile 3. See fig. 2.22 for well locations. 


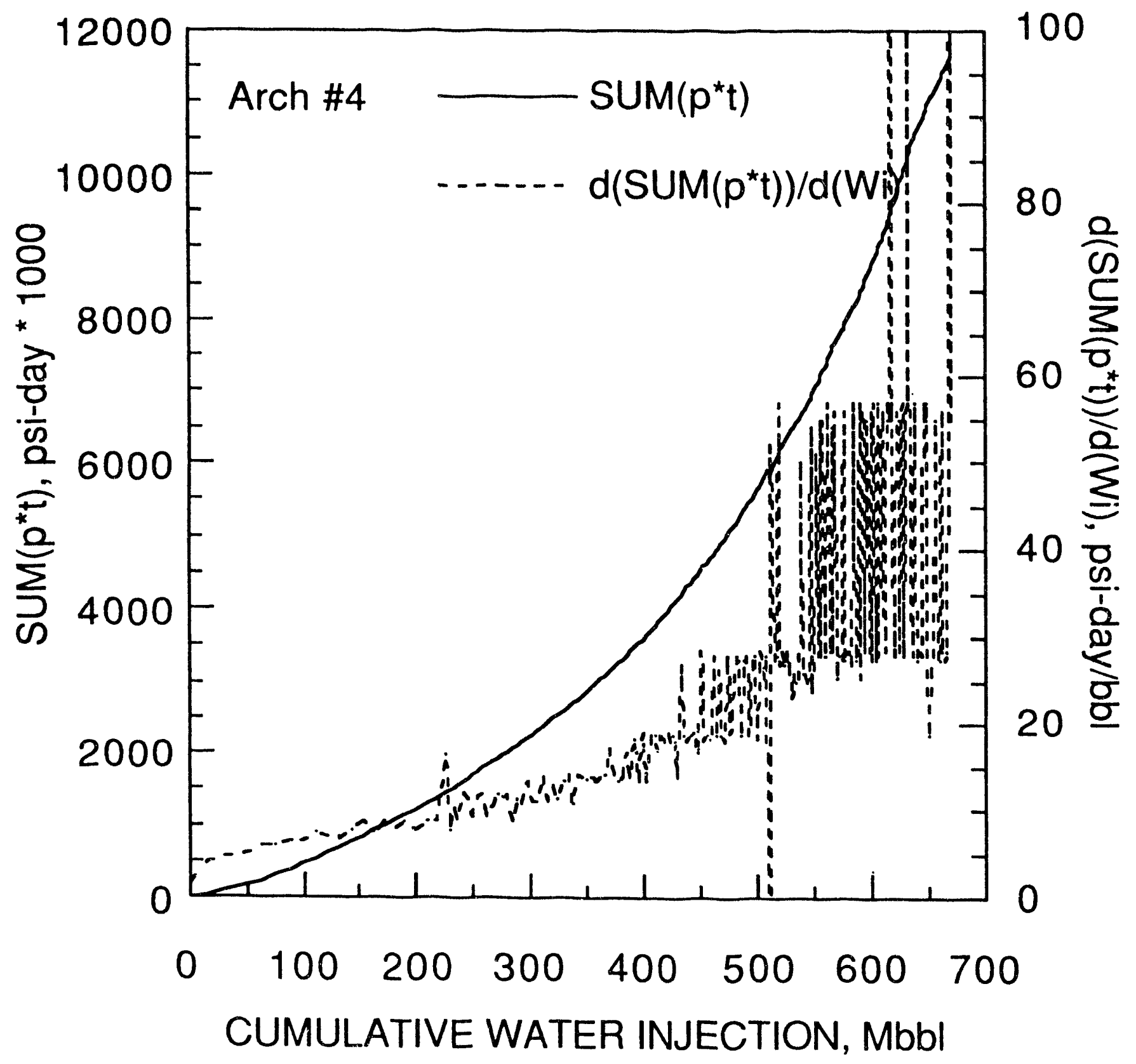

Figure 2.42 - An cxample Hall plot from Arch wcll 4. 


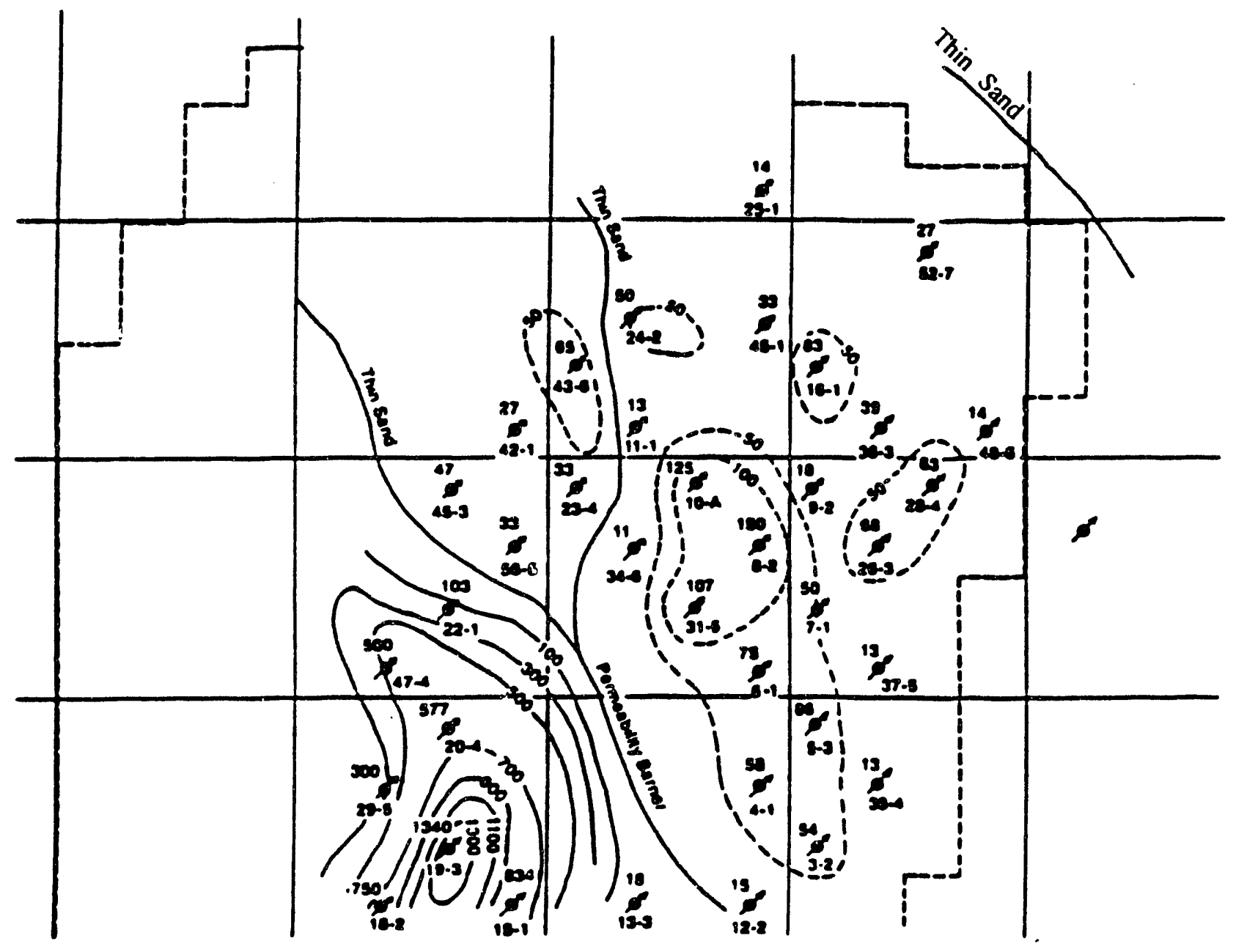

Figure 2.43 - Calculated $k_{w h}$ (Hall plot) distributions of UA-5 sand water injectors. Contour Interval $=\mathbf{2 0 0} \mathrm{md}$-ft. 


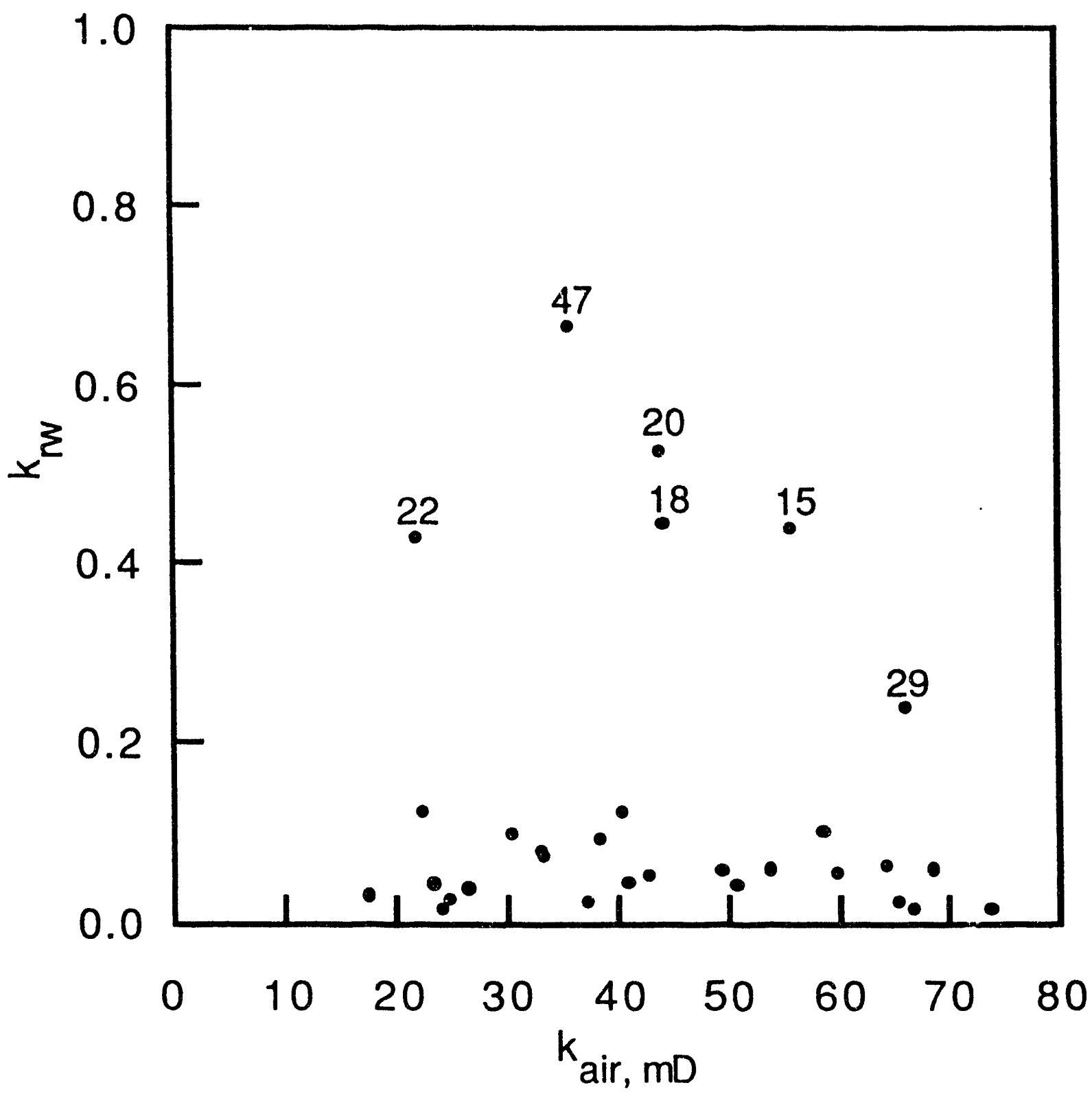

Figure 2.44 - Plot of $k_{r w}$ from Hall Plot analysis vs. $k_{\text {air }}$ from core analysis. 


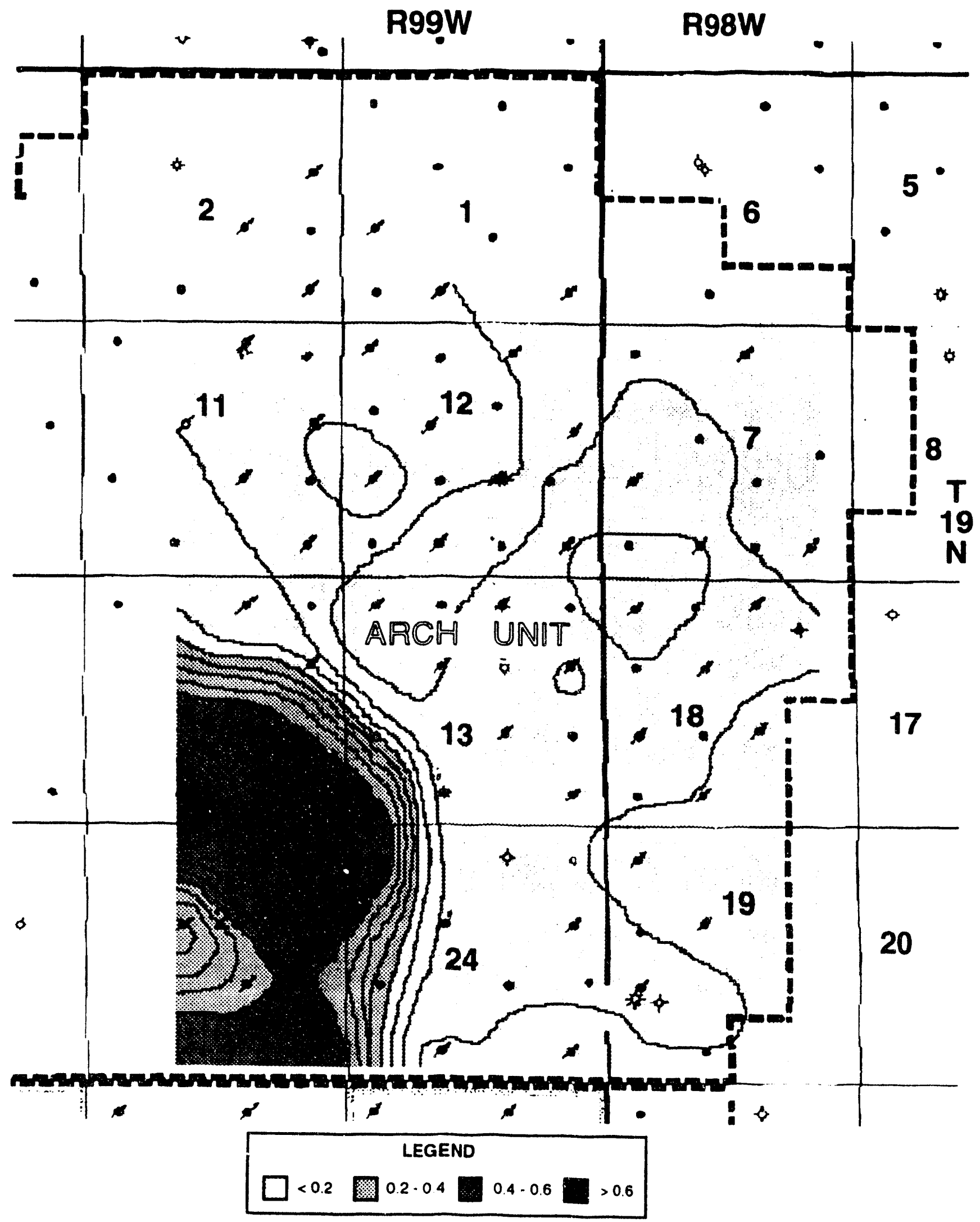

Figure 2.45 - Distribution of $\mathrm{k}_{\mathrm{rw}}$ calculated from water injection. Contour interval = 0.05 . 

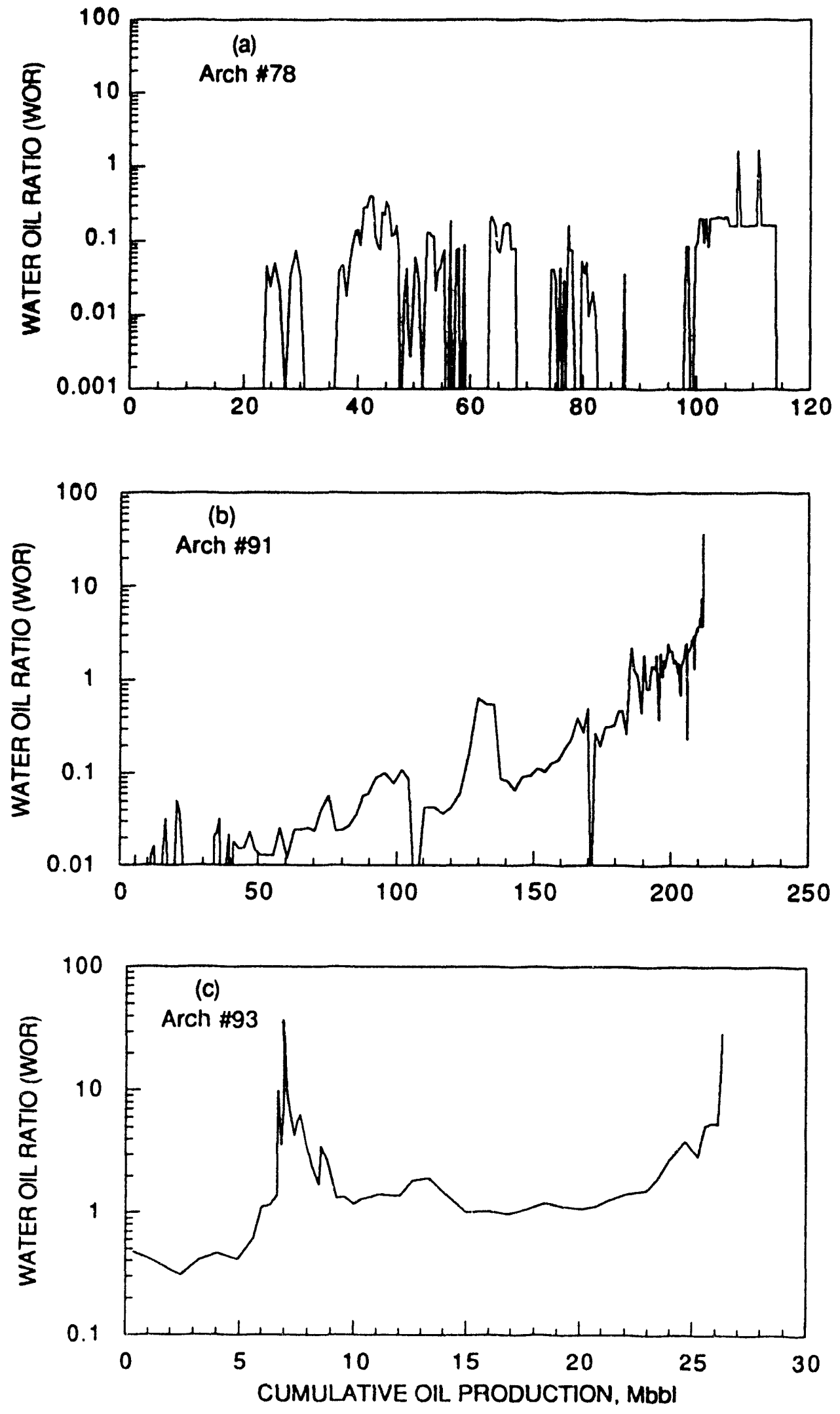

Figure 2.46 - Watcr-oil ratio (WOR) vs. cumulative oil production plot illustrating three types of curves (a) noisy or irregular data, (b) asymptotic response, and (c) double water breakthrough. 


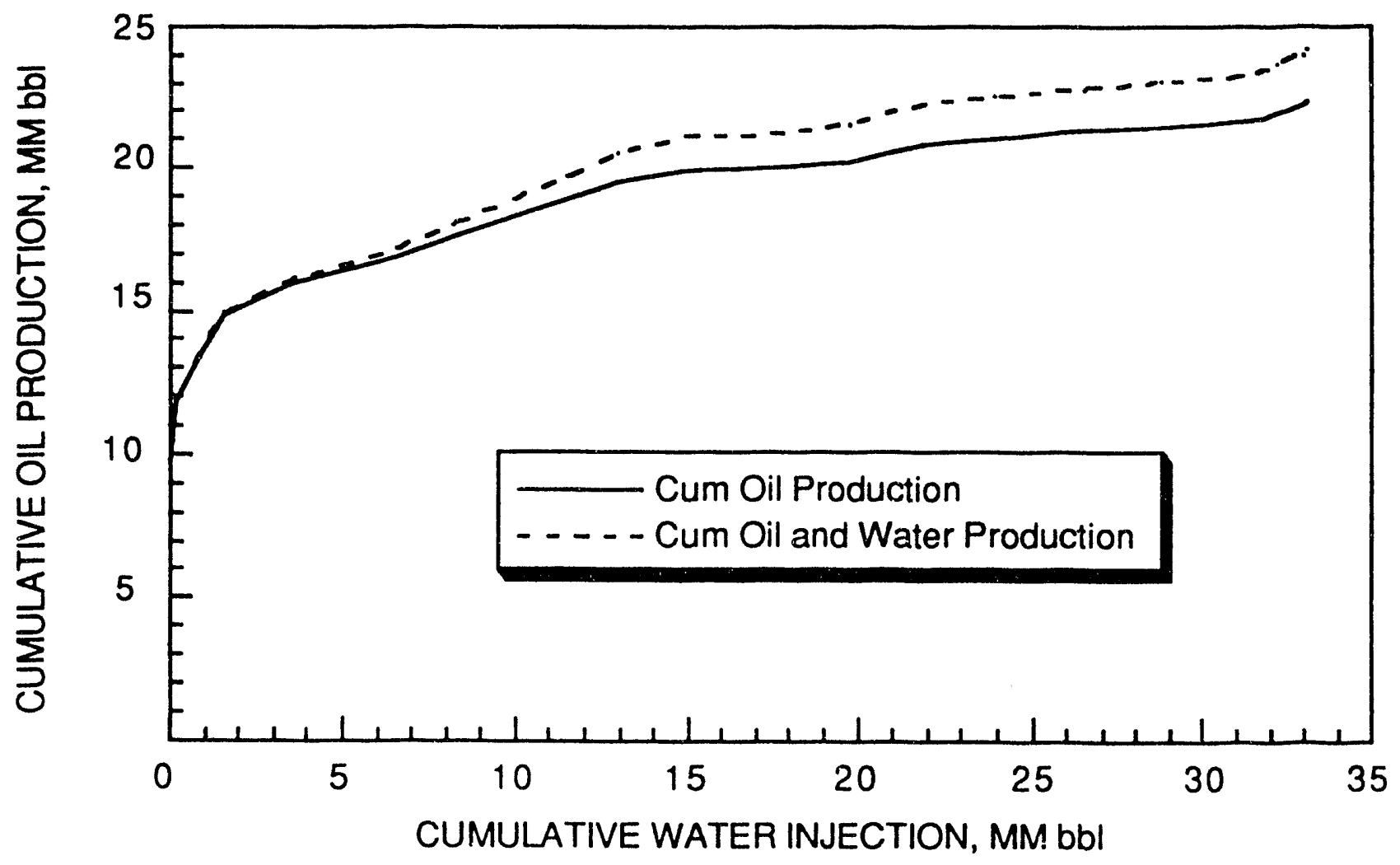

Figure 2.47 - Cumulative oil production volume and cumulative fluid (oil and water) production volume vs. cumulative water injection, through 1983 for the Arch Unit. 


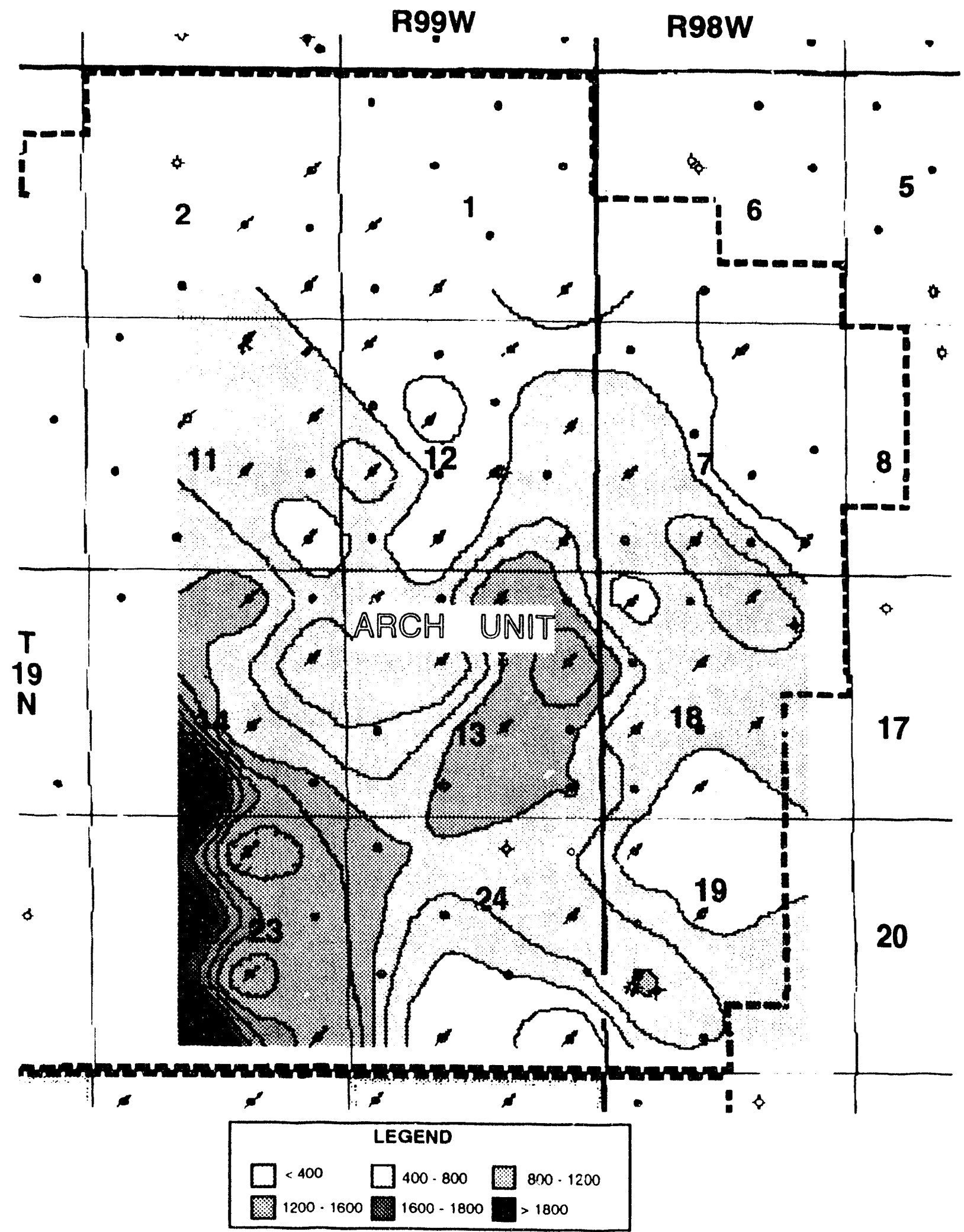

Figurc 2.48 - Distribution of total water injection. Contour interval $=200 \mathrm{Mbbl}$. 


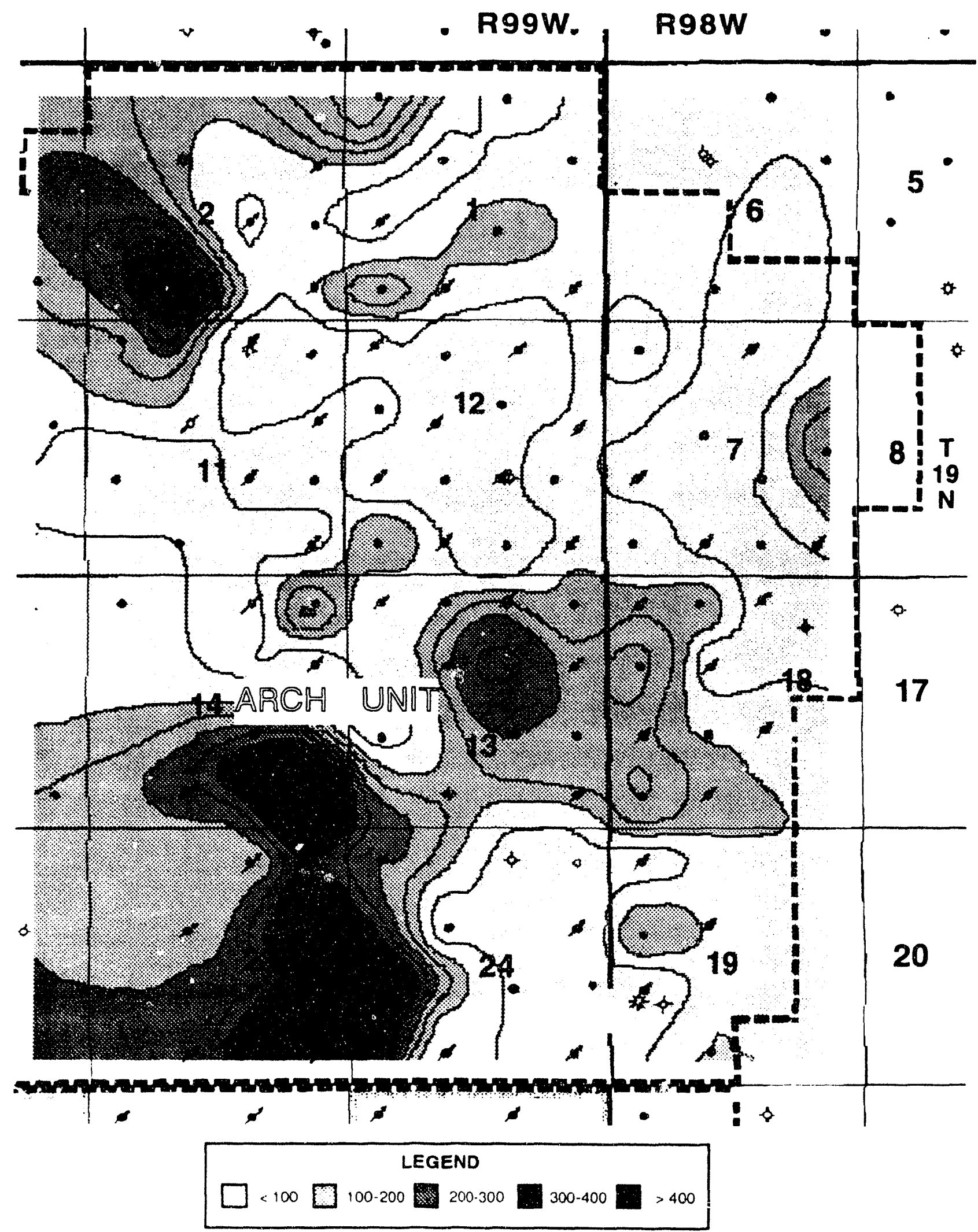

Figure 2.49. Disuribution of cumulative oil prodiction from 1966 to 1986. Contour interval $=200 \mathrm{Mbbl}$. 


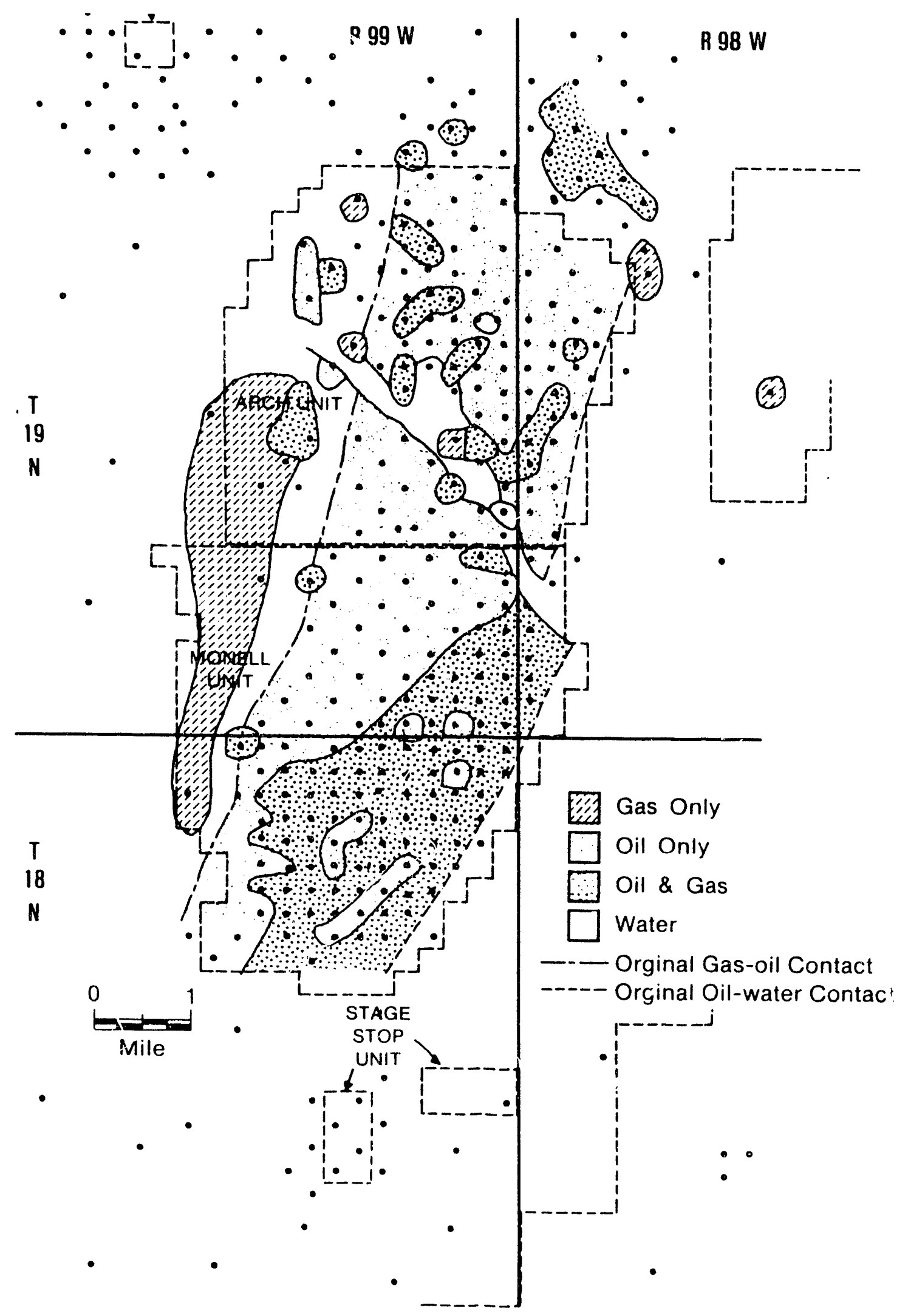

Figurc 2.50 - Distribution of wells producing single hydrocarbon phase (oil) versus those producing oil and gas during initial production in Patrick Draw field. 


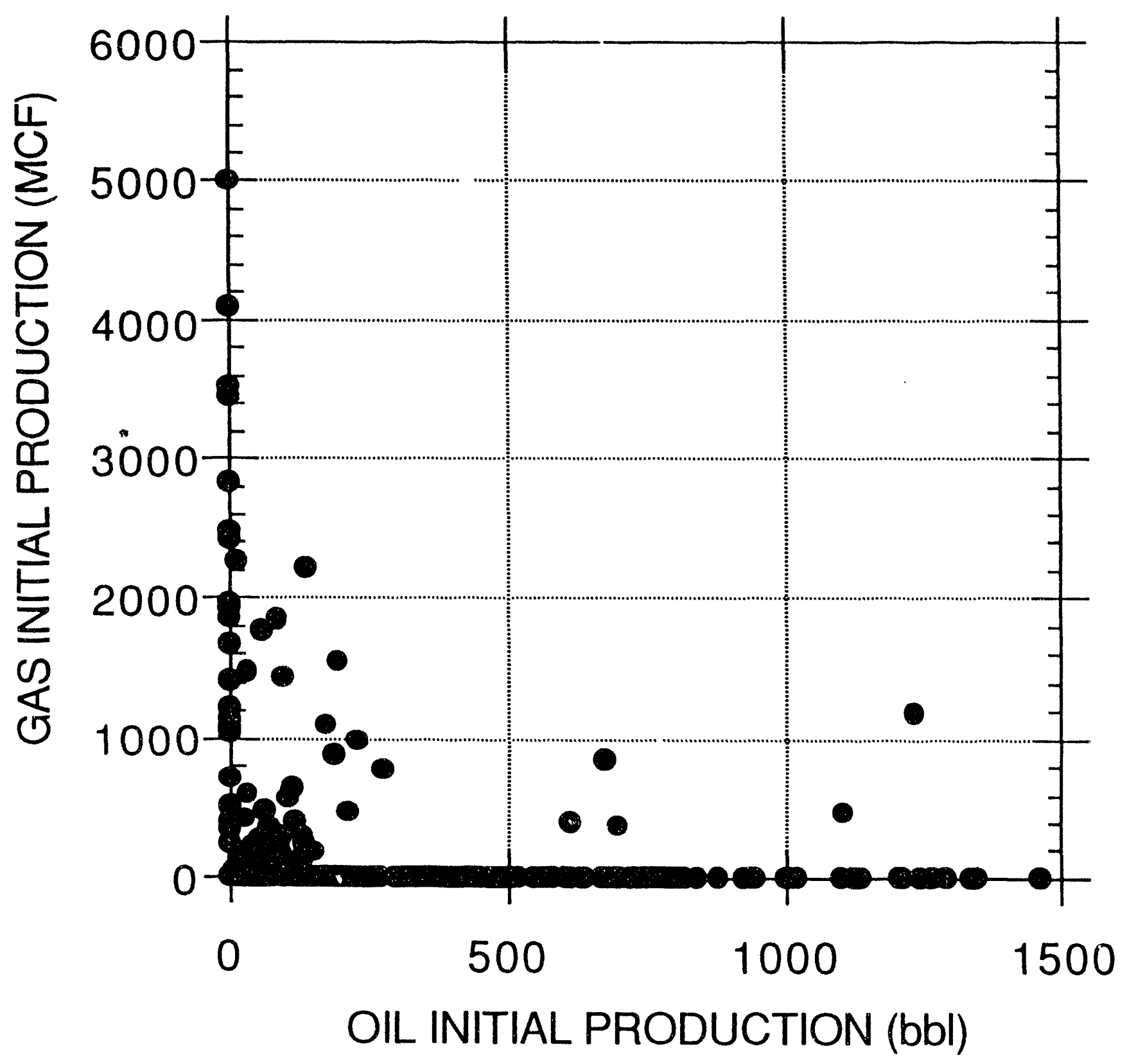

Figure 2.51 - Relationship of the initial oil and gas production in wells of the entire Patrick Draw field. 


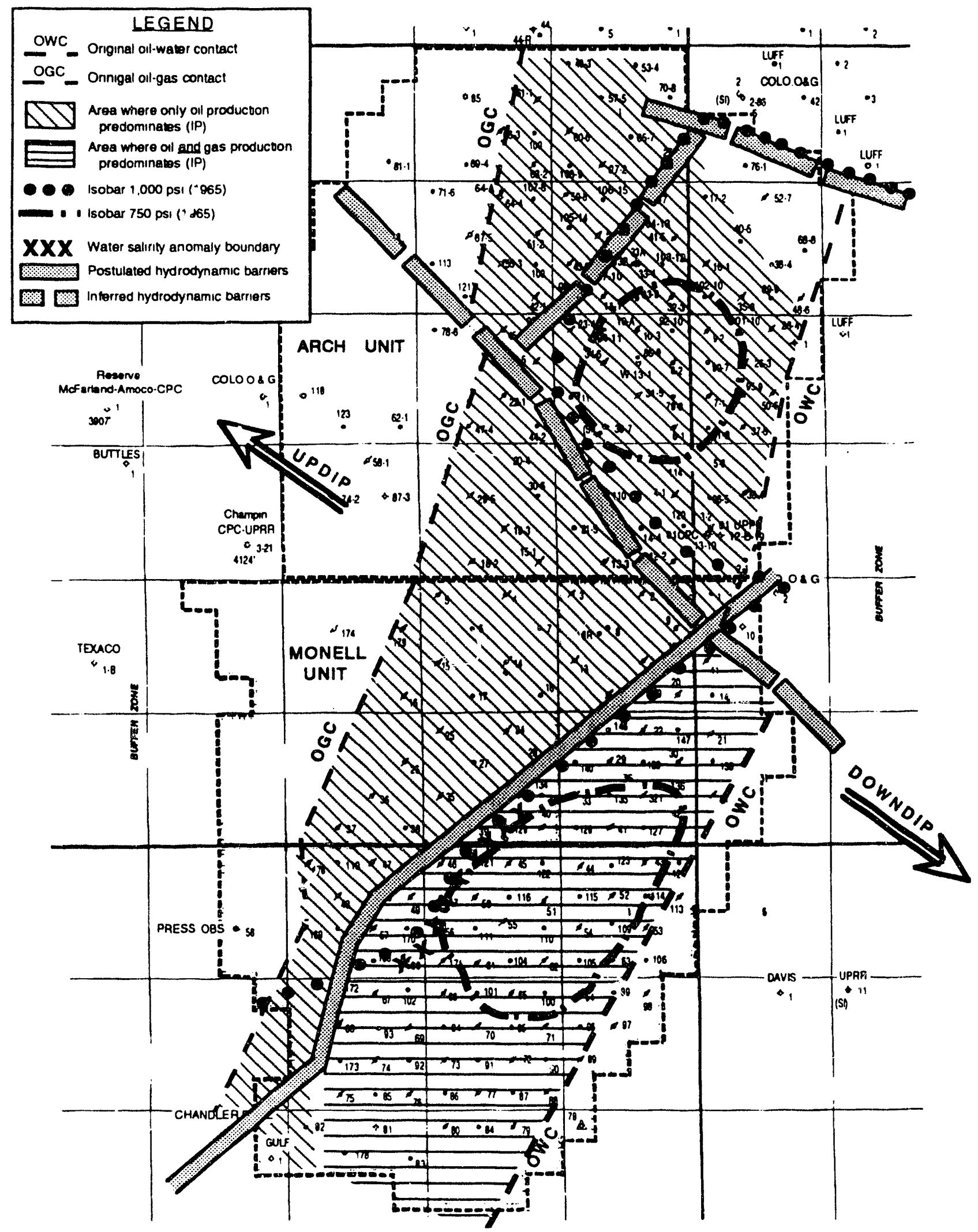

Figure 2.52 - Composite map illustrating major fluid, pressurc, and production anomalies in Patrick Draw field and postulated hydrodynamic barriers to fluid flow. 


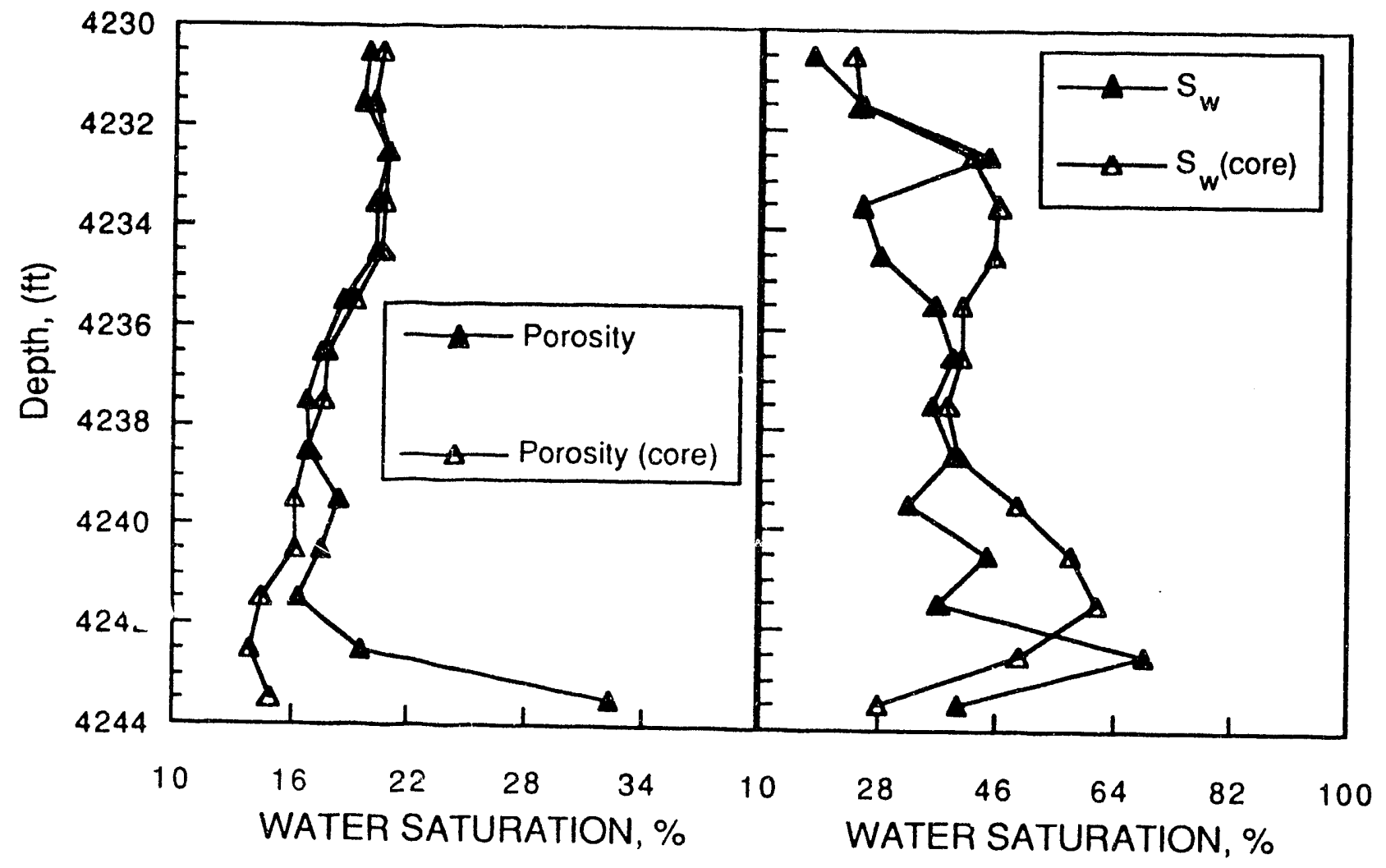

Figure 2.53 - Distributions of $\log$ derived and laboratory measured porosity and water saturations in UA-6 sand in well 81 . Note the high porosity values due to coal at the bottom of the sandstone. 


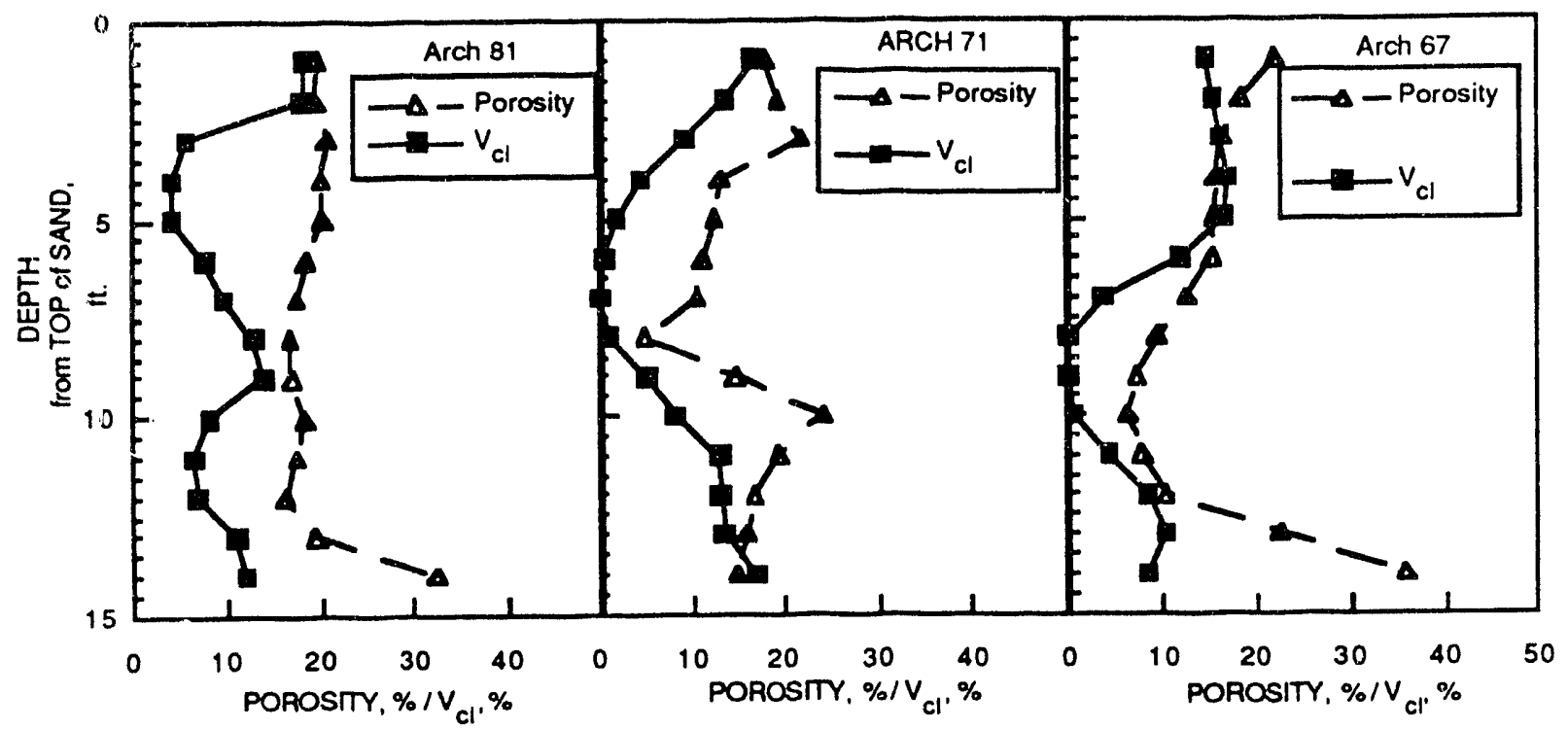

Figurc 2.54 - Distributions of clay content $(\mathrm{Vcl})$ and porosity in the UA-6 sand obtained from log interpretations in wells 81,71 and 67 . Note high porosity values due to coal at the bottom well 81 and low porosity, cemented zones in the middle of sandstones in wells 71 and 67.

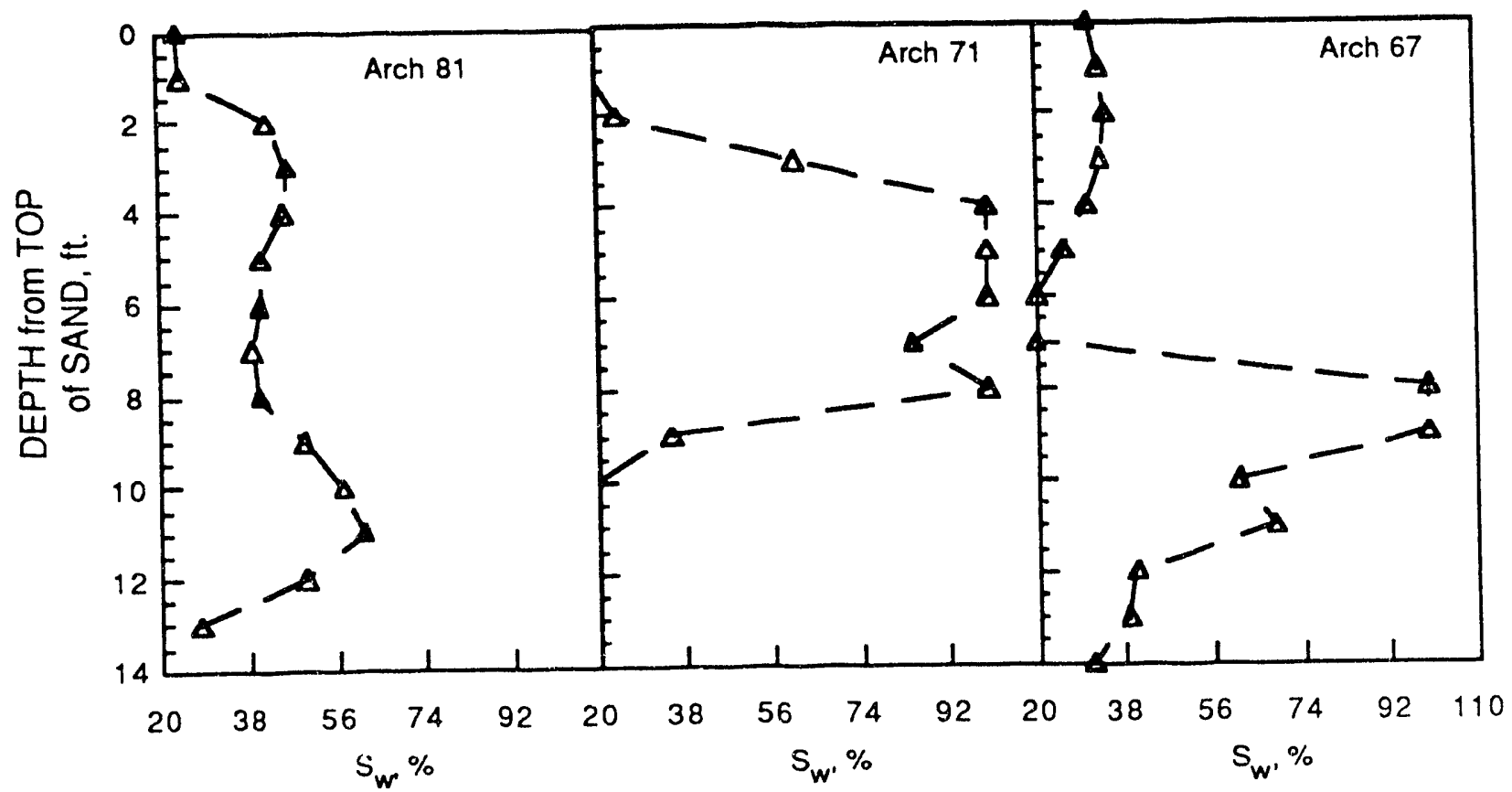

Figure 2.55 - Distributions of log derived water saturations in highly hetcrogencous UA-6 sand in wells 81,71 and 67. 


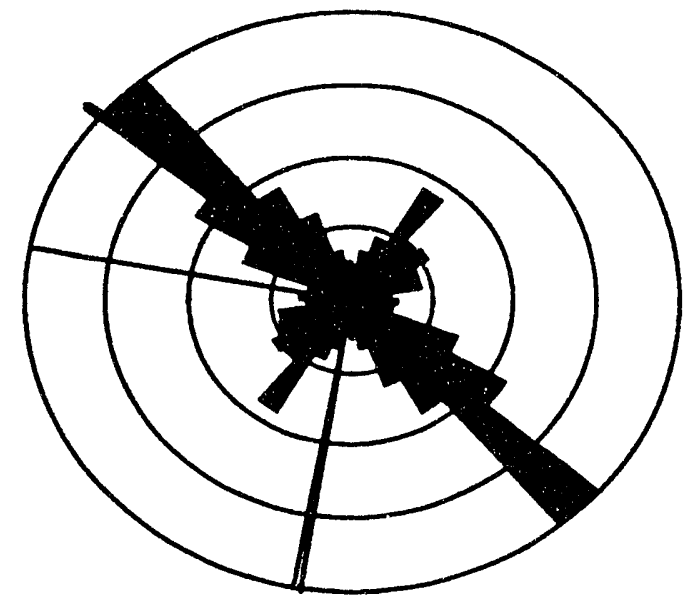

Outcrops 91 all frac.data

$\mathrm{N}=923$ Cumulative Length $=0.0$

Class Interval $=10$ degrees

Maximum Percentage $=19.1$

Mean Percentage $=5.56$

Standard Deviation $=4.07$

Vector Means $=309.5$

Conf. Angle $=11.74$

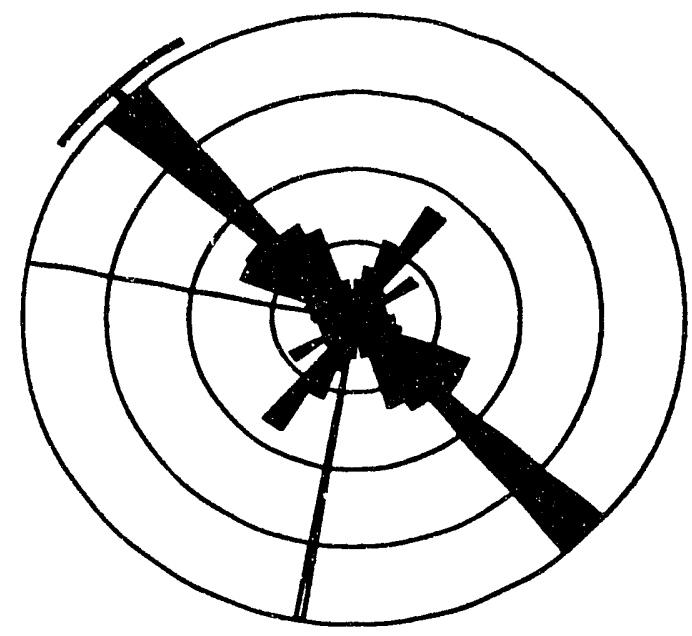

G-all trac. data

$\mathrm{N}=434 \quad$ Cumulative Length $=0.0$

Class Interval $=10$ degrees

Maximum Percentage $=22.1$

Mean Percentage $=5.56$

Standard Deviation $=4.75$

Vector Mean $=315.9$

Conf. Angle $=13.91$

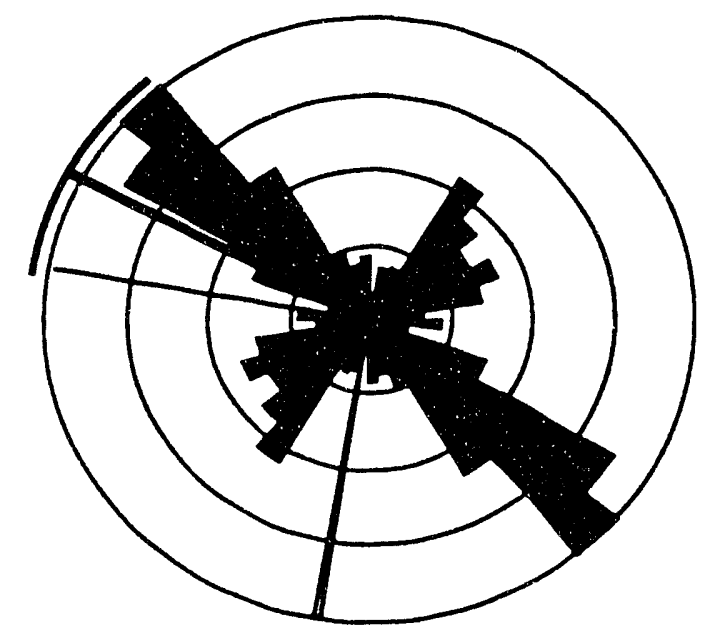

$$
\begin{aligned}
& \mathrm{H} \text {-all frac. data } \\
& \mathrm{N}=422 \text { Cumulative Length }=0.0 \\
& \text { Class Interval }=10 \text { degrees } \\
& \text { Maximum Percentage }=15.4 \\
& \text { Mean Peracentage }=5.56 \\
& \text { Standard Deviation }=3.86 \\
& \text { Vector Mean }=297.7 \\
& \text { Cont. Angle }=20.22
\end{aligned}
$$

Figure 2.56 - Rose diagrams of fracture orientations and related statistics for the all measured outcrops located on the southeastern flank of the Rock Springs Uplift, all sandstone intervais in outcrop G, and all sandston: intervals in outcrop $\mathrm{H}$. 

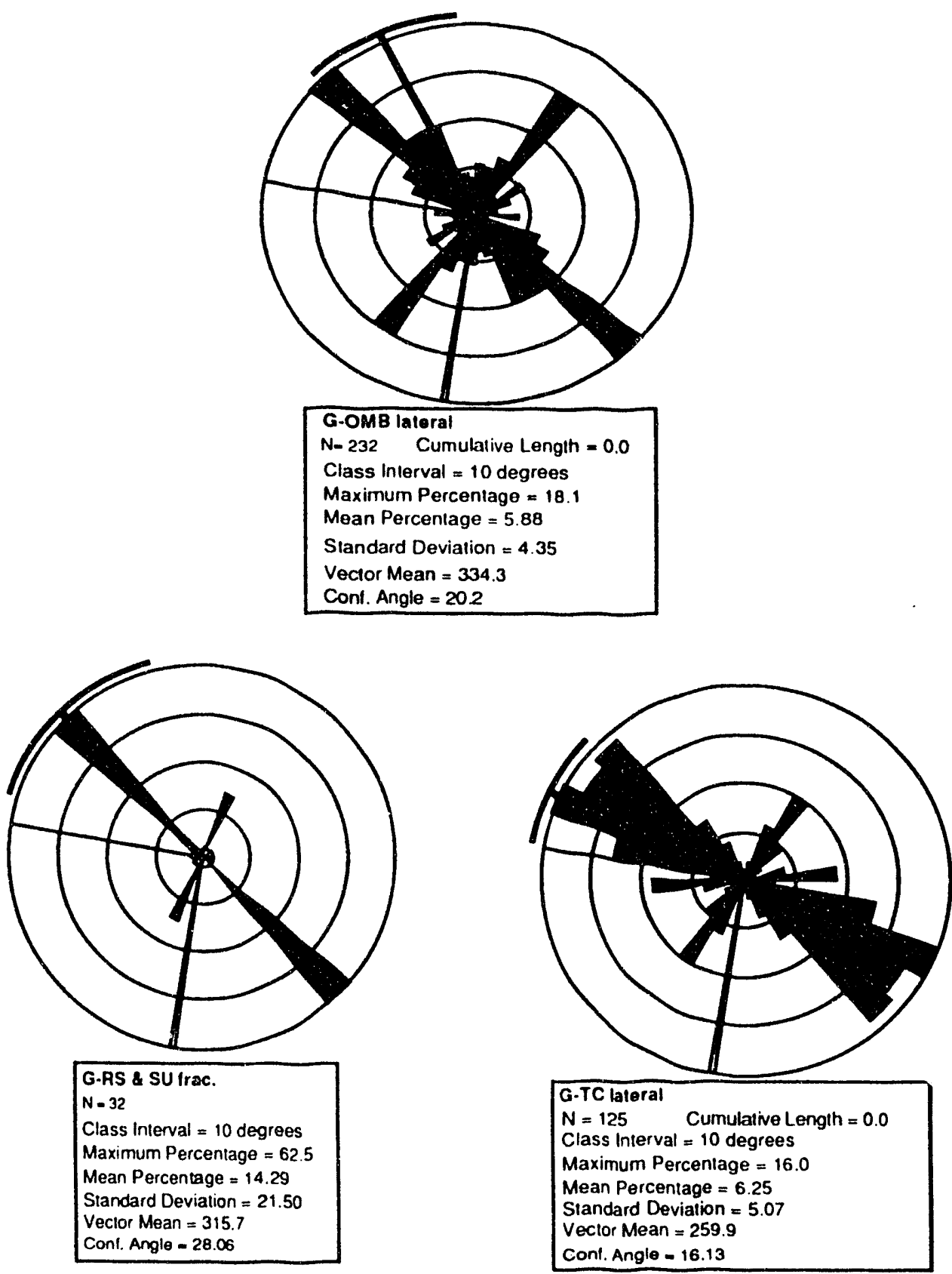

Figure 2.57 - Rose diagrams of fracture orientations and related statistics for the Oyster Marker Bed (OMB); Tidal Channel; and Spit and Shoreface facies in outcrop G. 


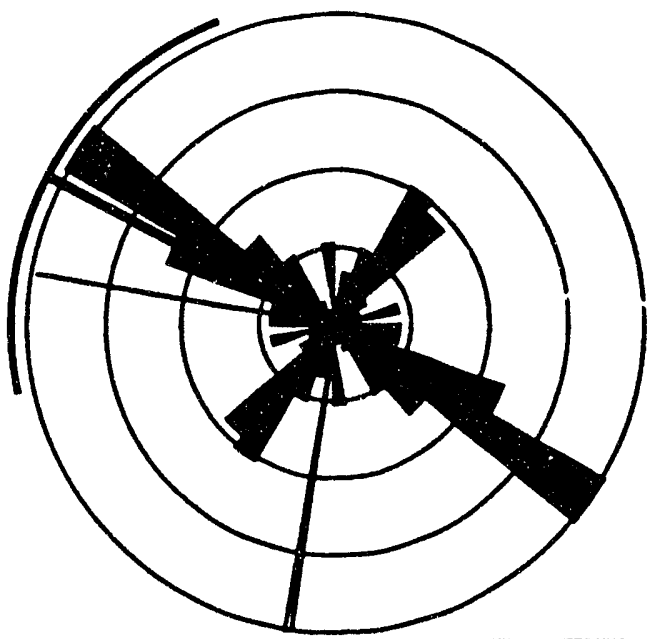

H-TDF,TI,TCH-RH3

$N=116 \quad$ Cumulative Length $=0.0$

Class Interval $=10$ degrees

Maximum Percentage $=20.7$

Mean Percentage $=6.25$

Standard Deviation $=4.88$

Vector Mean $=297.7$

Conf. Angle $=40.32$
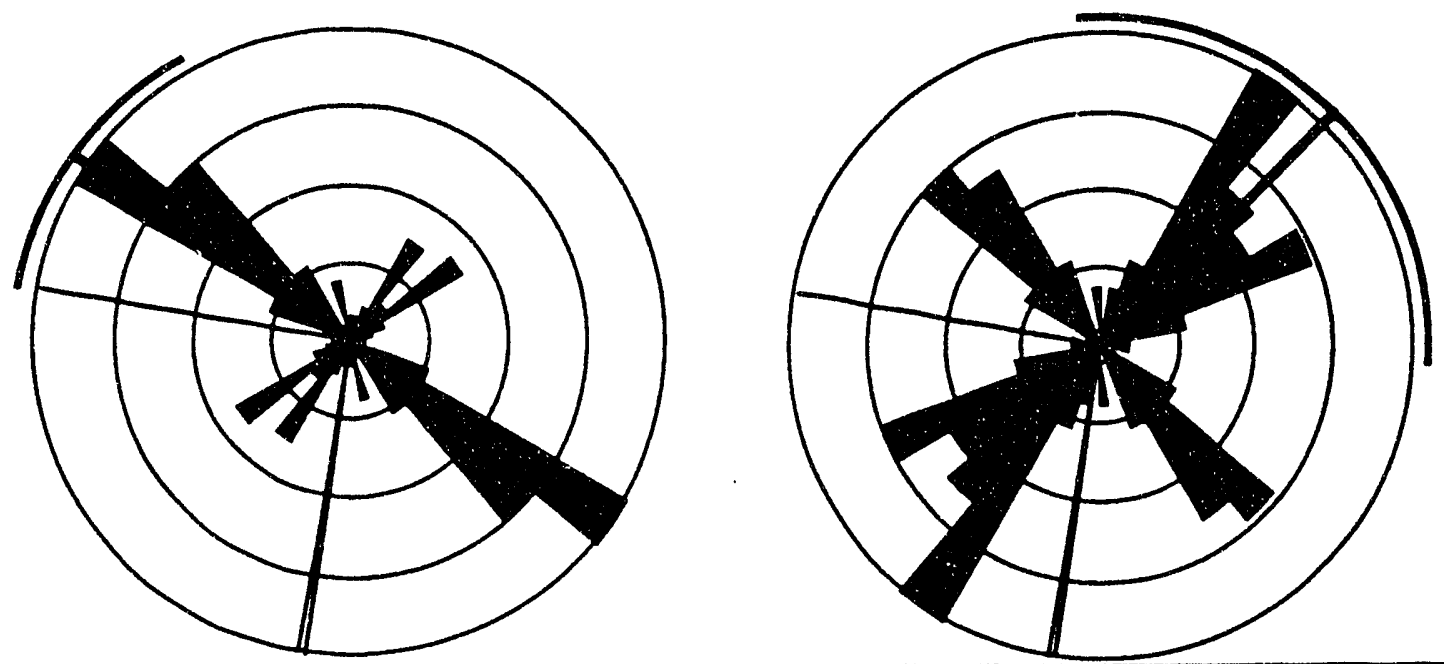

H-TCH,TD fract.plot

$\mathrm{N}=105$ Cumulative Length $=0.0$

Class Interval $=10$ degrees

Maximum Percentage $=25.7$

Mean Percentage $=6.67$

Standard Deviation $=7.01$

Vector Mean $=304.3$

Conf. Angle $=25.19$

H.TF\&TF,TCH

$\mathrm{N}=66 \quad$ Cumulative Length $=0.0$

Class Interval $=10$ degrees

Maximum Percentage $=16.7$

Mean Percentage $=6.67$

Standard Deviation $=4.70$

Vector Mean $=44.8$

Cont. Angle $=48.59$

Figure 2.58 - Rose diagrams of fracture orientations and related statistics for three major sandstone layers in outcrop H ( Tidal Channel and Tidal Delta; Tidal Flat and Tidal Channel; Flood Tidal Delta. Tidal Inlet, and Tidal Channel facies stacked in stratigraphically ascending order). 

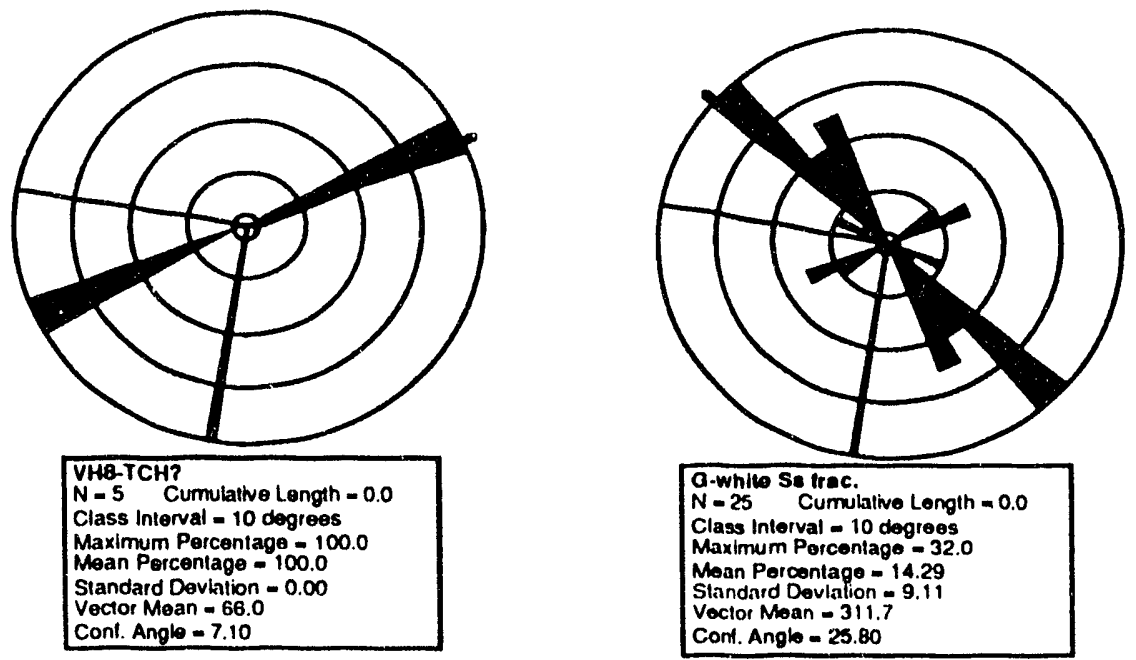

Figure 2.59 - (a) Rose diagram of fracture orientations and related statistics in outcrop VH8 (Van Horn art.a).(b) Rose diagram of fracture orientations and related statistics in "White Sands" overlying bar G in outcrop G.
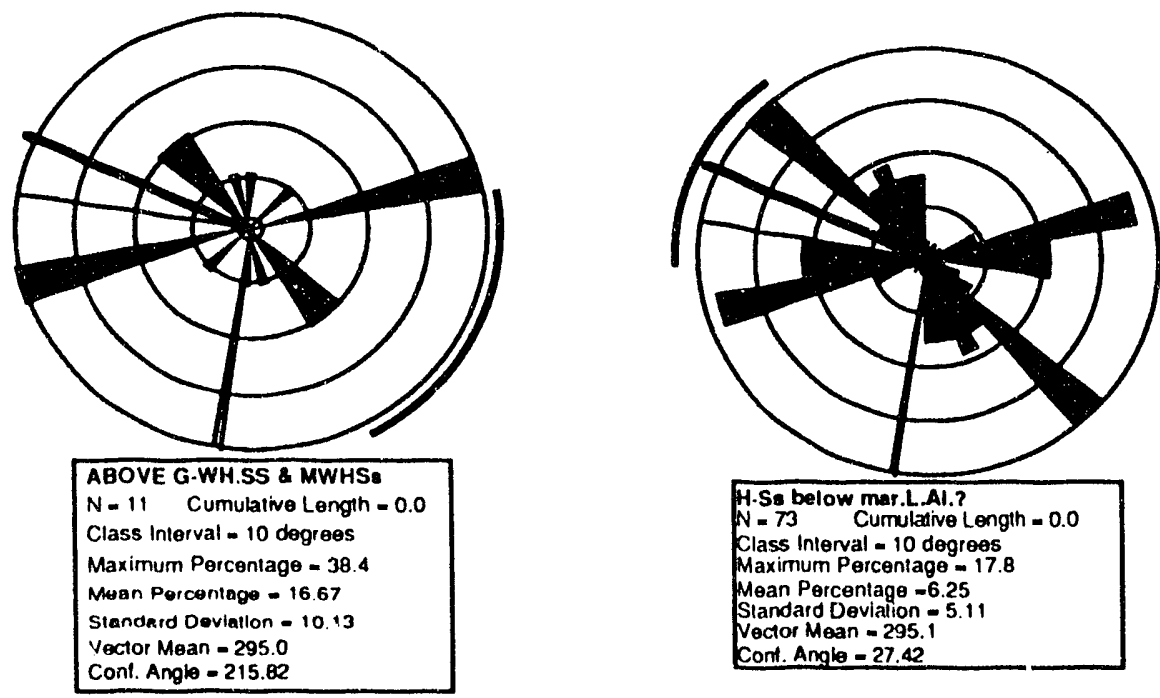

Figure 2.60 - (a) Rose diagram of fracture orientations and related statistics in outcrops "White Sands 2" and "Major White Sands" northeast and north of outcrop G. (b) Rose diagram of fracture orientations and related statistics in sandstones underlying marine sequence of the Upper Almond in outcrop $\mathrm{H}$. 


\section{Chapter 3}

\section{SIMILARITIES AND DIFFERENCES AMONG VARIOUS SIIORELINE BARRIER SYSTEMS (TASKS 1 AND 2.)}

\section{COMPARISON OF FACIES GEOMETRY AND DIMENSIONS FROM OTHER SHORELINE. BARRIER DEPOSITS REPORTED IN THE LITERATURE}

Common geometries (shapes) and dimensions of seven major potentially productive tide related facies in recent and ancient mesotidal shoreline barrier systems were compiled from several sources of literature and from ficld observations. Results are illustrated in table 3.1. Volumetrically, the shoreface and foreshore facies of mesotidal-formed barrier islands are the dominate facies in the system. The sand bodies in these facies have the largest average lengths ( 2 to $12 \mathrm{mi}$.), significant widths (0.6 to 4 mi.) and one of greatest thicknesses (12 to 90 ft). The major barrier island facies are typ cally deposited in a high energy environment and repre ient good to excellent petrophysical parameters.

The second largest sand bodics are deposited as tidal delas on the marint: side (ebb tidal delta) and on the lagoonal side (flood tidal delta) of the tidal inlet which cut a barricr island perpendicular to the shorcline. Ebb tidal deltas tend to dominate volumetrically over flood tidal deltas, ir particular when shoals are attached to them. Shoreface, shoal, and ebs tidal drltas, if preserved, may form continuous, and the most $\mathrm{x}$ ensive, sand bodics in a whole shoreline barricr system. The potential for accumulating large amounts of fluids in such a system is excellent. In transgressive sequences, however, the preservation potential of these facies is relatively low.

Tidal channels are deep erosional features and typically become filled with coarsening upward material deposited by strong currents and originating from redeposited marine facies. Preservation potential and original petrophysical properties of tidal channel deposits are very good. They form convergent, linear sandbodies and may become excellent oil reservoirs. Volumetrically the tidal channels rank third in the tide dominated mesotidal shoreline barrier system.

Washovers and spits are genetically associated with barrier island core and typically possess good petrophysical parameters. However, their volumetric capacity to accumulate and transmit fluids is limited. Also, they are generally thin bedded which may decrease vertical permeability.

Comparatively, the tide related facies of the Upper Almond Formation in Patrick Draw ficld (UA-5 and UA-6 sandstones) and those studied in outcrops located on the southeast flank of the Rock Springs Uplift (UA-1, 2, 3 sandstones) fall within typical dimensional limits for corresponding mesotidal facies described in the litcrature.

\author{
COMPARISON OF THE (BEOLOGICAL \\ MODELS AND ATTRIBUTES OF \\ PATRICK DRAW AND BELL CREEK FIELDS
}

\author{
Comparison of the Cieneral Models for \\ Microtidal and Mesotidal Eacies Architecture
}

Barricr shorelines commonly form along low lying coasts with an abundant supply of sediments that are reworked by waves and longshore currents (Hayes, 1979; Hayes and Kana, 1976). Barricrs are often associated with and located downdrift from deltaic depocenters. The morphology of the shoreline barricrs changes in response to the interaction of tidal range and wave energy effects. Hayes (1979) has shown that coastal plain shorclines with medium wave energy (wave heights of $6010150 \mathrm{~cm}$ ) exhibit distinct differences in morphology in ascas with different tidal ranges (microtidal and mesotidal). Becausc tidal range may be magnified toward the head of a coastal embayment (such as the Rock Springs Embayment), and because areas with greater wave energies require more tidal range to produce mesotidal sediment packages than areas with less wave energy, coastlines with microtidal (wave dominated) and mesotidal (tide dominated) barricr island types may be in close geographical proximity to one another. Barrier shorelines do not form under macrotidal conditions, i.c., greater than $4 \mathrm{~m}$ tidal range (King, 1972).

The general morphological differences between shoreline barriers developed under microtidal and mesotidal conditions is shown in figure 1.1. The characteristic differer. os between these two end members of barricr deposition are summarized in table 3.2 and include:

a. Barriers that form on microtidal coasts are long (not interrupied by abundant inlets), linear, and have a predominance of storm washover features that connect the shoreface with the back barrier and lagoon.

b. Barriers that form on mesotidal coasts are short and often "drumstick" shaped. These barrier islands are separated by abundant tidal inlets, and tidal deltas (both flood and cbb) are much more important.

Based on study of barrier islands on the east coast of the United States, Hayes and Kana (1976) determined that sedimentary deposits related to migrating tidal inlets can make up 30 to $50 \%$ of the sediments deposited in the barrier island compiex. The principal sand units involved include flood-tidal deltas, cbb-tidal deltas, and the recurved spit-inlet fill sediments associated with inlet migration. Hayes (1979) and Hayes and Kana (1976) showed that the large cbb-tidal deltas common to mesotidal barrier coasts play an important role in shaping the morphology of the adjacent barrier islands by storing large volumes of sand which 
become available to the island and by strongly influencing wave-refraction patterns. Hayes (1979) also noted that in areas of low wave energy $(<60 \mathrm{~cm}$ wave height), smaller tidal ranges are required to produce tide-dominated morphology than on medium energy wave coasts. Coasts with higher wave energy (heights $>150 \mathrm{~cm}$ ) required larger tidal ranges in order to produce a tide-dominated morphology.

Fixed inlet positions are generally related to preexisting depressions such as flooded river valleys. However, the importance of tidal inlet migration on facies architecture of mesotidal barriers is profound. As the inlet migrates gradually downdrift, or occasionally rapidly shifts some distance updip, associated new lobes of flood and ebb-tidal deltas move in the same direction and the old inlets arc closed. In the areas that have been abandoned by active tidal delta deposition, the flood tidal deposits are covered by lagoonal fines. On the scaward side of the barrier island, down drift migration of the inlet is also associated with development of new lobes of the typically large cbb tidal deltas. Migration of the inlet itself is generally related to dominantly erosional processes on the downdrift side and depositional process such as spit accretion on the updrift margin of the inlet.

The preservation potential is highest for facies deposited in relative low areas. Because the common lateral migration of tidal inlets along mesotidal coastlines often creates a large, elongate zone of dominated by multiple tidal delta and associated tidal channel fill deposits, these zones of back-barrier deposits may have high potential to berome petroleum reservoirs. It has been suggested that batriersheltered and barricr associated sardstones may predominate over barrier island facies on transgressive coastlines (Honarpour et al., 1989; Szpakicwic\% ol al., 1991). However, it is equally probable that at least some part of the large cbb-tidal deltas should be preserved and would provide equally good reservoirs.

\section{Comparison of Muddy Formation (Bell Creek) and Almond Formation (Patrick Draw) Shoreline Barrier Facies Architecture}

A chain of mesotidal barrier islands that formed along the western margin of the Rock Springs Embayment (southwestern Wyoming) are prescrved in the upper Almond Formation. The Rock Springs Embayment resulted from a major marine transgression and associated submergence of the coastal plain. Southward longshore migration of sands from the Red Desert Delta accumulated at the head of the cmbayment and provided the source for the barrier chain (Rochler, 1988). These shoreline barrier accumulations (UA-1 to UA-3) within the upper part of the Almond Formation are now exposed in oucrops of the Rock Springs Uplift and are analogous to stratigrapinically lower (but still upper Almond) shorcline barrier deposits (UA-5) of Patrick Draw ficld iocated only about 8 miles cast of the nearcst Almond outcrops.
Rochler $(1979,1988)$ studied upper Almond barrier bar RG in the outcrops of the Rock Springs Uplift. He concluded that barrier bar RG exhibited classical mesotidal origin characteristics including: bar RG islands that are 5 to 7 miles long, islands that are roughly drumstick-shaped, washover fans that are present but not common, tidal inlets that are numerous, flood-tidal deltas that are large-as wide as several miles, and ebb-tidal deltas are moderately large to small.

Various depositional processes were responsible for shaping different facies within barrier bar RG. Wave and along-shore currents deposited berm, foreshore and upper shoreface, middle shoreface, and lower shoreface facies. Acolian (wind) processes deposited dunes above the level of high tides. Tidal current processes were dominant in ebband flood-tidal delta sedimentation as well as that of tidal flats. Storms created washover fans where sand from the more seaward portions of the barriers were pushed over the barricrs onto the backbarricr tidal flats and into the lagoon.

The sandstone unit that Rochler (1988) called barrier bar $\mathrm{RG}$ is part of a generally north trending shoreline deposit that is lenticular in cross section, more than 60 miles long, has a maximum thickness of $95 \mathrm{ft}$, and is about 3.5 miles wide. It is subdivided into tidal channel, tidal inlet, tidal delta, dune, washover fan, and shoreface facies. The palcogeographic map of barricr bar RG (fig. 3.1) is equally well representative of the depositional setting for Almond Formation stratigraphic horizon UA-5 as preserved at Patrick Draw ficld.

The main oil productive sandstone at Patrick Draw field is the UA-5 sandstone which has been interpreted as a prograding barrier shoreline sand that was deposited in a mesotidal regime (Jacka, 1970; Irwin, 1976). The UA-5 sandstone ranges in thickness from 0 to is more than $30 \mathrm{ft}$ within Patrick Draw field. The reservoir quality UA-5 sandstone extends over an area at least 20 miles long and 6 to 8 miles wide. Within the lower part of the stratigraphic interval (UA-5B) the sand is divisible into at least two bars in Arch Unit which are separated by a generally north-south oriented low permeability zone. The two bars are nearly separate reservoirs with different oil-water contacts and one bar has a gas cap while the other does not. The permeability barrier between the two bars is a depo vitionally-controlled heterogencity consisting of oyster coquina layers, carbonaceous shale, and impermeable sandstonc of probable lagoonal origin. In Patrick Draw field low permeability zones ( $<30 \mathrm{md}$ ) in otherwise good quality sandstones are created by dolomite cementation, calcite cementation, scams of clay matrix, zones where leached, collapsed remnants of mineral grains block pore throats, and by compaction (Szpakiewicz et al., 1991).

By examination of outcrop and reservoir cores it was determined that tidal inlet, tidal channel, and tidal delta depositional facies dominate within stratigraphic interval UA-5 at Patrick Draw ficld in contrast to the dominant shoreface and foreshore facies at Bell Creck field.

The depositional setting for the Muddy Formation at Bell Creek field (Powder River Basin, MT) and analogous 
Muddy Formation outcrops was that of a microtidal shoreline barrier which was syndepositionally and postdepositionally modified by valley cut and fill processes. The depositional model, (fig. 3.2) shows the relationship between the barrier-related facies and their incision by a valley cut. Foreshore and shoreface (supratidal, intertidal, and subtidal) facies not only have the best preservation potential, but comprise most of the producing barrier island sandstone interval. At Bell Creck field stacking of barrier sequences resulted from relative sca level drops (regressions) and sea level rises (transgression). During periods of regression, older barrier island sequences were partially eroded. During subsequent transgression, additional barrier island sequences were deposited over the remnants of older ones. Erosion of older barriers was partial to complete, sometimes extending below the base of the barrier sandstone. The crosion of significant portions of the barricr thickness strongly affected its storage capacity and transmissivity. Complete hydraulic disconnection was noted at Bell Creek field between Units 'A' and 'B'.

Based on cutcrop and core study there is evidence for two periods of valley incision during late Muddy deposition: an earlier stage affected, generally, only barrier island deposits, and a later stage, that affected barrier island and earlier valley fill deposits. It was also determined that outcrop information facies distribution patterns, stacking patterns, and continuity of sandstone units could be applied to the subsurface in Unit 'A' of Belı Creek field (Honarpour et al., 1989).

Reservoir quality and productivity potential of barrier island sediments coincided with patterns of vertical stacking of facies, changes in barrier thickness due to erosion, and the range of permeability values in the productive facies. It was therefore concluded that depositional features provided the predominant control of reservoir performance at Bell Creek. A similar picture is emerging for Patrick Draw field; however, at Patrick Draw it appears that the smaller scale of lateral variations is more important.

The erosional disconformity between the barrier sandstont: and overlying valley fill deposits is often not identifiable on logs. Separation of these two genetic units is almost impossible on the hasis of a SP log alone. Gamma ray logs help to define the lithological variations more closely and the sonic logs help to locate the contact based on porosity changes. It is particularly important to distinguish these two genetic units in a field such as Bell Creck because the initial production rate potential in Unit ' $\mathrm{A}$ ' is largely controlled by the distribution of barrier facies. The location of valley cuts form hydraulically isolated units and reduce production over the distance of one well spacing $(1,320 \mathrm{ft})$.

Foreshore, middle shoreface, and upper shoreface facies may be grouped together in the microtidal type of rescrvoir at Bell Creek because they contain similar reservoir properties. These facies have the highest reservoir quality and comprise most of the reservoir. The lower shoreface facies had distinct sedimentological and inferior reservoir quality characteristics. Paralic facies including washover, lagoon, estuarine, tidal channel, and tidal dela exhibit variable reservoir quality, with the washover facies having the best reservoir quality from this group, but a limited volumetric importance. The overlying valley fill deposits consist of both reservoir and nonreservoir quality sediments, but typically they are poorer reservoir quality facies.

Based on outcrop and subsurface studies it was found (Jackson et al., 1991) that while calcite cemented zones could be traced lateially for thousands of feet in an outcrop, no such zones were identified within the reservoir at Bell Creek. Additionally, no tight clay-cemented zones were recognized in the outcrop, while in the reservoir such zones affect the entire reservoir section and vary over lateral distances of about $1,500 \mathrm{ft}$.

In the construction of the flow unit model for the Tertiary Incentive Project (TIP) area in Unit ' $\mathrm{A}$ ' at Bell Creek ficld, layers were subdivided laterally based on the average permeabilities and porosities at each well. The resulting model is one of a mosaic of flow unit blocks where lateral changes generally correspond to fault locations and to diagenetic clay content.

Variogram analysis of average permeability per well at Bell Creek indicates an isotropic, nested pattern consisting of two ranges of corrclation lengths: 0.25 miles and 1.5 to 2.5 miles. The shorter range is nearly equal to the distance between wells and reflects permeability variations within the flow unit (Jackson et al., 1991).

The longer range is on the order of the width of the sandstone body in Unit ' $A$ '. This correlation range is consistent with the outcrop permeability variation observed, where similar meon permeability and vertical profiles extend over at least 1.5 miles. These observations led Jackson et al. 1991) to conclude that:

a. The greatest variability of permeability on the interwell scale occurred laterally on a scale of 0.25 miles, and was controlled by structural and diagenetic processes that, in places, significantly modified the depositionally related permeability pattern. The unmodified depositional pattern and and relatec. production characteristics can extend (in this type of a system) lateraily on the order of a few miles.

b. Two ranges of correlation length from variogram analysis appear to represent features resulting from diagenetic processes (shorter range) and depositional processes of barrier island formation and subsequent erosion by fluvial processes (longer range).

\section{Comparison of Almond Formation and Muddy Formation. Surface and Subsurface Sandstone Mineralogy and Petrography}

Quantitative XRD mineralogical analysis of Muddy Formation samples is presented in table 3.3. Individual barrier lacies cannot be distinguished by either framework mineralogy or clay content alone. The high quart\% content of Muddy Formation barrier sandstones from Bell Creek 
reservoir (average $=89 \%$ ) contrast with the generally lower quartz content of reservoir sandstones from Patrick Draw ficld (average $=75.8 \%$ ), but have similar quart $z$ content as the Almond outcrop samples (average $=89 \%$ ). Muddy Formation valley fill facies also have a higher quart/. content (average $=92 \%)$ than do Almond sandstones.

$X$-ray diffraction analysis of Muddy Formation barricr island and valley fill sandstones from the subsurface and analogous outcrops revealed different clay assemblages. Within the barrier island sandstones the clays generally exhibit a 2:1 ratio between kaolinite and illite and comprise less than $15 \%$ by weight. In valley fill sandstones and mudstones, smectite and kaolinite dominate the clay assemblage.

Reservoir sandstones from Patrick Draw are dominated by kaolinite clay and lesser amounts of illite and mixed layered illite/smectite (table 3.4). The ratio of kaolinite to illite plus illite/smectitc ranges from $1: 1$ to as much as $4: 1$. Data from outcrop samples indicate a general kaolinite to illite ratio of about $1: 1$ and a complete absence in the analyzed data of evidence for mixed-layered illite/smectite. The greatest mincralogical difference between the Muddy and Almond Formation samples analyzed is the abundance of smectite in Muddy valley fill facies, and its near absence in any of the Almond facies. Analysis of a limited number of thin sections indicates that kaolinite clay cement tends to be more common in Patrick Draw reservoir sandstones than is clay matrix. In both Muddy and Almond rescrvoir sandstones the presence of diagenetic kaolinite appears to be derived from the decomposition of feldspars and other lessstable grain such as rock fragments. In the Muddy Formation samples, chert is the most common surviving lithic fragment, and $\mathrm{K}$-feldspars are virtually the only type of feldspar represented, accounting for no more than 2 to $3 \%$ of the total rock volume. In Almond reservoir sandstones chert, organic fragments, as well as sedimentary, volcanic, and metamorphic rock fragments are present. Pclitic (clay-rich) rock fragments are common in Almond rescrvoir sandstones. Plagiociasc and K-feldspars are present in about cqual proportions in Almond reservoir sandstones and outcrop samples analyzed, comprising on average $5 \%$ of reservoir sandstones and $7 \%$ of outcrop sandstones, or more than twice the amount found in Muddy Formation sandstones.

When the essential framework components of sandstones are recalculated $1010(0 \%$ and plotted on a quartz-feldsparrock fragments (Q-F-R) diagram (fig. 3.3) comparison between Almond and Muddy Formalion shoreline barricr sandstones become apparent. The Q-F-R ficlds for Almond reservoir sandsioncs and Muddy reservoir sandstones do not overlap becausc Almond reservoir sandstones generally have less quarty content than those from the Muddy Formation. Becausc of these compositional differences, Almond reservoir sandstones tend to be sublitharenites, litharenites, and feldspathic litharenites while the inuddy reservoir sandstores tend to be sublitharenites, subarkoses, and some quartarenilcs.
The quarzose nature of Muddy reservoir sandstones contrasts with the somewhat less quartzose but low feldspathic outcrop Muddy sandstones. Subsurface Almond andstones tend to have a higher average quart. content than the outcrop Almond sandstones, although the data set of outcropping Almond sandstones is very small. Based on the data in figure 3.3 it appears that average Almond outcrop sandstones have a higher feldspar content than many Almond reservoir sandstones and a higher feldspar content than virtually all Muddy outcrop sandstones.

The diagenetic history of both the Almond and Muddy marine reservoir sandstones is complex. Nine stages have been recognized in the Almond Formation (Keighin et al, 1989). The Almond reservoir rocks are typically fine to very fine-grained and contain an appreciable amount of unstable rock fragmenis such as chert and shale as well as carbonate. Eight paragenetic stages have been recognized in Muddy reservoir sandstones (table 3.5 ). The fine to very fine-grained Muddy reservoir sandstones also contain some chert rock fragments; however, petrographic analysis has indicated that most sedimentary rock fragments have been removed by dissolution (Szpakicwic\% et al., 1989) often resulting in oversized pores. Carbonate minerals are extremely rare in the Muddy reservoir rocks, probably having been removed by the same strong carly diagenetic stage of dissolution that leached rock fragments and produced the oversize pores. The relative increase in sedimentary rock fragments, particularly those of shale, tend to make the Almond Formation more susceptible to compaction with attendant decreases in porosity and permeability (Keighin el al., 1989). The Mudd" Formation, in contrast contains relatively few finc-grained rock fragments; however, the distribution and crystallographic habits of kaolinite and illite (in the Almond Formation) and dominantly of kaolinite (in the Muddy Formation) makes both barrier reservoirs sensitive to the migration of fines during completion and production (Priisholm et al., 1987, Honarpour et al. 1989, Keighin et al., 1989).

In both rescrvoirs early stage lcaching was important with respect to modifications of the pore system which in turn has a strong control on the petrophysical properties of the reservoirs. At Bell Creck early leaching may have been the dominant process controlling petrophysical properties within much of the reservoir. At Patrick Draw field the reservoir rocks were subjected to less intense leaching than the Muddy Formation. The effects of early leaching at Patrick Draw appear to have been a limited dissolution of feldspars, chert, and shale grains, often resulting in the creation of microporosity. In the Muddy Formation reservoir at Bell ${ }^{\circ}$ ieck virtually all diagenetic stages subsequent to =arly stage leaching affected the evolution of the rock in a potentially negative manner. Although early leaching was important to the evolution of petrophysical propertics of the Almond reservoir at Patrick. Draw, the process was not so intense as at Bell Creck. The subscquent porosity-reducing diagenctic stages, particularly compaction, cementation by calcite, dolomite, and ankerite, 
porosities that are similar, although there is a shift in equivalent outcrop facies to higher porosity values (Honarpour et al., 1989). Distribution of porosity data from the Almond Formation (fig. 3.13) also shows a shift to higher porosity values for outcrop samples, but the difference between outcrop and subsurface values for comparable facies is generally much greater for Almond facies.

Scatter plots show more clearly the differences in distribution between Muddy and Almond Formation porosity and permeability. The porosity versus permeability scatter piot for the Muddy Formation (fig. 3.14) indicates thii for a given permeability the outcrop data are more porous, and this relationship has been demonstrated on a facies basis (see fig. 60 of Honarpour et al., 1989). In contrast, although the outcrop data generally have greater porosity values, the perosity versus permeability scatter plot for the Almond Formition (fig. $3.15)$ shows that a more clear-cut distinction is between the greater permeability of outcrop samples relative to subsurface samples. If one contrasts the distribution of outcrop and subsurface permeability for the Almond (fig. 3.16) and for the Muddy Formations (fig. 3.17), the similarity of Muddy mean permeabilities for equivalent facies can also be seen to contrast with dissimilar mean permeabilities for equivalent outcrop and subsurface facies in the Almond. Probable reasons for these differences may be duc to sampling, to different processes having affected the sandstones, or to the possibility of different sources for the sandstones.

Scatter plots of permeability versus mean grain size for outcrop and subsurface facies in the Almond Formation (figs. 3.18 and 3.19) suggest a trend (not statistically significant), but with a very low slope. Strongly cemented samples are clearly distinguished on these crossplots, as their points lie far below the rest of the data. Although the small data set makes it unwise to over-interpret these scatter plots, two groups of Almond facies seem to be present: first, the finer grained and slightly less permeable tidal creek and tidal flat facies, secondly, the coarser grained and slightly more permeable tidal channel and tidal delta facies. It should be noted that the very low slope of the visual trend of data in figures 3.18 and 3.19 with outcrop data clustcring around $400 \mathrm{mD}(\operatorname{lnk}=6)$ and subsurface facies clustering around $55 \mathrm{mD}$ (Ink = 4) may indicate near independence between the two parameters. Additional sampling and analysis appear to be necessary in order to make more definitive conclusions about the relationship between permeability and mean grain size in the Almond Formation. Straight forward relationships between permeability and mean grain size at the time of deposition may have becn obscured by compaction and the relative cflects duc to ductile sedimentary rock fragments, to variable amounts of cementation by carbonates or clays, to selective leaching or removal of grains, or to any process that would change the size and number of permeabilitycontrolling pore throats.
Scatter plots of permeability versus mean grain size for outcrop and subsurface facies in the Muddy Formation (figs. $3.20 \& 3.21$ ) also exhibit visual (not statistically significant) trends. However, in the Muddy Formation the slope of the visual trend is much steeper, indicating that large increases in permeability are associated with modest. increases in mean grain size. The transition facies in outcrop is finer grained and has very low permeability, while foreshore and middle shorcface facies have increased permeability and are somewhat coarser grained. Muddy subsurface data show much the same relationship between permeability and mean grain size. In the subsurface, valley fill and transition facies have low permeabilities and are slightly finer grained while foreshore, middle shoreface and upper shoreface facies are significantly more permeable and show a tendency to be slightly coarser grained. Both outcropping and subsurface middle shoreface samples showed a wide range of permeability values in the Muddy Formation.

Porosity and mean grain size relationships are also different for samples from the two formations. The wide range of porosity in Muddy outcrop facies (fig. 3.22) is associated with relatively little change in mean grain size (from about 100 to 150 microns) indicating a general independence of the two parameters. Almond outcrop facies in contrast can be divicied into two general facies associations based on the relationship between porosity and mean grain size. The first group, including tidal creek, middle shoreface, and tidal channel facies (fig. 3.23) is clearly finer grained and somewhat less porous; the second group, including tidal swash bar, oyster bed, and tidal delta facies is slightly more porous (for examined samples) and is definitcly more coarse grained.

Subsurface Muddy Formation data show a well defined visual trend (but still not statistically significant) between porosily and mean grain size (fig. 3.24) where valley fill and transition facies are finer grained and less porous than middle shoreface, upper shoreface, and foreshore facies Once again, lower shoreface porosity values are widely divergent. Almond subsurface data (fig. 3.25) are poorly organized, and on a facies basis, although tidal flat and tidal creck facies tend to be finer grained and less porous, tidal delta and tidal channel facies show a tendency to be coarser grained and more porous.

\section{COMPARISON OF THE PRODUCTION/INJECTION PERFORMANCE ATTRIBUTES OF PATRICK DRAW AND BELL CREEK FIELDS}

\section{Comparison of Initial Oil Production in Bell Creek (MT) and Patrick Draw (WY) Fields}

Comparison of initial oil production (IP) from the Lower Cretaceous Muddy Formation marine shoreline barrier sandstones deposited in a microtidal environment at Bell Creck ficld (Jackson et al.,1991) with the Upper Cretaceous Almond Formation, mostly mesotidal back barrier 
sandstones at Patrick Draw field (fig. 3.26), reveals somewhat similar productivity potential for the $t w 0$ subsystems of the shoreline barricr type deposits. Geological characteristics of the two reservoirs such as stratigraphy and depositional architecture of reservoir and non-reservoir units (facies assemblages and their continuity) are, however, very different (Szpakiewicz et al., 1989). Because of these differences it is quite possible that the similarity of IP between the two shoreline barrier reservoirs may be purely coincidental, or at least not related to the depositional system. Permeability contrasts also are very high (hundreds and thousands of millidarcics in Bell Creek versus tens up to 150 millidarcics in Patrick Draw) mostly due to varied diagenetic effects. A reason for such high initial production in Patrick Draw ficld (greater than 1,500 BOPD from a few wells and greater than 700 BOPD in numerous wells) despite the rather unfavorable geological and petrophysical properties can partially be attributed to high initial formation pressure (about 1,900 psi vs.1,200 psi in Bell Creek) which caused high fluid flow to production wells.

Bell Creck reservoir appears to have been underpressured while the Patrick Draw reservoir was near hydrostatic pressure at the initial stage of hydrocarbon production. The two reservoirs also differ in hydrocarbon gas content. Litule gas has been produced from Bell Creck field, and gas caps were virtually non-existent except in Unit C. At Patrick Draw ficld, however, an extensive gas cap is present above the major oil producing horizons (UA-5 and UA-6 sandstones). Some wells produce oil and gas while others produce only a single hydrocarbon phase. This may indicate horizontal compartmentalization of fluids. Little water is being produced in Patrick Draw ficld, and its salinity and ionic composition vary greatly across the field, once again indicating poor horizontal communication between updip and downdip portions of the reservoir. These and other features differ between the Bell Creek and Patrick Draw reservoir systems. As yet it is unclear which features are common (inherited from the environment of deposition) and which are unique, resulting from unrclated postdepositional processes.

\section{Comparison of Lniection and Secondary Production Performance of Bell Creek and Patrick Draw Fields}

\section{Injection Performance}

Table 3.6 compares the basic reservoir propertics of the Bell Creck and Patrick ficlds, including basic data, OOIP, primary and secondary recoverics. In general, Bell Creck ficld has higher permeability and porosity, and lower water saluration than that in Patrick Draw ficld.

The 5-spot flood pattern is the dominant one used in the Arch Unit while the line drive is used in Bell Creek Unit 'A'. Hall plot analvsis was used to analyze the water injection wells in Bell Creek (Tertiary Incentive Project, known as TIP, area) and Arch Unit of Patrick Draw field.
Overall, the Bell Creck TIP area has a better water injectivity than that of the Arch Unit. The average Hall plot slope for Bell Creck (TIP area) and Paurick Draw (Arch Unit) is 1 and $25 \mathrm{psi}$-day/bbl, respectively; water injection $\left(k_{w} h\right)$ is 2,328 and 155 md-ft, respectively (Szpakiewicz ct al., 1991). Thus water injectivity is significantly better in Bell Creck than Patrick Draw field. However, both fields display significantly lower water relative permeability than oil relative permeability based on core flood tests and injection well data analysis. Water relative permeability $\left(k_{r w}\right)$ at residual oil saturation $\left(S_{\mathrm{Or}}\right)$ of the Bell Creek (TIP area) and Patrick Draw is 0.064 and 0.035 , respectively. From Hall plot analysis of the water injection data of both ficlds, the calculated water relative permeability is 0.066 and 0.138 . The water injectors surrounding the well no. 1 CPC 12 B-19 of section 19 in the Arch Unit where a core sample was taken to measure oil and water relative permeability have calculated $k_{r w}$ values in the neighborhood of 0.035 , showing a good agreement between laboratory measured $k_{r w}$ and actual field injection $k_{r w}$. Because of the high absolute permeability in Bell Creck field (in the Darcy range), the much lower $\mathrm{k}_{\mathrm{rw}}$ did not affect the water injectivity. On the other hand, at Patrick Draw field, which has a much lower average permeability of 36 md, a significantly lower $k_{r w}$ led to poor water injectivity. The significantly lower $k_{r w}$ in the Bell Creck (TIP area) is due to the local presence of high clay content. The cause of the much lower permeability in the Arch Unit of Patrick Draw ficld is not clear but, at this point, may be ascribed to some combination of formation damage, percent clay content, or the presence of a different type of pore and throat system than at Bell Creck ficld.

\section{Secondary Production Performance}

Table 3.6 also shows the recovery figures for the Arch and Moncll Units of the Patrick Draw field and the Unit 'A' of the Bell Creck ficld. The average secondary recovery for the Patrick Draw and Bell Creek Unit 'A' is 13 and $37 \%$, respectively. Thus waterflood oil recovery in Bell Creck was almost 2.5 times more than in the Patrick Draw field. The main reasons are due to the much higher permeability and lower heterogeneity in the former field. Recall that both ficlds have about the same primary oil recovery of around $18 \%$. Also, the low relative permeability to water in Arch Unit has resulted in poor water injectivity and possible channeling effects have subsequently caused low waterlood oil recovery. Other factors that may have increased reservoir heterogeneity, and thus decreased secondary production performance in the Arch Unit, may include poor reservoir continuity in this part of the field and the presence of faults, fractures, and coals that may be responsible for channcling. 


\section{SUMMARY OF THE SIMILARITIES AND DIFFERENCES BETWEEN BELL CREEK AND PATRICK DRAW SHORELINE BARRIER RESERVOIRS}

The most important geological and reservoir similaritics and differences between Bell Creek and Patrick Draw reservoir may be summarized in the following lists:

Differences:

1. Type of shoreline barrier

- Bell Crcck, microtidal

- Patrick Draw, mesotidal

2. Dominant productive facies

- Bell Creek, coastal marine (shorcface, forcshore)

- Patrick Draw, brackish marine (tidal channel, tidal delta, inlet)

3. Secondary productive facies

- Bell Creck, brackish marine valley fili

- Patrick Draw, coastal marinc

4. Stratigraphic scquence

- Bell Creck, brackish marine valley fills commonly overly marine facies

- Patrick Draw, tidal inlet erosive cuts underlic marine facies fill

5. Diagenesis

- Shcll layers common at Patrick Draw, absent at Bcll Creck

- Shell layers probably provided abundant source for calcite cement at Patrick Draw

- Oversizc porcs created by strong leaching present at Bell Creck, absent at Patrick Draw

6. Early stage leaching was intense at Bell Creck, providing a major improvement of peirophysical properties. Early stage lcaching was relatively insignificant at Patrick Draw, but later stagc cementation by carbonates and clays significantly degraded the petrophysical propertics.

7. Porosily averages

$\begin{array}{lll}\text { - Bell Creck } & \text { Unit 'A' } & 28.5 \% \\ \text {-Patrick Draw } & \text { Arch Unit } & 19.6 \% \\ & \text { Moncll Unit } & 19.7 \%\end{array}$

8. Permcability averages

$\begin{array}{lll}\text { - Bcll Crcck } & \text { Unit 'A' } & 2,25() \mathrm{md} \\ \text { - Patrick Draw } & \text { Arch Unit } & 36 \mathrm{md}\end{array}$

9. Gas cap

Moncll Unit 36 md

- Bell Creck, absent or of sccondary importance

- Patrick Draw, present

10. EOR projects

- Bell Crcek, compjlctcd

- Patrick Draw, planned

11. Incremental production due to waterllood operations was much less at Patrick Draw (Arch Unit) than at the TIP area of Bell Creck ficld, Unit 'A'.

12. The lithologies of the reservoir quality sandstones are different between the two reservoirs. Bell Creck sandstones are more quart\%ose, consisting dominantly of sublitharenites, subarkoses, and some quartz arenites. In contrast Patrick Draw reservoir sandstones consist dominantly of litharenites, feldspathic litharenites, and some sublitharenites.

13. Scale of major depositional heterogeneities - Bcll Crcek, large (thousands of $\mathrm{ft}$ along strike)

- Patrick Draw, smaller (tens to hundreds of $\mathrm{ft}$ common)

14. Of the several factors that influence productivity, only sandstone thickness, geometry, and continuity appear to be related to the deposystem. Grouping of petrophysical properties, drainage area, type of produced fluids and their relative permeability, reservoir pressure, and reservoir boundaries are to a large part site specific.

Similarities:

1. Large recoverable oil resources

2. Location in intermontane basins

3. Cretaceous age and comparable depth of occurrence

4. Typical stratigraphic traps

5. Reservoirs represent typical end members of a shoreline barrier system deposited under medium wave energy conditions

- Bell Creck, microtidal facies architecture

- Patrick Draw, mesotidal facies architecture

6. Both shoreline barrier seltings comprise marine barrier, and barrier associated depositional facies which have been modified by syndepositional and postdepositional processes, and probably are associated with with nearby deltaic systems

7. Both reservoir systems are compartmentalized: Bcll Crcck ficld into 6 major units and Patrick Draw field into at least 3 major units

8. Horizontal continuity of sandstone bodies is good within production units of both reservoirs

9. The limits of production in both reservoirs do not extend to the limits of all the known shoreline barricr sandstones

10. Faults play an important role in both reservoirs and probably are responsible for significant geochemical anomalies and possible hydrodynamic communication with another reservoir or aquifer

11. Pay thicknesses are comparable: $22.9 \mathrm{ft}$ in Bell Creck, and $20 \mathrm{ft}$ in Arch and Monell Units of Patrick Draw

12. Oil gravity is comparable in both cases: $32.5^{\circ}$ API in Bell Creck (range 31.5 to $40^{\circ} \mathrm{API}$ ) and $42^{\circ} \mathrm{API}$ in Arch and Moncll Units of Patrick Draw ficld

13. Although the coarsest grained Almond sandstones are somewhat coarser grained than those in the Muddy Formation, the overall grain size range for barricr and barricr associated 
sandstones from both formations is similar and consists of fine to very-fine graincd sandstone.

14. Initial production (IP) rates for both reservoirs are similar, although the IP rates may be related to different facies geometries and to different produced fluids (oil, gas-saturated oil, gas).

15 Initial production in both reservoirs appcars to be strongly influenced by the architecture of the depositional systems. Later production (cg. waterflood, EOR), however, appears to have been more closely controlled by heterogencitics other than those created by the depositional system or its microtidal vs. mesotidal varicties.

16. Later stages of production (post primary production) are dominantly controlled by heterogeneities other than those created by the depositional systcm.

\section{CONCLUSIONS}

In summary, the following conclusions can be made by examining sedimentological aspects, mineralogical composition, grain size, sorting, and diagenesis and comparing them with petrophysical properties and production/injection performance attributes of the Almond and Muddy Formations.

1. Comparison of the microtidal shoreline system of the Muddy Formation with the mesotidal shoreline barrier system of the Almond Formation on a facics basis is difficult because of the generally different suites of depositional facies recognized from each system. Nevertheless, because both systems are examples of end member types within the class of shoreline barricr reservoir settings, it is appropriate to compare and contrast the characteristic features of each of these types of shoreline barricrs.

Stratigraphic interval UA-5B at Patrick Draw field, which provides most of the production at this field, is sedimentologically analogous with the outcropping upper Almond barrier bar RG. These shoreline barricr deposits have a mesotidal type of facies architecture that is characterized by short barricr island segments that are scparated by abundant tidal inlets. Tidal inlet fill, tidal delta, and tidal channel/tidal creek deposits are all well represented at Patrick Draw and in the analogous outcrops. Lateral migration of the tidal inlets was the dominant process lcading to formation of a broad belt bchind the barrier that is dominated by tidal delta and tidal channel deposits. The dimensions of facies, both in the reservoir and in the outcrops, appear to fall within the limits of other mesotidal systems reported in the literature, which are generally smaller than for microtidal shoreline barrier systems.

The Muddy Formation at Bell Creek ficld is an example of a microtidal shoreline barrier. The barriers were elongate and not often broken by tidal inlets. Tidal deltas facies were not encountered in cores examined from Bell Creck ficld. The marine microtidal barricr (foreshore, and middle to upper shoreface facies which possess similar rescrvoir propertics) comprise the bulk of the elongate barricr deposits. Storm washover features are more prominent in the microtidal system. At Bell Creck field the washover facies often possess good petrophysical propertics, however, this facics is volumetrically insignificant and only locally important. In addition, the microtidal shoreline barricr setting at Bell Creck ficld was syndepositionally and postdepositionally modificd by valley cutting and deposition of generally low reservoir quality fill.

Variogram analysis of average permeability in the Niuddy Formation indicated two ranges of correlation length: a) a shorter ( 0.25 mile) distance representing features resulting from diagenetic processes, and b) a longer ( 1.5 to 2.5 milc) distance representing features created by depositional processes of barrier island formation and subsequent crosion by fluvial processes. Variogram analysis of the Almond Formation has not yet been completed, however, we have noted that it is often difficult or impossible physically to correlate depositional facies over distances of only a few tens of feet in the outcrop.

2. Grain size for Almond Formation depositional facies ranges from coarse silt to finc sand (30) to 22.5 microns) and mean grain size of outcrop samples is coarser than mean grain sizc of subsurface (UA-5) samples. Mean grain size for Muddy Formation depositional facies (95 to 150 microns) is similar to that of the Almond Formation. Grain size distributions in the Muddy Formation samples differ from those of the Almond in the following respects: they generally lack sands with mean grain size coarser than 150 microns, outcrop and subsurface distributions are very similar, marine facies have a generally narrower range of grain size, and mean grain size is very comparable for equivalent subsurface and outcrop facies.

3. Standard deviation of grain size (sorting) of corresponding Muddy outcrop and subsurface facies is similar. The range of sorting values of Muddy and Almond Formation samples overlap; however, Almond facies have a much larger range of sorting values than do Muddy lacies and sorting for equivalent Almond outcrop facies is consistently worse than for Almonci subsurface facies.

4. The differences in distribution of grain size and sorting between the Muddy and Almond Formations may be related to the different intensities of various processes (eg. tidal currents) which are reflected in different facies associations. The microtidal facies association of the Muddy Formation is dominated by forcshore, shoreface, and valley fill facics. In contrast, the mesotidal facies association in the Almond Formation is dominated by tidal facies including those of tidal channel, tidal delta, tidal inlet fill, and tidal creck origins. 
5. A good correlation has been found between sorting (standard deviation of grain size) and mean grain size for facies in both the Almond and Muddy Formations. The general trend of increased grain size with decreased sorting probably represents a fundamental relationship caused by availability of a wider range of grain sizes for the coarser samples. It should be remembered that the total range of mean grain size represented in combined Almond and Muddy shoreline barrier samples is only from 30 to 225 microns, or no coarser than fine sand.

Scatter plots of sorting versus mean grain size for the Muddy Formation show two overlapping groups: first, a finer grained, better sorted group of facies including valley fill and transition facies; second, a gencrally coarser grained, less well sorted group of barricr facies. Because grain size measurements were taken from the framework grains alone, the amount of depositional matrix (mostly clay) has been ignored in constructing these groups. Clearly, if matrix were taken into account the valley fill and transition facies could not be considered well sorted.

Scatter plots of sorting versus mean grain size for the subsurface and outcrop Almond samples show different patterns. Subsurface Almond data indicate a well developed trend of increasing mean grain size and decreased sorting as one proceeds from tidal flat/tidal creck to tidal delta, and then with some overlap of data to tidal channel facies. Outcrop Almond data indicate a trend of increasing mean grain size and decreased sorting procecding from tidal creek/middle shoreface, to tidal channel and then with no overlap of data to tidal delta facies. At present not all facies are represented by analyzed samples from both outcrop and subsurface and future sampling could alleviate this problem. However, because the linear relationship between facies has been established for outcrop and the subsurface on this crossplot, major unknown barricr-related facies from stratigraphic interval UA-5 may be identified with a degree of confidence based on sorting data alone. The implication is that small rock samples the size of cuttings may prove useful in determining depositional facies at Patrick Draw field.

6. The lithological and mineralogical composition of present Bell Creck and Patrick Draw rescrvoir sandstones is a function of both initial lithologies and diagenctic history. Whan plotted on a Q-F-R diagram the present lithologies of Bell Creek and Patrick Draw reservoir sandstones do not overlap, those from Bell Creck being more quartzose. In addition, Almond outcrop sandstones contain about twice the feldspar content of outcropping Muddy sandstones. Because of these key mincralogical differences the present lithologies of Bell Creck and Patrick Draw rescrvoir sandstones tend to be different.

Almond reservoir rocks tend to contain an appreciable amount of unstable rock fragments such as chert and shale. In contrast, most sedimentary rock fragments were leached from the Muddy Formation at Bell Creck ficld, of ten resulting is oversize pores. Relative increase in the anount of argillaceous sedimentary rock fragments in the Almond
Formation make the UA-5 ruservoir at Patrick Draw field more susceptible to compaction and reduced pore throat sizes, while the distribution and crystallographic habits of kaolinite and illite in the Muddy Formation make the Bell Creck field reservoir sensitive to the migration of fines during completion and production.

Early stage leaching was important to the development of the pore/throat system in both fields. At Bell Creek early stage leaching was the dominant diagenetic process affecting the distribution of petrophysical properties within groups of similar facies. Virtually all subsequent diagenetic stages at Bcll Creck affected the pore/throat system in a negative manner, but did not greatly change the petrophysical properties. The effects of early stage leaching at Patrick Draw appear to be limited to some leaching of grains, particularly feldspars, chert, and shale fragments creation of some secondary porosity and abundant microporosity. However, early stage leaching was not as intense at Patrick Draw as it was at Bell Creek. Later diagenetic stages of carbonate cementation by dolomite, ankerite, and calcite and by clays played a much greater role at Patrick Draw where porosity and permeability is significantly inferior to that at Bell Creek.

7. In the Muddy Formation it has been demonstrated that for a given permeability, outcrop sandstones are more porous. In the Almond Formation, however, the data indicate that a for a given porosity the outcrop sandstones are generally more permeable, and this relationship is generally true on a facies basis as well. In contrast, mean permeability for equivalent outcropping and subsurface Muddy facies are very similar.

8. Significant differences in hydrodynamics and palcogeographic position of deposited sediments make the Almond Formation more heterogeneous and less predictable from production viewpoint than the Muddy Formation because of higher degree of lateral and vertical variation of facies and lithologies, as well as their complicated geometries and stacking pattern resulting from progradation of depositional and crosional forms.

9. Despite the very different geological and petrophysical characteristics of the mesotidal (Patrick Draw field) and the microtidal (Bell Creek field) shoreline barrier systems their initial productivity (IP) is somewhat comparable and in both cases varics between less than 200 BOPD to more than 700 BOPD per well. A reason for such high initial production in Patrick Draw field (greater than 1,500 BOPD from a few wells and greater than 700 BOPD in numcrous wells) despite the rather unfavorable geological and petrophysical properties can partially be attributed to high initial formation pressurc (about 1,900 psi vs.1,200 psi in Bcll Creek) which provided strong motive power for fluid flow to production wells. However, because the IP data are similar for reservoirs with different depositional facies, different internal facies architecture, different fluid types produced, and different relative permeabilitics to each of 
these fluids, the IP similarities may be no more than coincidental.

10. Based on primary and waterflood production/injection analysis at Patrick Draw and Bell Creck fields:

a. Water relative permeability is very low compared to oil relative permeability at both Patrick Draw and Bell Creck ficlds. Although $\mathrm{k}_{\mathrm{rw}}$ is low in both fields water injectivity and waterflood oil recovery are significantly less at Patrick Draw ficld.

b. Sandstone thickness is the major control of primary production performance in the Arch Unit.

c. Bcll Creek (TIP area) and Patrick Draw (Arch Unit) have similar primary production characteristics but different waterflood performances. Bell Creek recovered about 2.5 times more oil than at Patrick Draw ficld.

\section{REFERENCES}

Bernard, H. A., C. F. Major, Jr., and B. C. Parrott. 1959, The Galveston Barrier Island and Environs: A Model for Predicting Reservoir Occurrence and Trend. Transactions of the Gulf Coast Association of Geological Socictics, v. IX, p. 221-224.

Cuevas, M. M., E. Donsclaar, and S. D. Nio. 1985, Eocene Clastic Tidal Deposits in the Tremp-Graus Basin (Provs. of Lerida and Huesce), in Mila, M. D., and J. Rosel, eds., 6th I.A.S. European Regional Meeting. Excursion Guidebook. Institut D'Estudis Illerdens (Lleida), p. $215-266$.

Donselaar, M. E. 1984, Flood Tidal Delta Sedimentation in the Late Cretaceous Menefee Formation (Mcsaverde Group), San Juan Basin, Northwest New Mexico. Geologie en Mijnbouw, v. 63, p. 323-331.

Donselaar, M. E. 1990, Facies and Geometry of Fossil Flood-Tidal Deltas (Abs.), in, Davis, R. A. Jr., D. Nummedal, and R. W. Tillman, conveners. Tidal inlet and Related Sand Bodics: Modern and Ancient-Abstracts of Technical Program. SEPM Research Conference, San Juan Basin, New Mexico.

Fitzgerald, D. M., S. Penland, and D. Nummedal. 1984 , Control of Barrier Island Shape by Inlet Sediment Bypassing: East Frisian Islands, West Germany. Marine Geology, v. 60. Elsevier Science Publishers B. V., Amsterdam-Printed in The Netherlands, p. 355-376.

Flores, R. M. 1978, Barricr and Back-Barrier Environments of Deposition of the Upper Cretaceous Almond Formation, Rock Springs Uplift, Wyoming. The Mountain Geologist, v. 15, no. 2, p. 57-65.

Hayes, M. O., and W. J. Sexton. 1989, Modern Clastic Depositional Environments, South Carolina. Field Trip
Guidcbook T-371, 28th International Geological Congress. American Geophysical Union, p. 1-85.

Haycs, M. O. 1979, Barricr Island Morphology as a Function of Tidal and Wave Regime. In Leatherman, S.P., ed., Barricr Islands from the Gulf of St. Lawrence to the Gulf of Mexico. Academic Press, N.Y., p. 1-27.

Hayes, M. O. and T. W. Kana. 1976, Terrigenous Clastic Depositional Environments- Some Modern Examples. AAPG Ficld Course Guidebook and Lecture Notes. Tech. Rept. No. 11-CRD, Coastal Res. Div., Dept. of Geology, Univ. of S. Carolina, Columbia, Part I, 131 p., Part II, $184 \mathrm{p}$.

Honarpour, M. et al. 1989, Integrated Reservoir Assessment and Characterization. Final Repont Department of Energy Report No. NIPER-390, February 336 p.

Hoyt, J. H., and V. J. Jenry, Jr. 1965, Significant of Inlet Sedimentation in the Recognition of Ancient Barrier Islands. in. R. H. DeVoto and R. K. Bitter (Eds.) Sedimentation of Late Cretaccous and Tertiary Outcrops, Rock Springs Uplift, Nineteenth Field Conference. Wyoming Geological Association, p. 19()-194.

Irwin, D. 1976, Arch and Monell Units, Patrick DrawTable Rock Area, Swectwater County, Wyoming- Upper Almond Sandstone Study. in, Unpublished Union Pacific Resources Co. Data Files.

Jacka, A. D. 1970, Sediment Economics of Upper Cretaccous Sandstones Rocky Mountain Region. Wyo. Geol. Assoc., 22nd Ann. Ficld Conf. Guidcbook, p. $187-$ 219.

Jackson, S. R., L. Tomutsa, M. J. Szpakiewicz, M. M. Chang, M. M. Honarpour, and R. A. Schatzinger. 1991, Construction of a Rescrvoir Model by Integrating Geological and Engincering Information - Bell Creck Field, A Barricr/ Strandplain Reservoir. In Lake, L. W. et al., eds., Reservoir Characterization II, Academic Press, San Dicgo, Calif., p. 159-182.

Keighin, C. W., B.E. Law, and R. M. Pollastro. 1989, Petrology and Reservoir Characteristics of the Almond Formation, Greater Green River Basin, Wyoming, in Coalson, E. B., ed., Petrogenesis and Petrophysics of Selected Sandstone Reservoirs of the Rocky Mountain Region. The Rocky Mountain Association of Geologists, Denver, Colorado, p. 281-298.

King, C. A. M. Beaches and Coasts. 1972, 2nd Ed., Arnold Pub., London, 570 p.

Priisholm, A., B.L. Niclson, and O. Haslund. 1987 , Fines Migration, Blocking, and Clay Swelling of Potential 
Gcothermal Sandstone Reservoirs, Denmark. SPE Formation Evaluation, v.2, p.168-178.

Reinson, G. E. 1984, Barrier Island and Associated Strand Plain System; in R. G. Walker, ed., Facics Models. Gcoscience Canada, Reprint Serics, No. 1, p. 119-140.

Rochler, H. W. 1979, Palcogcography and Lithofacies of Barricr Bar G and Associated Rocks, Almond Formation, Southeast Rock Springs Uplift, Wyoming. Rocky Mountain Section SEPM Ficld Trip - Cretaccous of the Rock Springs Uplift, Wyoming, p. 2-21.

Rochler H. W. 1988, The Pintail Coal Bed and Barrier Bar G - A Model for Coal of Barrier Bar - Lagoon Origin, Upper Cretaceous Almond Formation, Rock Springs Coal Ficld, Wyoming. U.S Geological Survey Professional Paper 1398, p.1-60.

Sha Li Ping. 1990, Scdimentological Studies of the EbbTidal Deitas Along the West Frisian Islands, The Netherlands. Geologica Ultraicctina no. 64, p 160.

Sncider, R. M., C. N. Tinker, and N. D. Sullivan. 1984, Sandstone Rescrvoir Models from Recent Deposits, Texas Gulf Coast. Gcology and Gcological Enginecring Ficld Trip Guide, SPE-AIME 59th Annual Technical Conference, Houston, TX. R. M. Sncider Exploration, Inc.

S\%pakicwicz, M., S. Jackson and R. Tillman. 1986, NIPER's Gcologicla Ficld Obscrvations; Mustang and Padre Islands, Texas, Decembir Open File.
Gcoscience Canada, Reprint Scries, No. 1, p. 119-140.

Szpakicwicz, M., S. Jackson, R. Schatzinger and R. Tillman. 1990 and 1991, NIPER's Gcological Ficld Observations; Almond Formation Outcrops, East Flank of the Rock Springs Uplift, Wyoming, Open File.

Szpakicwič, M., R. Schatzinger, M. Honarpour, M. Tham, and R. Tillman. 1989, Gcological and Engincering evaluation of Barricr Island and Valley-Fill Lithotypes in Muddy Formation, Bell Creck Ficld, Montana, in Coalson, E. B., ed., Petrogenesis and Petrophysics of Selected Sandstone Reservoirs of the Rocky Mountain Region. The Rocky Mountain Association of Gcologists, Denver, Colorado, p. 159-182.

Szpakiewicz, M., R. Schatzinger, S. Jackson, B. Sharma, A. Cheng, and M. Honarpour. 1991, Selection and Initial Characterization of a Second Barricr Island Reservoir System and Refining of Methodology for Characterization of Shoreline Barrier Reservoirs. Department of Energy Report No. NIPER-484, 170 p.

Van Horn, M.D. 1979, Stratigraphy of the Almond Formation, East-Central Flank of the Rock Springs Uplift, Sweetwater County, Wyoming: A Mesotidal Shoreline Model for the Late Cretaceous. M.S. Thesis, Colorado School of Mines, $150 \mathrm{p}$. 
TABLE 3.1 - Common shapes and dimensions of major tide related facies in Recent and ancient mesotidal shoreline barrier systems 1
Facies Name
Thickness (ft)
Width (mi)
Length (mi)

and shape

Mesotidal Barrier

12.0 to 90.0

0.6 to 4.0

2.01012 .0

(Shoreface \&

Foreshore Facies);

clongated oval,

drumstick

Washover Fan \&

Terrace;

0.5106 .0

0.4 to 1.6

0.8 to 1.8

fan or terrace

Spit Platform;
accreted cycles

Tidal Inlet;

strait or

slightly curved

Tidal Channel \&

Tidal Creck;

convergent, sinuous

Flood Tidal Delta;

lobate fan,

tear-shaped

Ebb Tidal Delta

\& Shoal;

lobatc fan, oval
3.0 to 15.0

0.5 to 3.0

0.3 to $1.0+$

5.0 to $100.0+$

$0.1101 .0+$

$0.6104 .0+$

$5.010100 .0+$

0.02 10 0.8

$1.0103 .0+$

6.0 to 30.0

0.3 to 4.0

1.0 to 3.0

15.0 to 75.0

1.0 to 10.0

1.5 to 6.0

1'Data compiled from Bernard et al., 1959; Cucvas et al., 1985; Donsclaar, 1984, 1990; Fitzgcrald ct al., 1984; Flores, 1978; Hayes and Sixton, 1989; Hoyt and Henry, 1965; Reinson, 1979; Roehler, 1979, 1988;

Sha Li Ping, 1990; Sncider ct al., 1984; Van Horn, 1979, and from NIPER's ficld obscrvations (Szpakiewicz et al., 1986, 1990-91). 
TABLE 3.2 - Some general gcomorphological differences between Microtidal and Mesotidal barricr islands. After Hayes and Kana, 1976

\begin{tabular}{lllllll}
\hline Barricr type & Length & Shape & $\begin{array}{l}\text { Washover } \\
\text { features }\end{array}$ & $\begin{array}{l}\text { Tidal } \\
\text { inlets }\end{array}$ & $\begin{array}{l}\text { Flood-tidal } \\
\text { deltas }\end{array}$ & $\begin{array}{l}\text { Ebb-tidal } \\
\text { deltas }\end{array}$ \\
\hline Microtidal & $\begin{array}{l}\text { long } \\
(30-1(0) \mathrm{km})\end{array}$ & $\begin{array}{l}\text { clongated } \\
\text { hot dog }\end{array}$ & $\begin{array}{l}\text { abundant; } \\
\text { washover } \\
\text { terraces } \\
\text { and wash- } \\
\text { over fans } \\
\text { numerous }\end{array}$ & infrequent & $\begin{array}{l}\text { large; com- } \\
\text { monly coupled } \\
\text { with washovers }\end{array}$ & $\begin{array}{l}\text { small to } \\
\text { absent }\end{array}$ \\
Mesotidal & stunted & drumstick & $\begin{array}{l}\text { minor; beach } \\
\text { ridges or } \\
\text { washover ter- } \\
\text { races; wash- } \\
\text { over fans rarc }\end{array}$ & numcrous & $\begin{array}{l}\text { moderate size } \\
\text { to absent }\end{array}$ & $\begin{array}{l}\text { large with } \\
\text { strong wave } \\
\text { refraction } \\
\text { effects }\end{array}$ \\
\hline
\end{tabular}


TABLE 3.3 - Quantitative XRD determination in weight percent of mineralogy for subsurface samples from Bell Creck ficld and a nearby outcrop ( $\mathrm{GM}=$ Green Mountain outcrop)

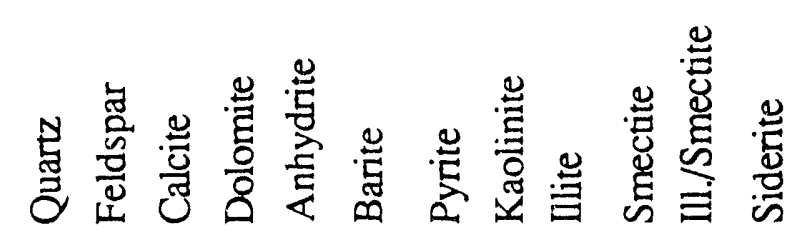

\begin{tabular}{|c|c|c|c|c|c|c|c|c|c|c|c|c|c|c|}
\hline Well & $\begin{array}{l}\text { Depth, } \\
\text { ft }\end{array}$ & Depositional sctting & & & & & & & & & & & & \\
\hline \multicolumn{15}{|c|}{ Subsurface } \\
\hline C-8 & 4351 & Lagoon & 76 & 3 & - & 4 & - & - & - & $T$ & 8 & tr & - & 2 \\
\hline $27-16$ & $4303-3$ & Washover & 88 & 2 & ur & ur & - & - & - & 6 & 4 & - & ur & tr \\
\hline W-14 & 4309.3 & U./L./Shoreface & 89 & 3 & tr & ur & - & - & tr & 5 & 3 & tr & - & - \\
\hline $27-14$ & 4309.5 & U. Shoreface/:orcshore & 94 & tr & tr & u & - & - & - & 4 & 2 & tr & - & - \\
\hline $27-14$ & 4331.5 & U. Shoreface/foreshore & 90 & 2 & - & 2 & - & - & ur & 4 & 2 & ur & 1 & - \\
\hline W-16 & 4308.6 & Forcshore & 91 & 2 & 1 & 1 & - & $\mathbf{t r}$ & - & 3 & 3 & 1 & - & - \\
\hline W-16 & 4318 & U. Shoreface & 88 & 2 & 1 & 1 & - & tr & - & 5 & 3 & tr & - & - \\
\hline W-7 & 4405.5 & Estuarine & 88 & 4 & - & tr & - & - & - & 2 & tr & 6 & - & - \\
\hline W-7 & 4410.0 & Estuarine & 79 & 4 & - & - & - & - & - & 2 & tr & 15 & - & - \\
\hline W-7 & 4417.5 & Swamp & 92 & 3 & - & - & - & - & - & 3 & tr & 2 & - & _- \\
\hline W-7 & 4418.9 & $\begin{array}{l}\text { Alluvial Channel, } \\
\text { Valley Fill }\end{array}$ & 96 & 1 & - & - & - & - & - & 3 & tr & tr & - & - \\
\hline W-7 & 4419.5 & U. Shoreface & 94 & 2 & - & - & - & - & - & 2 & 2 & tr & - & - \\
\hline W-7 & 4431.3 & U. Shoreface & 91 & 3 & - & - & - & 2 & - & 2 & 2 & ur & - & - \\
\hline \multicolumn{15}{|l|}{ Qutcrop } \\
\hline GM & 0 & Fluvial channel ss & 93 & 2 & - & tr & $!$ & - & - & 3 & 1 & tr & & \\
\hline GM & 10 & Fluvial channel ss & 97 & tr & - & - & - & - & - & 2 & tr & 1 & & \\
\hline GM & 52 & Continental silts. & 96 & tr & -. & ur & ur & - & _- & 2 & ur & 2 & & \\
\hline $\mathrm{GM}$ & 65 & Fluvial ss & 97 & tr & - & tr & tr & - & - & 1 & tr & 22 & & \\
\hline
\end{tabular}


TABLE 3.4 - Whole rock X-ray diffraction analysis in weight percent, for samples from Patrick Draw and outcropping upper Almond Formation

\begin{tabular}{|c|c|c|c|c|c|c|c|c|c|c|c|c|c|c|}
\hline Well & Depth, ft & $\begin{array}{l}\text { Strat. } \\
\text { Interval }\end{array}$ & 点 & 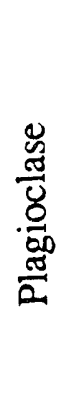 & 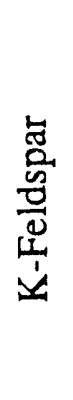 & $\frac{.}{\mathscr{E}}$ & 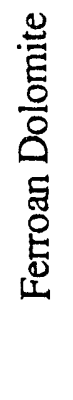 & 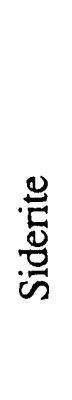 & 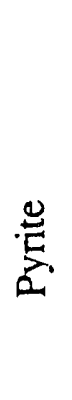 & $\frac{\stackrel{\mathscr{U}}{\mathrm{e}}}{\mathrm{e}}$ & $\sum_{0}^{E}$ & 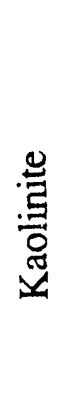 & 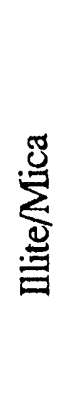 & 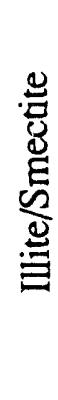 \\
\hline $7-18-1$ & 4,945 & UA5 & 61 & 4 & 4 & - & 21 & - & 3 & 3 & - & 3 & 1 & tr \\
\hline $45-14-3$ & 4.450 & UA5 & 5 & - & tr & - & tr & - & - & 93 & - & 2 & tr & tr \\
\hline $78-14-6$ & 4,305 & UA5 & 78 & 2 & 3 & 5 & ur & 2 & 1 & 5 & - & 2 & 2 & ur \\
\hline $49-1-3$ & 4,615 & UA-6 & 69 & - & 2 & 10 & 15 & - & 1 & 1 & - & 2 & 2 & $\mathrm{t}$ \\
\hline Arch 120 & $4,942.4$ & UA5 & 52 & 1 & 2 & 1 & - & - & 4 & 36 & - & 2 & 1 & 1 \\
\hline & $4,944.6$ & UA5 & 66 & 3 & 3 & 19 & - & - & 2 & 3 & - & 3 & 1 & tr \\
\hline & $4,948.7$ & UA5 & 82 & 2 & 4 & 1 & - & - & 3 & 4 & _- & 3 & $i$ & - \\
\hline & $4,949.5$ & UA5 & 88 & 3 & 3 & tr & - & - & 1 & 1 & - & 3 & 1 & tr \\
\hline & $4,962.4$ & UA5 & 91 & 3 & 2 & tr & - & - & us & tr & - & 4 & tr & tr \\
\hline & $4,962.5$ & UA5 & 86 & 3 & 4 & - & -- & tr & 2 & tr & - & 4 & 1 & ir \\
\hline & $4,966.5$ & UA5 & 85 & 3 & 2 & 4 & - & - & 3 & tr & - & tr & 2 & 1 \\
\hline \multicolumn{15}{|c|}{ Outcrop Samples } \\
\hline G7-26B & & & 89 & 2 & 3 & 3 & - & - & - & - & - & 1 & 1 & - \\
\hline $67-47$ & & & 95 & 1 & 2 & ur & - & - & - & tr & - & 1 & 1 & - \\
\hline G7-91 & & & 83 & 5 & 8 & tr & _- & - & - & tr & - & 1 & 1 & _- \\
\hline G7-174 & & & 89 & 4 & 4 & tr & - & - & - & $\ldots$ & tr & 2 & 1 & - \\
\hline G7-191 & & & 90 & 3 & 4 & 1 & - & tr & - & $\ldots$ & - & 1 & 1 & - \\
\hline
\end{tabular}


TABLE 3.5 - Major diagenetic phases identified within the barrier sandstone facies and their potertial effect on porosity and permeability. Muddy Formation, Bell Creck f:eld,Unit 'A'

\begin{tabular}{|c|c|c|}
\hline Diagenctic phase & Suggestcd causc & Potential effect \\
\hline $\begin{array}{l}\text { Dominant leaching } \\
\text { creates secondary porosity } \\
\text { creates oversizc pores } \\
\text { effects chert, feldspars, sed. } \\
\text { rock fragments } \\
\text { carly kaolinization }\end{array}$ & Metcoric water lens & Major $\emptyset$ incrcasc \\
\hline Siderite cement & $\begin{array}{l}\text { Mixing of } \\
\text { waters at low Eh }\end{array}$ & $\begin{array}{l}\text { Insignificant } \emptyset \\
\text { docrease }\end{array}$ \\
\hline $\begin{array}{l}\text { Compaction } \\
\text { increases rock heterogeneity } \\
\text { disjoints pore system } \\
\text { creates silt size detritus } \\
\text { creates pseudomatrix }\end{array}$ & Overburden pressurc & Major k decreasc \\
\hline $\begin{array}{l}\text { Silica overgrowths } \\
\text { increase grain eccentricity } \\
\text { reduce pore throats } \\
\text { increased grain contact }\end{array}$ & $\begin{array}{l}\text { Solution- } \\
\text { reprecipitation }\end{array}$ & $\begin{array}{l}\text { Minor } \phi \text { decreasc } \\
\text { Minor } k \text { decrease }\end{array}$ \\
\hline $\begin{array}{l}\text { Calcite cement } \\
\text { usually fills all porosity } \\
\text { beds subdivide facies } \\
\text { stops compaction }\end{array}$ & $\begin{array}{l}\text { Deoxygenation, } \mathrm{pH} \\
\text { and/or temperature } \\
\text { changes causing } \\
\text { oversaturation }\end{array}$ & $\begin{array}{l}\text { Major } \emptyset \text { decreasc } \\
\text { Major } k \text { decreasc }\end{array}$ \\
\hline $\begin{array}{l}\text { Late leaching } \\
\text { corrodes grains and prior } \\
\text { cements }\end{array}$ & $\begin{array}{l}\text { Recstablished } \\
\text { mctcoric water lens }\end{array}$ & $\begin{array}{l}\text { Major or Minor } \$ \\
\text { increasc } \\
\text { Major k increase }\end{array}$ \\
\hline $\begin{array}{l}\text { Clay cement } \\
\text { fills or lines pores } \\
\text { blocks throats } \\
\text { creates microporosity }\end{array}$ & $\begin{array}{l}\text { changing subsurface water } \\
\text { chemistry; new diagenetic } \\
\text { fluids along faults }\end{array}$ & $\begin{array}{l}\text { Minor } \emptyset \text { decrease } \\
\text { Major k decrease }\end{array}$ \\
\hline Hydrocarbon migration & $\begin{array}{l}\text { Hydrodynamic } \\
\text { forces }\end{array}$ & $\begin{array}{l}\text { Retards or stops } \\
\text { diagenesis } \\
\text { Oil trapped }\end{array}$ \\
\hline
\end{tabular}


TABLE 3.6 - Reservoir data and history for Patrick Draw and Bell Creek fields

\begin{tabular}{|c|c|c|}
\hline & Patrick Draw & Bell Creek 'A' \\
\hline Discovered & 1959 & $196 ?$ \\
\hline OOIP - Arch unit, MM STB & 97.6 & \\
\hline OOIY-Monell unit, MM STB & 112.5 & \\
\hline Total OOIP, MM STB & $220-250$ & 127 \\
\hline Primary production & Solution Gas & Solution Gas \\
\hline Arch, $\%$ & 17.7 & -- \\
\hline Monell, \% & 20.0 & -- \\
\hline Bell Creek, \% & - & 17.3 \\
\hline Secondary production & Five-spot waterflood & Linedrive \\
\hline Arch, $\%$ & 12 & ... \\
\hline Monell, \% & 15 & -- \\
\hline Bell Creek, \% & -. & 36.7 \\
\hline Total recovery, MM STB & 78.5 (35\% OOIP) & $68.6(54 \%$ OOIP $)$ \\
\hline ROS after waterflood, \% PV & 39 & 35 \\
\hline $\mathrm{S}_{\mathrm{Or}}, \% \mathrm{PV}$ & 19.5 & 30 \\
\hline Oil viscosity,cP & 0.52 & 2.76 \\
\hline Porosity, \% & $19.8(12-22)$ & 28.5 \\
\hline Permeability, md & $35.9(5-200)$ & $915(50-7000)$ \\
\hline Interstitial water saturation, \% & $30-50$ & $20-35$ \\
\hline Gas-oil contact, $\mathrm{ft}$ & +2525 & +2475 \\
\hline Water-oil contact, $\mathrm{ft}$ & +1450 & +1635 \\
\hline Oil gravity, ${ }^{\circ} \mathrm{API}$ & 42 & 32.5 \\
\hline \multicolumn{3}{|l|}{ Initial oil formation volumc } \\
\hline factor vol/vol & 0.52 & 0.76 \\
\hline Temperature, ${ }^{\circ} \mathrm{F}$ & 121 & 110 \\
\hline Initial pressure, psi & 1790@+2000' & $1204 @-800^{\prime}$ \\
\hline Saturation pressure, psi & $1790 @+2000$ & $1204 @-800^{\prime}$ \\
\hline Initial solution $\mathrm{GOR}, \mathrm{SCF} / \mathrm{bbl}$ & 450 & 200 \\
\hline Net pay, $\mathrm{ft}$ & 20 & 22.9 \\
\hline Field size, acres & 16,540 & 7,219 \\
\hline Length - width, miles & $9-3$ & $5-2$ \\
\hline Depth, $\mathrm{ft}$ & 5100 & 4500 \\
\hline DIP, degrees & 4 & 1 \\
\hline HC Porosity & 0.13 & 0.2 \\
\hline Dominent clay & Kaolinite/Illitc-Smectitc & Kaolinite \\
\hline
\end{tabular}




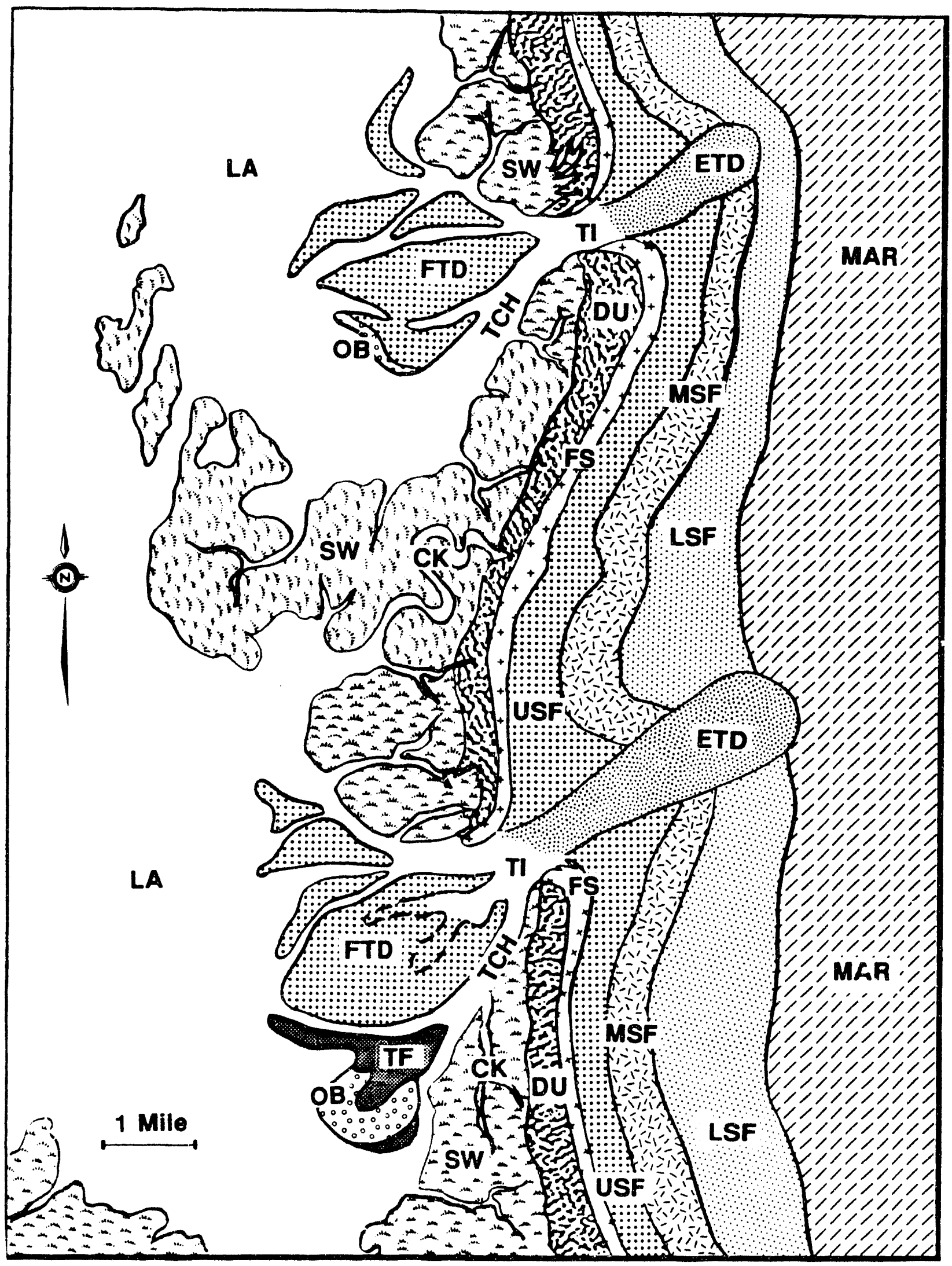

Figure 3.1 - Paloogeographic map of upper Almond Formation barrier bar $G$ and associated facies located in the Rock Springs Uplift, WY. Abbreviations: SW, swamp and tidal creeks; LA, lagoon; WO, washover; FD, flood-tidal delta; ED, ebb-tidal delta; TI, tidal inlet; OB, oyster bed; DU, dunes; FS, beach; MS+USF, middle and upper shoreface; M, offshore marine. Modified from Roehler $(1979,1988)$. 


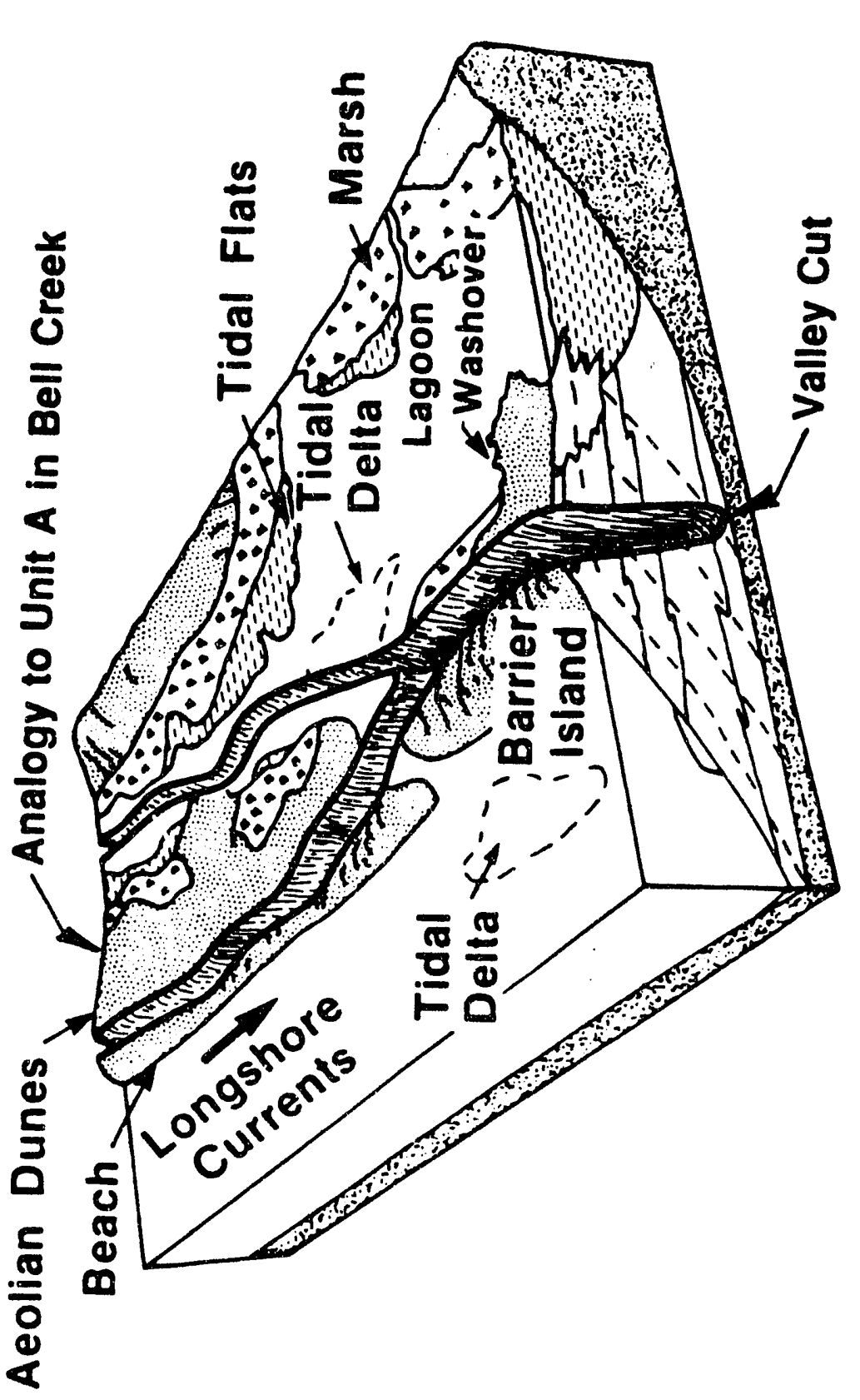

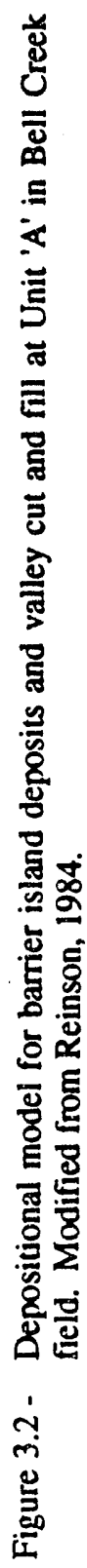




\section{BARRIER SANDSTONES}

\section{Muddy Formation}

- Outcrop

- Subsurface

Almond Formation

$\Delta$ Outcrop

O Subsurface

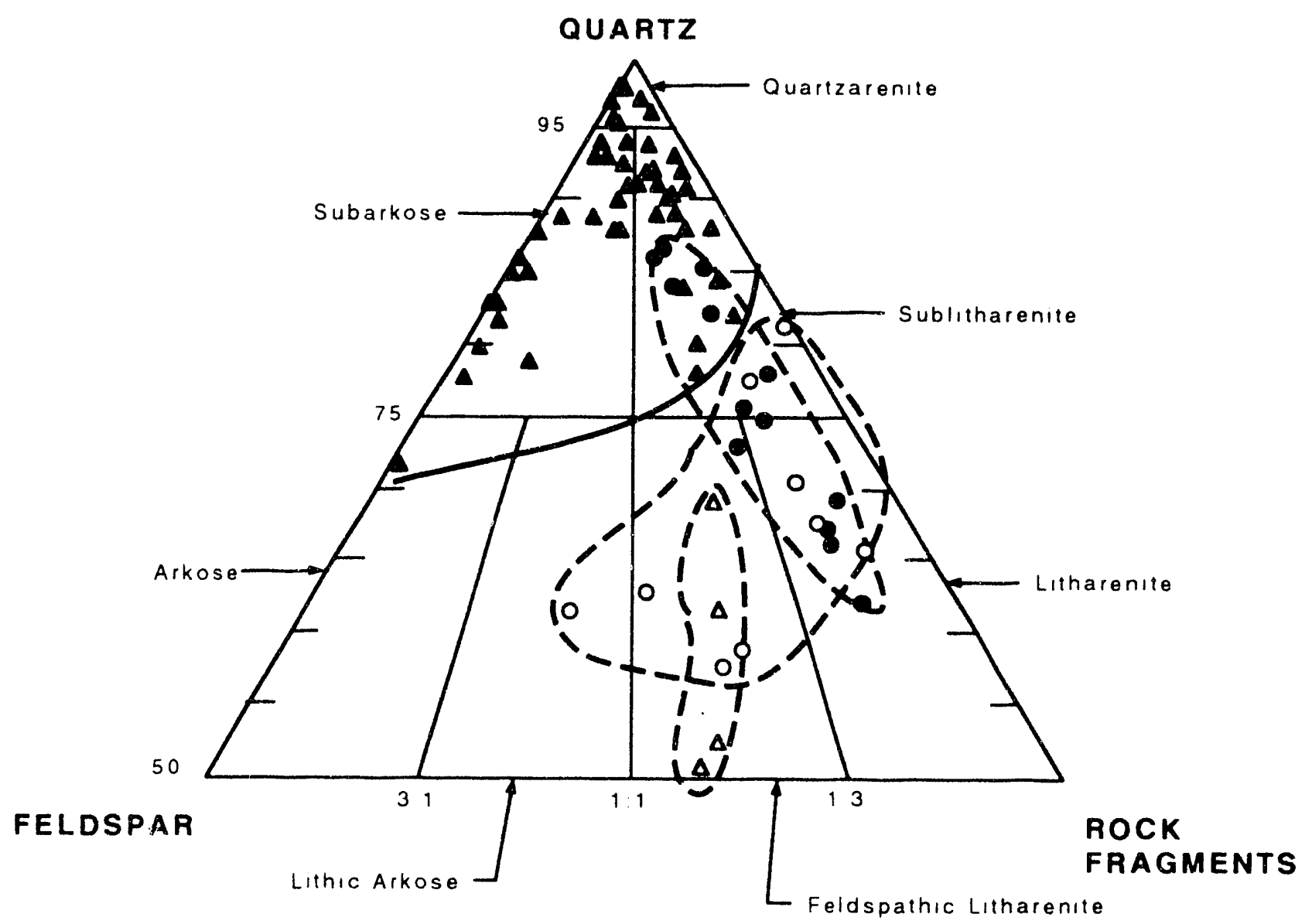

Figure 3.3 - Ternary plot of quarz-feldspar-rock fragment composition of outcrop and subsurface Almond and Muddy Formations. Note that the Almond Formation samples are generally less quartzose, and are more rich in rock fragments than corresponding Muddy Formation samples. 


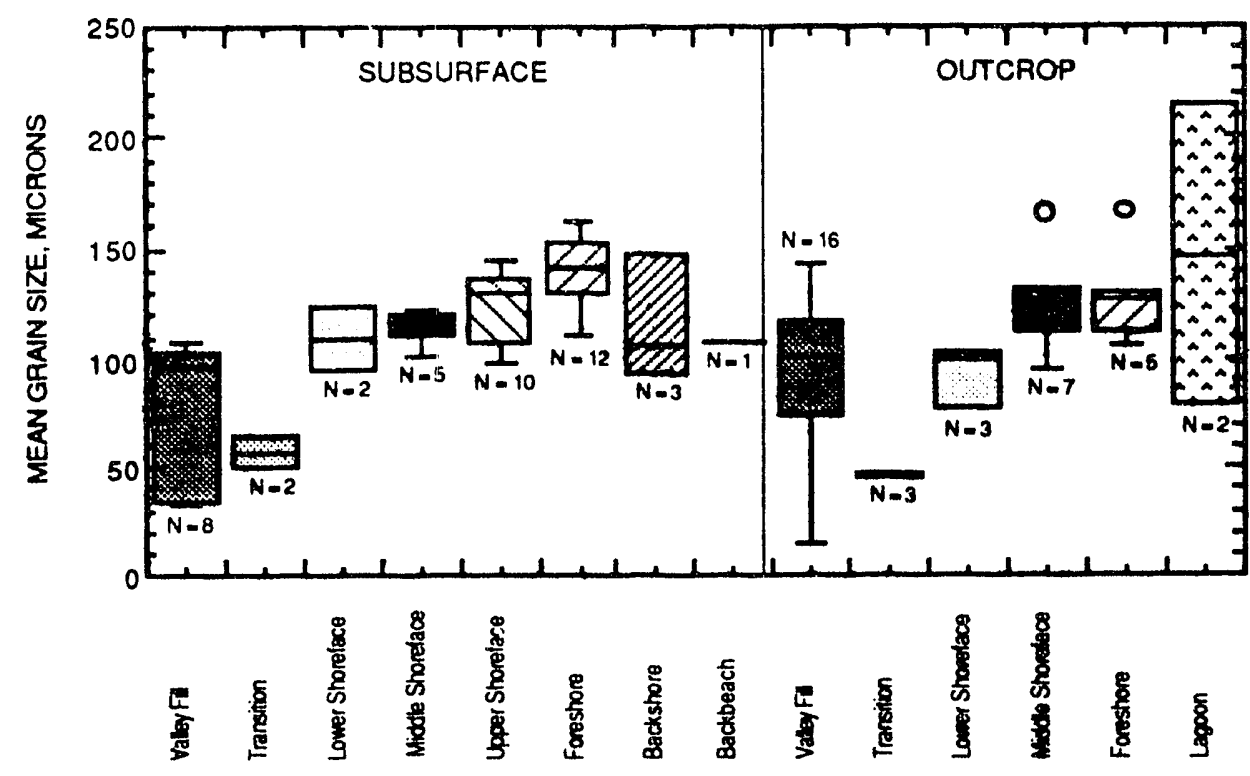

Figure 3.4 - Comparison of outcrop and subsurface grain size distribution for various Muddy Formation facies in and around Bell Creek field, MT. Boxes indicate limits of second and third quartiles, "whiskers" indicate ranges of daxa to 5 th and 95th percentiles, circles indicate data outliers beyond 5th and 95th percentiles. "N" represents number of samples in each class of data.

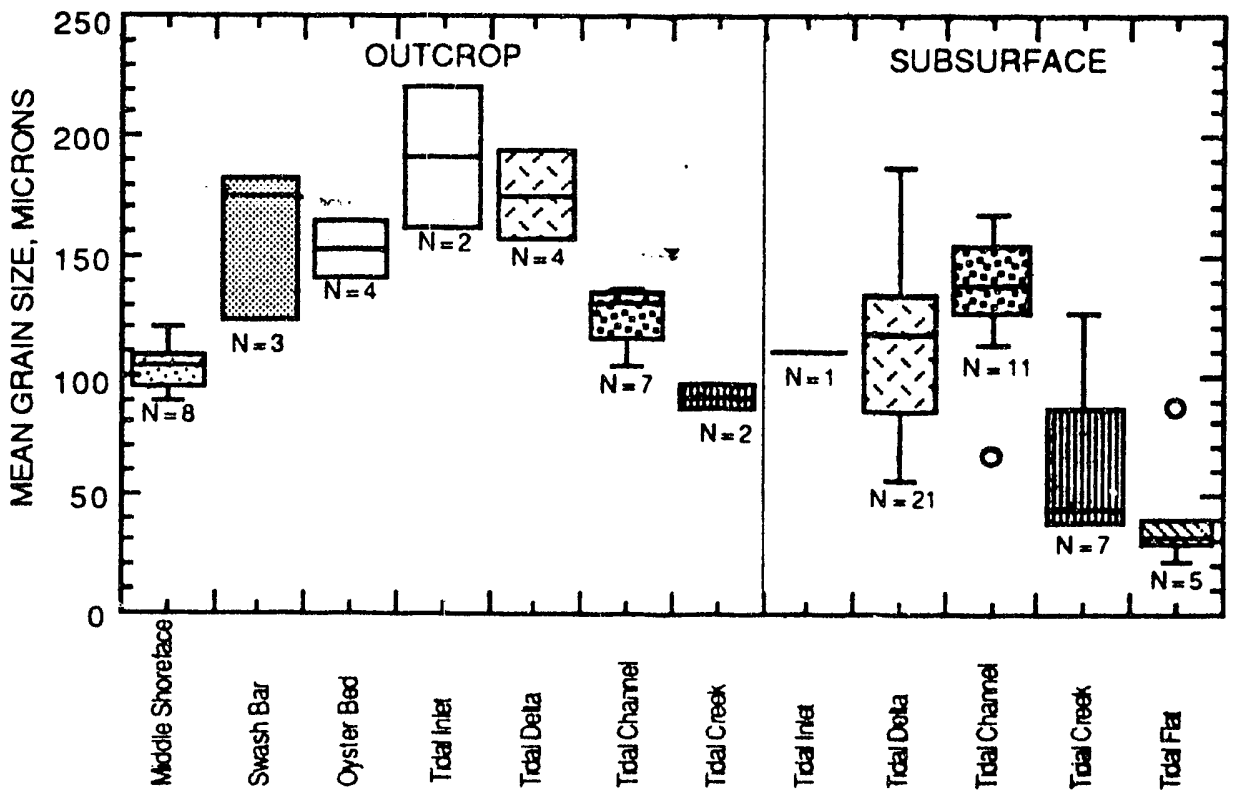

Figure 3.5 - Comparison of outcrop and subsurface grain size distribution for various facies in the Almond Formation. For explanation of symbols see fig. 3.4. 


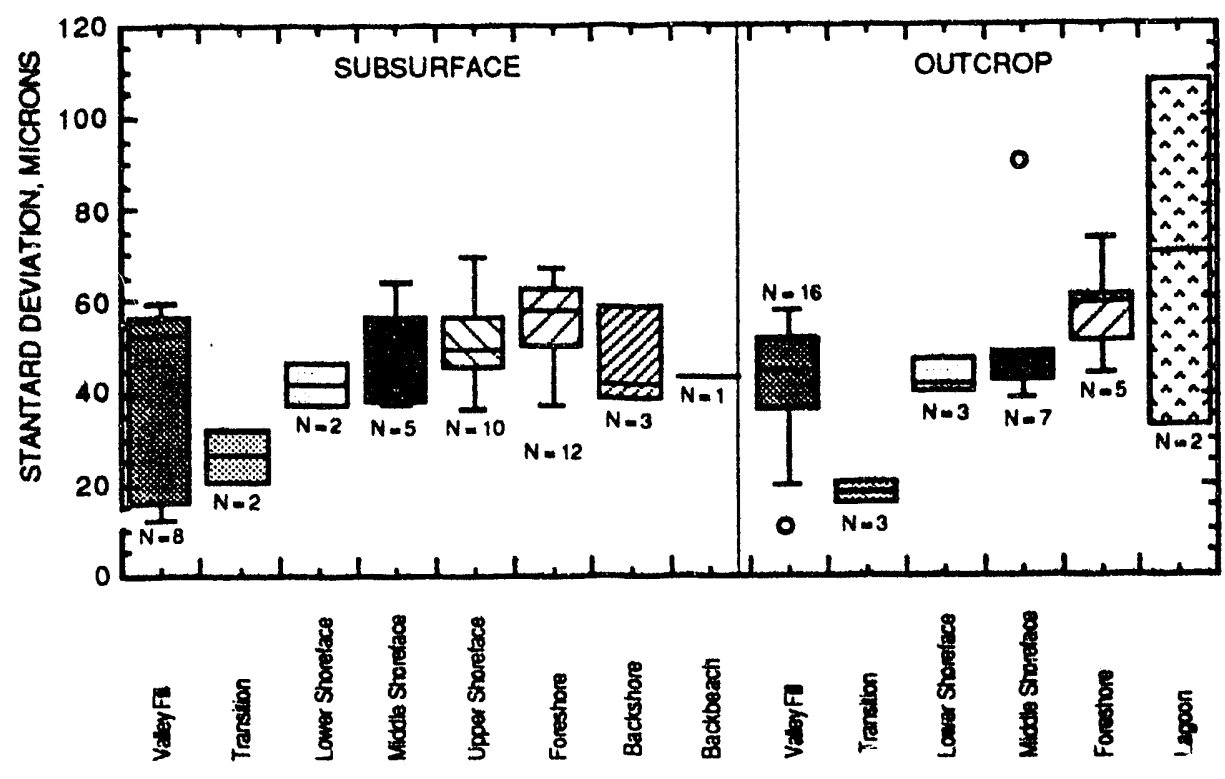

Figure 3.6 - Comparison of outcrop and subsurface standard deviation of grain size for various Muddy Formation facies in and around Bell Creek field, MT. For explanation of symbols see fig. 3.4.

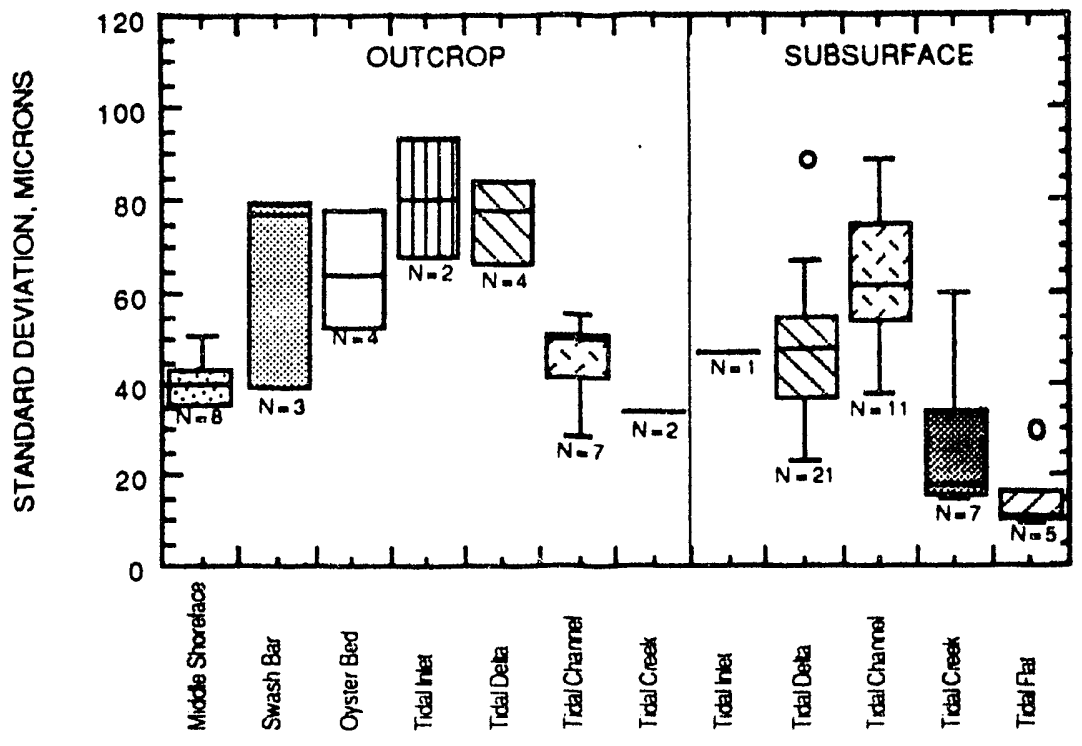

Figure 3.7 - Standard deviation (sorting) for various outcrop and subsurface facies in the Almond Formation. For explanation of symbols see fig. 3.4. 


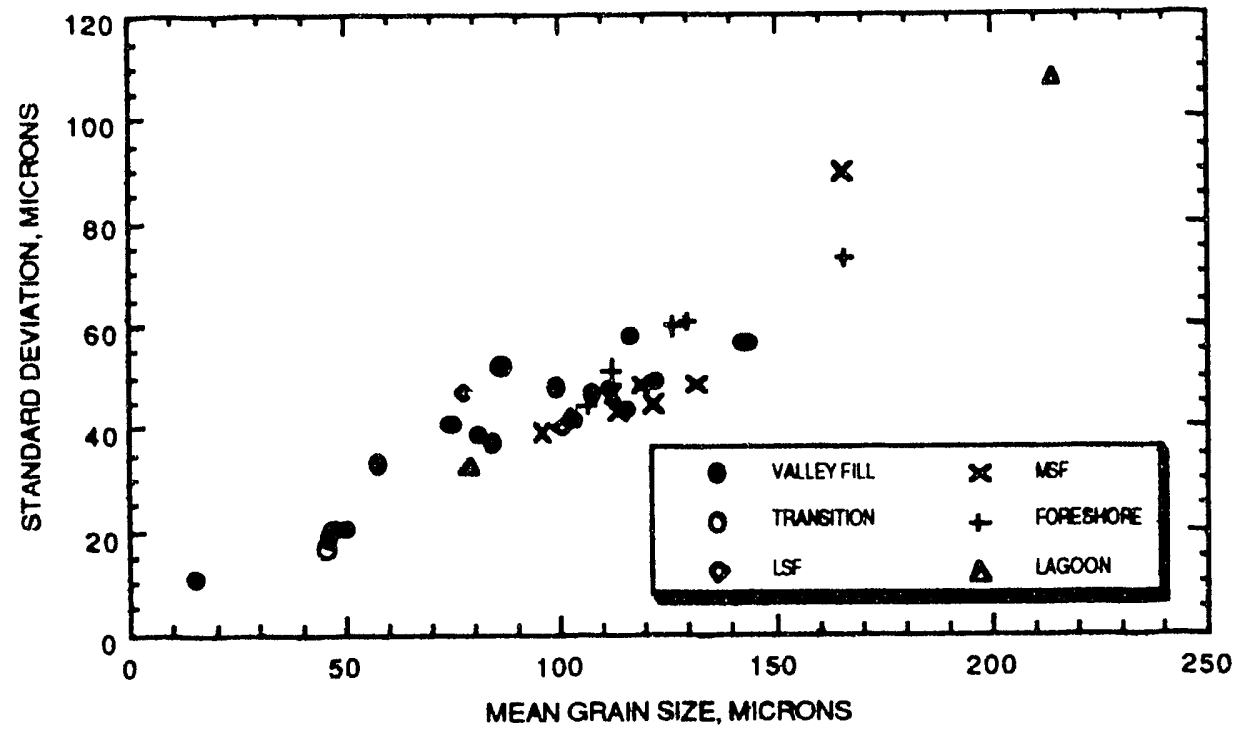

Figure 3.8 - Standard deviation of grain size versus mean grain size for Muddy Formation outcrop facies. Abbreviations: LSF, lower shoreface; MSF, middle shoreface; USF, upper shoreface.

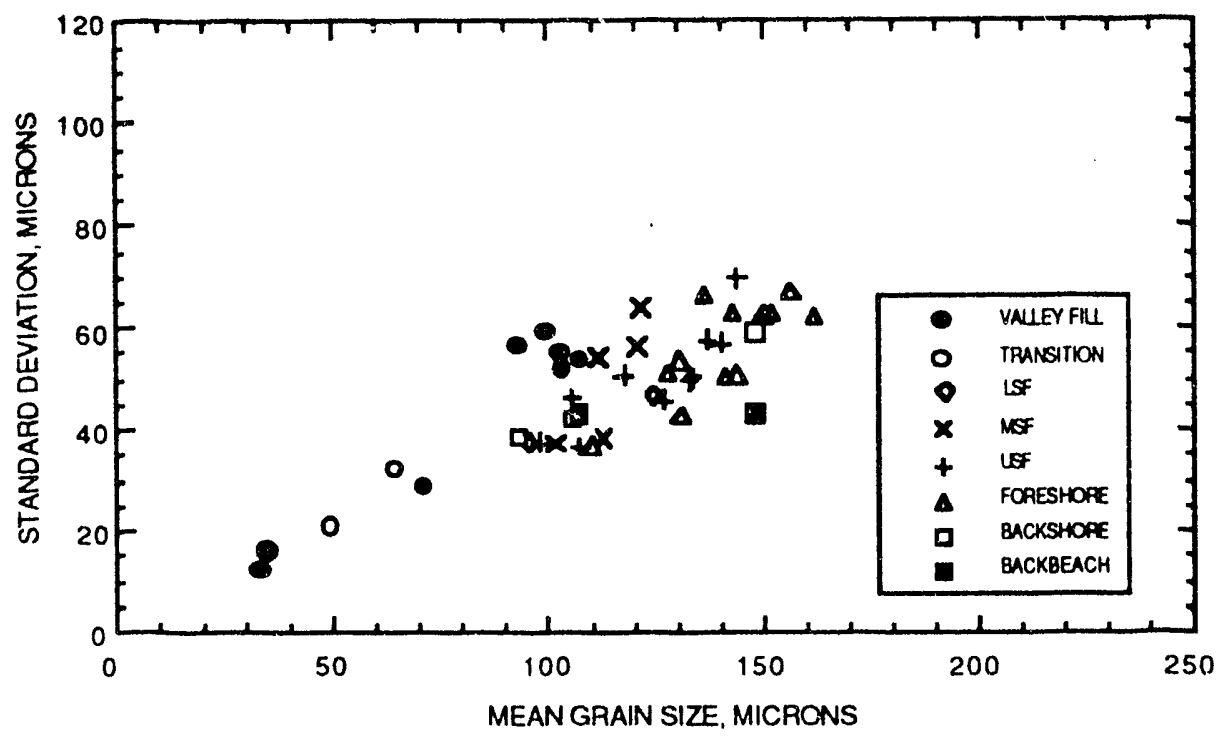

Figure 3.9 - Standard deviation of grain size versus mean grain size for Muddy Formation subsurface facies. Abbreviations listed in fig. 3.8. 


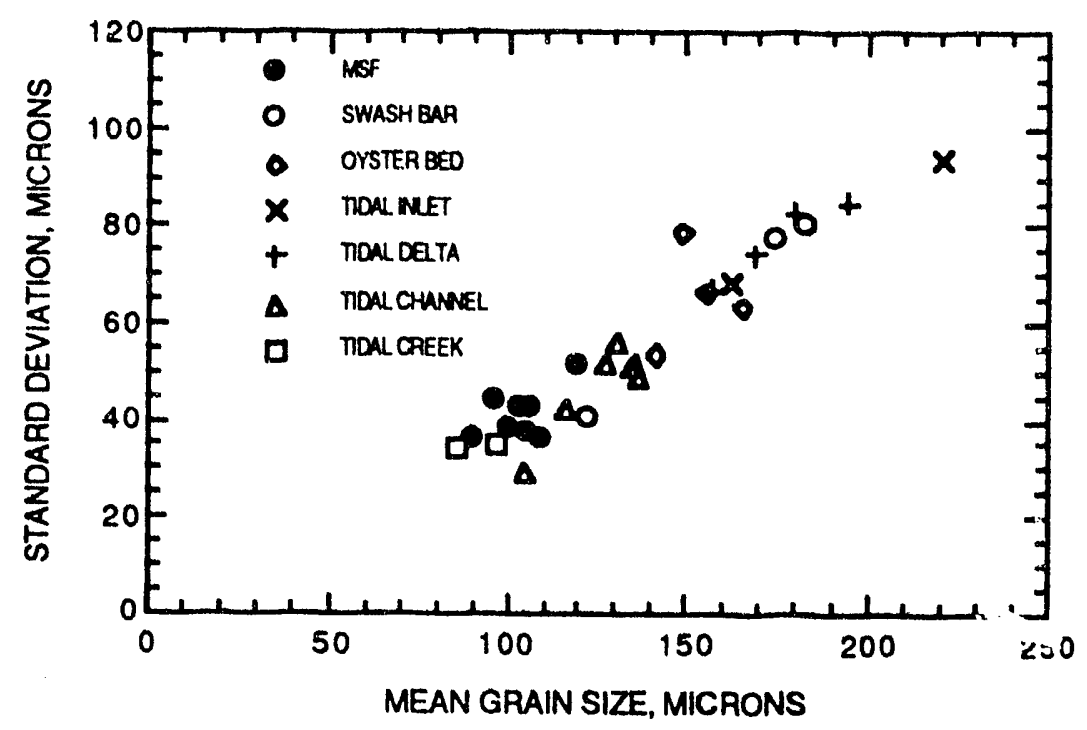

Figure 3.10 - Standard deviation (sorting) versus mean grain size for outcrop Almond Formation facies. Based on image analysis of $\mathbf{3 0 0}$ points for each thin section.

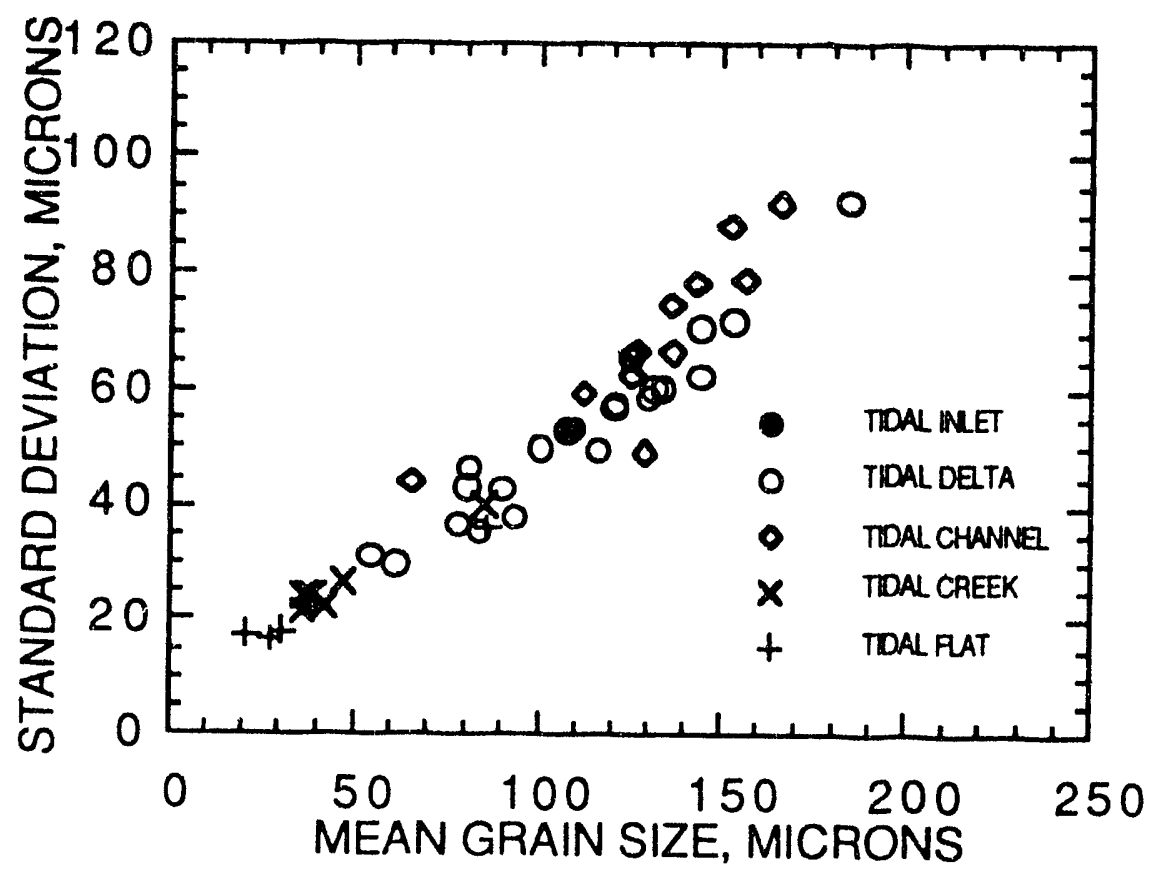

Figure 3.11 - Standard deviation (sorting) versus mean grain size for subsurface Almond Formation facies. Based on image analysis of 300 points for each thin section. 


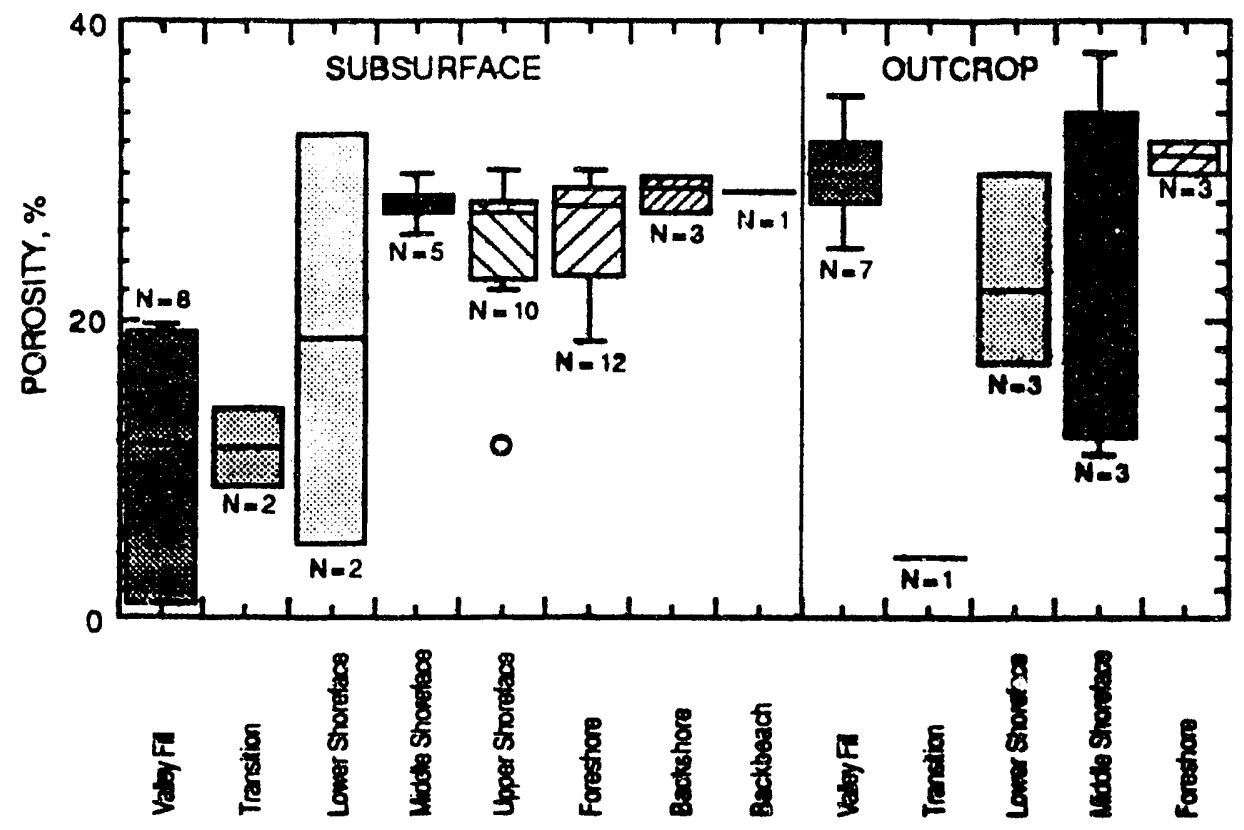

Figure 3.12 - Comparison of outcrop and subsurface porosity for various facies in the Muddy Formation in and around Bell Creek field, MT. For explanation of symbols see fig. 3.4.

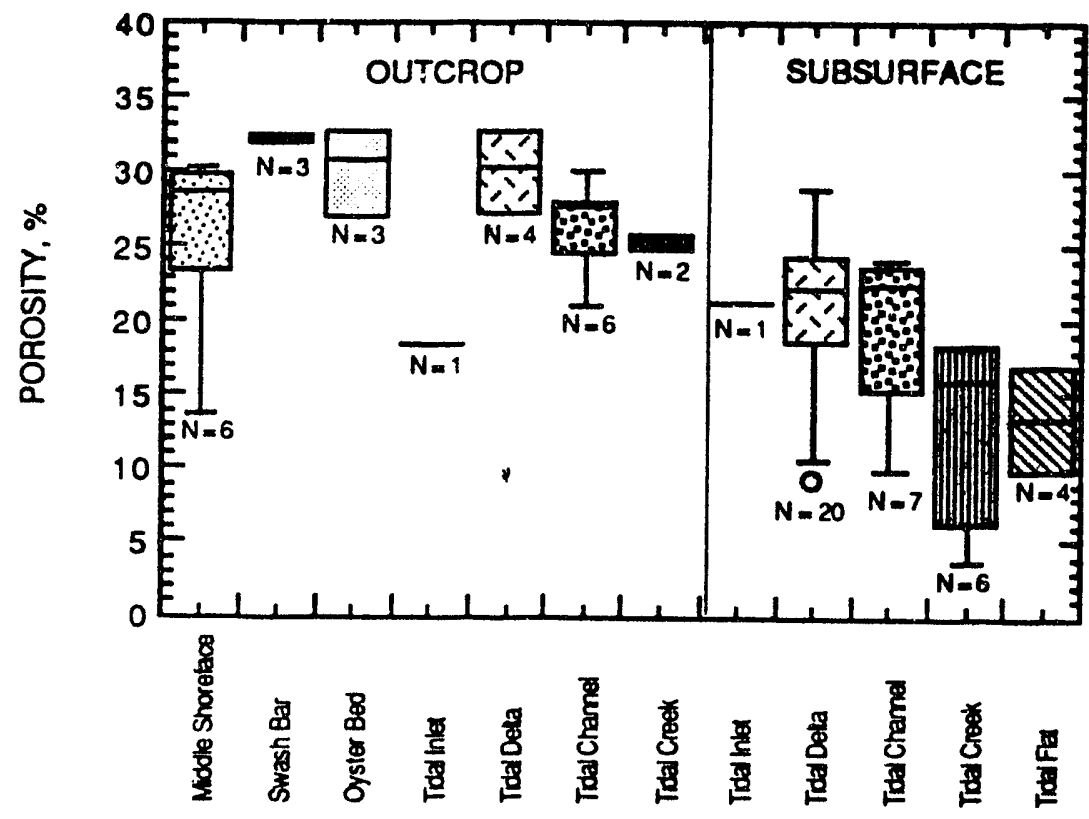

Figure 3.13 - Comparison of subsurface and outcrop facies porosity, Almond Formation. For explanation of symbols see fig. 3.4 . 


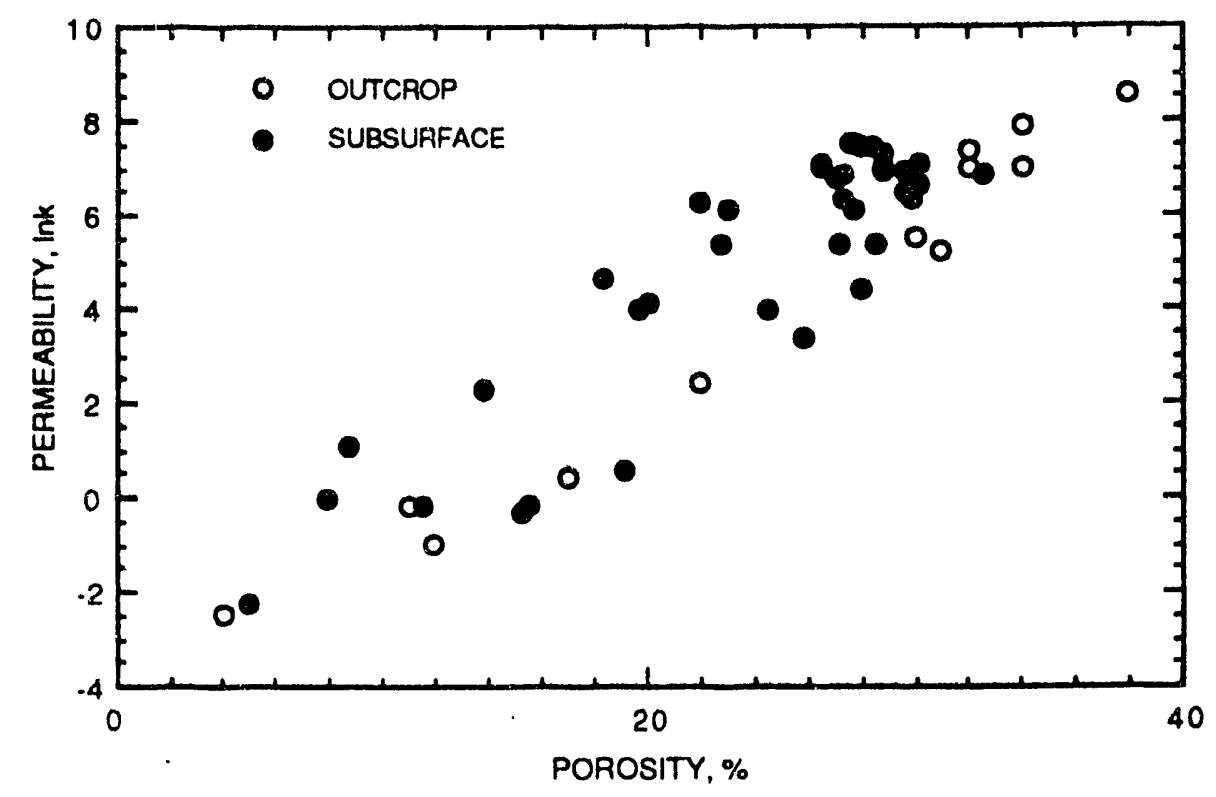

Figure 3.14 - Natural log of permeability (Ink) versus porosity for combined outcrop and subsurface Muddy Formation samples.

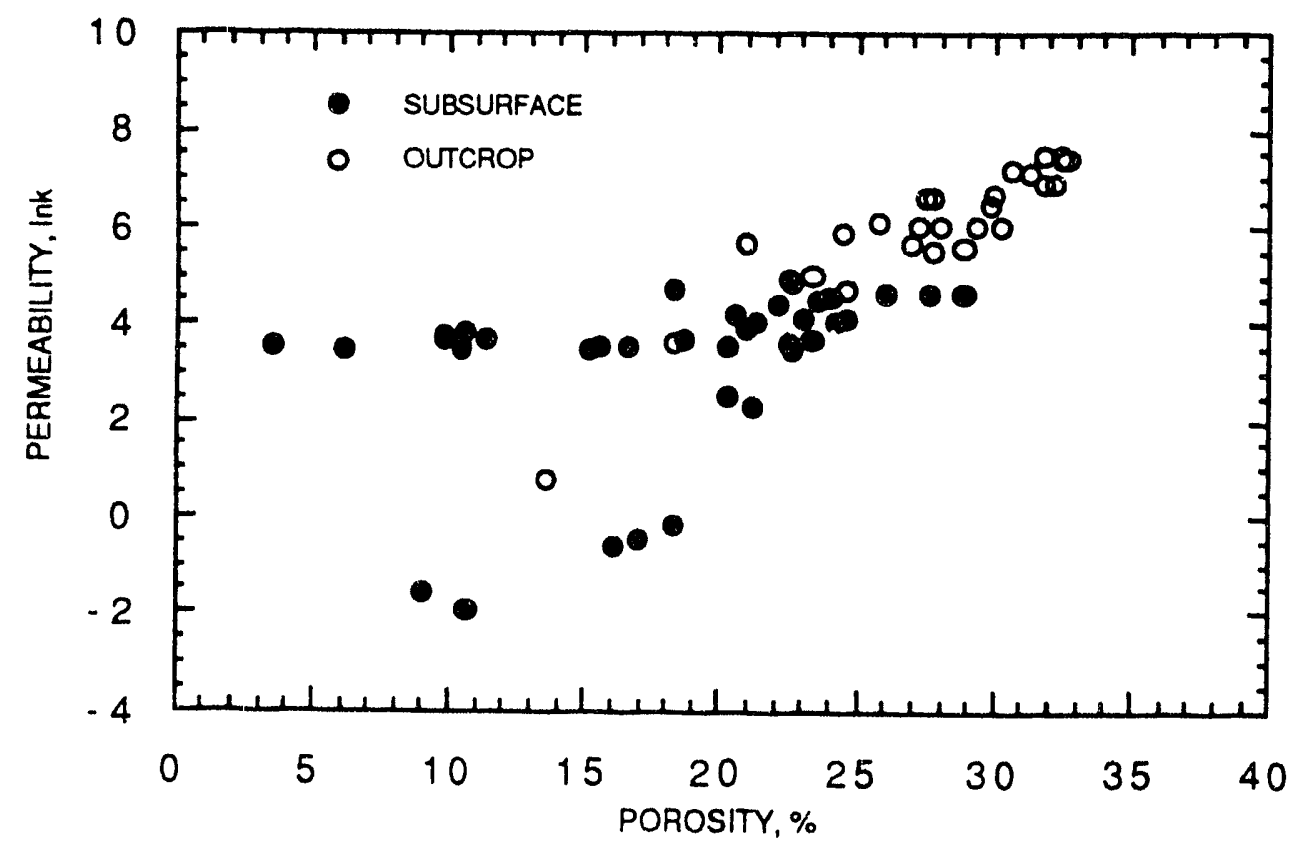

Figure 3.15 - Natural log of permeability versus porosity for outcrop and subsurface Almond Formation. 


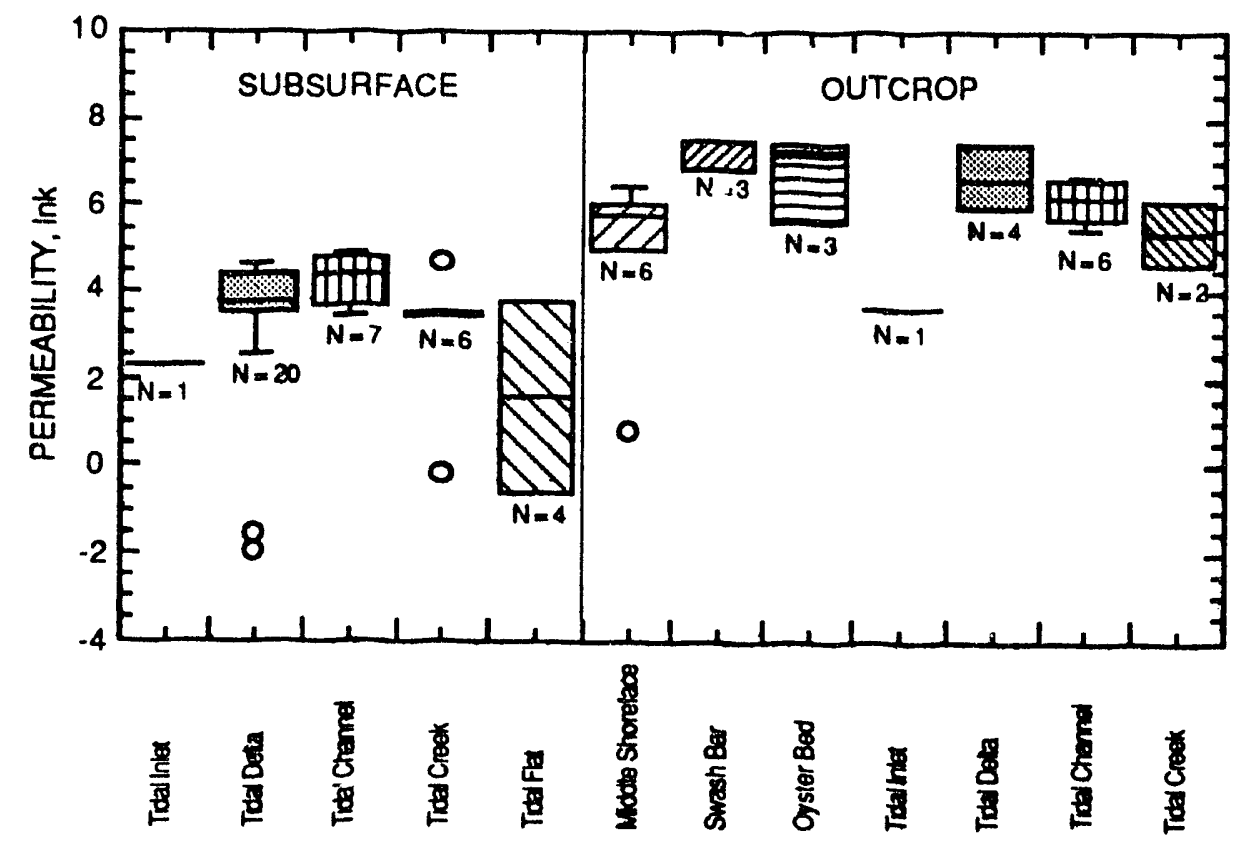

Figure 3.16 - Comparison of subsurface and outcrop permeability distribution for Almond facies. For explanation of symbols see fig. 3.4.

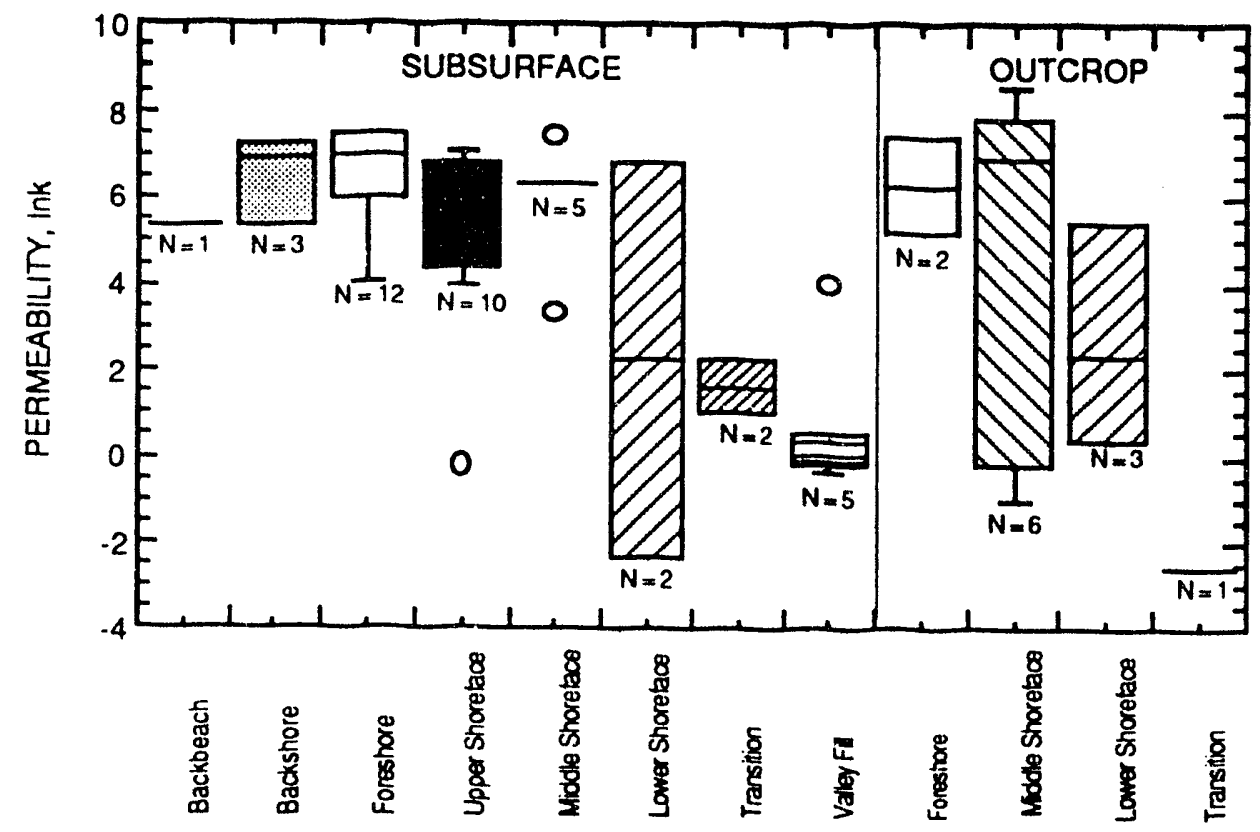

Figure 3.17 - Comparison of outcrop and subsurface natural log of permeability for various facies in the Muddy Formation in and around Bell Creek field, MT. For explanation of symbols see fig. 3.4. 


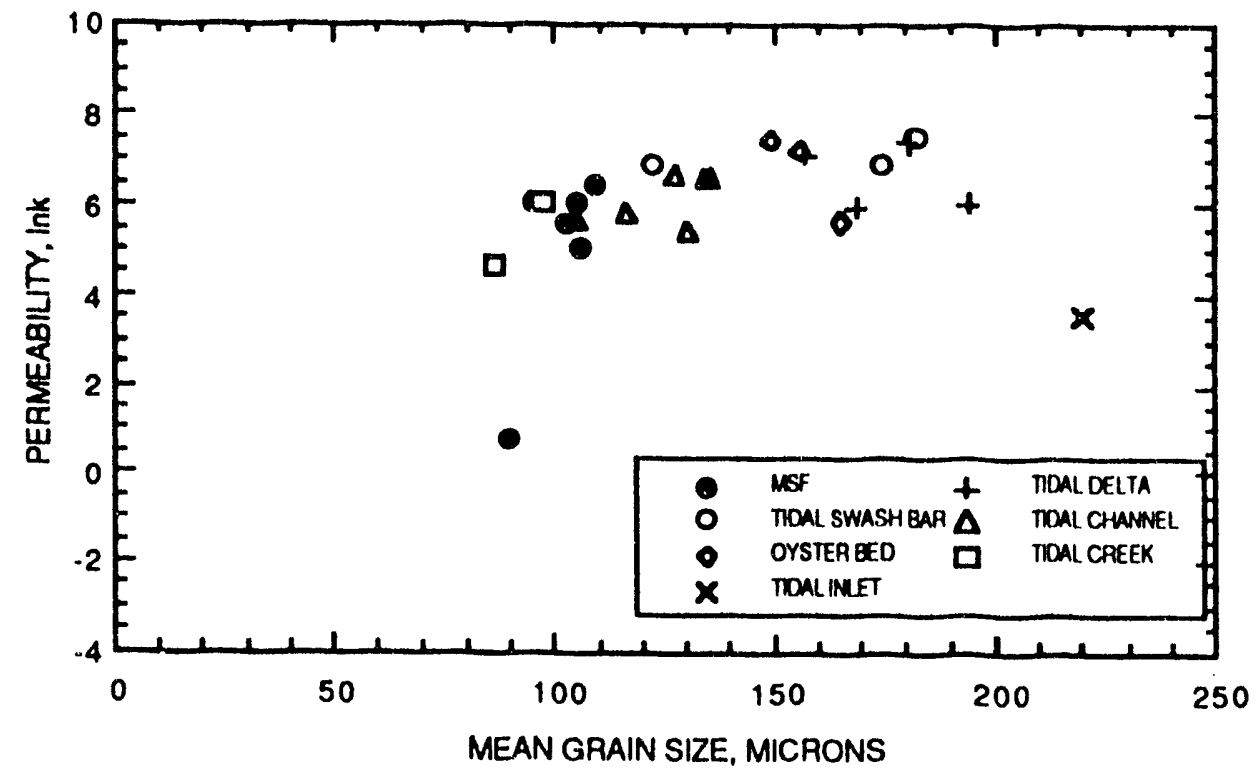

Figure 3.18- Natural log of permeability (Ink) versus mean grain size for outcropping Almond Formation facics. Abbreviations listed in fig 3.8.

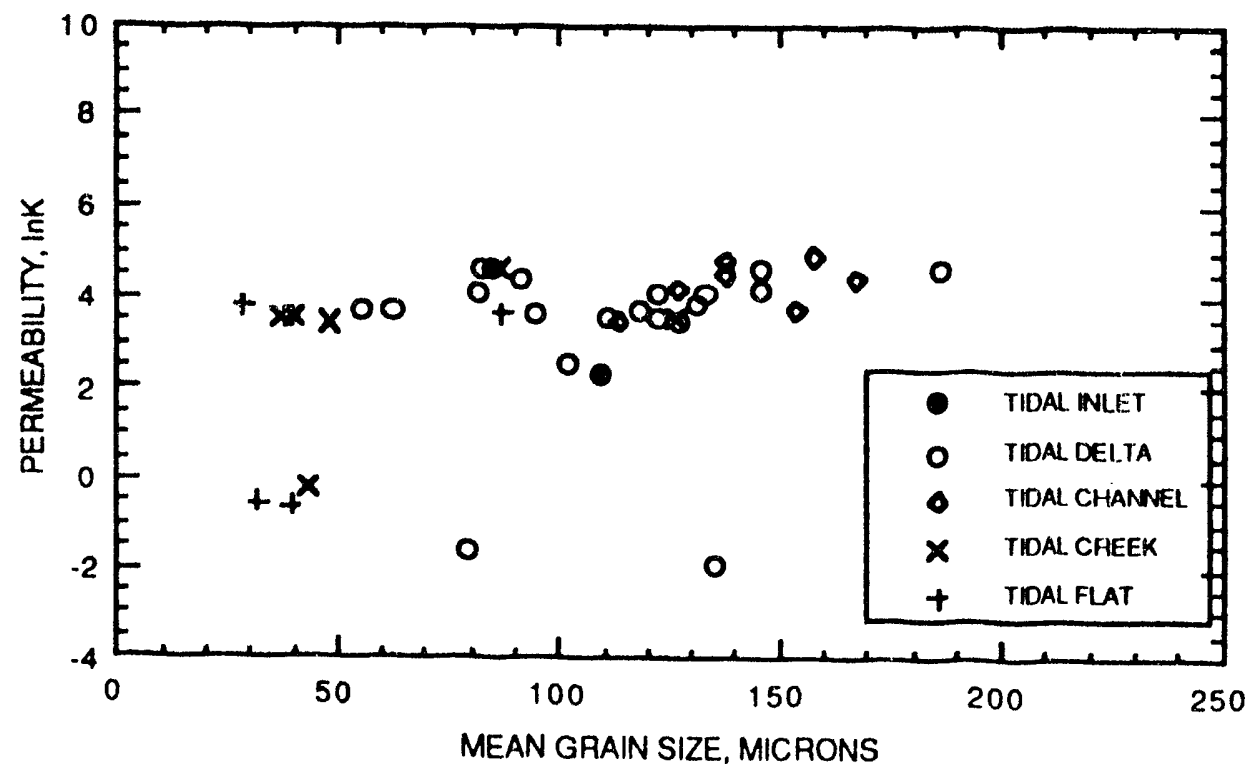

Figure 3.19 - Natural log of permeability (Ink) versus mean grain size for subsurface Almond Formation facies. 


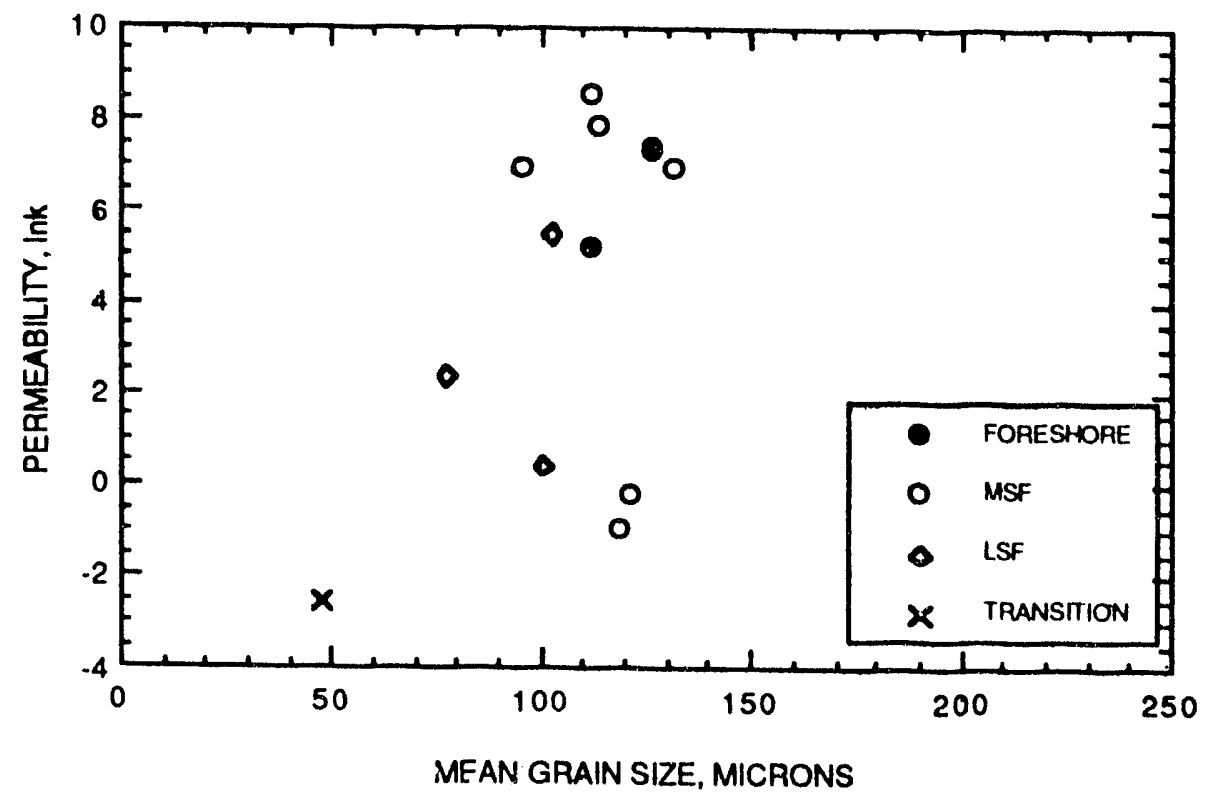

Figure 3.20 - Natural log of permeability (lnk) versus mean grain size for outcropping Muddy Formation facies. Abbreviations listed in fig. 3.8.

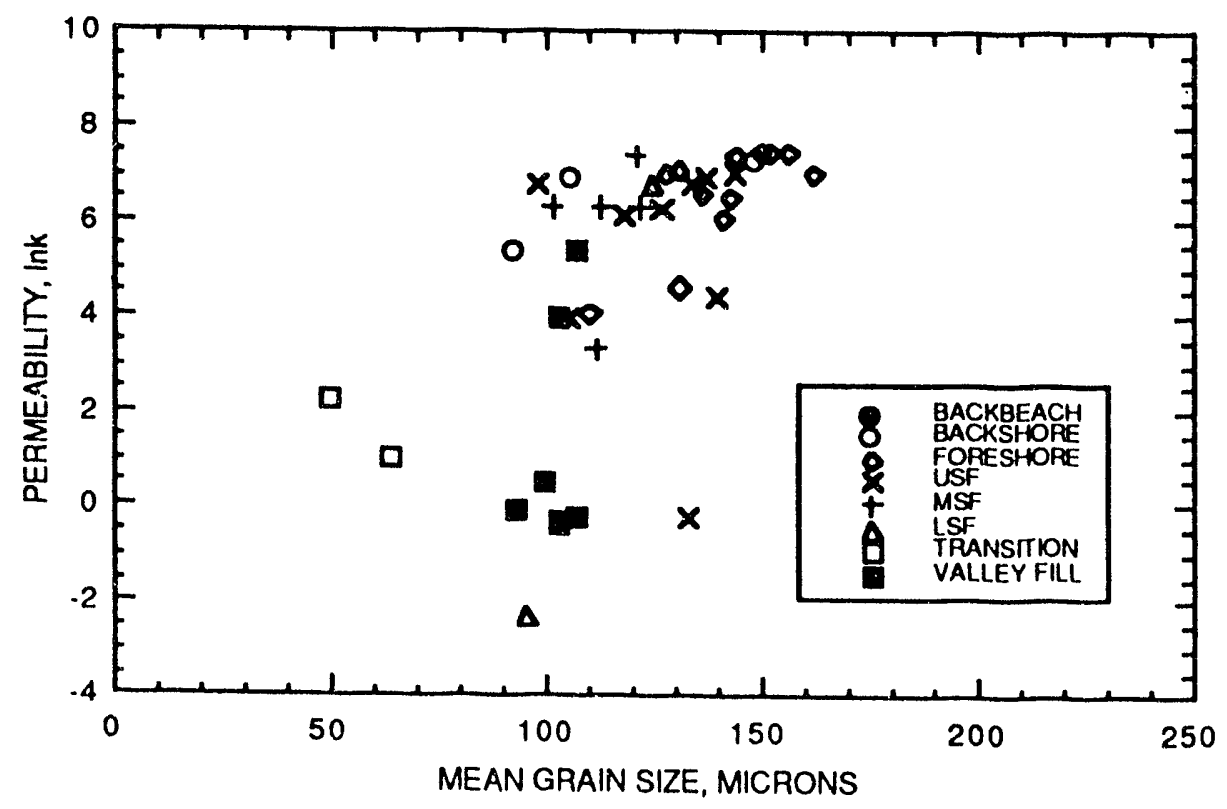

Figure 3.21.- Natural log of permeability (Ink) versus mean grain size for subsurface Muddy Formation facies. Abbreviations listed in fig. 3.8. 


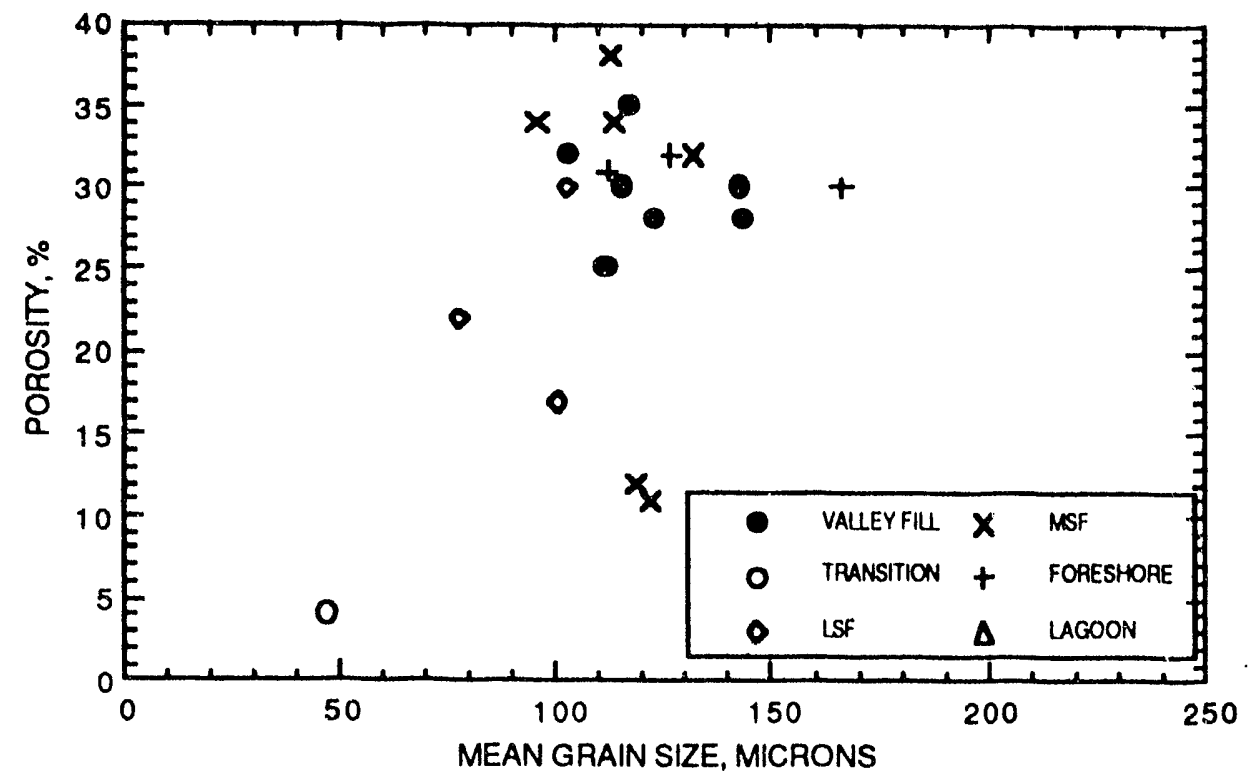

Figure 3.22- Porosity versus mean grain size for outcropping Muddy Formation facies. Abbreviations listed in fig. 3.8 .

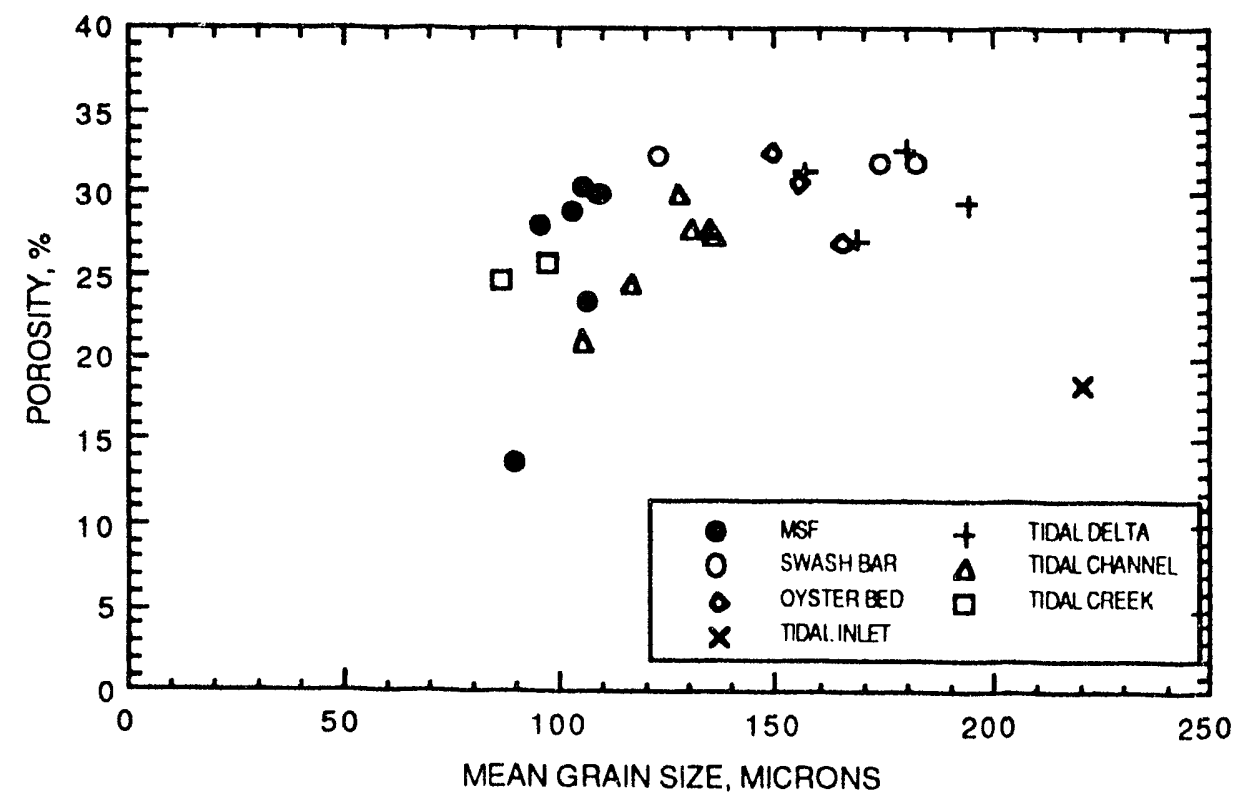

Figure 3.23 - Porosity versus mean grain size for outcropping Almond Fomation facies. Abbreviations listed in fig. 3.8 . 


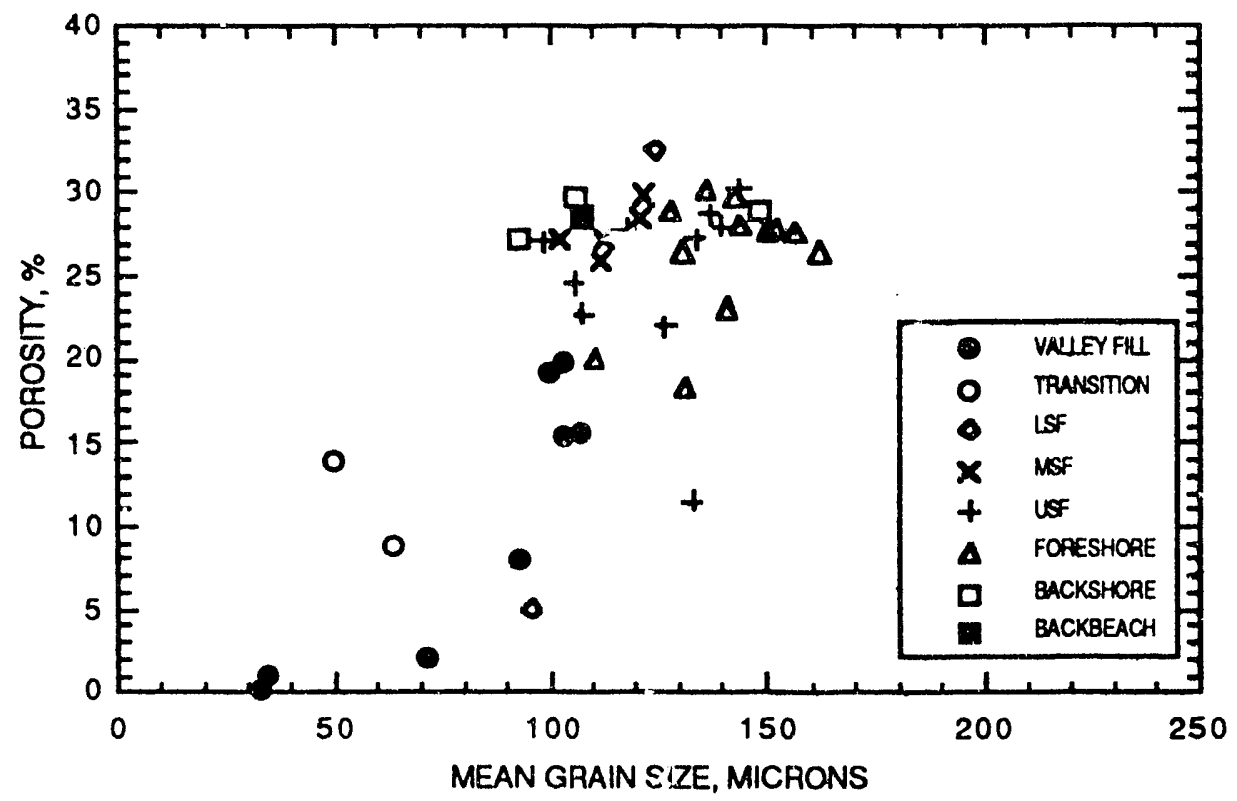

Figure 3.24 - Porosity versus mean grain size for subsurface Muddy Formation facies. Abbreviations listed in fig. 3.8.

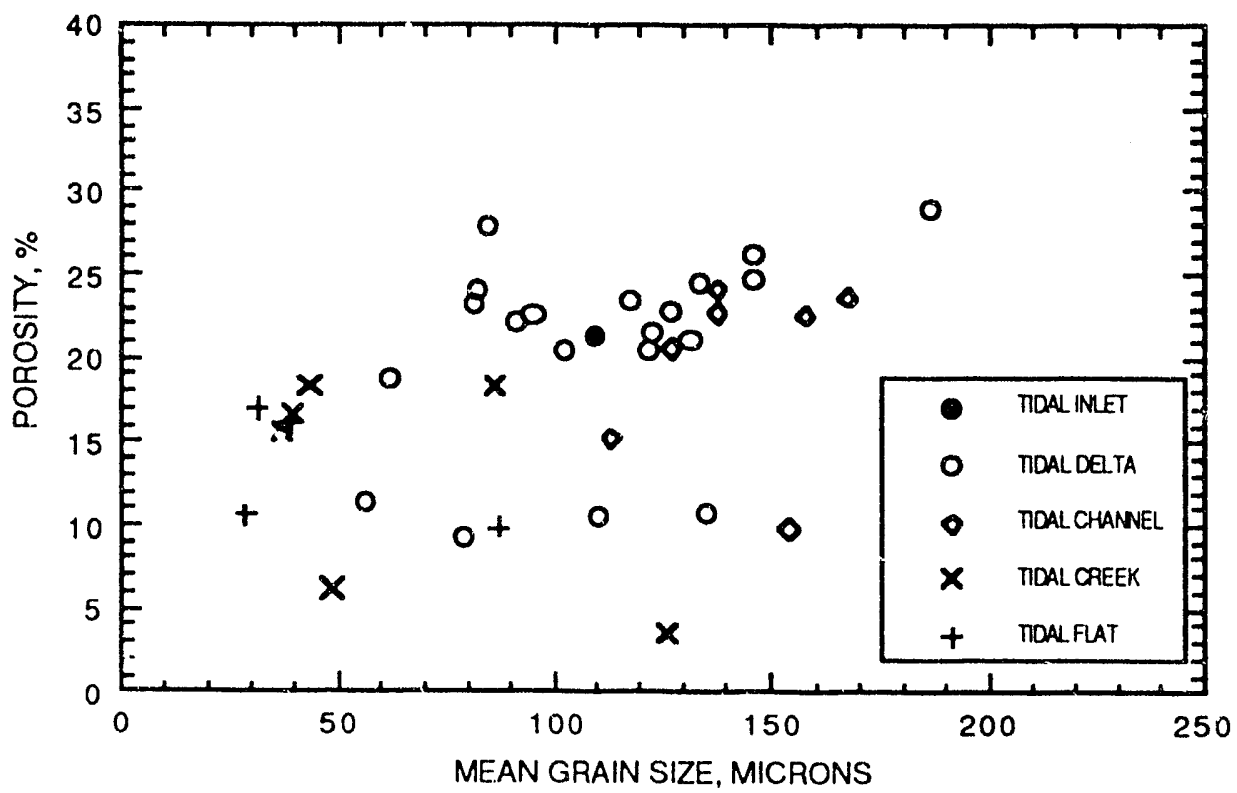

Figure 3.25 - Porosity versus mean grain size for subsurface Almond Formation facies. 


\section{Chapter 4}

\section{EFFECTIVE TECHNIQUES FOR CHARACTERIZING SHORELINE BARRIER RESERVOIRS (TASKS 3 AND 4)}

Prcliminary results from investigations of geostatistical techniques and wircline log subsurface stress analysis are discussed in this section. Geostatistical icchniques are required for reservoir characterization and subsequent rescrvoir modeling becausc of the inability to completely (detcrministically) sample a reservoir. Tic goal of developing geostatistical techniques is to cnable reservoir model construction that reflects both the deterministic and the statist:al sature of the data and that is compatible with the geolog: al understanding of the reservoirs. An important application of this investigation is to identify those reservoir properties that are characteristic of shoreline barrier reservoirs and can be used in reservoir model development. Insitu stress analysis from wircline logs will allow the prediction of natural fracture occurance and density.

\section{GEOSTATISTICAL STUDIES}

\section{Variogram and Cross-Variogram Analysis}

The aim of geostatistical analysis of data at various locations is to estimate values at unsampled locations. To achicve that aim, variogram analysis is used to define and model the spatial variability of samples. Variogram analyses are required for mapping formation propertics using linear kriging or indicator kriging techniques.

The variogram (Journcl, 1978) is a measure of the variability of two variables or onc variable but at two different points or locations. The larger the value of variogram, the greater the variability. For the same variable at different locations, the variogram function is shown to increase as the distance between the sample locations increases. The distance at which the variogram function reaches its maximum value is calied a corrclation scale length. The maximum value of varigram is called a sill, and the scale lerigth defines the range where a spatial correlation exists for the studied variable. Several possible corrclations have been defined which relate variogram function to the scale length.

The experimental variogram of $n$ sample points can be determined by

$$
\gamma_{h}=\frac{1}{2 n(h)} \sum_{i=1}^{n(h)}\left(Z_{i}(x)-Z_{i}(x+h)\right)^{2}
$$

where $n(h)$ is the number of pairs of data approximately $h$ distance apart. Typically, at least five pairs of data points are needed for each distance to make a reliable estimate of the variogram. Theoretically, the variogram value should be zero when distance h equals zero, because measurements at the same location should be equal. However, if the sampling distance is larger than the scale of variability, the variogram value will not be \%cro. This positive variogram value at distance h equal zero is called the nugget effect.

in contrast to the measurement of variability of the same variables with distance in variogram analysis, crossvariogram analysis measures the scalc of variability of two different variables with distance. The experimental crossvariogram of $n$ sample points can be determined by:

$$
\gamma_{x h}=\frac{1}{2 n(h)} \sum_{i=1}^{n(h)}\left(Z_{i}(x)-Z_{i}(x+h)\right)\left(Y_{i}(x)-Y_{i}(x+h)\right.
$$

where $n(h)$ is the number of pairs of data $\left(Z_{i}\right.$ or $\left.Y_{i}\right)$ approximatcly $h$ distance apart. Cross-variograms are applicable where the estimated value at the unsampied location can be related to measured values of different attributes. A good example would be an estimation of permeability values based on measurement of both permeability and porosity values.

\section{Variogram and Cross-Variogram Analysis of Porosity and Permeability Distribution}

A computer program was written to calculatc of variograms and cross-variograms of well profiles in Patrick Draw field based on the formulas given above. The variogram valuc at each distance was computed based on at lcast two pairs of data in this study. Therefore, the maximum distance of the variogram corresponds to one half of the total profile of the studied well.

Figure 4.1 presents the variograms of porosity and permeability profiles of well 15 in Arch Unit, Patrick Draw fieid. Well 15 produced more than 1 million barrels of oil in its primary production stage and is the best oil producer in Arch Unit. Both porosity and permeability values were measured in the laboratory from cores at onefoot spacing. The porosity profilc shows a correlation scalc length of 10 fect and the permcability profile shows a correlation scale length of $6 \mathrm{fcet}$. Both variograms exhivit little nugget effect since the value of the variogram approaches zero as the vertical distance decreases to zero. The smooth shape and the absence of a nugget effect of the cross-varicgram between porosity and permeability profiles indicates a well-established correlation between porosity and permeability for well 15 within a vertical distance of 10 fcet.

The variograms of porosity and permcability from well 20 are shown in fig. 4.2. Well 20 is one of the good oil producers in Arch Unit. Both variograms have correlation lengths of about 4 fect. Tine "hole" effect or cyclic change in wave shape in the variograms shows the layering 
phenomenon in well 20. The same scale length of 4 feet is observed in the cross-variogram of porosity and permeability data for well 20 (fig. 4.3).

The variogram of permeability for the 30 feet of pay studied in well 88 increases with vertical distance (fig. 4.4) for the entire correlation range of $15 \mathrm{fect}$. The permeability variogram has low values at distances of 5 to $10 \mathrm{fect}$, respectively. This corresponds to the flow unit thickness of 5 and 10 feet of well 88 in fig. 2.14. In contrast, the porosity variogram of well 88 shows a large nugget effect and litle correlation with distance. The low values in the porosity variogram at distances of 7 and 14 feet indicate a thickness of the "porosity-layer" of $7 \mathrm{fcet}$. The cross-variograms for porosity and permeability (fig. $4.5)$ of wcll 88 shows two correlation lengths at 3 and 11 fcet, respectively. Well 88 is a moderate producer with a cumulative oil production of 262,380 barrcls from primary production.

The variograms and cross-variograms derived this year will be used later for mapping interwell porosity and permeability values using kriging and cokriging techniques.

\section{Indicator Conditional_Simulation}

Conventional kriging provides an unbiased estimatc of parameters chosen at an unsampled location with minimum error variance. The technique is not designed to indicate patterns of spatial continuity, especially of extreme values. Instcad, conventional kriging generates a very smooth distributions which may not reveal typical extreme patterns critical to reservoir flow. Indicator function or indicator kriging can be effectively used to climinate this drawback of the conventional kriging method.

\section{Indicator Kriging}

Indicator kriging is based on the assumption that a data set can be divided into several groups or sub-data sets. Therefore, the indicator kriging field is not continuous but is grouped into discrete classes. Indicator kriging only indicates the class to which the simulated value belongs rather than providing a continuous value. However, these classes need not be of equal size, so onc can focus on that part of the range of variability most consequential to the mapping parameter.

Given a set of spatially distributed values, the indicator kriging algorithm defines a process for adding a valuc at any unsampled location such that the new value is consistent with the spatial correlation or variogram. Once obtained, this new simulated value is added to the initial $\mathrm{set}$ as an additional conditional data point, and the procedure is repeated. The final simulated ficld, by construction, will have the imposed spatial correlation and honor all initial data. The basic terms and procedures for calculating indicator valucs at unsampled locations are described bricfly as follows.
The indicator random variable at location $x$ and for threshold $Z^{\prime}$ can be defined as the following binary transform:

$$
\begin{aligned}
& I\left(x ; Z^{\prime}\right)=0 \text { if } Z(x)>Z^{\prime} \\
& I\left(x ; Z^{\prime}\right)=1 \text { if } Z(x) \leq Z^{\prime}
\end{aligned}
$$

The conditional expected value of $I\left(x ; Z^{\prime}\right)$ is

$$
\begin{aligned}
E & \left\{I\left(x ; Z^{\prime}\right) \mid Z\left(x^{*}\right), *^{*} \in(n)\right\} \\
= & 0 \times P\left\{Z(x)>Z^{\prime} \mid Z\left(x^{*}\right),{ }^{*} \in(n)\right\} \\
& +1 \times P\left\{Z(x) \leq Z^{\prime} \mid Z\left(x^{*}\right),{ }^{*} \in(n)\right\} \\
= & P\left\{Z(x) \leq Z^{\prime} \mid Z\left(x^{*}\right),{ }^{*} \in(n)\right\}
\end{aligned}
$$

Therefore, one can estimate the value of the conditional probability $\mathrm{P}\left\{\mathrm{Z}(\mathrm{x}) \leq \mathrm{Z}^{\prime} \mid \mathrm{Z}\left(\mathrm{x}^{*}\right),{ }^{*} \in(\mathrm{n})\right\}$ by estimating the corresponding indicator expectation $E\left\{I\left(x ; Z^{\prime}\right) \mid Z\left(x^{*}\right)\right.$, * $\in(n)\}$.

The estimation of that conditional expectation is made by kriging from the indicator transform of the conditional data (Journel, 1986). Kriging will provide the best linear unbiased estimator of the expectation

$\mathrm{E}\left\{\mathrm{I}\left(\mathrm{x} ; \mathrm{Z}^{\prime}\right) \mid \mathrm{Z}\left(\mathrm{x}^{*}\right),{ }^{*} \in(\mathrm{n})\right\}$ conditioned to the indicator data values corresponding to the $\mathrm{Z}\left(\mathrm{x}^{*}\right)$ data. The estimate of the conditional probability, $\mathrm{F}$, is obtained as a linear combination of the indicator data:

$$
\begin{aligned}
F\left\{x ; Z^{\prime} \mid Z\left(x^{*}\right),{ }^{*} \in(n)\right\} & =P^{*}\left\{Z(x) \leq Z^{\prime} Z\left(x^{*}\right),{ }^{*} \in(n)\right\} \\
& =\sum_{*=1}^{n} \lambda^{*}\left(x ; Z^{\prime}\right) I\left(x^{*} ; Z^{\prime}\right)
\end{aligned}
$$

where $\mathrm{I}\left(\mathrm{x}^{*}, Z^{\prime}\right)$ is the indicator transform of the sample value $Z\left(x^{*}\right)$ for the threshold $Z^{\prime}$ and $\lambda^{*}\left(x, Z^{\prime}\right)$ is the corresponding indicator kriging weight. The weights are obtained by solving a kriging system using the indicator covariance function $\mathrm{C}_{\mathrm{I}}\left(\mathrm{h} ; Z^{\prime}\right)$ specific to the binary random function $\mathrm{I}\left(\mathrm{x} ; \mathrm{Z}^{\prime}\right)$ :

$$
\begin{aligned}
& \sum_{\beta=1}^{n} \lambda_{\beta}\left(x ; Z^{\prime}\right) C_{1}\left(x_{\beta}-x^{*} ; Z^{\prime}\right)+\mu\left(x ; Z^{\prime}\right) \\
= & C_{I}\left(x-x^{*} ; Z^{\prime}\right) \quad\left({ }^{*}=1, \ldots, n\right) \\
& \sum_{\beta=1}^{n} \lambda_{\beta}\left(x ; Z^{\prime}\right)=1
\end{aligned}
$$

where $\mu$ is the Lagrange multiplier

Thus, as many indicator covariance functions $\mathrm{C}_{\mathrm{I}}\left(\mathrm{h} ; \mathrm{Z}^{\prime}\right)$ as threshold values $Z^{\prime}$ used to discretize the range of variability of $Z(x)$ must be inferred.

\section{Indicator Conditional Simulation}

The generation of cquiprobability maps with a given spatial structure is termed stochastic simulation. If the 
maps are made to honor the data at the sample locations then the technique is termed stochastic conditional simulation or conditional simulation. The term simulation here does not refer to simulation of the dynamic fluid flow in reservoirs. Instead, it refers to the generation of static rock properties based on a limited set of data.

An indicator kriging conditional simulator ISIM3D, developed at Stanford University, was used in this study. The algorithm and detailed procedure implementing indicator simulation in ISIM3D is explained by Gome\%Hemandez and Srivastava (1990).

ISIM3D was developed for the Macintosh computer in C language. Three types of input files are required for ISIM3D simulation: geometry, variogram, and conditional data files. The geometry file defines the reservoir size, reservoir grids, and searching ellipsoid radii in threc directions during simulation. The variogram file specifies types and related parameters of variograms for data to be simulated. The values and locations of sampled data to be honored are listed in the conditional data file.

Indicator conditional simulations were conducted to map permeability data from two areas: Shannon Sandstone outcrop data, Natrona Co., WY and Patrick Draw ficld, Sweetwater Co., WY. Samples from the Shannon Sandstone outcrop were used to test the ISIM3D model because they are closely spaced $(0.5 \mathrm{ft})$ and well characterized from previous NIPER studies.

\section{Shannon Outcrop Simulations}

Permeability values from 1 -inch diameter core plugs drilled from the Shannon sandstone outcrip, a shelf sand ridge system, from a 21 by $4 \mathrm{ft}$ area, spaced approximatcly $0.5 \mathrm{ft}$ apart (fig. 4.6) were mapped using indicator simulation techniques. This work, along with work funded by industrial clients was presented at the Third International Reservoir Characterization Technical Conference (Tomutsa, et al., 1991). The arca is located within the High Energy Ridge Margin facies (HERM), which is a highly stratified unit that consists of 0.25 to $0.5 \mathrm{ft}$ thick trough and subhorizontal cross-beds. The permeability distribution at this outcrop is bimodal and reflects the presence of the two stratification types and lithologies. The glauconite-rich cross-beds have a mean permeability of about 500 md while the finer-grained beds have a mean permeability of about $50 \mathrm{md}$. The lateral extent of these beds ranges between 10 and 20 feet. The detailed permeability distribution based on geological observations of the studied Shannon outcrop in fig. 4.6 is called geological model in this study.

\section{Permeability Simulations}

Permeability values from the 21 by 4 ft outcrop area was simulated in a $2 \mathrm{D}$ model divided into 85 by 17 grid blocks creating 3 by 3 inch grid blocks. A spherical variogram was assumed for the permeability distribution with a normalized nugget value of 0.2 . The scale lengths studied ranged from 5 to $20 \mathrm{fect}$ in the horizontal direction and 3 to 6 inches in the vertical direction.

The first indicator simulation of permeability distribution was conditioned using all permcability measurements from 50 outcrop plugs. It was thought that the best mapping could be oblained by using all the control data available. Among these, 33 (or $66 \%$ ) have permeability values greater than $200 \mathrm{md}$. This is in contrast to $25.5 \%$ of high permeability sandstone shown in fig. 4.6. These "biased" permeability input data in the indicator simulation explain the high permcability arcas in the simulation result in fig. 4.7. The correlation scale lengths used are $20 \mathrm{ft}$ in the horizontal direction and 6 inches in the vertical direction.

A significant improvement over the degree of similarity to the geological model in fig. 4.7 was obtained from an alternative set of indicator simulations which were conditioned at two vertical profiles of permeability values at the two opposite edges of the outcrop study area. Eight of thirty-four permeability values (or $23.5 \%$ ) in the two vertical profiles are greater than $200 \mathrm{md}$. This ratio is close to the percentage of high-permeability sand found in the studied Area B. The simulated permeability distribution, shown in fig. 4.8 , reflects similar proportion and distribution of high-permeability sand compared to the distribution of permeability in outcrop (fig. 4.6) or the geological model. The correlation scale lengths used are $20 \mathrm{ft}$ and 3 inches, respectively, in horizontal and vertical directions. The seeds used in random number generations in simulations are $10,30,50$, and 100 , respectively, for simulation maps shown in figs. $4.8 \mathrm{~A}-\mathrm{C}$. The seed value is used in random number generating formula to generate a set of random numbers. Different sets of random numbers resulting frorn different seed values provide equal-probable permeability maps which all honor the same geostatistical parameters. The probabilistic character of these permeability maps stems from the uncertainty based on limited permeability information (34 permeability conditioned values out of 1,445 grids, or $2.4 \%$ ) available from the two permeability profiles.

The effects of correlation length values on simulations of the 21 by 4 ft outcrop area were studied. Figure 4.9 shows the permeability maps gencrated using the same geostatistical parameters as those in fig. 4.8 except that the vertical correlation length was changed from 3 to 6 inches. Three seed values were used, respectively, for generating figs. 4.9A-C. Compared to fig. 4.8 , the decrease in correlation length contrast between horizontal and vertical directions in fig. 4.9 reduced the continuity of highpermeability sand in the horizontal direction and increased the distribution scattering in the vertical direction.

As expected, the small horizontal correlation length reduces the horizontal continuity or connectivity of sands in indicator simulations. The horizontal correlation length was reduced to $10 \mathrm{ft}$ in fig. 4.10A and $5 \mathrm{ft}$ in lig. 4.10B. A seed value of 30 was used and the vertical correlation length was kept constant at 6 inches. While the permeability map in fig. $4.10 \mathrm{~A}$ is similar to that in fig. 
$4.9 \mathrm{~B}$ due to a limited model width of $21 \mathrm{fect}$, a short corrclation length of $5 \mathrm{fect}$ in fig. 4.10B showed a considerable scattering of high-permeability sand in the vertical direction.

\section{Waterflood Simulations}

Reservoir simulations of oil recovery from waterflooding were conducted on Shannon outcrop for both the geological model (fig. 4.7) and indicator conditional permeability models (fig. 4.9A-C) of the Sannon outcrop. A black oil reservoir simulator modified from BOAST (Fanchi et al., 1982) to incorporate multiple relative permeability tables was used. Two sets of PVT values, which correspond to oil gravities of API $35^{\circ}$ and API $20^{\circ}$, respectively, were uscd in simulations for studying oil recoveries from different permeability models. Only water and oil phases were assumed to be present in the model with initial oil saturations of $80 \%$ and $50 \%$, respectively, which werc assigned to arcas with permeability values above and below $200 \mathrm{mD}$, respectively In the simulation configuration the water injection (or source) was assigned to all grid blocks at one edge of the model and production (or sink) was from all grid blocks at the opposite cdge.

Predicted oil recovery from waterflood simulations of threc indicator conditional models were compared to those predicted for the gcological model of Shannon outcrop using $35^{\circ}$ API gravity oil. The geologic model contained the maximum amount of detcrministic information and is considered the most accurate of all the models generated. Predicted oil recoverics from the indicator models are slightly optimistic compared to those of the geological model (fig. 4.11). The higher predicted recovery rates are due to an improved sweep efficiency duc to poor connectivity of the high permeability layers in the indicator permeability models. In the geological model, a continuous high-permeability layer channels the water and reduces the sweep efficiency. Oil recovery predictions among the three indicator models were within $7 \%$ of cach other.

In contrast to optimistic predicted recoveries for $35^{\circ} \mathrm{API}$ gravity oil, the three indicator permeability models predicted slightly pessimistic recovery for $20^{\circ}$ API gravity oil compared to the geological model (fig. 4.12). The poor connectivity of high permeability layers in the indicator models forced the injected water into low-permeability sands which aggravated the water channeling phenomena in an environment of mobility ratio greater than 1 . Oil recovery predictions among the threc indicator models were within 5\% of cach other for the $20^{\circ}$ API oil casc. Comparison of the oil recovery predictions from indicator permeability models and the geological model indicated that the indicator permeability models reasonably represent the detailed geological model (figs. 4.11 and 4.12).

In conclusion, indicator simulation conducted on permeability data from Shannon outcror ' $:$ an appropriatc technique for mapping interwell permcability when (1) epprescritative proportion of high and low permeability data, and (2) correct correlation lengths derived in permeability variograms are used for simulations.

\section{Interwell Simulations in Patrick Draw Field}

Indicator conditional simulations were performed to generatc two- and three-dimensional interwell permeability distributions in wells in Patrick Draw field. The purpose of this preliminary interwell simulation was to study the feasibility of applying indicator kriging on 3D simulations using field data.

\section{Two-Dimensional Simulations}

Figure $4.13 \mathrm{~A}$ shows the cross sectional permeability map conditioned on the permeability from well 15 , which is the first column on the left edge and the permeability from wall 21 on the 46th column on the right side of the map. Table 4.1 lists the input data which includes the geostatistical parameters. The original permeability measurements of wells 15 and 21 are listed in table 4.2. To simulate the two lithologies in the outcrop an indicator function value of 1 is assigned for the permeability value greater than $100 \mathrm{mD}$ in the input for the glauconite-rich cross-beds and an indicator value of 0 is assigned to permeability value less than $50 \mathrm{mD}$ for fine-grained beds. The interwell cross section is dimensioned at 50 grids in the horizontal direction and 33 grids in the vertical direction. Two variogram models with scale length of $1,000 \mathrm{fect}$ and $6,000 \mathrm{fect}$, respectively, are superimposed to establish the permeability variogram. A seed value of 10 is used in generating random numbers during the indicator simulation. The simulated permeability distribution shown in fig. $4.13 \mathrm{~A}$ has high permeability zones (represented by a value of 1) scattered between the two wells studicd. The high permeability layer observed at the bottom part of well 15 does not continuc to well 21 in fig. $4.13 \mathrm{~A}$.

Figures $4.13 \mathrm{~B}$ and $\mathrm{C}$ show the permeability maps derived from same data files as those in fig. $4.13 \mathrm{~A}$ except that different seed values were used for the random number generation. A secd value of 30 was used for generating fig. $4.13 \mathrm{~B}$ and 100 was used for fig. $4.13 \mathrm{C}$, respectively. Figures 4.13A-C show quite different permeability distributions, however, all of them predict a poor flow continuity between wells 15 and 21 .

\section{Three-Dimensional Simulations}

Threc dimensional indicator simulations were conducted to map interwell permeability for wells 13,15 , and 21 . The reservoir model was dimensioned at grids of $(30 \times 30 \times$ 8). The input data including the variogram model parameters are listed in table 4.3. The arcal permeability distributions derived for 8 layers are shown in fig. 4.14. Permeability values at the leficorner on the top row are conditioned by the permeability profile of well 15, and 
permeability values at the right corner on top and bottom rows were conditioned by permcability data from wells 21 and 13 , respectively. The seed value used was 10 .

The indicator simulation predicted a high permeability sand in layers 6 and 7 close to the bottom of the pay (fig. 4.14). Layer 6 extends from well 15 to well 21 and layer 7 connects all three wells. High permeability sands which scatter around one well or between two wells lail to connect other wells in the rest of the layers. More than $30 \%$ of the sands show good permeability (above $50 \mathrm{md}$ ) from three simulated cored wells; however, only $25 \%$ of the pay (or 2 out of 8 layers) was predicted to have interwell continuity of good sands. The lack of interwell continuity of good permeability sands compared to well permeability profiles of wells 13,15 and 21 suggests that the fluid injectivity would be poorer in this area than for those models that assume continuous layers of high permeability sands between wells. Field results of wells 13,15 , and 21 will be compared with wateritood predictions based on the indicator simulation ristadel developed in this section.

A map of equally probable interwell spatial permcability distributions based on seed number of 30 was generated for wells 13,15 and 21 using indicator simulation. Interwell continuity of good permeability sands was predicted for layers 1 and 7. The distribution of good permeability sands, similar to that observed in fig. 4.14, was found in other layers. Again, the discontinuity of good permeability sands between wells indicates a potential for low injectivity in this area.

Preliminary indicator simulations showed that ISIM3D can be used to perform 3D simulations of permeability values in Patrick Draw ficld. Permeability correlation lengths from variogram analyses are required for reliable indicator simulations.

\section{Small-Scale Permeability Variation}

Permeability is an important formation characteristic because this elementary rock property dictates the fluid flow within the formation. Heterogeneous permeability profiles determine the injection profiles and fingering phenomena in the vertical direction and flow paths in the horizontal direction. However, the permeability profile at small-spacing is not generally available due to the time consuming procedure of conventional methods of measuring permeability. An alternative for measuring rock permeability is the use of a portable mini-permeameter (MPM).

\section{Mini-Permeameter}

The MPM is a simple gas-flow measuring device designed to make a large number of rapid, localized, nondestructive permeability measurements. MPM does not require the drilling of core plugs, and therefore, saves data collection time.
The MPM measures the flow rate and injection pressure of gas to determine permeability. A MPM designed and constructed at NIPER was used to measure permeability of outcrop. rock in this study. Flow, gencrated by a compressed gas source, passes through the pressure gauge and the flow meter tube before it reaches the rock to be measured. A pressure gauge monitors the pressure of the now at the point where the injection-tip touches the rock surface. Two gauges having different pressure ranges, 5 and 30 psig, provide a larger range of permeability valucs to be measured than single pressure gauge. Two fiow meters can be used to measure flow rates ranging from 1 to $25 \mathrm{~mL} / \mathrm{sec}$. This combination of pressure gauges and flow meters makes it possible to measure permeability values ranging from 10 to $3,()()$ ) milidarcics.

Nitrogen was used as the gas source because it is noncombustible and inexpensive. The sizc of the injection-tip is 0.25 and 0.75 inches for the inside and outside diameters, respectively. A good seal between the injection(ip) and the rock surface is critical for accurate measurements of both pressure drop and llow rate. A flat rock surface is necessary at the measurement point. Another procedure used to improve seal quality was the preparation of a pliable end at the injection-tip using the silicon rubber scal. Silicon rubber deforms slightly to adjust to small irregularitics on the rock surface. The silicon rubber on the injection-tip needs to be replaced periodically to insurc a good quality of scal.

\section{Calibration of Mini-Permeameter}

The MPM was calibrated for ils measurement of pressure, llow rate, and permeability before use. The pressure gauges were calibraled against a mercury manometer. The heights of two mercury columns of the manometer were recorded for each reading of the pressure gauge. The height difference between the two mercury columns was then converted to the pressure value in the calibration curve. Figure 4.15 shows the calibration curves for the two pressure gauges used in NIPER's MPM. The readings of the high pressure gauge appear to agrec well with readings from the low pressure gauge which are lower than measurements from mercury columns. This indicates less reliable readings from the low pressure gaugc in this MPM.

The flow meters were calibrated against a bubble meter. The procedure consists of measurements of the time required by a nitrogen gas bubble to travel a fixed volume in the tube in the bubble meter. At the same time, flow rate readings of two balls within the flow meter column were recorded. The black ball has a lighter weight than the silver ball to provide the black ball a larger range of flow rate measurement than the silver ball. The resulting calibration curves of two flow meters for black and silver balls, respectively, are shown in fig. and 4.16.

The permeability measurements of the MPM were calibrated against rock of known permeability. The calibration procedure consists of stcady-state measurements 
of the gas rate $(\mathrm{Q})$ and injection pressure $(\mathrm{P})$ at the point of injection. The ratio of $Q$ over $P$ was plotted against the corresponding rock permeability to provide a calibration curve. The permeability calibration curve was found to be sensitive to the applied pressure from the gas source. This might be caused by different flow depths and paths of gas into the measured rock. Figure 4.17 shows the calibration curve of permeability at an applied pressure of $2.5 \mathrm{psig}$.

\section{Permeability Profile of Outcrop Corehole Number 2}

Corehole No. 2 is a hole drilled near the outcrop penetrating the upper Almond Formation drilled in the NE1/4 of Section 19 (T15N, R102W). More than 600 rock permeability values were measured on corehole No. 2 using the MPM. Permeabilities were measured at 1 -inch spacing for 16 fect of core ranging in depths of 56.6 to $64.8 \mathrm{ft}$ and 190.0 to $198.3 \mathrm{ft}$. Measurements were conducted at 3-inch spacing for a total of $147 \mathrm{fect}$ of core ranging from depths of 96 to $112 \mathrm{ft}, 146$ to $166 \mathrm{ft}$, and 198 to $295 \mathrm{ft}$. The measured permeability values show significant variations ranging from less than $10 \mathrm{md}$ to more than 1 darcy (fig. 4.18) although the macroscopic lithology variation is not evident. The rest of the rock from corehole No. 2 shows low permeability with values less than $20 \mathrm{md}$, or below the lower limit measurable from NIPER's MPM.

The permeability profile of corchole No. 2 was calculated into variograms (fig. 4.19-4.21) at three depths. The hole effect shown in all threc variograms suggests layers of thickness ranging from 18 to $27 \mathrm{ft}$. The amount of nugget effect indicates the randomness of rock permeability values. At depths from 56 to 89 fi the nugget effect is $23 \%$ of its largest variogram value (fig. 4.19) calculated in this range. The nugget effect shown in lig. 4.20 is $22 \%$ of its largest variogram value calculated from depths 96 to $112 \mathrm{ft}$. The variogram exhibits two peak values for permeability profile ranging from 190 to $295 \mathrm{ft}$. The nugget effect in this range is $37 \%$ of its first peak variogram value and $26 \%$ of its second peak value. The randomness of the permeability distribution at the small scale reflects the rock's local heterogeneity which dictates the development of fingering of fluid flow in porous media. The small-scale heterogeneity in rock permeability is able to reduce the fingering tendency and delay the break through time in waterflooding processes (Tomutsa, et al., 1991).

\section{Permeability Profiles of Cored Wells in Patrick Draw Field}

Using the MPM, permeability profiles (shown in figs. $4.22,4.23$, and 4.24) were obtained, respectively, for cored wclls 120, 121, and 123 in Patrick Draw ficld.

The permeability variogram of well 120 (fig. 4.23) indicates a layer thickness of $11 \mathrm{ft}$. The nugget effect is more than half of its largest variogram value for this well.
The permeability variogram of well 121 is shown in fig. 4.24. A layer thickness of $14 \mathrm{ft}$ is suggested by the minimum variogram values at that distance in the variogram. The permeability nugget is about $30 \%$ of its largest variogram values calculated. The nugget or randomness of permeability distribution provides important information to study its effect on fluid flow in rocks using the reservoir simulation technique.

Cored well 123 showed a large nugget effect in its permeability variogram (fig. 4.25). The small spatial correlation of permeability values in the vertical direction means a lack of layer permeability contrast that a nearly homogeneous fluid front is present around well 123. Also, none of the three cored wells mentioned above developed a complete variogram curve from which the correlation length could be derived.

None of the cores studied from the outcrop or Patrick Draw field showed completely developed variograms from vertical permeability profiles because of thin layers. However, certain varoigram models for permeability could be approximated for those cores for kriging calculations. Effects of permeability variations in the vertical direction on fluid flow will be studied later using numerical simulation techniques.

\section{WIRELINE LOG INVESTIGATION OF THE EFFECT OF SUBSURFACE STRESSES ON FLUID PRODUCTION IN PATRICK DRAW FIELD, WY}

The highly variable primary oil production rates and the very low waterflood recovery ( $4 \%$ of OOIP) in the $A_{1}$ ch Unit of Patrick Draw field raise the possibility that besides the effect of hetcrogencous lithology that reduces permeability, fractures (both natural and hydraulic), might contribute to unpredictable oil production patterns. From available density, sonic, and resistivity $\log$, reliable estimates of the distributions of overburden stresses and average formation fluid pressure gradient can be made for the depositional basin. This information is essential to determine if the formation pressure at Patrick Draw field is different from hydrostatic and if the stresses on the rock matrix is large enough to causc fractures in the type of lithology encountered in Patrick Draw field.

\section{Subsurface Stresses and Stress Gradients}

The subsurface stresses on reservoir rocks and on fluids within the pore spaces that have to be considered in understanding the fracture and flow properties of reservoir rocks are the overburden pressure, $S$, the pore fluid pressure, $P$, and the rock frame stress $\sigma_{v}$. For equilibrium conditions, the three stresses are related (Terhagi and Peck, 1948) as follows:

$$
S=\sigma_{1}+P
$$


Thus, when the formation fluid pressure is higher than normal, the stresses on the rock matrix diminish from the normal values. The overburden stress $S$ due to a load of sediments of density $\rho$ and thickness $D$ is given by the equation

$$
S=\rho g D
$$

where $\mathrm{g}$ is the acceleration due to gravity.

From the above equation, if density values are available from the density logs, the overburden stresses may be calculated at different depths by integrating the density logs. In fig. 4.26, the plots of ovcrburden stresses and overburden stress gradients (variation of stress with depth) for wells Arch 91 and Arch 100 are presented. Since Arch 100 was not logged above $2,272 \mathrm{ft}$, an average density obtained from Arch 91 was used for the computations in the shallow depth range in this well. Fig. 4.26 indicates that the overburden stress gradients in the two wells are very similar implying that there is no significant lateral variation in sediment densities between the two wclls. It should, however, be noted that if actual densities for Arch 100 were available for this shallow depth range (from surface to 2272') the stress-depth profiles for the two wells might show a different separation although the slopes in the two curves would still be the same. The almost linear variation of stresses with depth and small fluctuations in the gradient curves indicate that although $S$ is primarily a function of sediment loading. Lithological variations or tectonic stresses could also contribute to overall stresses at certain depths which are given in feet above sea level, (asl) in fig. 4.26. At the reservoir levels, the overburden stresses for the two wells studied are shown in table 4.4. The above stress gradients are slightly in excess of those encountered in the younger tertiary sediments in the Texas Gulf Coast region (Terhagi and Peck, 1948).

\section{Pore Fluid Pressure}

According to Hubert and Rubey's (1959) theory, the porosity of shales should decrease due to compaction as the depth of burial increases. Hottman and Johnson (1965) observed that this change in porosity due to compaction should be recognizable from changes in sonic transit times in shales (which compact much more than sandstones). Under normal hydrostatic conditions, the sonic transit time in shales was found to decrease linearly on a plot of logarithm of transit time against depth in the Texas Gulf Coast region. In the same areas, Hottman and Johnson (1965) also observed that the resistivity in shales showed a gradually increasing trend due to the expulsion of more and more saline water as a result of increasing compaction with depth (Hotuman and Johnson, 1965).

The logarithms of sonic transit times and induction resistivities of shales have been plotted as functions of depth given in elevations above sea level for wells Arch 79 and 84 (fig. 4.27). Overall, the transit times show a gradually decreasing trend with depth due to the effect of normal compaction in the study area. Deviations from the normal trend could be cither because the lithology of some of the data points is not pure shales or pore fluid pressures are significantly over or under normal hydrostatic pressures.

Unlike the Texas Gulf Coast arcas, the resistivitics show a decreasing trend with depth in the two wells studied (fig. 4.27). Apparentally, this is due to an increase in formation water salinity with depth in Patrick Draw field for the depth interval studied. An approximate estimation of formation water salinity from SP $\log$ in Arch 100 indicate that at shallow depths (above 2,000 ft from ground levcl) the salinity decreases but there is sharp increases in salinity below $2,000 \mathrm{ft}$ from the surface. The shale resistivity variation trend at Patrick Draw field, therefore, is the combined effect of salinity variations as well as fluid cxpulsion due to compaction. Also, the effect of resistivity decreases due to an increase of salinity with depth must be significantly high because it has completely annulled the effect of increasing resistivity with depth due to fluid expulsion as a rcsult of sediment compaction. Additional resistivity-depth or sonic transit time-depth plots will be necessary before a more definite conclusion about subsurface fluid pressure distribution at Patrick Draw ficld may be drawn.

From equation (1) above it may be seen that knowledge of overburden load or stress $S$ and formation fluid pressure $P$ is necded to determine grain-to-grain bearing strength $\sigma_{v}$ of the rock matrix. In an analogous study carried out by Crammer (1991) in the Bakken Shale reservoir it was shown how, as fluid pressure increased during hydrocarbon generation, the effective rock stress decreased which ultimately led to tensile rock failure and the development of vertical fractures. Such a fracture system may close partially when pore pressure decreases with fluid withdrawal (production). The effect of fracture volume compressibility is a reduction in permeability and oil displacement efficiency of the formation (Crammer, 1991).

In the next phase of investigation of in-situ stress distribution at Patrick Draw field, the magnitudes of the threc principal stresses in the formation, which are functions of the elastic properties of rocks besides overburden load and pore pressure, will be estimated. Whether a formation is likely to part will depend on the magnitude of the three principal stresses and the applied injection pressure.

\section{CONCLUSIONS}

1. Variogram and cross-variogram analyses of porosity and permeability profiles for wells 15,20 , and 88 in Patrick Draw licld showed spatial correlation lengths ranging from 4 to $15 \mathrm{fect}$.

2. Indicator simulations conducted on permeability data from the Shannon Sandstone outcrop is an appropriate technique for mapping interwell permeability when (1) a representative proportion of high and low permeability 
data, and (2) correct correlation lengths for permeability are used in the simulations.

3. Comparison of the oil recovery predictions from indicator permeability models and the geological model indicated that the indicator permeability models reasonably represent the detailed geological model.

4. Oil recovery predictions among the threc indicator models were within less than $5 \%$ of each other for the $20^{\circ}$ API oil case. In contrast to optimistic predictions of recoveries for $35^{\circ}$ API gravity oil, the three indicator permcability models predicted slightly pessimistic recoveries for $20^{\circ} \mathrm{API}$ gravity oil compared to the gcological model.

5. Indicator simulation results showed a lack of interwell continuity of good permcability sands among wells 13, 15 and 21 compared to permeability profiles of these three wells. This suggests that the fluid injectivity would be poorer in this area than for those models that assume continuous layers of high permeability sands between wells. Preliminary indicator simulations showed that ISIM3D can be used to perform 3D simulations of permcability values in Patrick Draw ficld.

6. A mini-permeameter was constructed and calibrated at NIPER for mcasuring permcability valucs of rock from outcrop and cored wells in Patrick Draw ficld. More than 600 rock permcability values were measured on outcrop corchole No. 2 at 1- to 3-inch spacing. Variogram analyses of this closely spaced permeability profile showed a nugget effect of $22 \%$ to $37 \%$ of its maximum variogram values and laycrs of thickness ranging from 18 to $27 \mathrm{fcct}$.

7. Very good estimation of overburden stresses could be obtained from integration of density logs.

8. Unlike in the Texas Gulf coast arcas where a remarkably consistent fluid pressure gradicnt of around $0.46 .5 \mathrm{psi} / \mathrm{ft}$ is obtained, the trend obtained from the transit lime data in shales in Patrick Draw ficld is not striclly lincar. The effect of non-shale lithology or over or under pressured zoncs may contributc to deviations from the normal trend. More work is needed to determine the nature of formation fluid pressure distribution at Patrick Draw ficld.

9. The variation of shale resistivity with depth in Patrick Draw ficld is not only a function of the amount of water in the pore spaces but also depends upon variation of salinity of formation water. There secms to be significant variation in salinity of pore fluids above the producing formation at Patrick Draw ficld. Further studies will be needed to obtain information on pore fluid pressures from the resistivity plot and brine compositions.

10. The propensity of rocks to fracture will depend upon the magnitude of overburden and formation fluid pressures and the elastical constants (Poisson's Ratio) (Eaton, 1969) of rocks. Poisson's ratio of different lithologies encountered at Patrick Draw field will be compared to identify the lithologies that are most prone to fracturing.

\section{REFERENCES}

Cramer, D. D. 1991, Understanding the Reservoirs. Importance to Successful Stimulation. Oil \& Gas Jour., v. 89, no. 16, p. $53-61$.

Eaton, B. A. 1969, Fracture Gradient Prediction and its Application in Oilfield Opcrations. J. Pet. Tech., v. 21, p. $1353-1360$.

Fanchi, J. R., K. J. Harpole, and S. W. Bujnowski. September 1982, BOAST: A Three-Dimensional, ThreePhase Black Oil Applied Simulation Tool. DOE/BC/1(0)33-3 (DE83000529), 180 p.

Gomez-Hernande\%, J.J. and R.M. Srivastava. 1990, ISIM3D: An ANSI-C Threc-Dimensional Multiple Indicator Conditional Simulation Program. Computers \& Geosciences Vol. 16, No. 4, p. 395-440.

Hottmann, C. E., and R. K. Johnson. 1965, Estimation of Formation Pressures from Log-Derived Shale Propertics. J. Pet. Tech., v. 17, p. 717.

Hubbcrt, M. K., and W. W. Rubcy. 1959, Role of Fluid Pressure in Mechanics of Overthrust Faulting, Part 1. GSA Bull., p. 70.

Journal, A.G. and C. J. Huijbregts. 1978, Mining Gcostatistics. Academic Press, London, $6(X) \mathrm{p}$.

Journel, A.G. 1986, Constrained Interpolation and Soft Kriging. Proc. 19th APCOM Symp. Pub. Soc. Min. Eng., Liltleton, Colorado, p.15-30.

Terhagi, K., and R. B. Peck. 1948, Soil Mechanics in Enginecring Practice. John Wilcy and Sons, Inc., New York, $566 \mathrm{p}$. 
TABLE 4.1 - Data file of Shannon outcrop for indicator simulation

Reservoir Grid Model:

grid spacing: $\quad 40 \mathrm{ft}$, by $1 \mathrm{ft}$, by $1 \mathrm{ft}$

grid domain: $\quad 50 \times 1 \times 33$

secd for random number gencration: 10

Nugget: 0.200

Max Covariance (for lincar models): $1 .(0(0)$

Number of structures $\rightarrow>2$

Structure 1

model

sill

range, $\mathrm{ft}$

$x$ direction

$z$ direction
Spherical

0.4

1,000

5)
Structure 2

Spherical

0.4

$6,00(0)$

$30)$ 
TABLE 4.2 - Permeability (k) profiles of wells 13, 15, and 21 in Arch Unit, Patrick Draw Field

\begin{tabular}{|c|c|c|c|c|c|}
\hline \multicolumn{2}{|c|}{ Well 13} & \multicolumn{2}{|c|}{ Well 15} & \multicolumn{2}{|c|}{ Well 21} \\
\hline $\begin{array}{l}\text { Depth } \\
\text { (ft) }\end{array}$ & $\underset{(\mathrm{mD})}{\mathbf{k}}$ & $\begin{array}{l}\text { Depth } \\
\text { (ft) }\end{array}$ & $\underset{(\mathrm{mD})}{k}$ & $\begin{array}{c}\text { Depth } \\
\text { (ft) }\end{array}$ & $\underset{(\mathrm{ml})}{\mathbf{k}}$ \\
\hline 4830 & 17 & 4576 & 39 & 4648 & 2.0 \\
\hline 4831 & 46 & 4577 & 14 & 4649 & 4.5 \\
\hline 4832 & 43 & 4578 & 11 & 4650 & 11.4 \\
\hline 4833 & 7.3 & 4579 & 10 & 4651 & 13 \\
\hline 4834 & 19 & 4580 & 71 & 4652 & 17 \\
\hline 4835 & 52 & 4581 & 47 & 4653 & 31 \\
\hline 4836 & 3.2 & 4582 & 76 & 4654 & 24 \\
\hline 4837 & 0.05 & 4583 & 62 & 4655 & 17 \\
\hline 4838 & 0.27 & 4584 & 44 & 4656 & 42 \\
\hline 4839 & 0.3 & 4585 & 24 & 4657 & 29 \\
\hline 4841 & 268 & 4586 & 23 & 4658 & 40 \\
\hline 4842 & 1.2 & 4587 & 22 & 4659 & 14 \\
\hline 4843 & 89 & 4588 & 31 & 4660 & 85 \\
\hline 4844 & 43 & 4589 & 15 & 4661 & 37 \\
\hline 4845 & 9.1 & 4590 & 22 & 4662 & 47 \\
\hline 4846 & 0.06 & 4591 & 9.1 & 4663 & 23 \\
\hline 4847 & 0.11 & 4592 & 8.3 & 4664 & 16 \\
\hline 4848 & 28 & 4593 & 23 & 4665 & 55 \\
\hline 4849 & 18 & 4594 & 10 & & \\
\hline 4850 & 21 & 4595 & 16 & & \\
\hline 4851 & 14 & 4596 & 23 & & \\
\hline 4852 & 3.2 & 4597 & 8.3 & & \\
\hline 4853 & 1.3 & 4598 & 99 & & \\
\hline 4854 & 43 & 4599 & 59 & & \\
\hline 4855 & 34 & 4600 & 139 & & \\
\hline 4856 & 11 & 4601 & 268 & & \\
\hline 4857 & 25 & 4602 & 265 & & \\
\hline 4858 & 12 & 4603 & 104 & & \\
\hline & & 4604 & 139 & & \\
\hline & & 4605 & 21 & & \\
\hline & & 4606 & 51 & & \\
\hline & & 4607 & 82 & & \\
\hline & & 4608 & 42 & & \\
\hline
\end{tabular}


TABLE 4.3. Input data of threc-dimensional indicator simulation for wells 13 , 15 , and 21 in Palrick Draw ficld

\section{Reservoir Grid Model:}

grid spacing: $100 \mathrm{ft}$, by $100 \mathrm{ft}$, by $4 \mathrm{ft}$

grid domain: $30 \times 30 \times 8$

seed for random number generation: 30

Nugget: 0.200

Max Covariance (for linear modcls): 1.000

Number of structures --> 2

\section{Struclure $1 \quad$ Struclure 2}

Model

Spherical

Spherical

Sill

0.4

0.4

Range, $\mathrm{ft}$

$x$ direction

$\mathrm{z}$ direction

10,000

50

6,000

30

TABLE 4.4 - Overburden stresses for Arch wells 91 and 100

\begin{tabular}{lccc}
\hline $\begin{array}{c}\text { Arch } \\
\text { well } \\
\text { no. }\end{array}$ & $\begin{array}{c}\text { Elevation, } \\
\mathrm{ft}\end{array}$ & $\begin{array}{c}\text { Overburden } \\
\text { stress, psi }\end{array}$ & $\begin{array}{c}\text { Stress } \\
\text { gradient, } \\
\text { psi } / \mathrm{ft}\end{array}$ \\
\hline 91 & 1,754 & 5,325 & 1.060 \\
100 & 2,349 & 4,700 & 1.008 \\
\hline
\end{tabular}




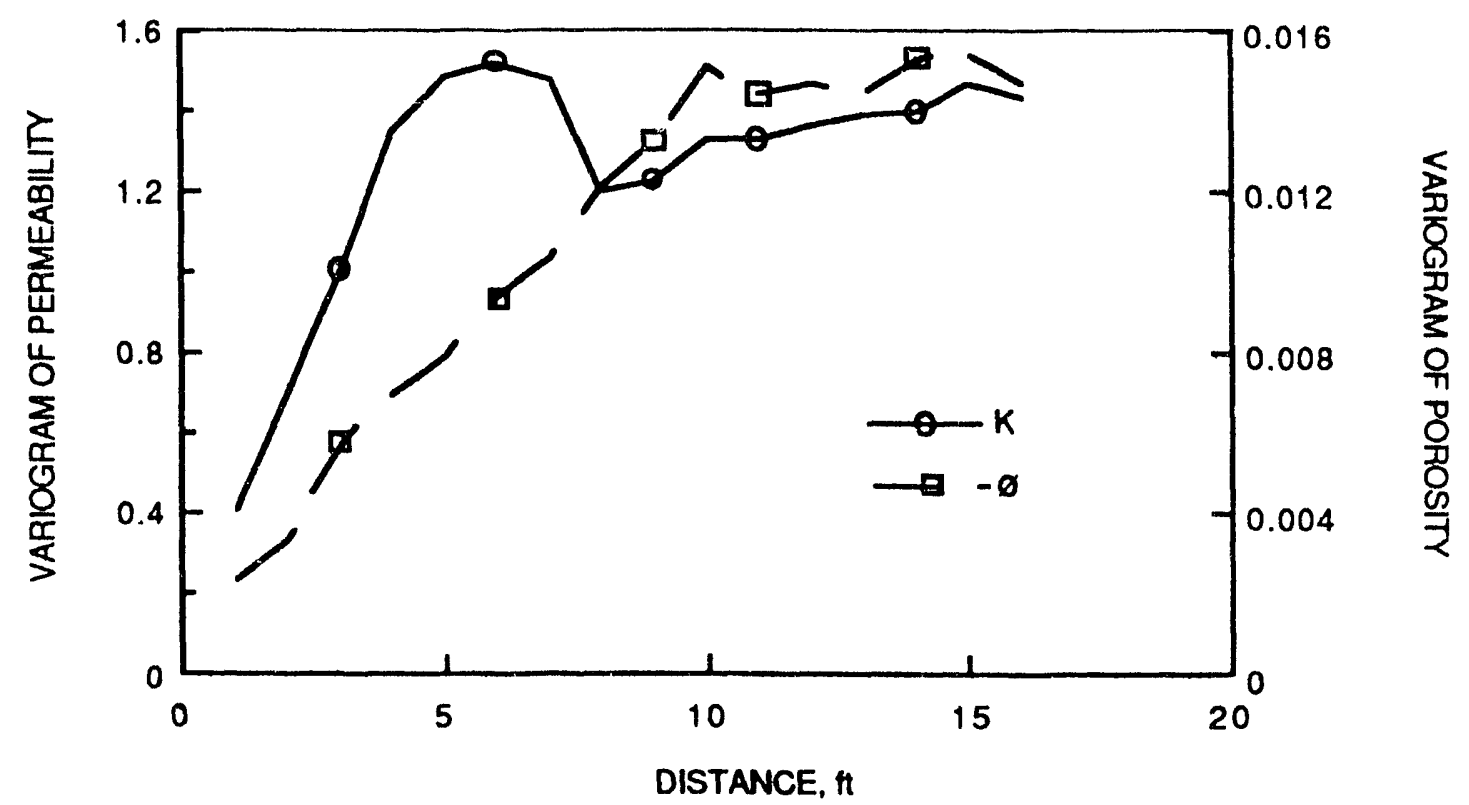

Figure 4.1 - Permeability and porosity variograms of well 15, Arch Unit, Patrick Draw field.

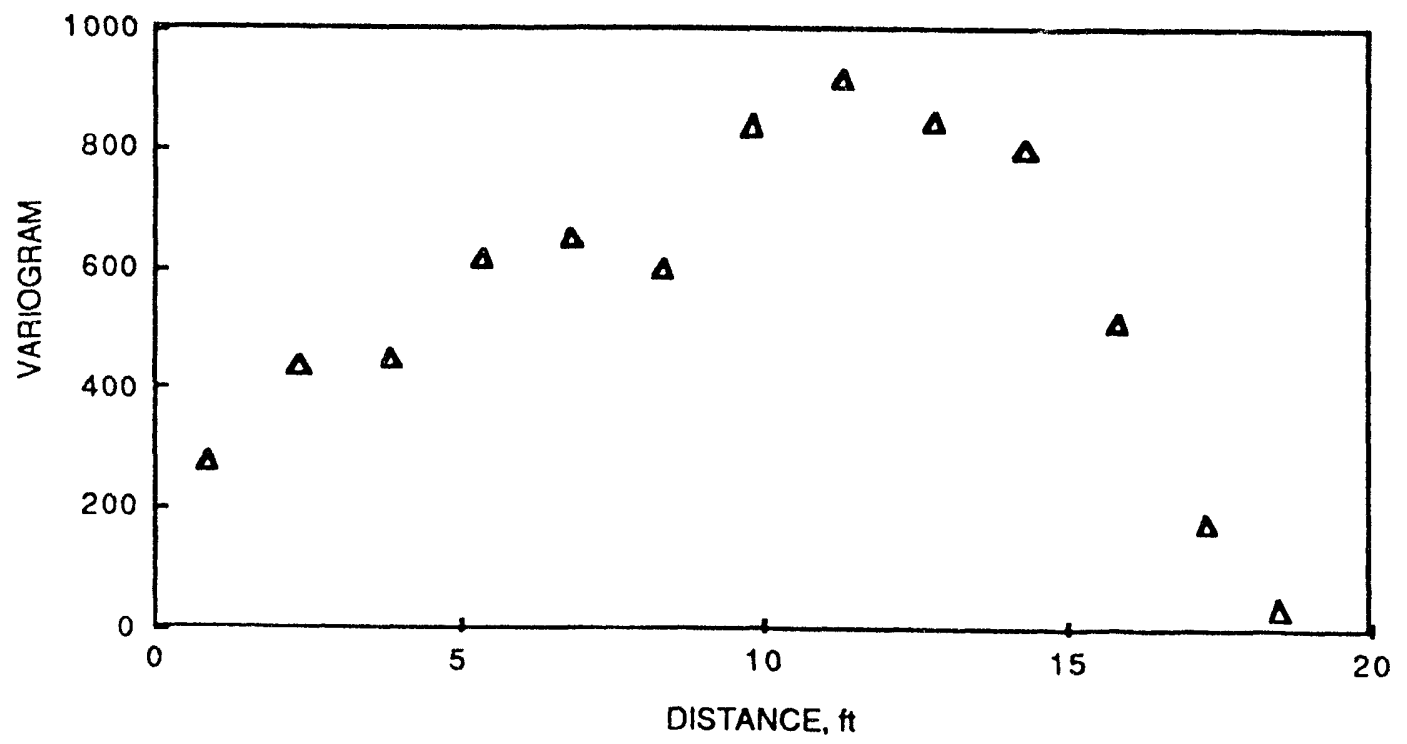

Figurc 4.2 - Permeability and porosity variograms of well 20, Arch Unit, Patrick Draw field. 


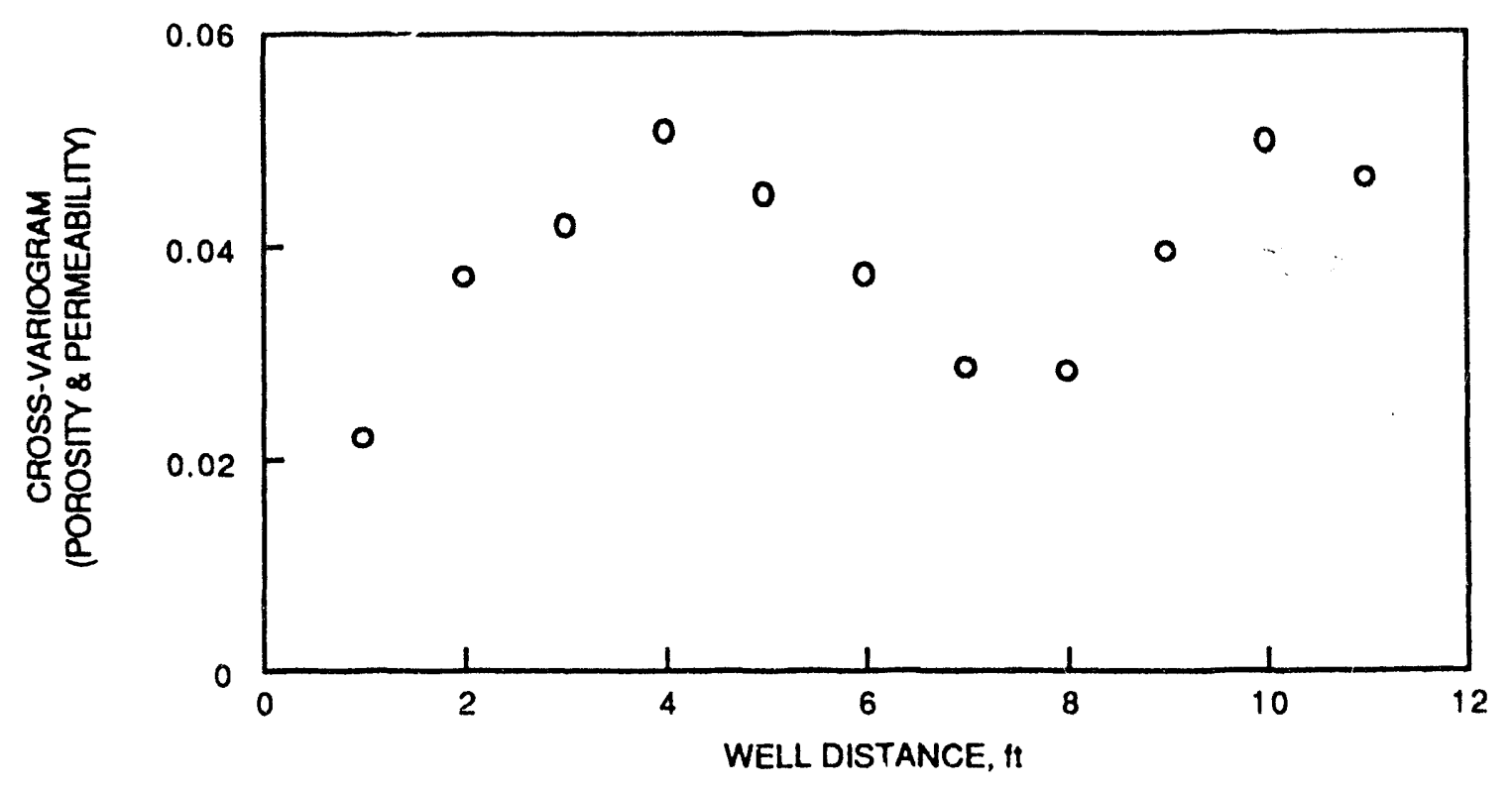

Figure 4.3 - Cross-variogram of permeability-porosity of well 20, Arch Unit, Patrick Draw field.

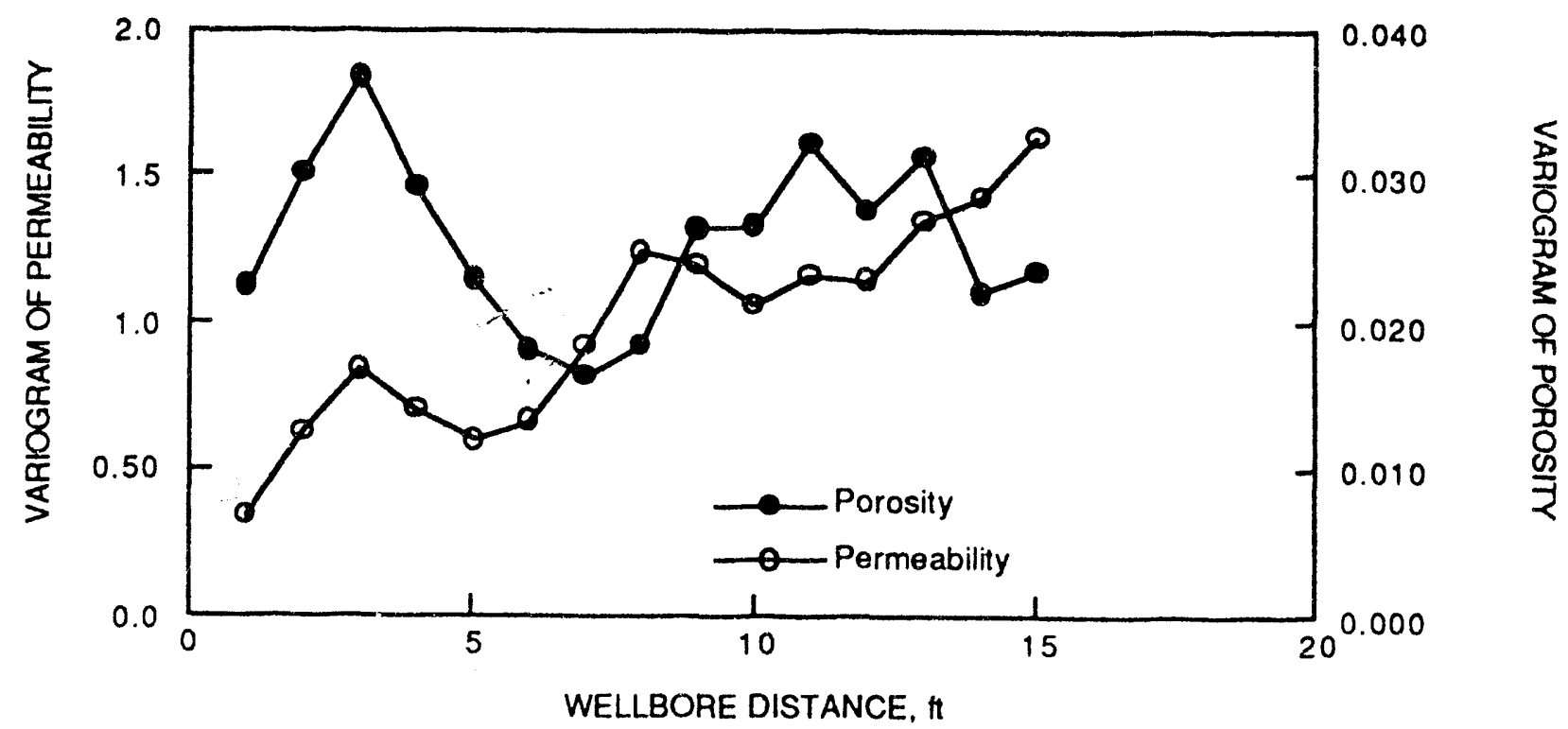

Figure 4.4 - Permeability and porosity variograins of well 88, Arch Unit, Patrick Draw field. 


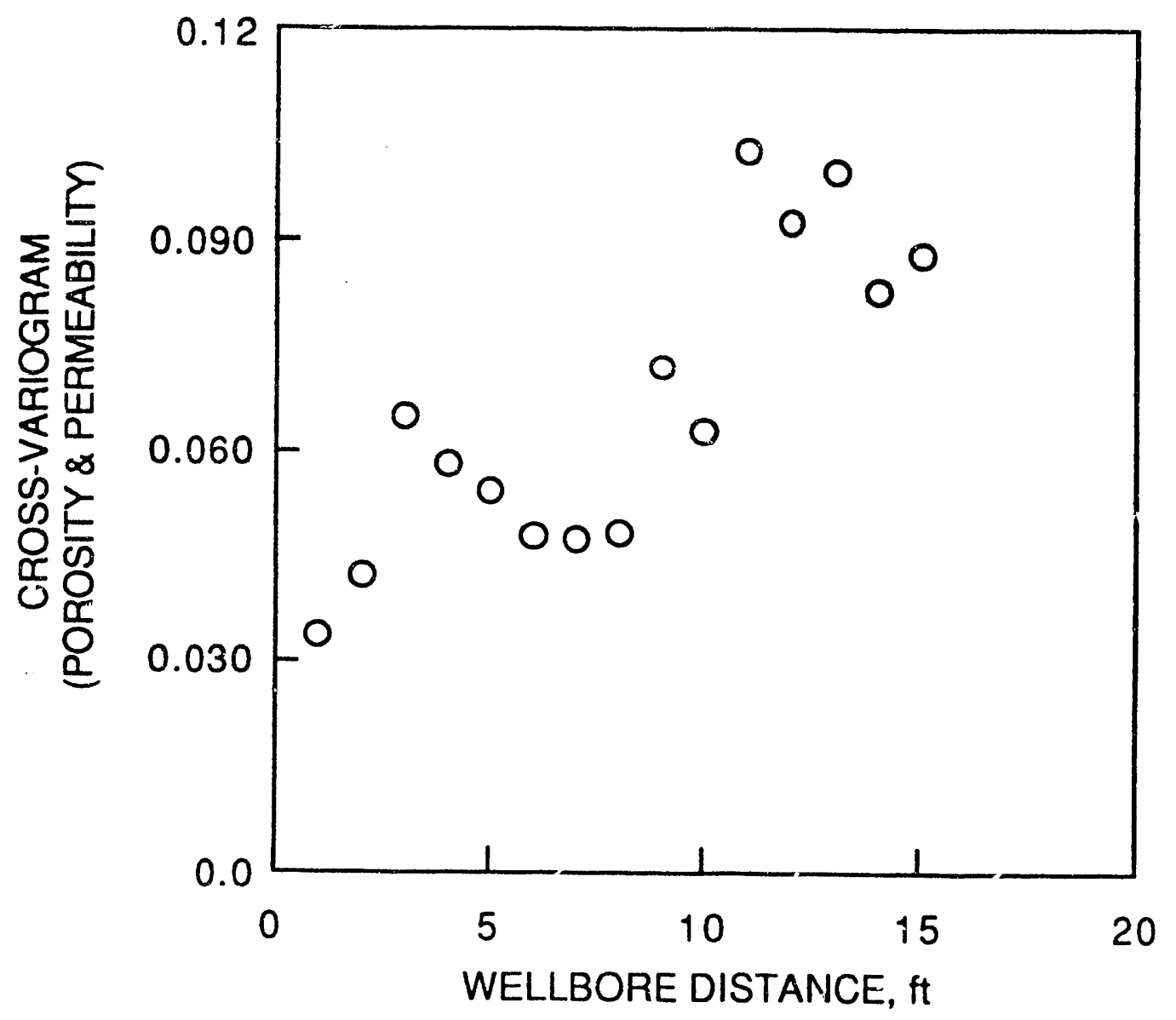

Fig:re 4.5 - Cross-variogram of permeability-por usity of well 88, Arch Unit, Patrick Draw field. 


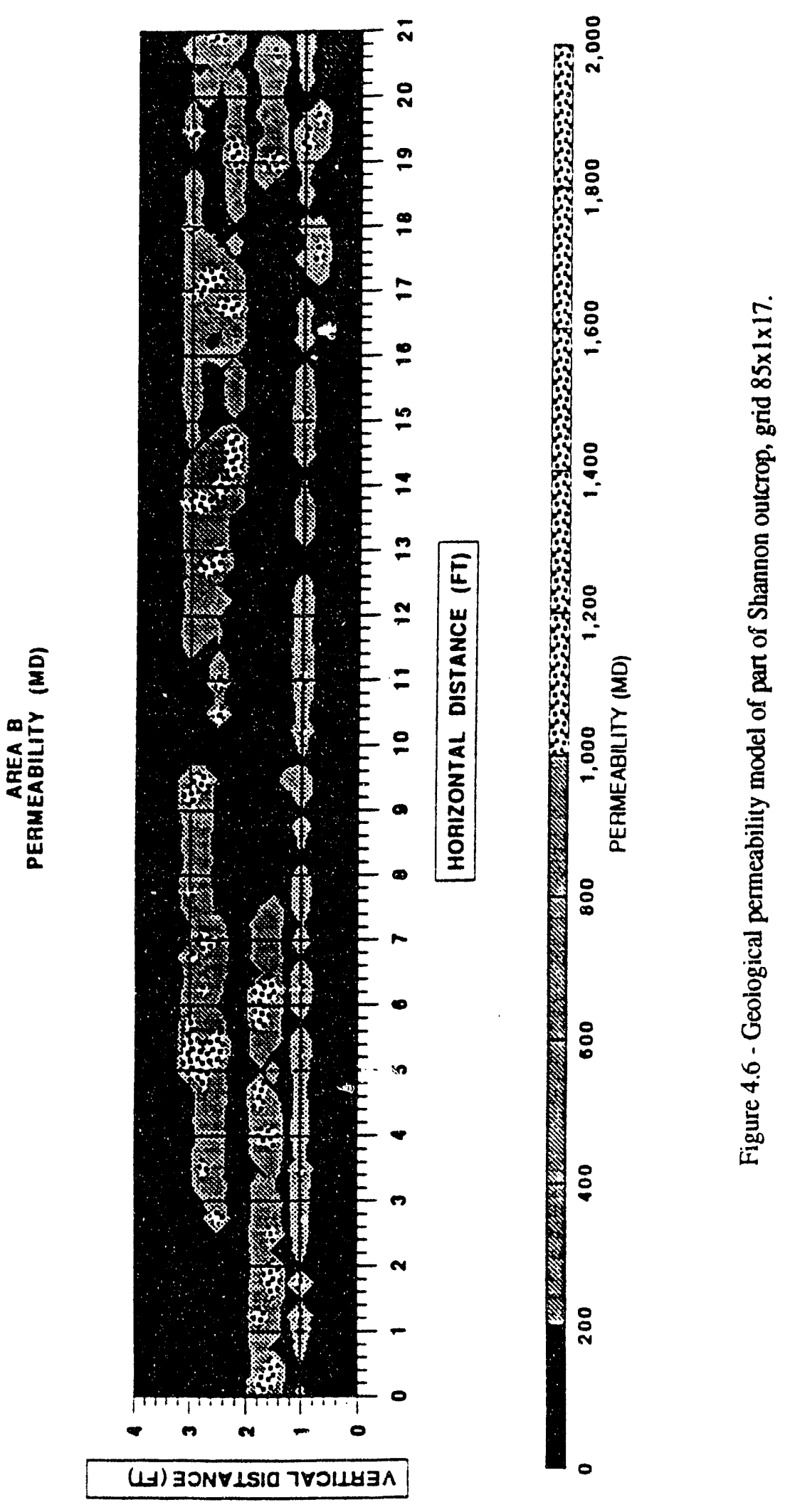


$4 \mathrm{ft}$.

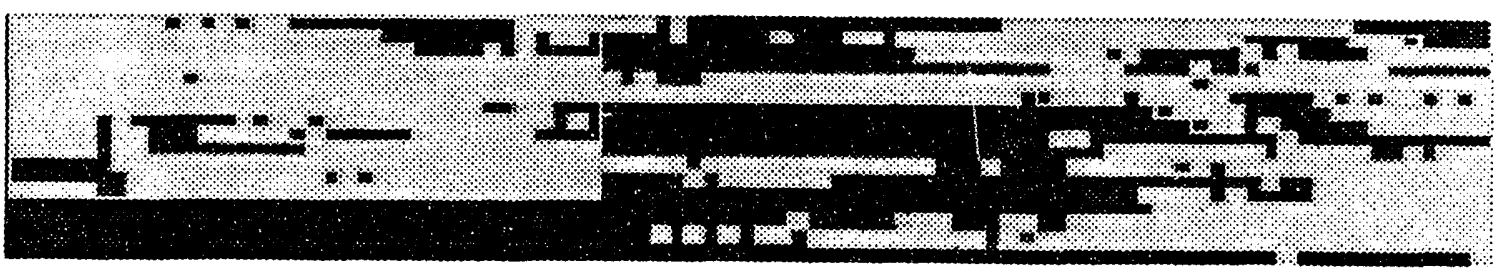

$21 \mathrm{ft}$.

Figure 4.7 - Indicator kriging permeability model of part of Shannon outcrop using 50 core control data. Dark shading indicates permeability $<200 \mathrm{mD}$, light shading indicates permeability $>200 \mathrm{mD}$. 
a

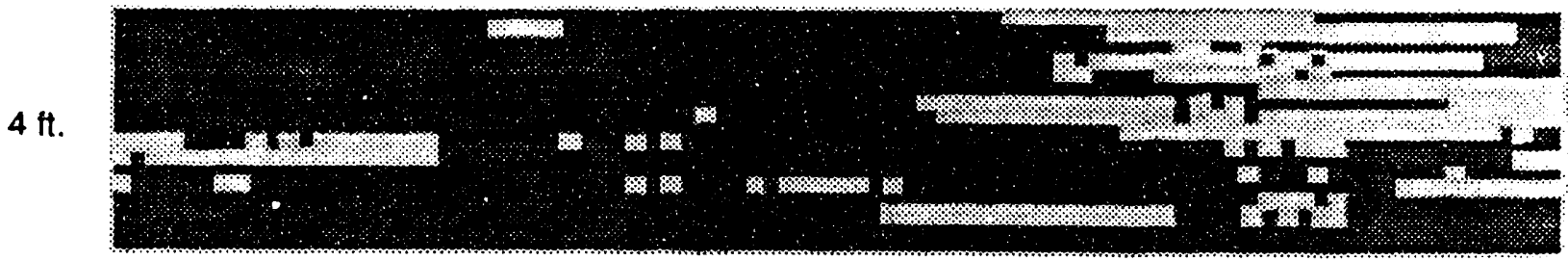

$21 \mathrm{ft}$.

b

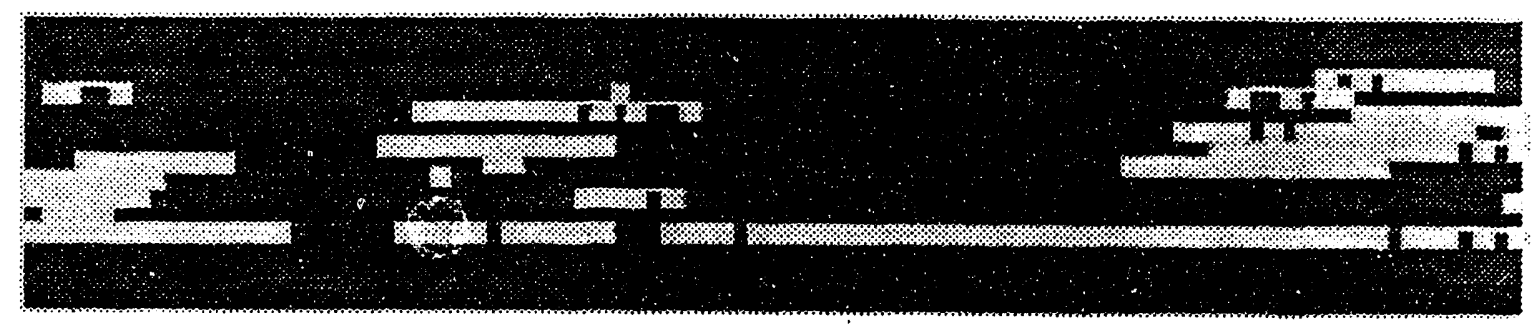

c

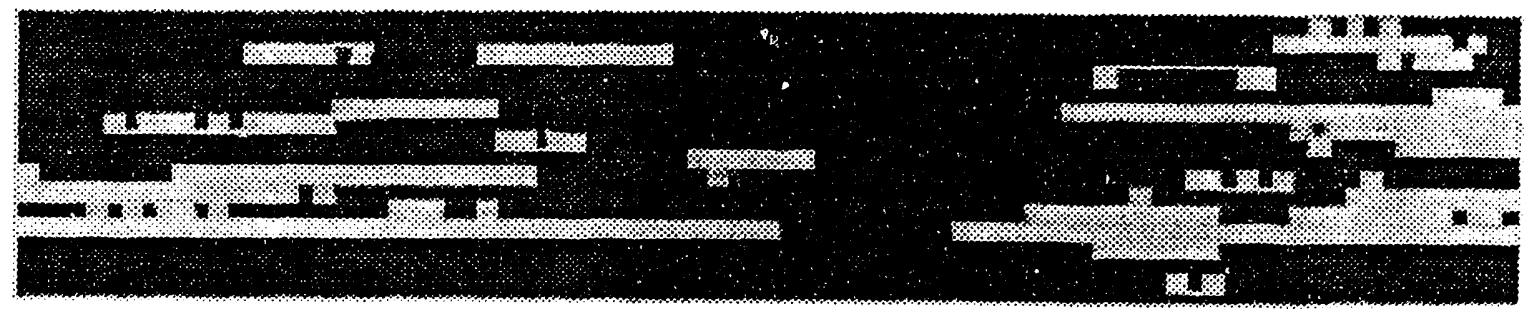

d

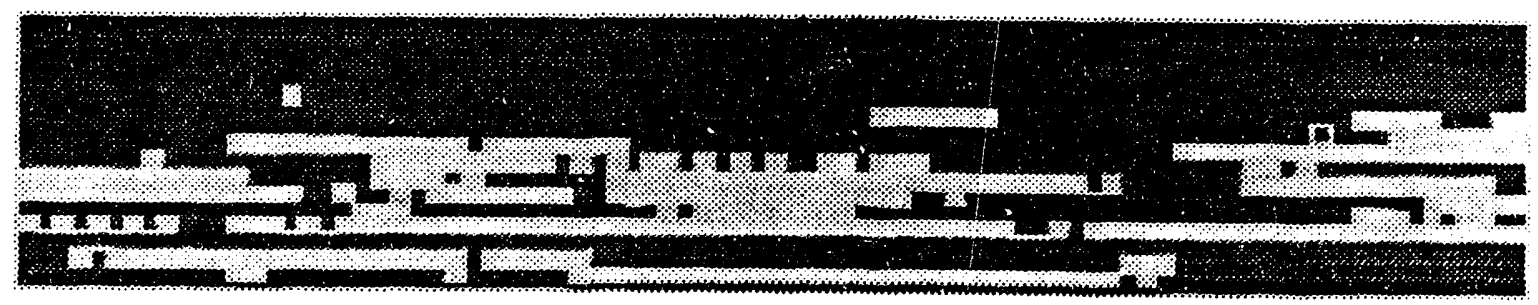

Figure 4.8 - Indicator kriging permeability model of part of Shannon outcrop using two vertical profiles of permeability as control data and various seed numbers: (a) 10, (b) 30, (c) 50, and (d) 100 . Horizontal scale length $=20 \mathrm{ft}$, vertical scale length $=1$ inch. Dark shading indicates permeability $<200 \mathrm{mD}$, light shading indicates permeability $>200 \mathrm{mD}$. 
a

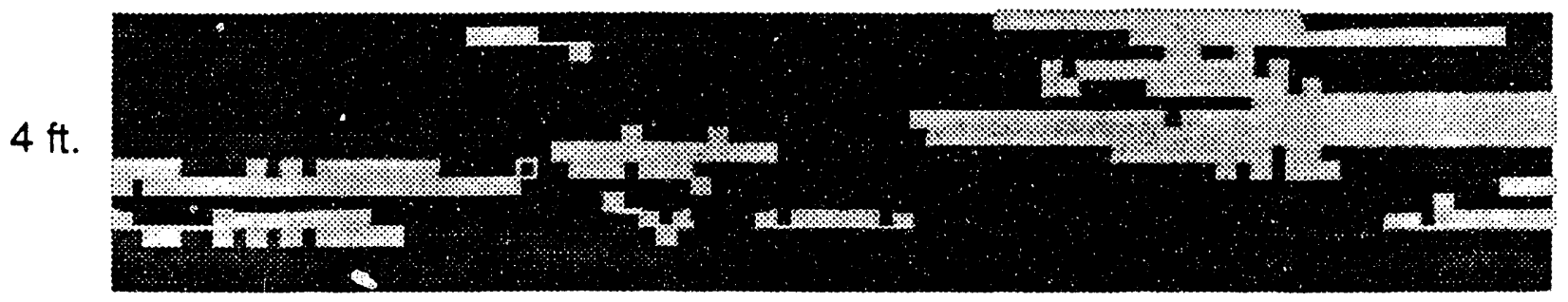

$21 \mathrm{ft}$.

b

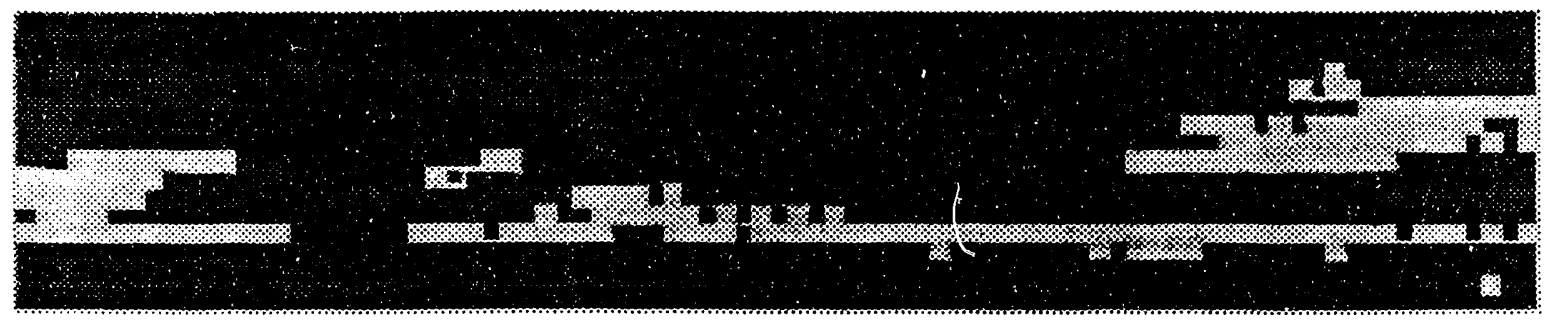

C

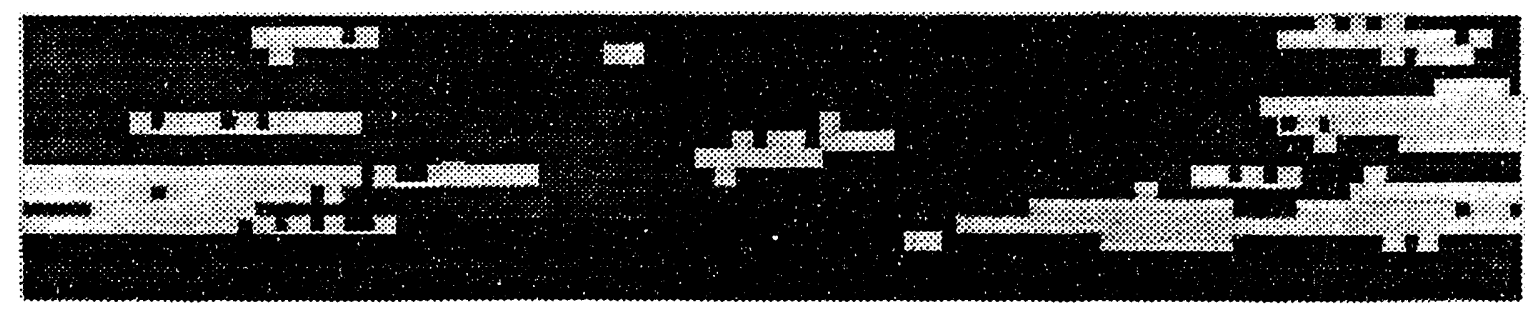

Figure 4.9 - Indicator kriging permeability model of part of Shannon outcrop using two vertical profiles of permeability as control data and various seed numbers: (a) 10 , (b) 30 , and (c) 50 . Horizontal scale length $=20 \mathrm{ft}$, vertical scale length $=2$ inches. Dark shading indicates permeability $<200 \mathrm{mD}$, light shading indicates permeability $>200 \mathrm{mD}$. 
a

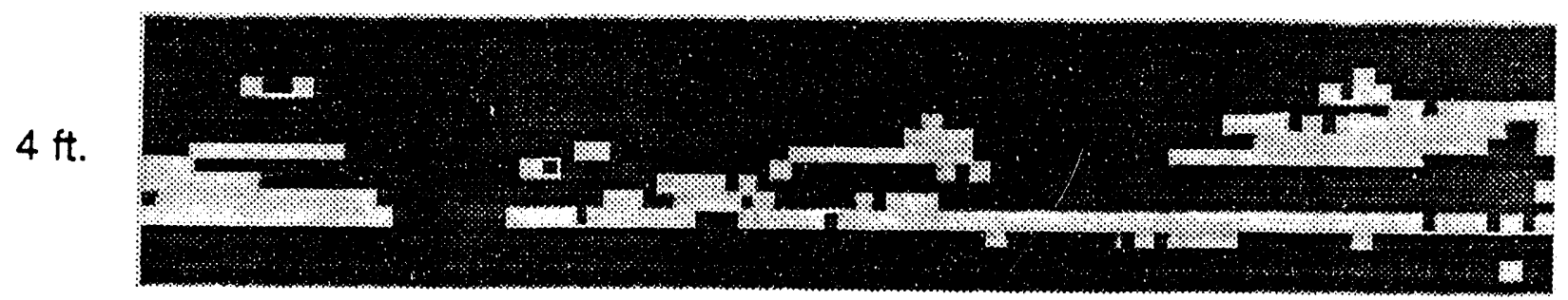

$21 \mathrm{ft}$.

b

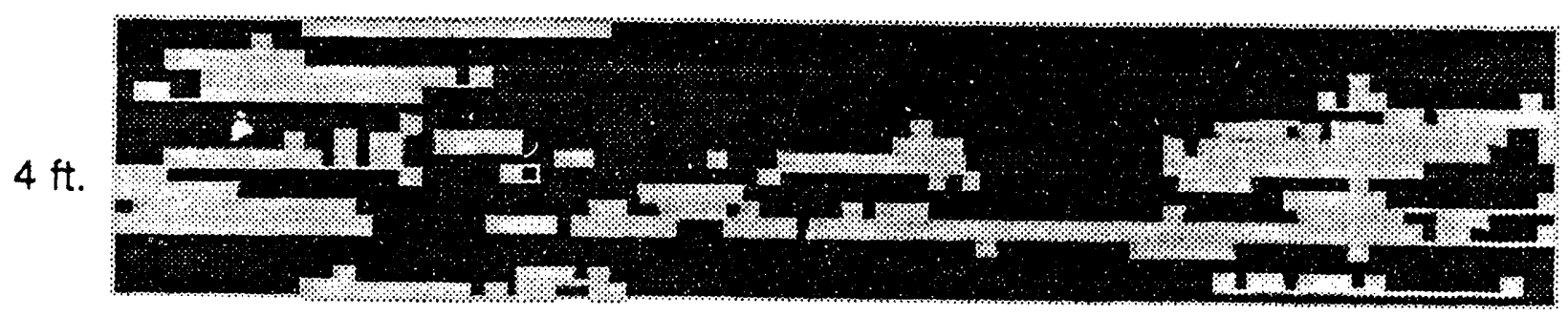

$21 \mathrm{ft}$.

Figure 4.10 - Indicator kriging permeability model of part of Shannon outcrop using two vertical profiles of permeability as control data and two horizontal scale lengths: (a) $10 \mathrm{ft}$, and (b) $20 \mathrm{ft}$. Vertical length $=2$ inches and seed number $=30$. Dark shading indicates permeability $<200 \mathrm{mD}$, light shading indicates permeability $>200 \mathrm{mD}$. 


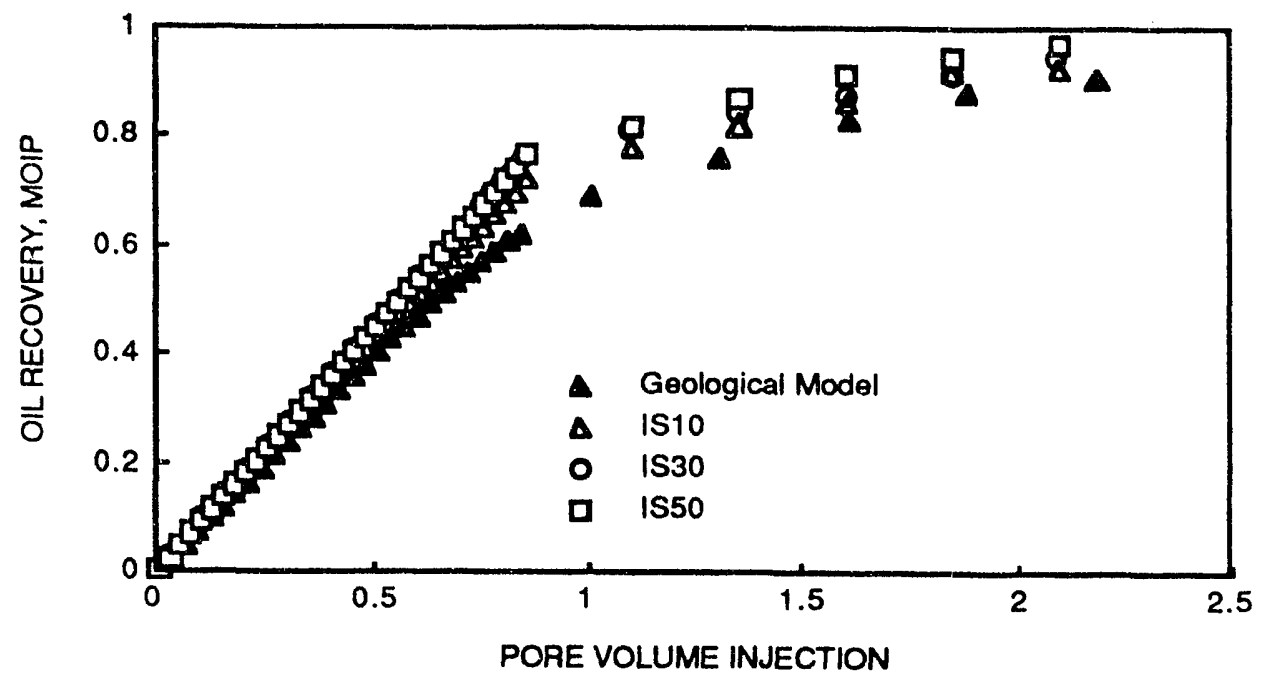

Figure 4.11 - Oil recovery of waterflood simulations from geological and indicator kriging models for oil gravity API $35^{\circ}$.

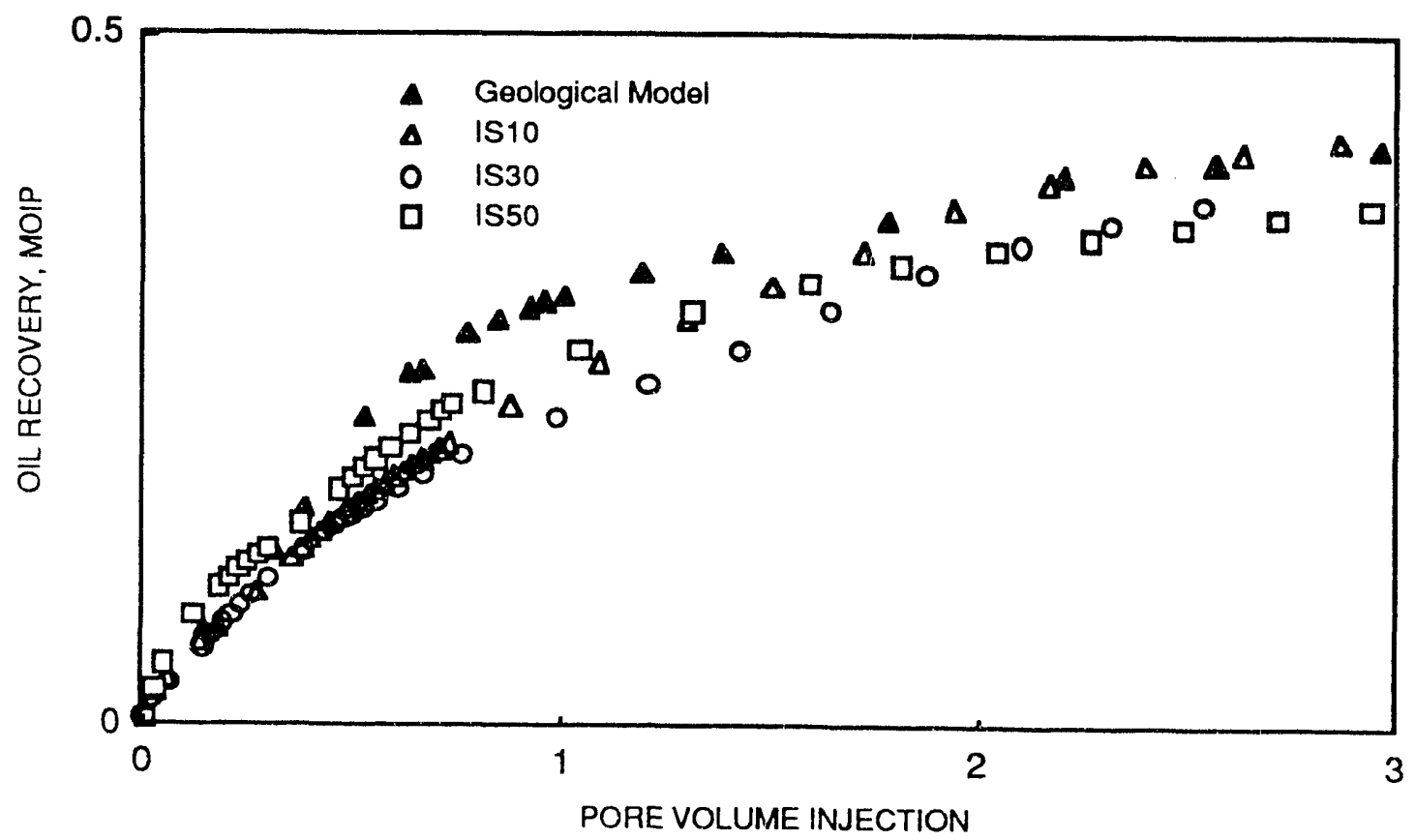

Figure 4.12 - Oil recovery of waterflood simulations from geological and indicator kriging models for oil gravity API $20^{\circ}$. 
a

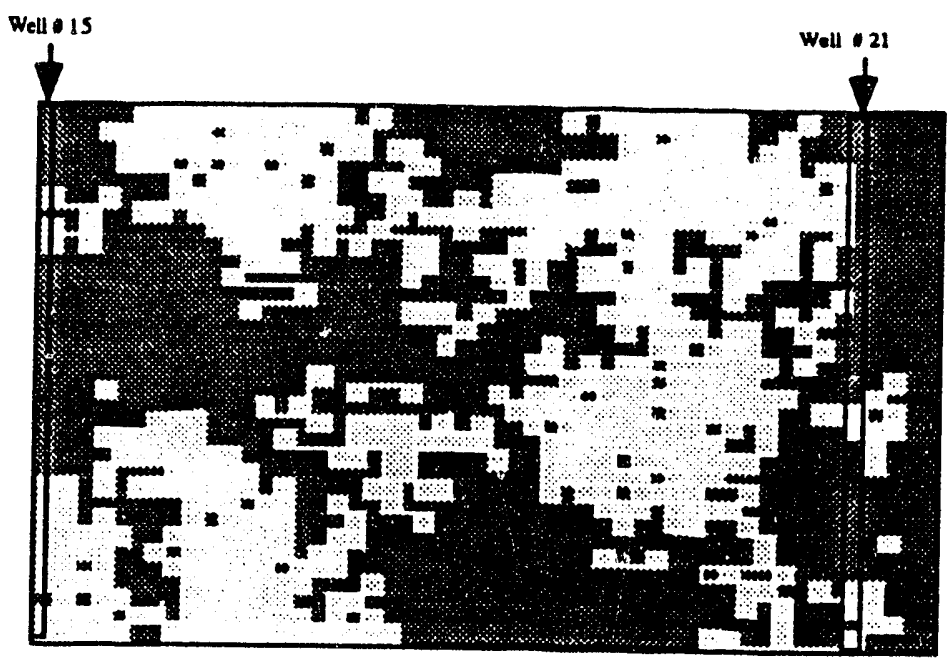

b
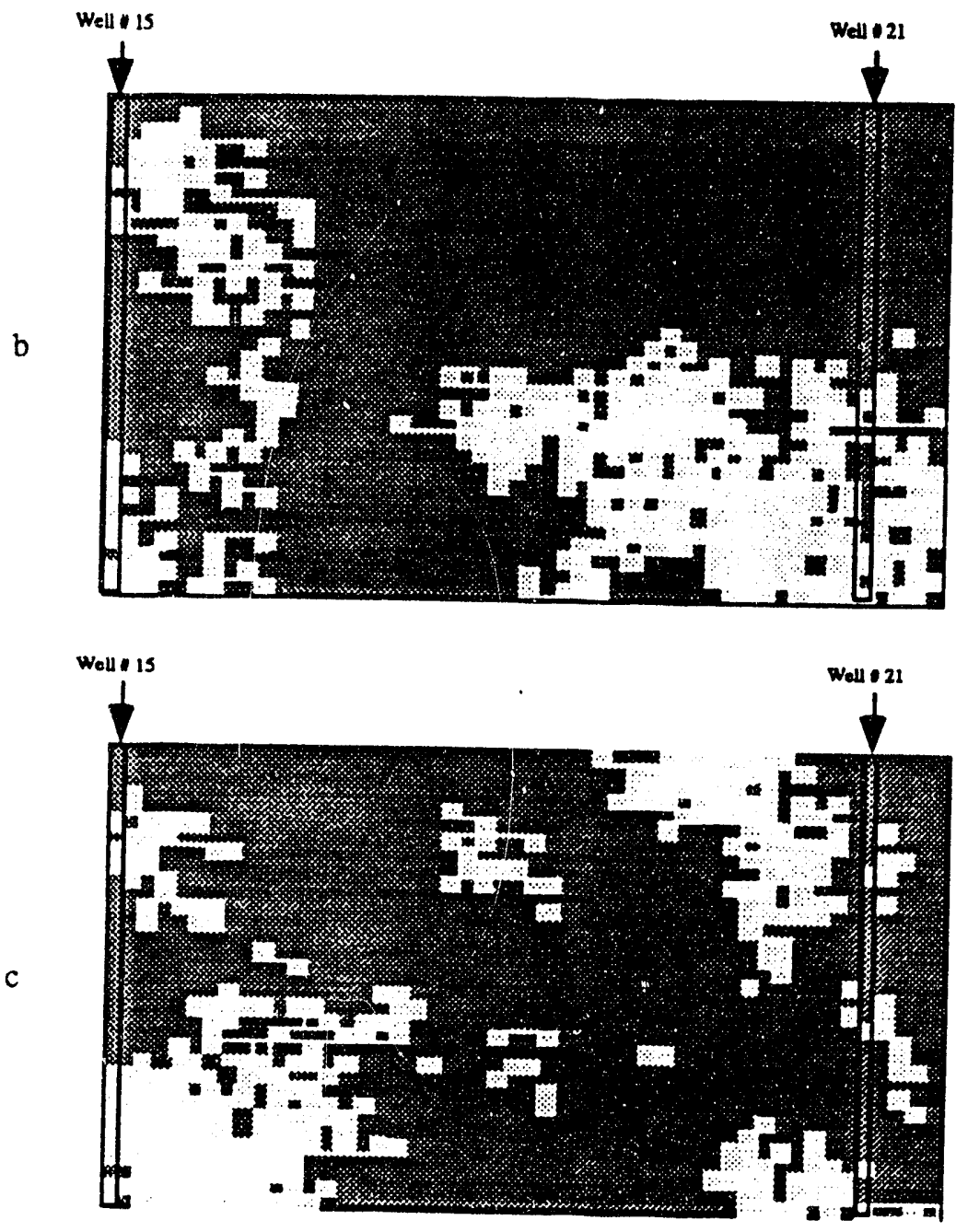

Figure 4.13 - Cross-section permeability models $(50 \times 1 \times 33)$ between wells 15 and 21 in Patrick Draw field from indicator kriging at three seed numbers: (a) 10, (b) 30, and (c) 100. Dark shading indicates permeability $<200 \mathrm{mD}$, light shading indicates permeability $>200 \mathrm{mD}$. 

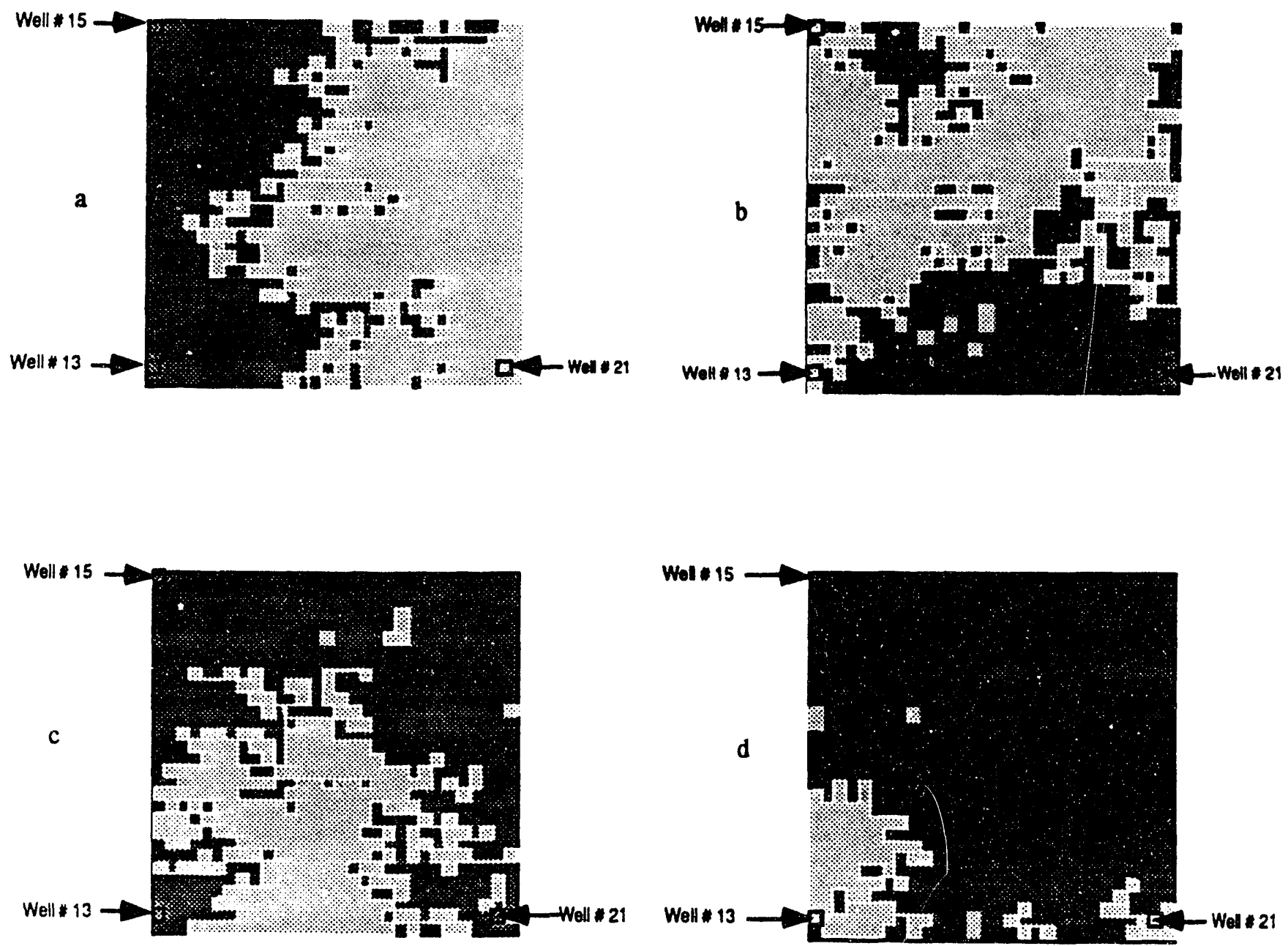

Figure 4.14 - Three-dimensional permeability models $(30 \times 30 \times 8)$ among wells 13,15 , and 21 in Patrick Draw field from indicator kriging using seed number 10. (a) layer 1, (b) layer 2, (c) layer 3, (d) layer 4. Dark shading indicates permeability $<200 \mathrm{mD}$, light shading indicates permeability $>200 \mathrm{mD}$. 

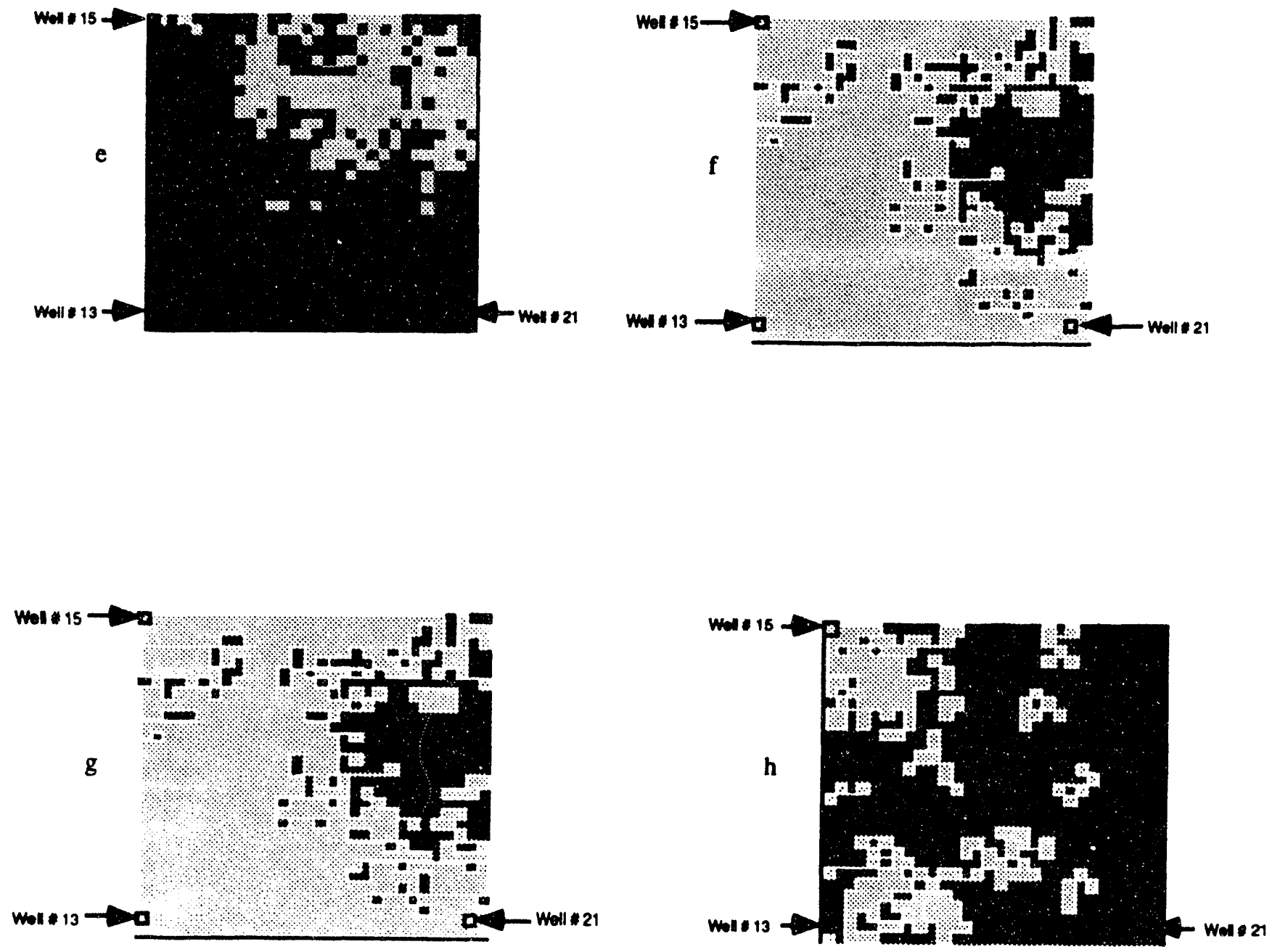

Figure 4.14 - Continued (e) layer 5, (f) layer $6,(\mathrm{~g})$ layer 7, (h) layer 8. 


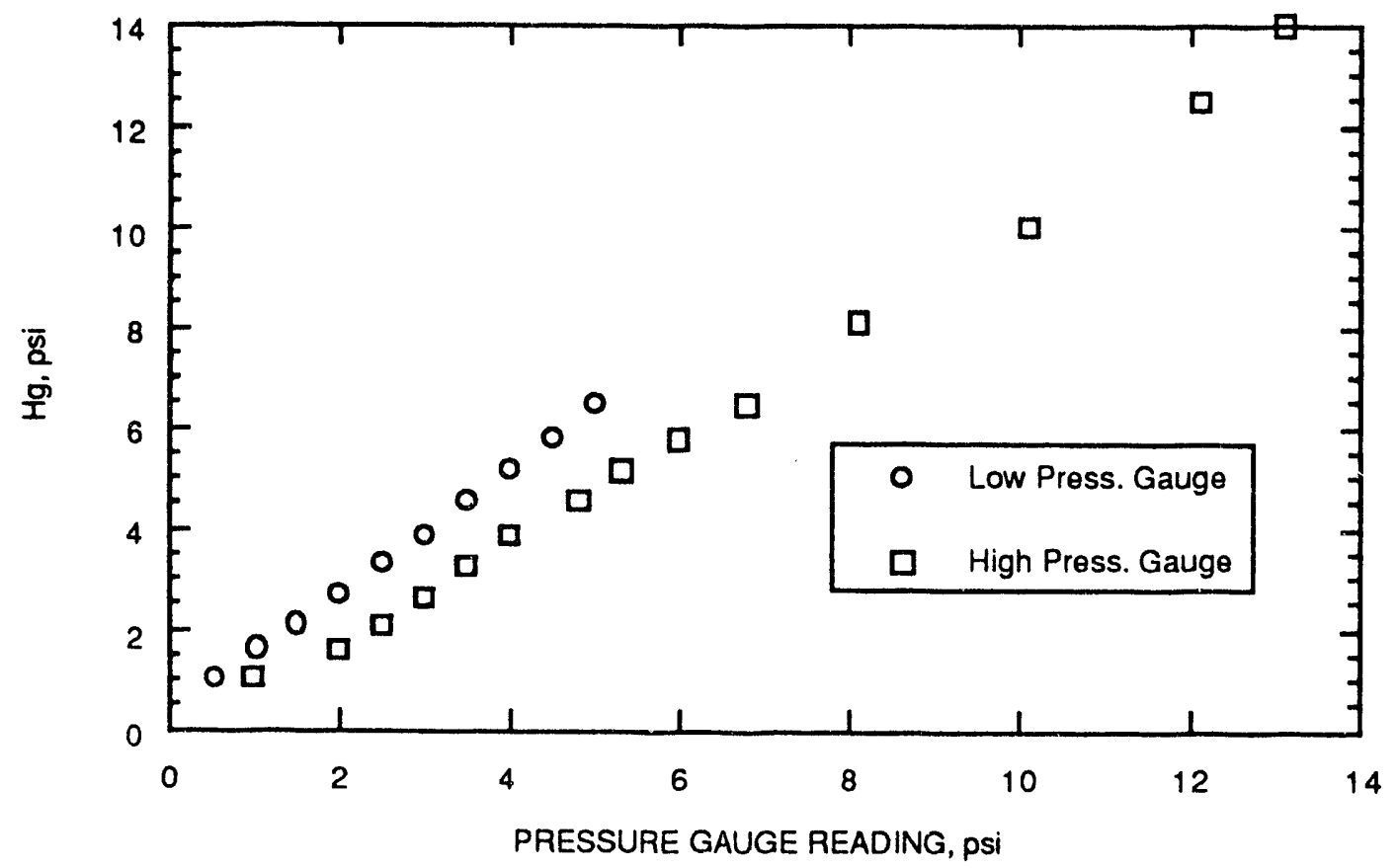

Figure 4.15 - Calibration of pressure gauges of mini-permeameter:

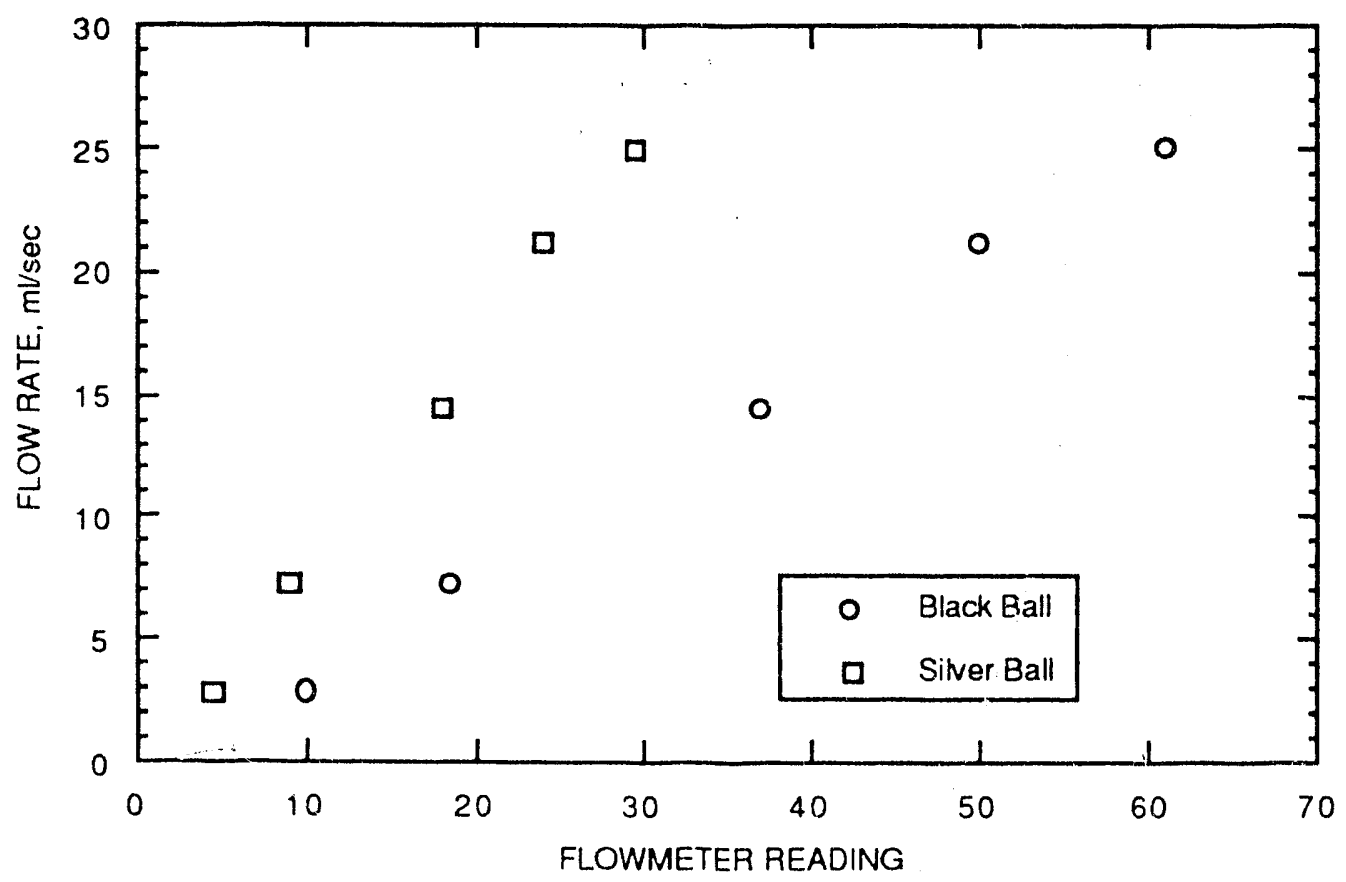

Figure 4.16 - Calibration of high-flow meter of mini-permeameter. 


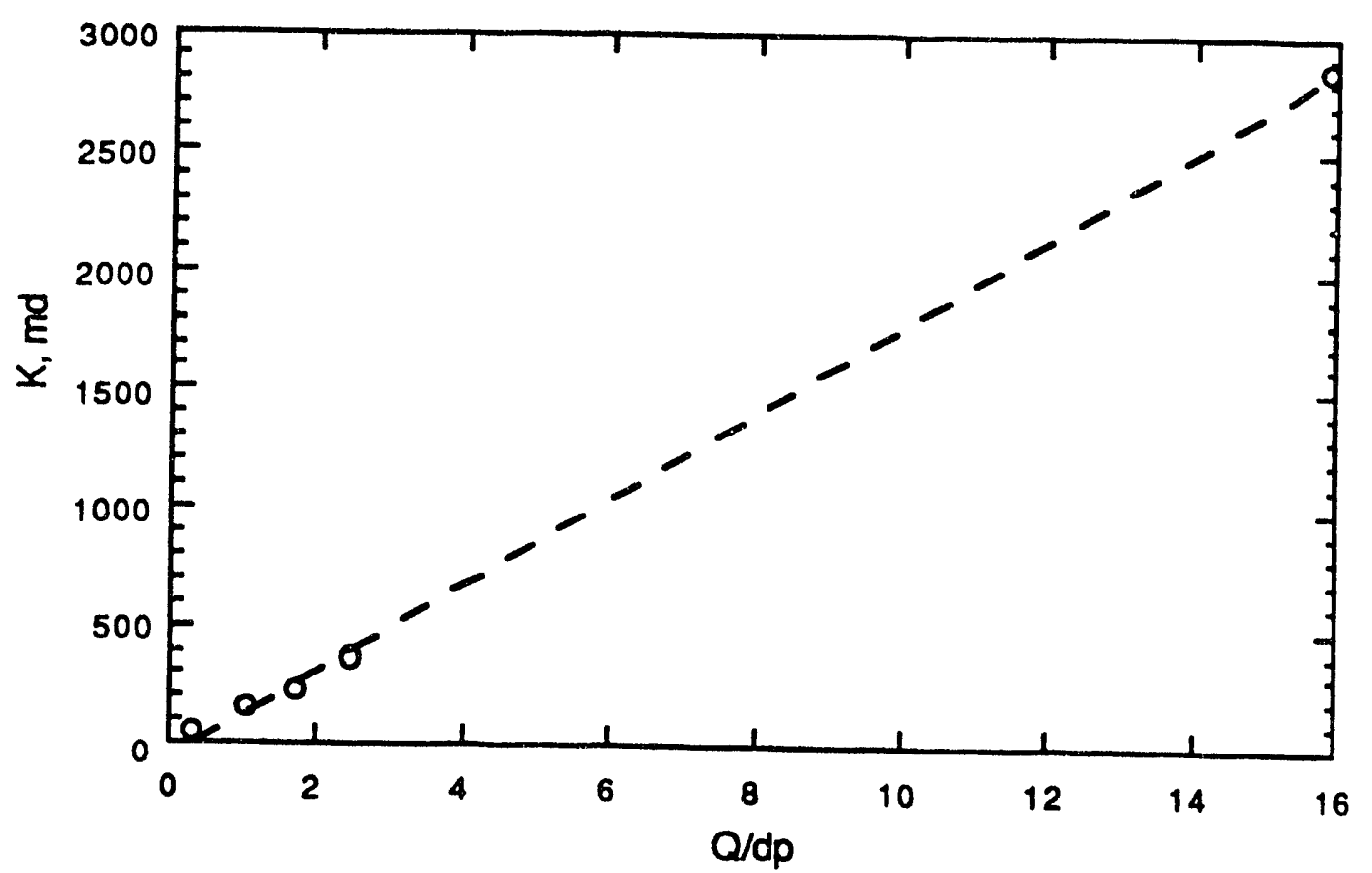

Figure 4.17 - Calibration of permeability measurements of mini-permeameter.

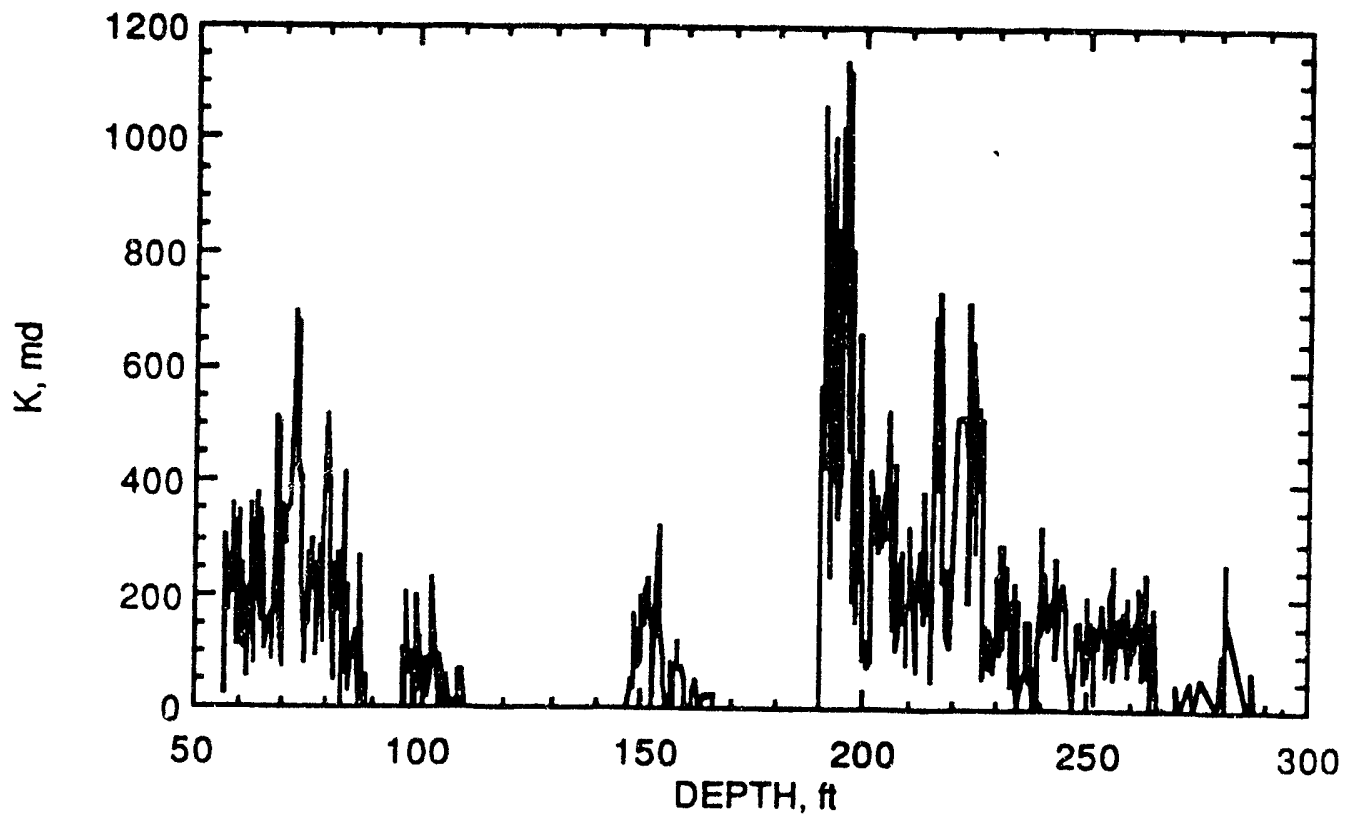

Figure 4.18 - Permeability profile of corehole No. 2.

140 


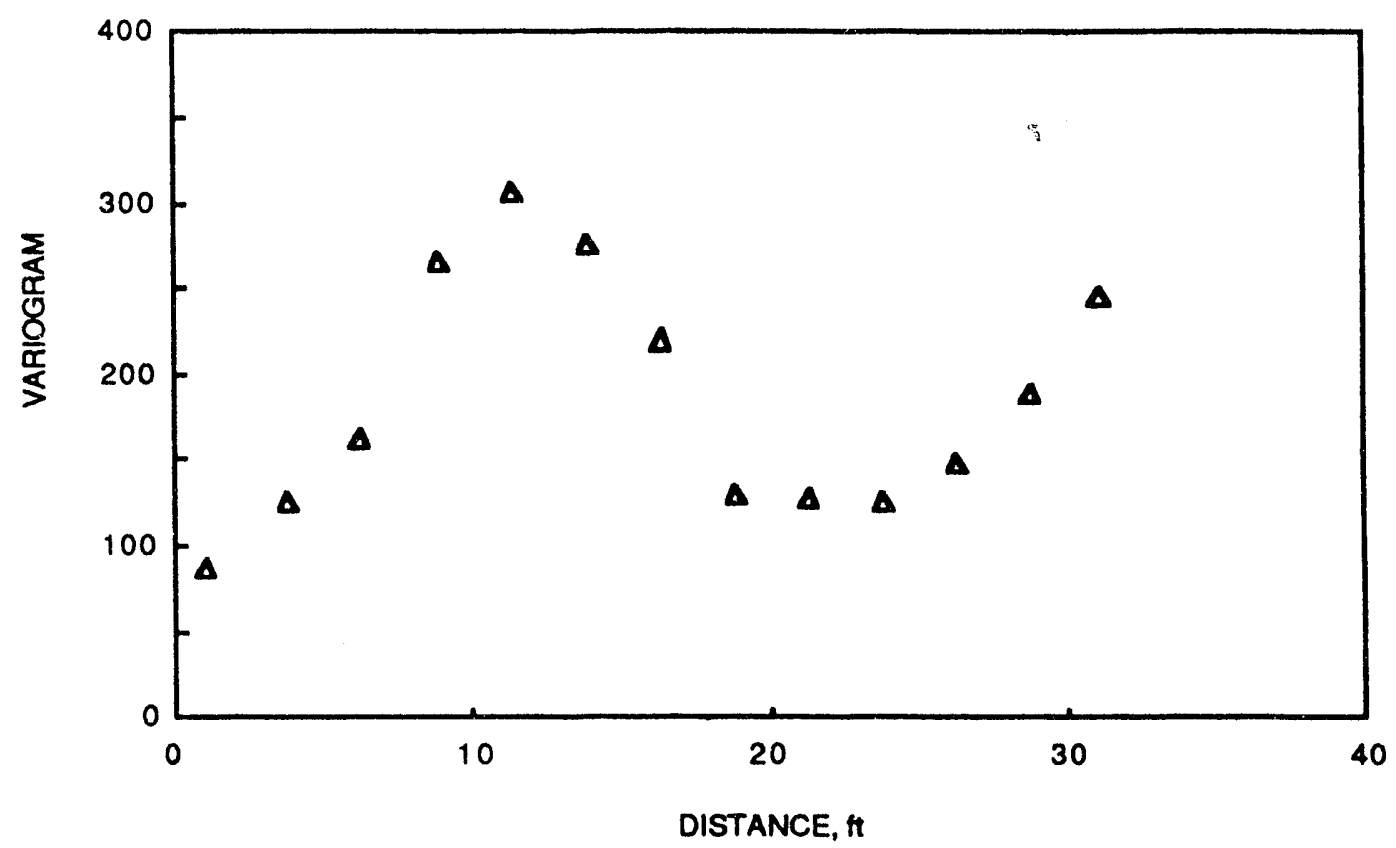

Figure 4.19 - Permeability variogram of corehole No.2, depth $56-89 \mathrm{ft}$.

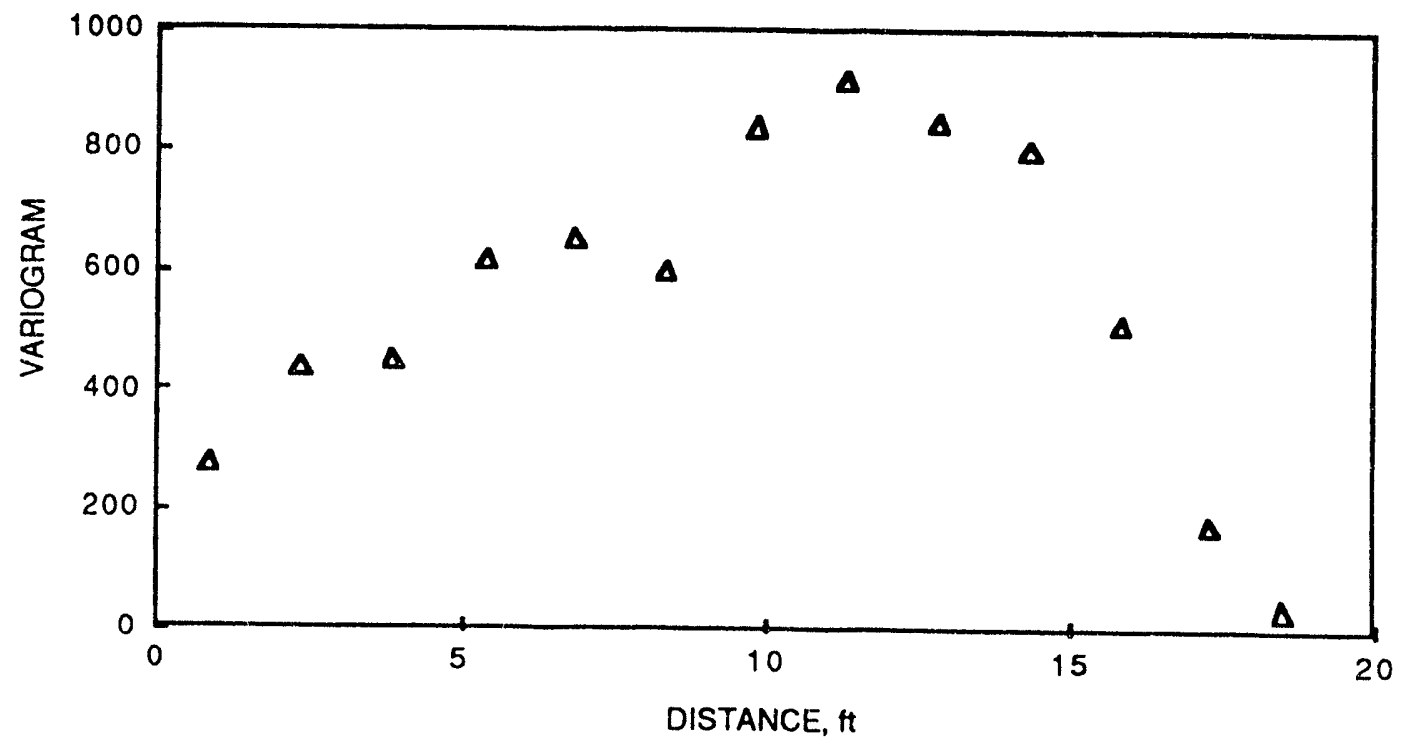

Figurc 4.20 - Permeability variogram of corchole No.2, depth $147-166 \mathrm{ft}$. 


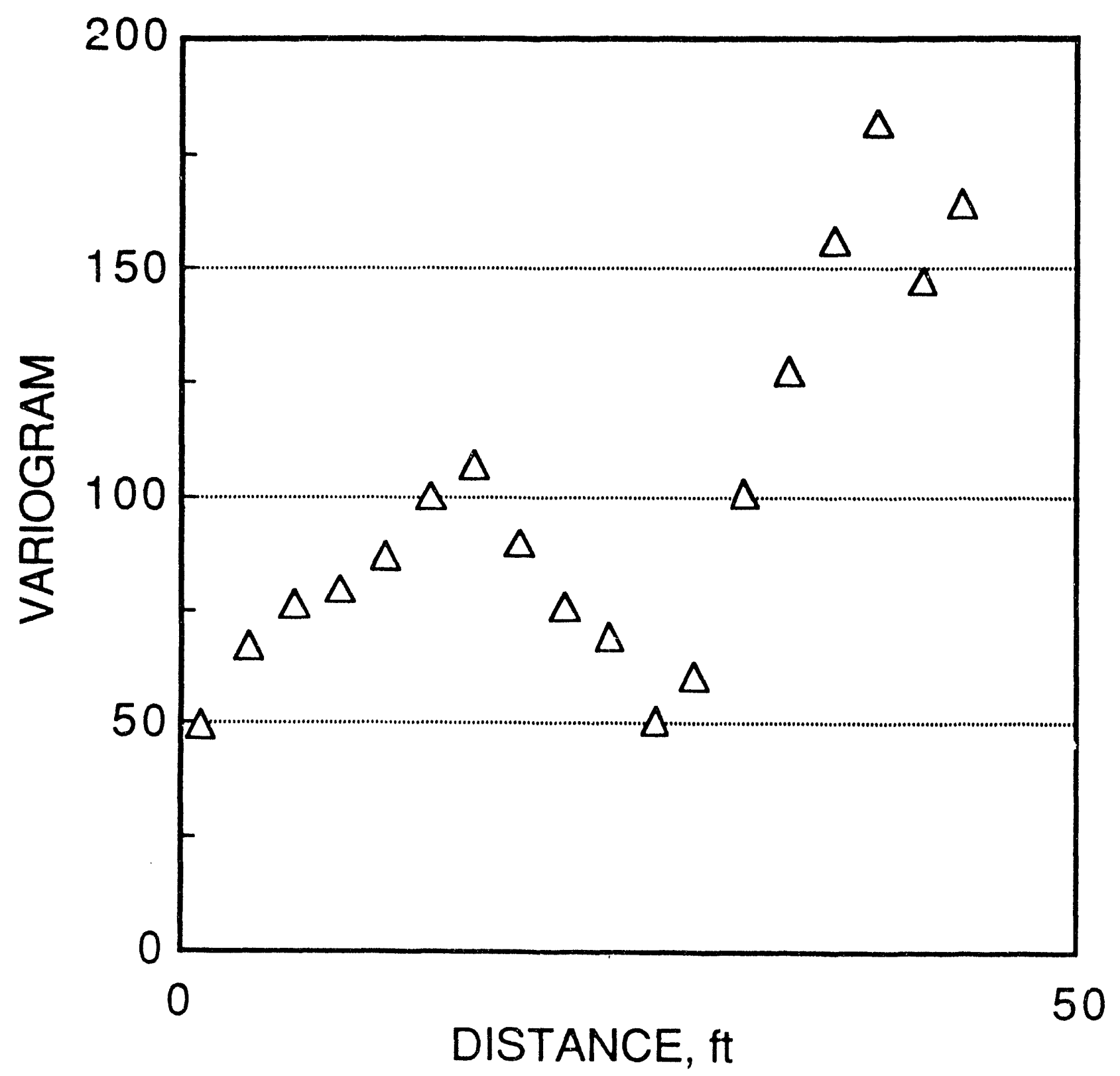

Figure 4.21 - Permeability variograrn of corehole No.2, depth $190 \cdot 266 \mathrm{ft}$. 

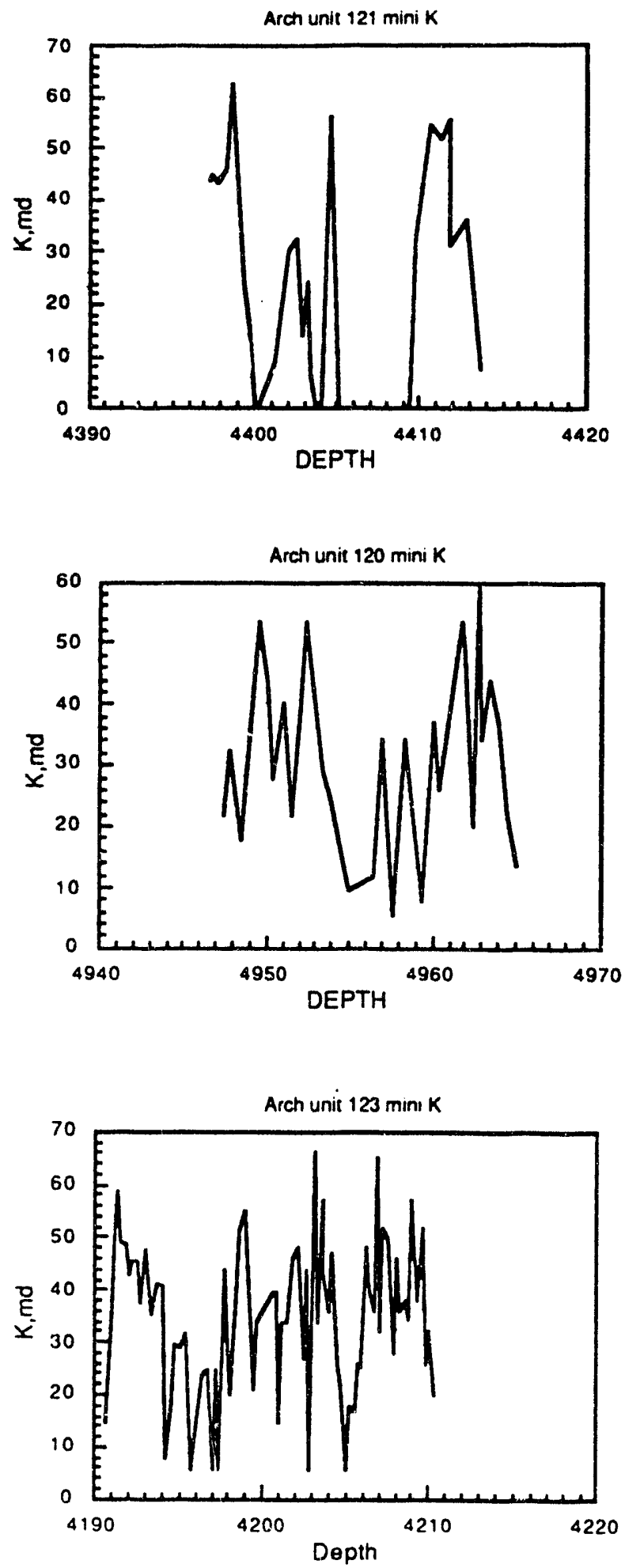

Figure 4.22 - Permcability profiles of wells 120, 121, and 123 of Patrick Draw field. Depth in fect. 


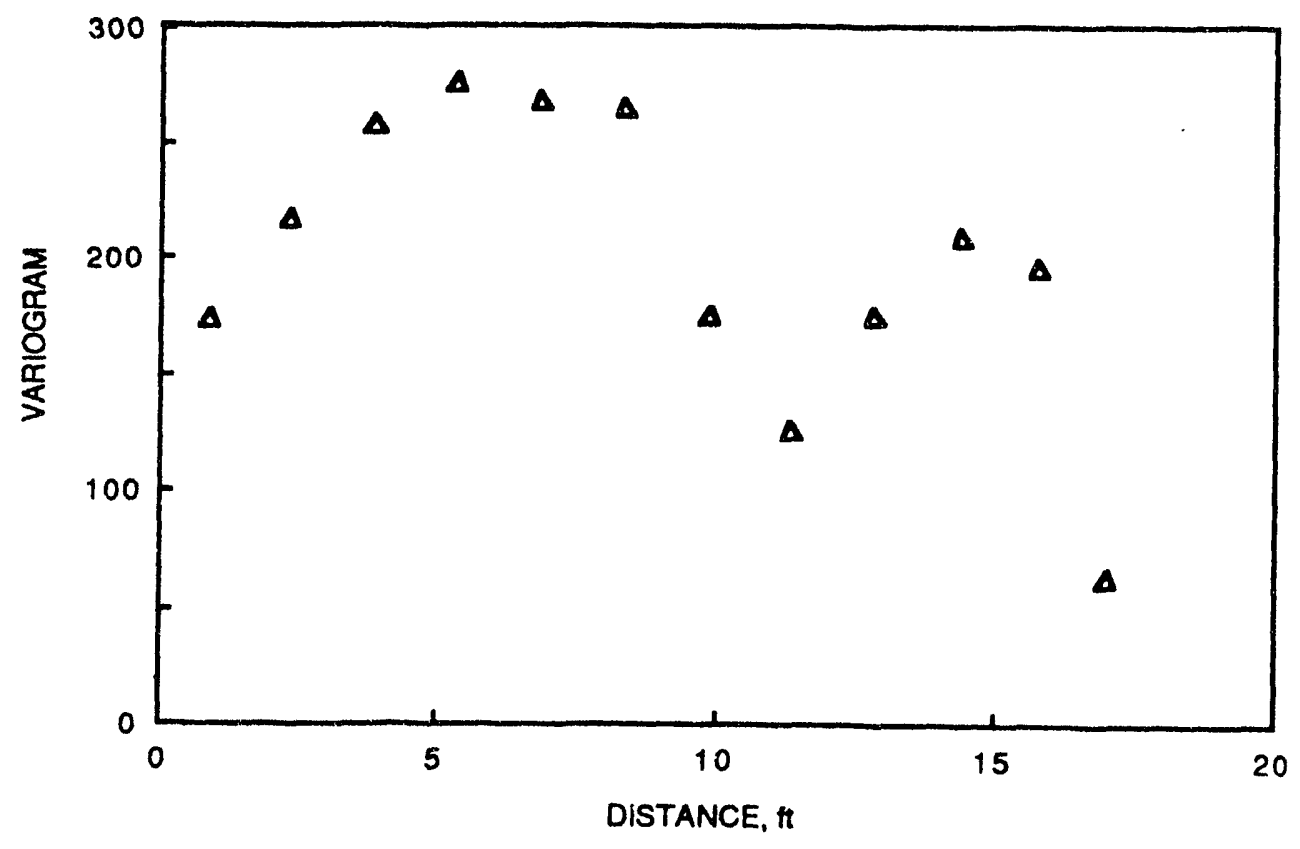

Figure 4.23 - Permeability variogram of well 120, Patrick Draw field.

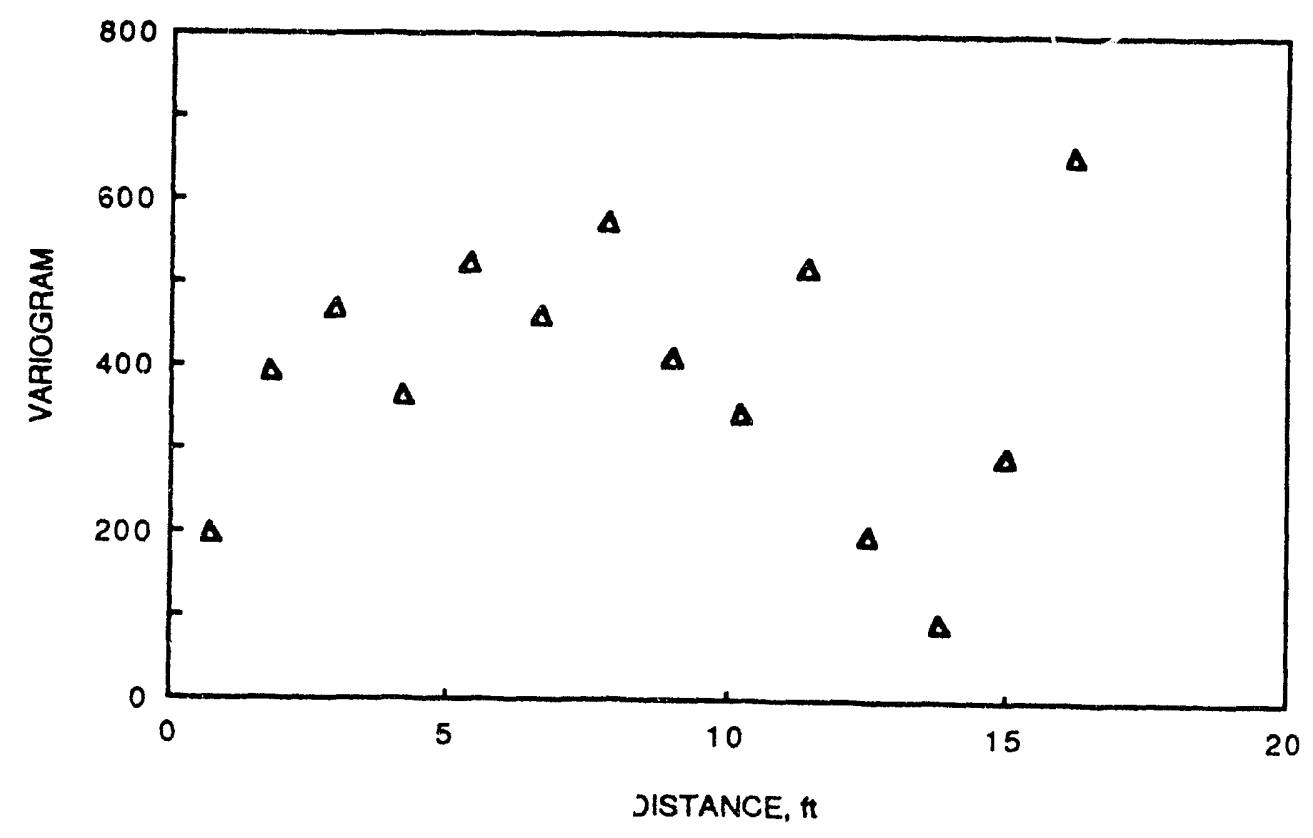

Figure 4.24 - Permeability variogram of well 121, Patrick Draw field. 


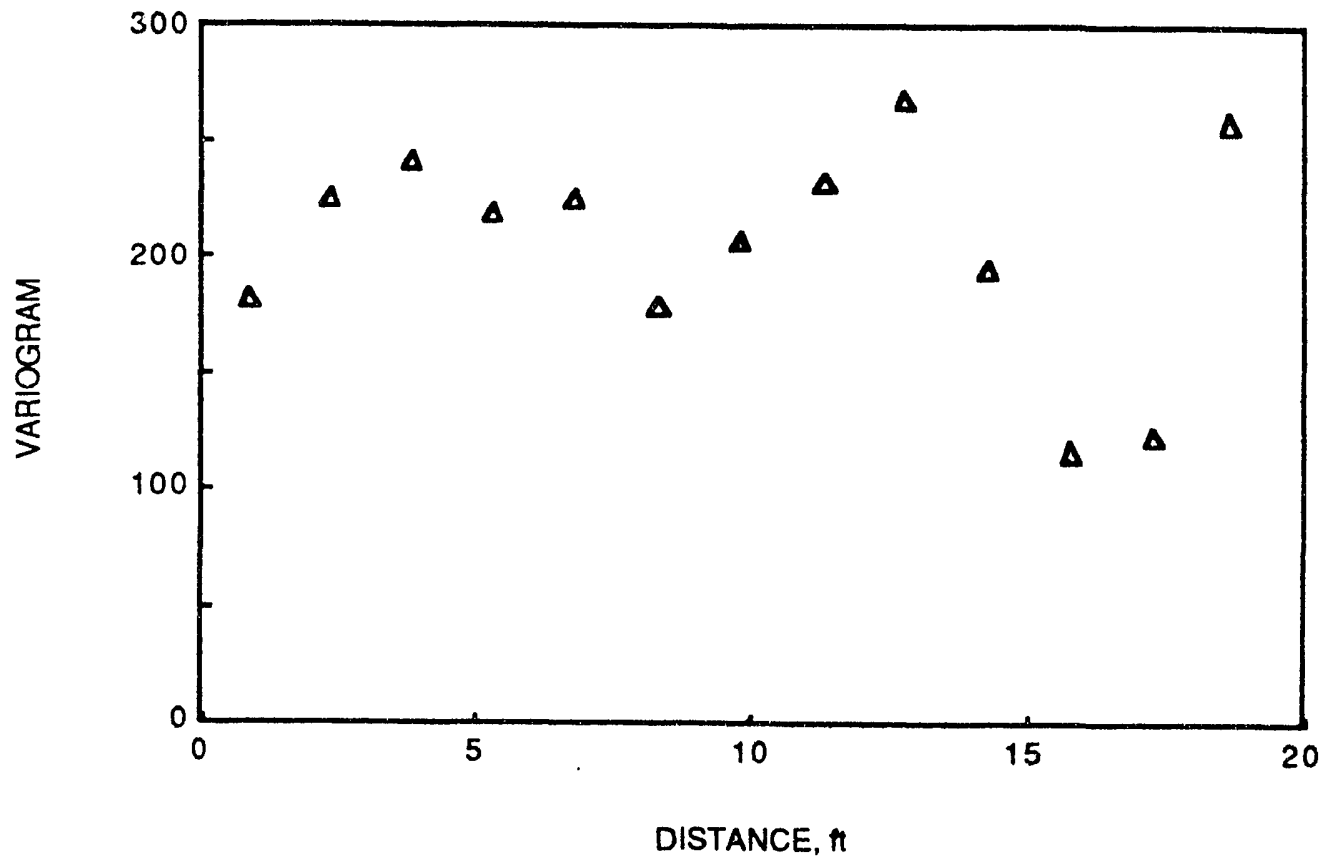

Figure 4.25 - Permeability variogram of well 123, Patrick Draw field.

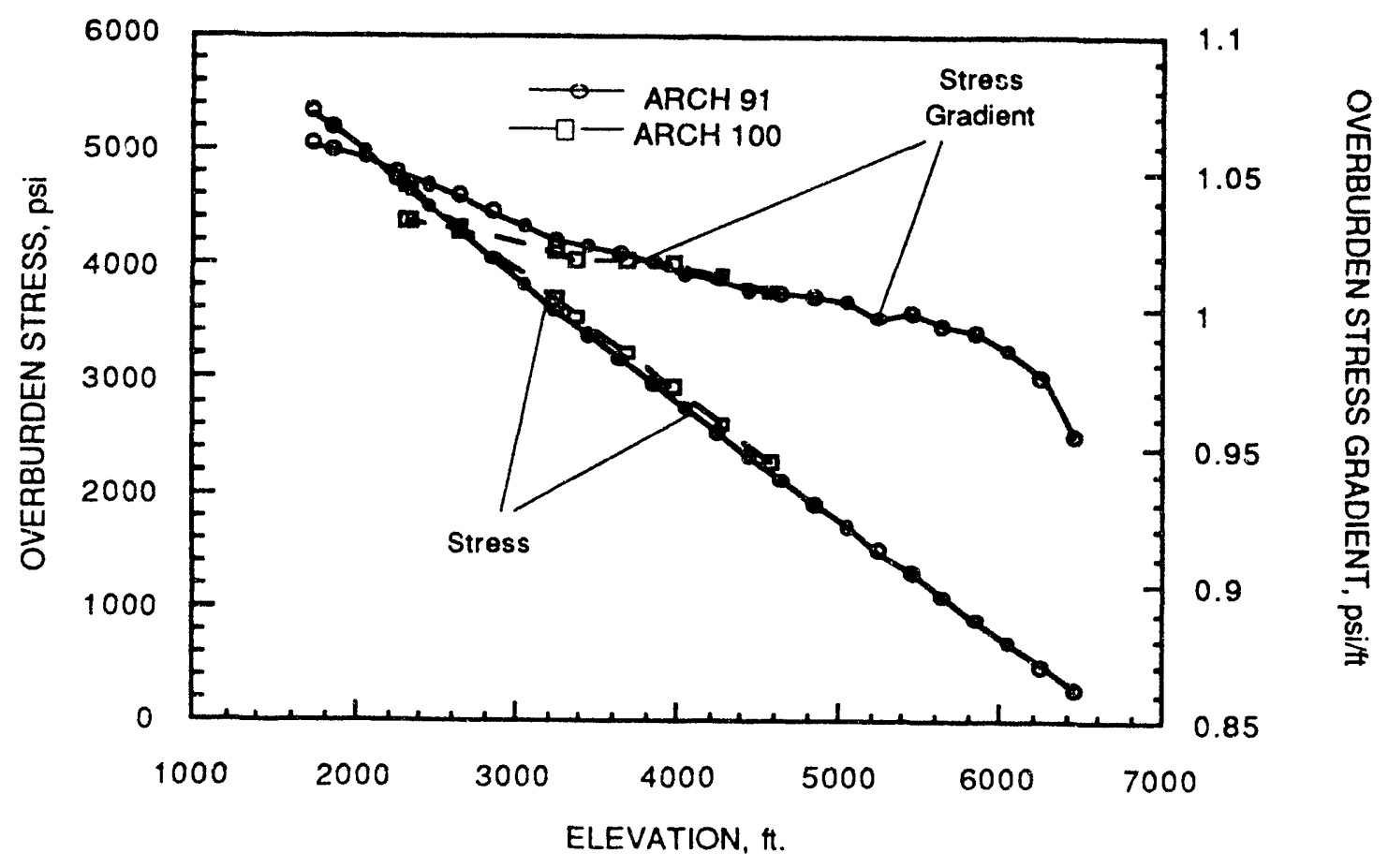

Figure 4.26 - Overburden stress and stress gradient as a function of depth for wells Arch 91 and Arch 100 derived from density wireline logs. 


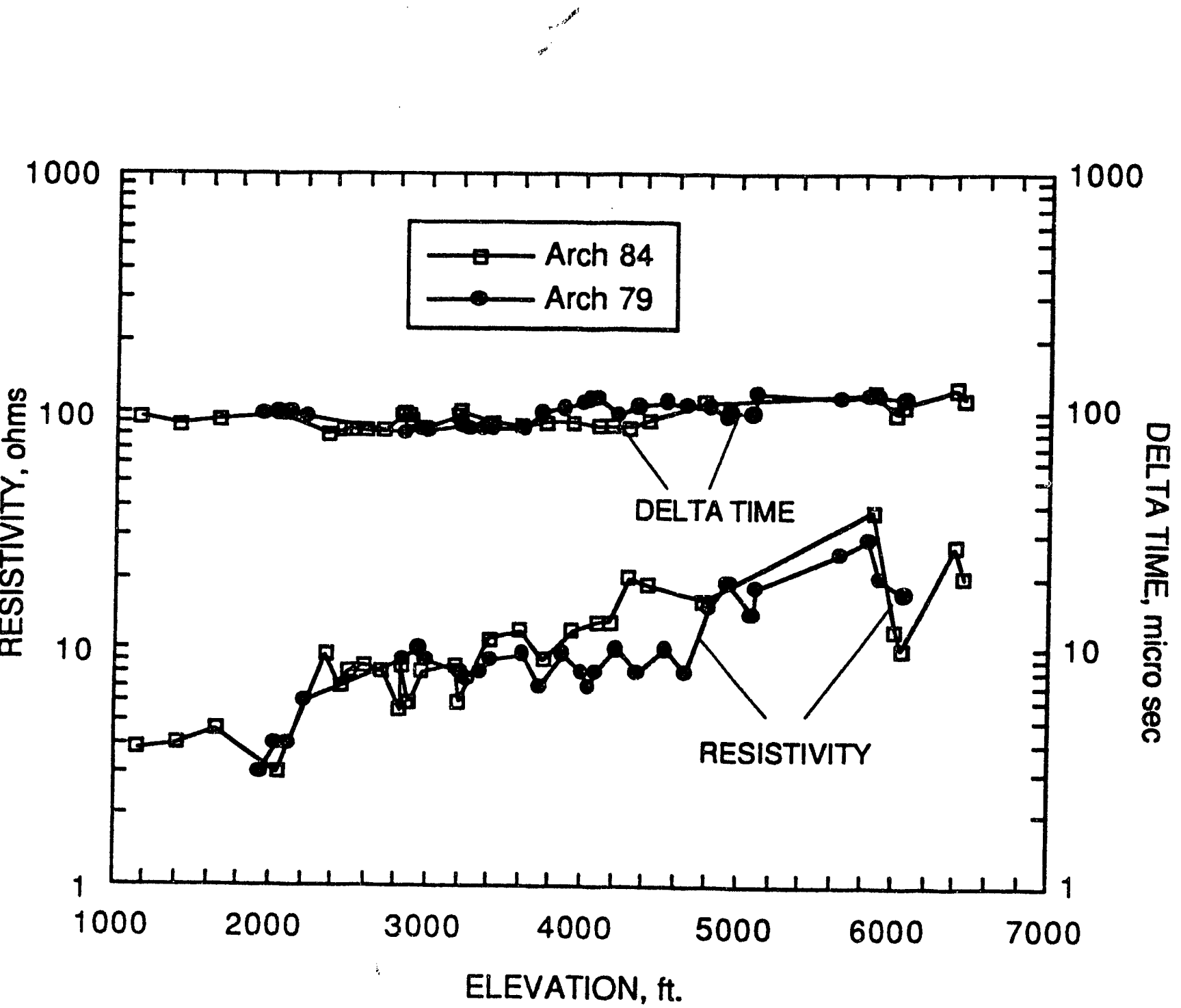

Figure 4.27 - Distribution of sonic transit times (delta time) and resistivity in shales as a function of depth in wells Arch 79 and Arch 84. 

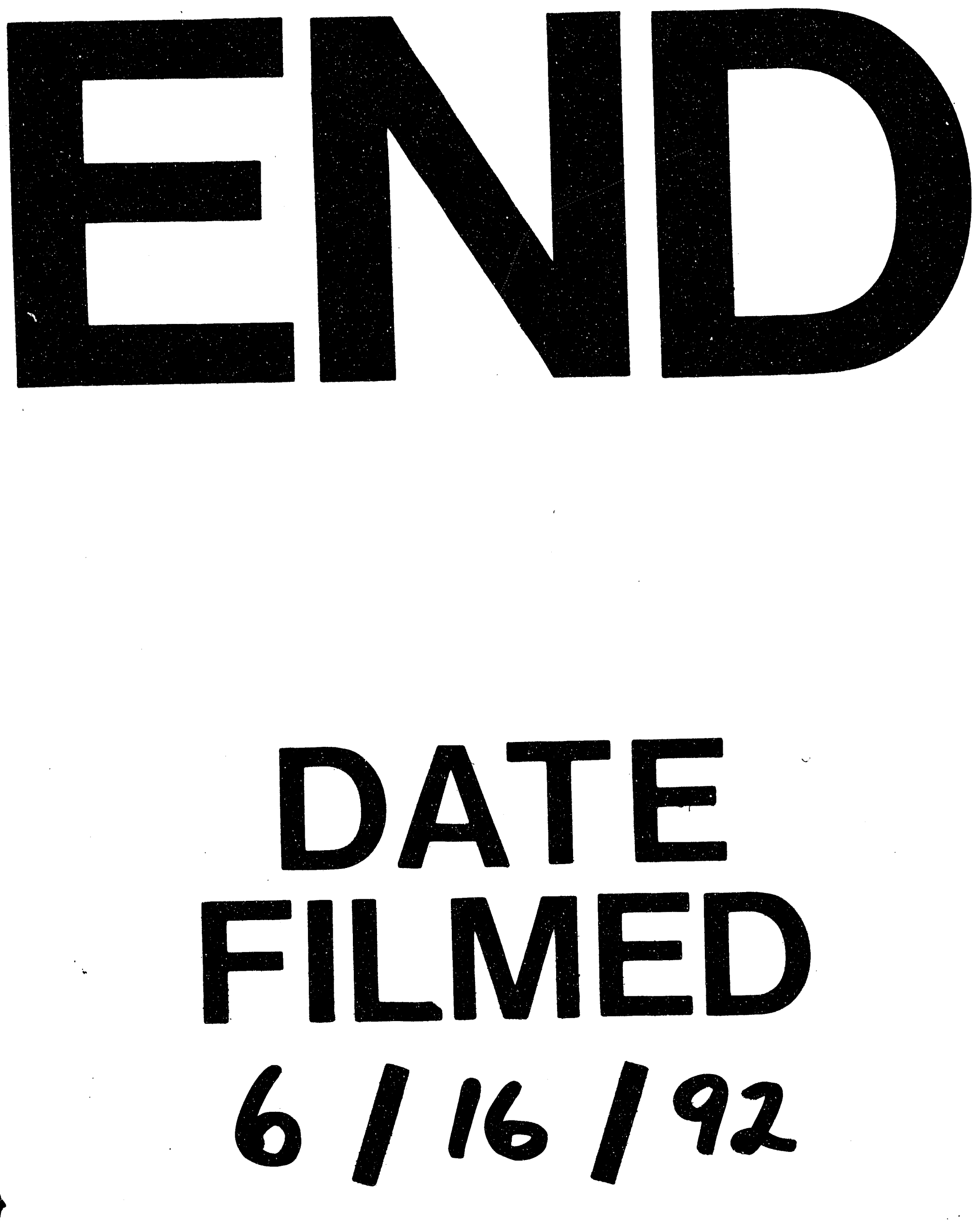
